Portland State University

PDXScholar

6-16-2021

\title{
Crime Patterns in Bend, Oregon Over a Twenty-Year Period
}

Holly Schorr

Portland State University

Follow this and additional works at: https://pdxscholar.library.pdx.edu/honorstheses

Part of the Criminology Commons

Let us know how access to this document benefits you.

\section{Recommended Citation}

Schorr, Holly, "Crime Patterns in Bend, Oregon Over a Twenty-Year Period" (2021). University Honors Theses. Paper 1070.

https://doi.org/10.15760/honors.1096

This Thesis is brought to you for free and open access. It has been accepted for inclusion in University Honors Theses by an authorized administrator of PDXScholar. Please contact us if we can make this document more accessible: pdxscholar@pdx.edu. 
Crime Patterns in Bend, Oregon Over a Twenty-Year Period

by

Holly Schorr

An undergraduate honors thesis submitted in partial fulfillment of the requirements for the degree of

Bachelor of Science

in

University Honors

and

Criminology \& Criminal Justice

Thesis Advisor

Kris Henning

Portland State University

2021 


\section{$\stackrel{\mathscr{P}}{P}$ Portland $\underset{U N I V E R S I T Y}{\operatorname{State}}$}

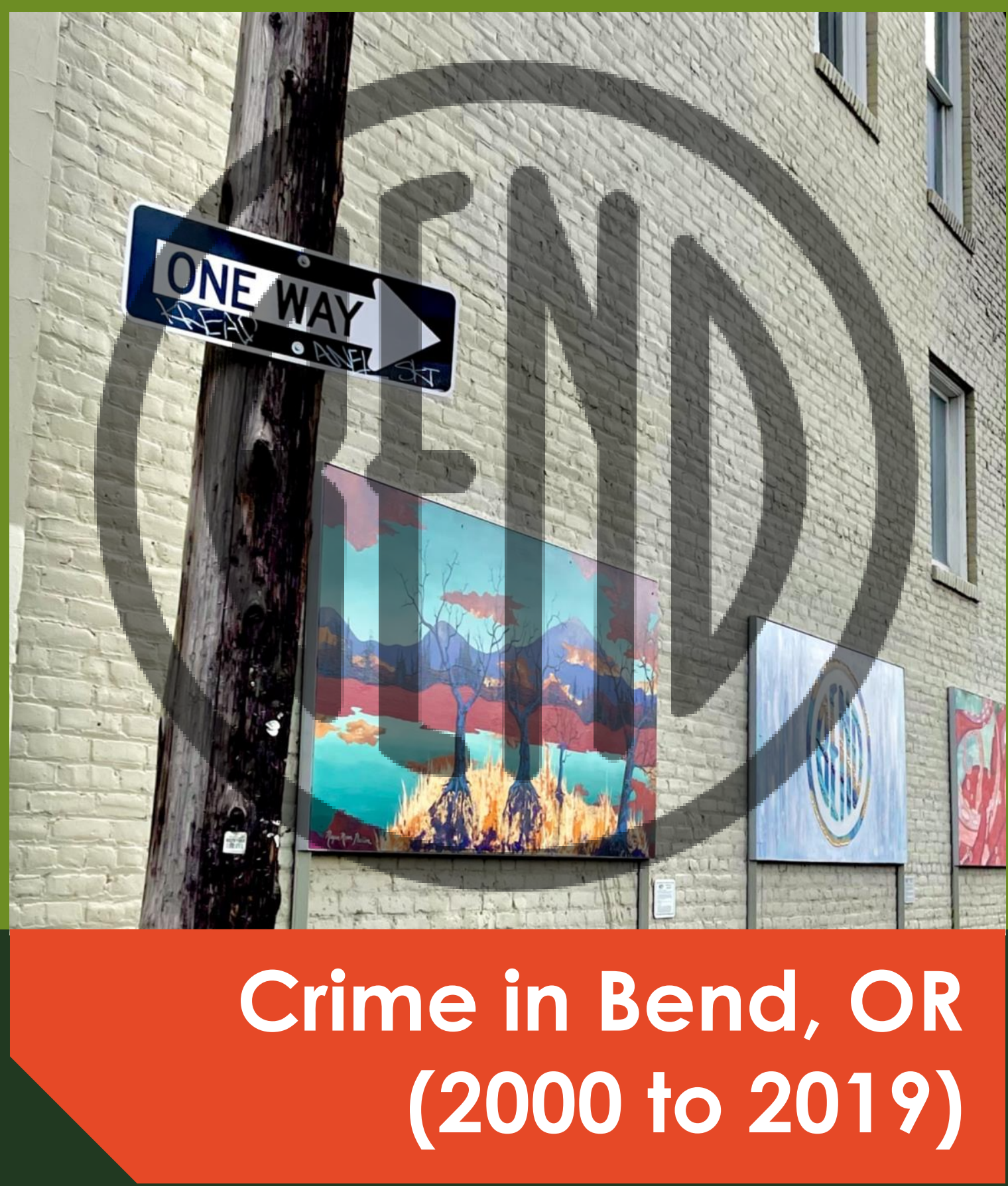

\section{Holly Schorr}

Kris Henning, Ph.D., Academic Advisor

Department of Criminology \& Criminal Justice

Email: khenning@pdx.edu Tel: 503-725-8520 


\section{TABLE OF CONTENTS}

INTRODUCTION

PROFILE OF TARGET CITY_ 9

LAW ENFORCEMENT IN BEND__ 10

DATA SOURCES _ 12

UCR or SRS System

NIBRS 12

Differences Between NIBRS/ SRS

Limitations for NIBRS/ UCR __ 13

NIBRS Variable Definitions — 14

Clearance Rate 14

Geographic Pattern__ 14

Number of Known Offenders (Co-Offending) _ 14

Property Loss- Directs Costs _ 14

Property Loss- Types of Loss 15

Property Loss- Mean Value Substitutions___ 15

Residency _ 15

Victim Type 15

INCIDENT TRENDS 16

UCR Data (2000-2019)__ 16

Violent Crime 16

Murder/ Non-Negligent Manslaughter__ 17

Aggravated Assault__ 18

Robbery 19

Rape 20

Property Crime _ 21

Larceny 22

Motor Vehicle Theft

Burglary__ 24

NIBRS Data (2010-2018) _ 25

Temporal Trends 25

Victim and Offender Statistics__ 26

Clearance _ 27

Property Loss _ 27

ASSAULT/INTIMIDATION OFFENSES___ 29

Introduction \& Offense Subtypes __ 29

Intimidation

Simple Assault _ 29

Aggravated Assault__ 30

Murder 30

Annual Trend

Temporal Patterns 30

Geographic Pattern 32

Victim \& Arrestee Demographic Profile __ 32

Age 32

Sex 33 
Race \& Ethnicity

Residency

Offense Characteristics _ 34

Victim-Offender Relationship __ 34

Victim Injuries

Number of Victims

Number of Known Offenders (Co-Offending) __ 34

Weapon Involvement 35

Clearance Rate__ 35

BURGLARY

Introduction \& Offense Definition __ 36

Annual Trend _ 36

Temporal Patterns 36

Geographic Pattern _ 37

Victim \& Arrestee Information___ 38

Victim Type __ 38

Arrestee Demographic Profile__ 38

Offense Characteristics _ 39

Method of Entry _ 39

Number of Known Offenders (Co-Offending) __ 39

Property Stolen 40

Costs Associated with Burglary __ 40

Property Stolen _ 41

Other Property Loss _ 41

Clearance Rate__ 42

DRUG OFFENSES _ 43

Introduction \& Offense Definition __ 43

Annual Trend

Temporal Patterns _ 44

Geographic Pattern 45

Arrestee Demographic Information __ 45

Offense Characteristics —46

Drug Offense Activities _ 46

Drugs Seized _ 47

LARCENY/THEFT OFFENSES ___ 49

Introduction \& Offense Subtypes __ 49

All Other Larceny __ 49

Shoplifting 49

Theft from Building $\quad 50$

Pocket-picking

Purse-snatching

Theft from Coin-Operated Machine or Device _ 50

Annual Trend

Temporal Patterns $\quad 51$

Geographic Pattern 53

Victim \& Arrestee Information __ 53 
Victim Type

Arrestee Demographic Profile

Property Stolen Losses

Property Descriptions

Costs of Stolen Property

Clearance Rate

THEFT OF/FROM A MOTOR VEHICLE

Introduction \& Offense Subtypes

Theft from a Motor Vehicle

Theft of a Motor Vehicle

Theft of Motor Vehicle Parts or Accessories

Annual Trend

Temporal Patterns

Geographic Pattern

Victim \& Arrestee Information

Victim Type

Arrestee Demographic Profile

Property Loss

Property Descriptions

Costs of Stolen Property

Clearance Rate

ROBBERY

Introduction \& Offense Definition

Annual Trend

Temporal Patterns

Geographic Pattern

Victim \& Arrestee Demographic Profiles

Age

Sex

Race \& Ethnicity

Residency

Offense Characteristics

Victim Type

Victim-Offender Relationship

Victim Injuries

Number of Victims

Number of Known Offenders

Weapon Involvement

Property Stolen Losses

Property Descriptions

Costs of Stolen Property

Clearance Rate

SEXUAL OFFENSES 
Fondling

Rape

Statutory Rape

Sodomy

Sexual Assault with an Object

Incest

Annual Trend

Temporal Patterns

Geographic Pattern

Victim \& Arrestee Demographic Profiles

Age

Sex

Race \& Ethnicity

Residency

Offense Characteristics

Victim-Offender Relationship

Victim Injuries

Number of Victims

Number of Known Offenders

Weapon Involvement

Clearance Rate

VANDALISM/ARSON

Introduction \& Offense Subtypes

Destruction/Damage/Vandalism of Property

Arson

Annual Trend

Temporal Patterns

Geographic Pattern

Victim \& Arrestee Information

Victim Type

Arrestee Demographic Profile

Sex

Race \& Ethnicity

Residency

Property Losses

Property Descriptions

Costs Associated with Vandalism/Arson __ 85

Clearance Rate

WHITE-COLLAR CRIME

Introduction \& Offense Subtypes

Impersonation

Counterfeiting/Forgery

False Pretenses/Swindle/Confidence Game

Credit Card/Automated Teller Machine Fraud

Identity Theft

Wire Fraud 
Embezzlement

Bribery

Annual Trend

Temporal Patterns

Geographic Pattern

Victim \& Arrestee Demographic Profiles

Age

Sex

Race \& Ethnicity

Residency

Offense Characteristics

Victim Type

92

Number of Victims

Number of Known Offenders

Property Losses

Property Descriptions

Costs Associated with White-Collar Crime

Property Stolen

Property Counterfeited/Forged

Clearance Rate 


\section{INTRODUCTION}

Crime is complicated. Although crime receives a lot of attention in the media, this does not necessarily mean that most of the public has an accurate understanding of crime. The portrayal of crime in mainstream media is often fettered by sensationalism, dramatization, and oversimplification. Because crime is highly nuanced and cannot be understood through a simple snap-shot lens, the public's perception of crime frequently does not align with reality, which often affects decisions they make in their everyday life due to the fear of becoming victimized.

Over the past few decades, there has been a push for law enforcement to become more data-driven in their strategies for combatting crime. This has resulted in large quantities of detailed criminal data that can be used to study many aspects of a city's crime problem; this includes temporal patterns, geographic patterns, victim and arrestee information, weapon involvement, property losses, etc. However, due to the ever-present need for shorter-term analyses to better inform city budgeting and policing strategies, long-term criminal analyses are not often a priority. Although the reason why this may be varies by agency, it is frequently because they lack the resources, time, or training necessary to conduct long-term detailed analyses on crime trends in their jurisdiction.

The purpose of this report is to provide a comprehensive overview of crime patterns in Bend, Oregon over the past few decades using thorough and nuanced data that is often not used in mainstream analyses. By utilizing both UCR and NIBRS data, this report will provide detailed information on both the nature of individual criminal incidents and the overarching crime patterns in Bend over an extended period. The results of these analyses can then provide accurate information to the public about current crime trends in Bend within the bigger picture and can further be used to inform local policies and law enforcement strategies for responding to crime.

This report will further be utilized as a template for future students in the Criminology \& Criminal Justice department at Portland State University. Criminal Justice majors in the Honors College at Portland State University will have the option to analyze crime patterns of an Oregon city as their culminating senior thesis project. In doing this, future students can provide communities with longterm trends and detailed information about crime that is often inaccessible to the public. Students at Portland State University will continue to use pre-existing crime data that is often overlooked and under-analyzed to help communities better understand crime in their area. 


\section{PROFILE OF TARGET CITY}

The city of Bend, Oregon is located almost directly in the center of Oregon, along the Deschutes River on the eastern edge of the Cascade Range. It is the largest city in Central Oregon and the county seat of Deschutes County. As of 2010, the land area of Bend is 33.01 square miles with a population per square mile of 2,322. Bend is a popular travel and retirement destination in Oregon, which comprises much of their local economy and has resulted in a fast-growing population.

Bend is one of the fastest growing cities in the country. Bend's population has grown from 76,639 residents in 2010 to 82,418 residents as of 2014 , an overall $7.5 \%$ growth in five years. Since then, Bend's population has continued to rapidly increase from 86,042 in 2015 to 100,241 residents in 2019 according to the U.S. Census Bureau's latest population estimate- a $16.5 \%$ population increase. In the past ten years alone, Bend's population has increased by $30.8 \%$. As of 2018 , there we 37,339 households in Bend, with the average persons per household being 2.4.

As of 2019, the U.S. Census Bureau reports that Bend is largely comprised of White residents $(85.6 \%)$ between the ages of 18 and $64(54.9 \%)$. Additionally, slightly more than half of the population $(52.0 \%)$ constitutes Female persons. The remaining demographics for race in Bend include Hispanic (9.1\%), people of two or more races (3.2\%), Asian (1.9\%), Black or African American (0.6\%), and American Indian or Alaska Native (0.4\%). Compared to the state of Oregon (86.7\%), Bend has a similarly sized population of White residents. However, Oregon as a whole has higher rates of other races than Bend including Hispanic (13.4\%), Asian (4.9\%), people of two or more races (4.0\%), Black or African American (2.2\%), and American Indian or Alaska Native (1.8\%). Additionally, $16.5 \%$ of Bend's residents are 65 or older, $22.6 \%$ are under 18 years old, and $6.0 \%$ are under five years old. In comparison, $18.2 \%$ of Oregon's residents are 65 or older, $20.5 \%$ are under 18 years old, and $5.4 \%$ are under five years old. Of the residents 25 years or older, $95.4 \%$ of Bend's population have a high school degree or higher and $43.3 \%$ have a Bachelor's degree or higher. This is somewhat higher than the state of Oregon, with $90.4 \%$ having at least a high school degree and $32.9 \%$ with a Bachelor's degree or higher.

According to Economic Development for Central Oregon, the overall top five employers in Bend as of 2019 include: St. Charles Health System, Bend La-Pine School District, Deschutes County, Mt. Bachelor Ski Resort, and Central Oregon Community College. The top five privately-owned employers in Bend also include Bright Wood Corporation and Sunriver Resort. Including people ages 16 and older, $67.1 \%$ of the population in Bend participate in the civilian labor force as of 2018. The Bend-Redmond MSA GDP per capita is $\$ 46,903$ as of 2017 , according to the Bureau of Economic Analysis. The median household income in Bend is $\$ 63,468$ as of 2018 , with $10.3 \%$ of residents living in poverty. In comparison, the median household income for the state of Oregon is lower at $\$ 59,393$ and $11.4 \%$ of the state's population lives in poverty. The median value of owner-occupied housing units in Bend as of 2018 is $\$ 363,200$, and the median gross rent for renters is $\$ 1,185$ monthly. This is significantly higher than the state of Oregon, with the median value of owner-occupied housing units being $\$ 287,300$ and the median gross rent being $\$ 1,050$. 


\section{LAW ENFORCEMENT IN BEND}

The City of Bend's police department is an accredited police agency that includes both sworn officers, as well as non-sworn employees. Sworn officers serve in several specialty assignments such as Patrol, K9, Investigations, Information Led Policing, Community Response Team, Community Service, School Resource, Traffic and Training. Nonsworn employees can work in departments such as Information Technology, Records, Support Services, Evidence, and Crime Analysis. Bend's police department also includes a Citizen Advisory Committee comprised of community members with diverse backgrounds

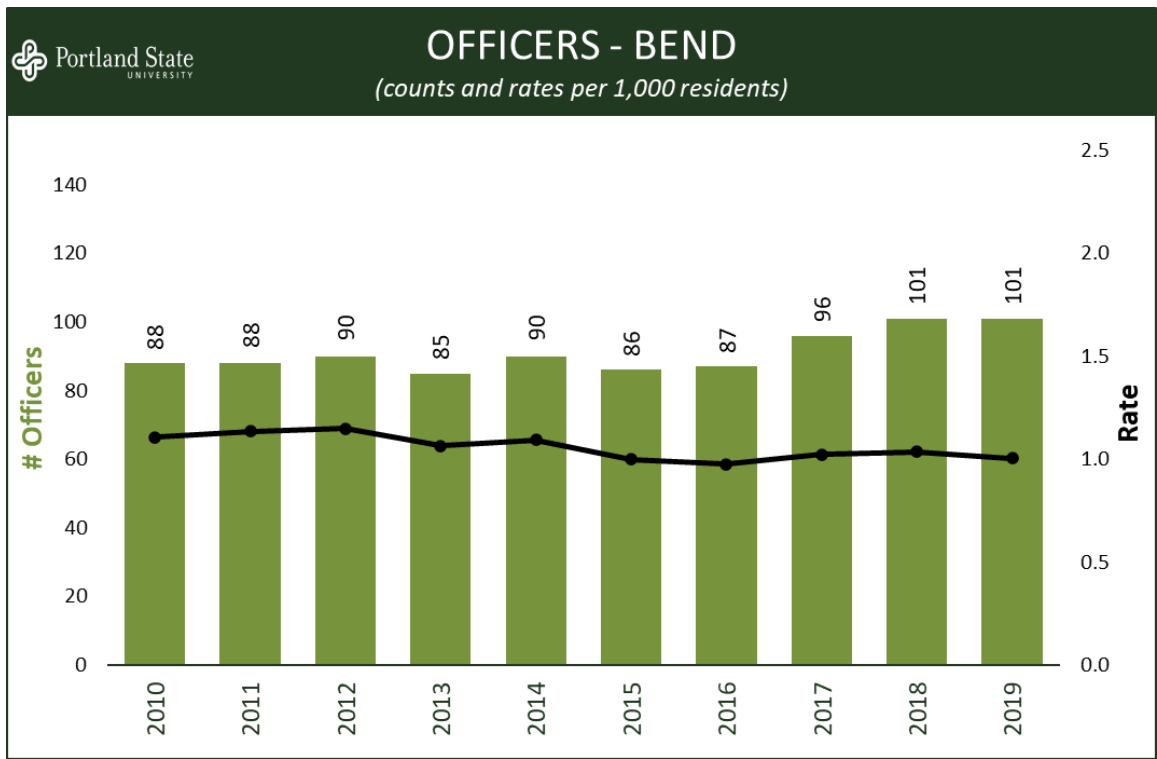

Figure 1 that meet with the Chief of Police periodically to provide input for department decisions.

Bend's sworn officer employment increased by 14.8\% between 2010 (88) and 2019 (101). However, during this ten-year period, Bend's population increased overall by $26.4 \%$ from 79,556 residents in 2010 to 100,588 in 2019.

After controlling for population, this means that Bend's number of officers per 1,000 residents decreased from 1.1 in 2010 to 1.0 in 2019 , an overall $-9.2 \%$ change. Oregon cities of a similar size also experienced a decrease in the number of officers per 1,000 residents, decreasing from 1.3 in 2010 to 1.1 in 2019, an overall $12.5 \%$ change. Oregon cities in aggregate followed this trend, decreasing from 1.5 officers per 1,000 residents in 2010 to 1.3 in 2019 , an overall $-11.3 \%$ change. U.S. cities of a similar size experienced a slight decrease ($5.2 \%$ ) in officers per 1,000 residents

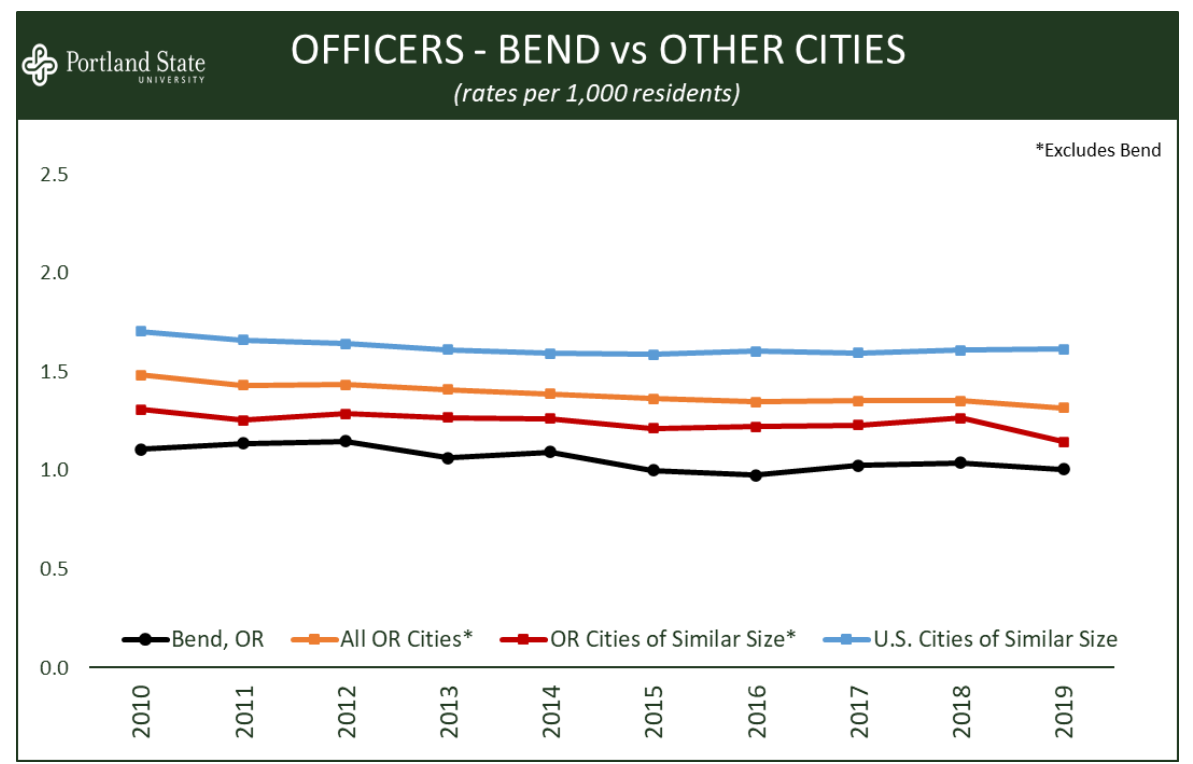

Figure 2 between 2010 (2.1) and 2019 (2.1), however their officer employment was almost twice Bend's despite the similar population size.

Between 2010 and 2019, Bend's sworn officer staffing rate was consistently lower in comparison to U.S. cities of a similar size, with the average staffing gap being 49 officers short. During this time, Bend's average rate of officers per 1,000 residents was 1.1 compared to 1.6 for U.S. cities of a similar size. See Figure 3 for a yearly breakdown. The typical staffing level for sworn officers was determined 
using 405 to 442 cities (varies by year) with a population comparable to Bend's. The combined rate of officers per 1,000 residents from these cities was used to calculate the number of officers Bend would have if they met the typical or average staffing level. Note that this analysis only controls for the population size, it does not control for level of crime or calls for service in Bend compared to other cities.

It is important to utilize other metrics such as crime rate or calls for service when comparing staffing levels because although Bend is lacking in officer staffing based on population, this does not consider the low rate of criminal activity in Bend that will be demonstrated throughout this report. Although cities with populations comparable to Bend may staff more officers, Bend may not require the same amount due to their relatively low crime rate. To control for crime rate, we used the same methodology by combining rate of officers per 100 Index Crimes from these cities to calculate the number of officers Bend would have if they met the typical or average staffing level.

Although the staffing gap between Bend and U.S. cities of a similar size is less significant after controlling for level of crime rather than population, Bend's staffing rate is still lower in comparison. Between 2010 and 2019, Bend on average had 22 officers less than U.S. cities of a similar size.

During this time, Bend's average rate of officers per 100 Index Crimes was 3.9 compared to 4.9 for U.S. cities of a similar size. See Figure 4 for a yearly breakdown.

It is important to note that although Bend staffs at a lower rate than U.S. cities of a similar size based on both population and level of crime, there is no single approach to determine exactly how many officers an agency should staff. Although there are many variables that can influence staffing decisions for law enforcement agencies, common factors that are primarily taken into consideration include workload, deployment, and response time. ${ }^{1}$ One metric that is commonly used to determine how many officers should be staffed based on workload is the number of calls for service. However, dispatch information was not available for the current report. This should be taken into consideration when reviewing Bend's law enforcement staffing.

\footnotetext{
${ }^{1}$ https://icma.org/documents/how-many-officers-do-you-really-need
} 


\section{DATA SOURCES}

\section{UCR or SRS System}

The Federal Bureau of Investigation's Uniform Crime Reporting (UCR) Program, also known as the Summary Reporting System (SRS), is a nationwide data collection system that reports on seven Part I Offenses that are determined to be the most serious by the FBI. These offenses, which are also known as Index Crimes, include: murder and non-negligent manslaughter, aggravated assault, forcible rape, robbery, burglary, larceny, and motor vehicle theft. An eighth crime, arson, was added to the SRS system in 1979, however we will not be reporting on this offense. UCR takes aggregate offense counts for each of these offenses reported by law enforcement agencies across the country; in incidents with multiple offenses, the UCR utilizes the Hierarchy Rule, which mandates that only the most serious offense in an incident is recorded. The UCR Program was first established by the FBI in 1930 and has since grown to include not only the SRS data collection, but also the National IncidentBased Reporting System (NIBRS), Law Enforcement Officers Killed and Assaulted (LEOKA) Program, and the Hate Crime Statistics Program. Due to its lengthy history and high rate of usage by law enforcement agencies (approximately $95 \%$ of agencies in the U.S.), there is significant quantities of UCR data.

\section{NIBRS}

The National Incident-Based Reporting System (NIBRS) is a data repository utilized by law enforcement agencies that collects incident-level data including detailed information about each offense that occurred, the victims and offenders involved, and the consequences of the incident. NIBRS was developed following its less detailed predecessor, the FBI's UCR Program. NIBRS includes 46 different offense codes and provides up to 53 contextual details about an incident such as the location and time of day, the victim-offender relationship, demographic information, if the offender had a weapon or was under the influence, drugs seized, property loss, whether an arrest was made, and so on (Strom \& Smith, 2017). Although use of NIBRS is not required, it has been implemented in 37 states and is utilized by approximately $44 \%$ of law enforcement agencies in the United States. Law enforcement agencies in Oregon currently participate in SRS and many are NIBRS compliant, however the $\mathrm{FBI}$ is in the process of implementing a nationwide transition to NIBRS-only data collection and retiring the SRS program.

\section{Differences Between NIBRS/ SRS}

NIBRS differs from the traditional UCR data system in the sense that it is significantly more detailed. One major difference between the two is that NIBRS does not utilize the Hierarchy rule for multiple offenses in an incident; instead, NIBRS reports each of the offenses that occurred in an incident and links them using a unique incident identification number. NIBRS codes for 52 offenses, compared to the UCR system's eight Index Crimes, and furthermore expands upon each offense with up to 53 contextual details. The data fields for contextual details have standardized codes that can be selected to promote uniformity in data. For example, the data field for location type includes 46 different codes such as Residence/Home, Highway/Road/Alley/Street/Sidewalk, Department/ Discount Store, Bar/ Nightclub, etc. 


\section{Limitations for NIBRS/ UCR}

Some limitations to consider when using both NIBRS and UCR data include:

- NIBRS and UCR only includes data on incidents that were reported to the police. This means that unreported incidents could account for a large portion of crime that was committed, but it will not be represented in the data.

- Additionally, some citizens within jurisdictions may report crimes more frequently than citizens in other jurisdictions, which could result in inaccurate crime rates. Because of this, one city may appear to have a higher crime rate than the other, when the latter just has lower rates of reporting.

- It is also not known to what extent jurisdictions are reporting data with the same frequency or in the same way. Some agencies included in the dataset may be reporting consistently and in accordance with NIBRS guidelines, while others may deviate from the standardized reporting practices. The extent to which agencies report either correctly or incorrectly is unknown.

- The person or agency inputting data may also have definitional differences for the codes provided. A common example is that state statutes may not always correspond with the FBl's offense definitions; agencies are then forced to make an uninformed decision, which could potentially result in coding inaccuracies.

- Certain types of crime can be primarily motivated by police activity and local crime policies, rather than actual criminal behavior. For example, drug crime is largely affected by the extent that agencies emphasize making drug arrests and to what extent drugs are criminalized in the jurisdiction. An area in which marijuana is legal and drugs are decriminalized will show much lower rates of drug crime although the actual rate of drug use may be the same, if not higher, than communities in which drugs are criminalized.

- UCR and NIBRS data is obtained from the FBI, who filters and ensures data quality. However, any updates that are made to the data after it has already been published are not accounted for in the datasets.

Some notable adjustments we have made in our data to account for errors include:

- Portland, Oregon is missing UCR data for the year of 2015 due to a transition in reporting systems. Although Portland is only one city, it is the largest city in the state of Oregon and represents a large portion of crimes in the state. Without this data, we cannot draw fair comparisons between Bend's crime rate and the overall state rate. To counteract these missing values, we took the average of Portland's incident counts in 2014 and 2016 to substitute for 2015's missing data.

- Portland, Oregon's vandalism counts in NIBRS data spiked dramatically in 2016 and 2017 due to a misinterpretation of reporting standards. The data was adjusted to account for this error. 


\section{NIBRS Variable Definitions}

In this section we will provide definitions for offense variables that reoccur throughout this report, as well as the caveats associated with these variables.

\section{Clearance Rate}

An agency's clearance rate is based on the number of arrests or citations of at least one suspect associated with a given crime. Offenses can also be cleared by exceptional means, including: Death of Offender, Juvenile/No Custody (the handling of a juvenile without taking him/her into custody, but rather by oral or written notice given to the parents or legal guardian in a case involving a minor offense, such as petty larceny), Prosecution Declined (by the prosecutor for a reason other than lack of probable cause), and Victim Refused to Cooperate (in the prosecution). Clearance rates are often used to evaluate police performance, however it is not necessarily the best metric to assess this for a couple of reasons. Firstly, clearance rates do not consider the type of police service that is provided other than whether an arrest was made. Secondly, clearance rates do not account for whether the arrestee was convicted of the crime. ${ }^{2}$ Additionally, it should be noted that NIBRS codes cases as "Cleared by Arrest" when a single suspect is arrested, even if there may be multiple suspects involved that are not arrested.

\section{Geographic Pattern}

Although NIBRS does not provide exact location information such as latitude and longitude for where crimes occur, NIBRS does group offenses into location categories. Some examples of location categories include: Residence/Home, Highway/Road/Alley/Street/Sidewalk, Bar/Nightclub, Park/Playground, etc. Some limitations regarding location categories include that only one location is reported for each offense, and the definition for each location type is subjective which could lead to inconsistencies in reporting between agencies. See the FBI's NIBRS User Manual for definitions for each location type. ${ }^{3}$

\section{Number of Known Offenders (Co-Offending)}

The NIBRS reporting system makes a distinction between suspects, or people identified to some degree in association with a crime, and people arrested for a given offense. While the arrestee demographic sections in this report address the latter, we will analyze co-offending in the sections titled Number of Known Offenders. This analyzes how many suspects were reported to have committed the offense by the victim or a witness, rather than the number of suspects identified and arrested for the offense. This is because some incidents will involve multiple offenders, however not all of them may be arrested or cited by law enforcement.

\section{Property Loss- Directs Costs}

When we refer to "direct costs" associated with a property loss resulting from an offense, we mean only the value for property items involved. Criminal offenses often come with additional direct (e.g., police response, prosecution, jails, prisons) and indirect costs (e.g., emotional impact, lost productivity, investment in security systems) that are not considered in this report. 


\section{Property Loss- Types of Loss}

There are four NIBRS categories of property losses included in this report: a) Stolen, b) Destroyed/Damaged/Vandalized, c) Burned, or d) Counterfeited/Forged. NIBRS also reports property losses that were Recovered or Seized; however, these categories are not applicable to this report.

\section{Property Loss- Mean Value Substitutions}

If the value of a property loss was unknown at the time of the initial report, officers are instructed to enter \$1. In order to estimate the total financial losses attributable to burglary we replaced these missing values with the statewide mean value for a given item and year. For example, if a stolen bicycle was reported in 2019 with a value of $\$ 1$ (i.e., missing), we replaced the value with $\$ 936$, the average cost for bikes stolen that year.

\section{Residency}

In NIBRS reporting, Residency refers to whether a person is a resident of the jurisdiction that the offense took place in. In this report, Residency likely refers to whether an involved person lives in Bend. However, there is no way of knowing whether officers in Bend report Residency this way or if they also include people who live in neighboring cities such as Sisters or Redmond as "Residents."

\section{Victim Injuries}

In this report there are three classifications for injuries sustained by a victim: None, Minor, and Major. Major Injuries include Apparent Broken Bones, Possible Internal Injury, Severe Laceration, Loss of Teeth, Unconsciousness, and Other Major Injury. The FBI does not provide a specific definition for Minor Injuries, however some likely examples include bruising or small lacerations.

\section{Victim Type}

For offenses that are not a person crime such as Burglary or Larceny/Theft, victim type will be analyzed rather than victim demographics. This is because in property crimes, victims are normally targeted based on other factors such as how secure the location is or whether someone is present, rather than who the victim is. Hence, in these sections we will only assess victims based on what NIBRS category they were reported as. Examples of victim type include: Individual, Business, Society/Public, etc. It should also be noted that victims can be double coded for victim categories; for example, if a business is burglarized and the offender also steals an employee's personal belongings, then the victim type can be reported as both "Business" and "Individual." This can result in the total number of victim types exceeding the actual number of offenses. 


\section{INCIDENT TRENDS}

\section{UCR Data (2000-2019)}

First, we will be analyzing UCR data from 2000 to 2018 to provide a long-term perspective of major crimes in Bend, Oregon. The total number of Index Crimes (i.e. murder and non-negligent manslaughter, aggravated assault, forcible rape, robbery, burglary, larceny, and motor vehicle theft) that occurred in Bend between 2000 and 2019 was 54,521 , with an overall $-27.8 \%$ change. Between 2000 and 2009, Index Crimes decreased from 2,871 to 2,236, a -22.1\% change. Index Crimes further decreased between $2010(2,657)$ and $2019(2,073)$ by $-22.0 \%$. During this twenty-year period, Bend's population almost doubled (+93.3\%) from 52,029 residents in 2000 to 100,588 in 2019. Bend saw the largest population surge between 2000 and 2009, when the population increased from 52,029 residents to $80,550(+54.8 \%)$. The population continued to grow from 79,556 residents in 2010 to 100,588 in $2019(+26.4 \%)$. Using population to control for rate, Bend's crime rate per 10,000 residents decreased by more than half over this twenty-year period. Between 2000 (551.8) and 2019 (206.1), Bend's total Index Crime rate decreased by $-62.6 \%$. The most notable decrease $(-49.7 \%)$ occurred between 2000 and 2009 when the crime rate dropped from 551.8 Index Crimes per 10,000 residents to 277.6. The crime rate continued to decrease from 2010 (334.0) to 2019 (206.1) by $-38.3 \%$.

\section{Violent Crime}

Between 2000 and 2009, Bend's overall violent crime incidents increased by $24.8 \%$ from 133 incidents in 2000 to 166 in 2009, with the average being 146.0 incidents per year. As Bend's population grew by $54.8 \%$ during this time, the rate for violent crime per 10,000 residents decreased by $19.4 \%$ from 25.6 in 2000 to 20.6 in 2009. Oregon cities of a similar size demonstrated a similar trend in violent crime rates, decreasing by $19.2 \%$ between 2000 (30.1) and 2009 (24.3). The state of Oregon experienced a larger decrease ($35.2 \%$ ) in violent crime between 2000 (46.5) and 2009 (30.1),

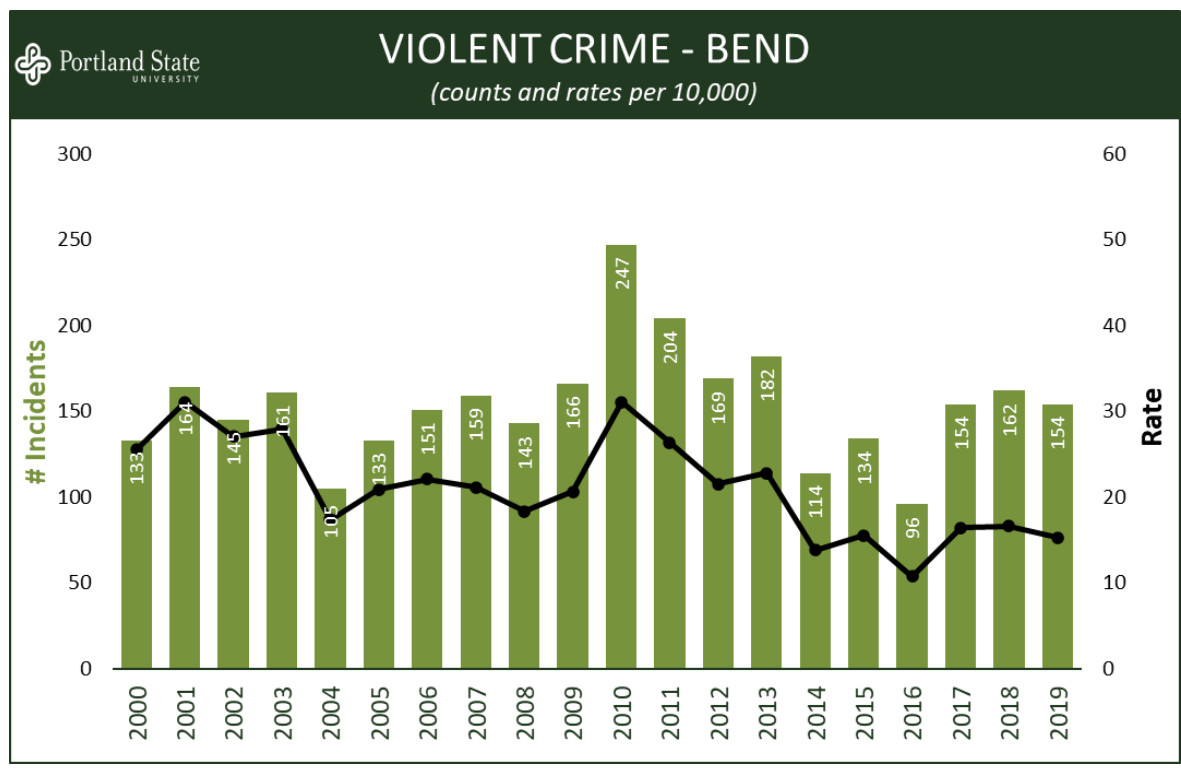

Figure 5 although the actual rates were higher than Bend and similarly sized Oregon cities. U.S. cities of a similar population size saw a less significant decrease in violent crime rates, decreasing by $-17.0 \%$ between $2000(50.8)$ and 2009 (42.2).

In the next ten-year period, Bend's violent crime decreased by more than a third (-37.7\%) between 2010 (247) and 2019 (154), with the average being 161.6 incidents per year. Bend's population 
continued to grow by $26.4 \%$, while the rate for violent crime per 10,000 residents decreased by more than half $(-50.7 \%)$ from 2010 (31.0) to 2019 (15.3). Oregon cities of a similar size decreased less significantly in violent crime rates between 2010 (27.2) and 2019 (21.8), with an overall $-20.1 \%$ change. Conversely, the state of Oregon experienced an increase in violent crime rates between 2010 (31.9) and 2019 (34.8), with an overall $9.1 \%$ change. U.S. cities of a similar size continued to decrease in violent crime at the same rate as the previous ten years $(-17.0 \%)$, from 40.2 incidents per 10,000 residents in 2010 to 33.3 incidents in 2019.

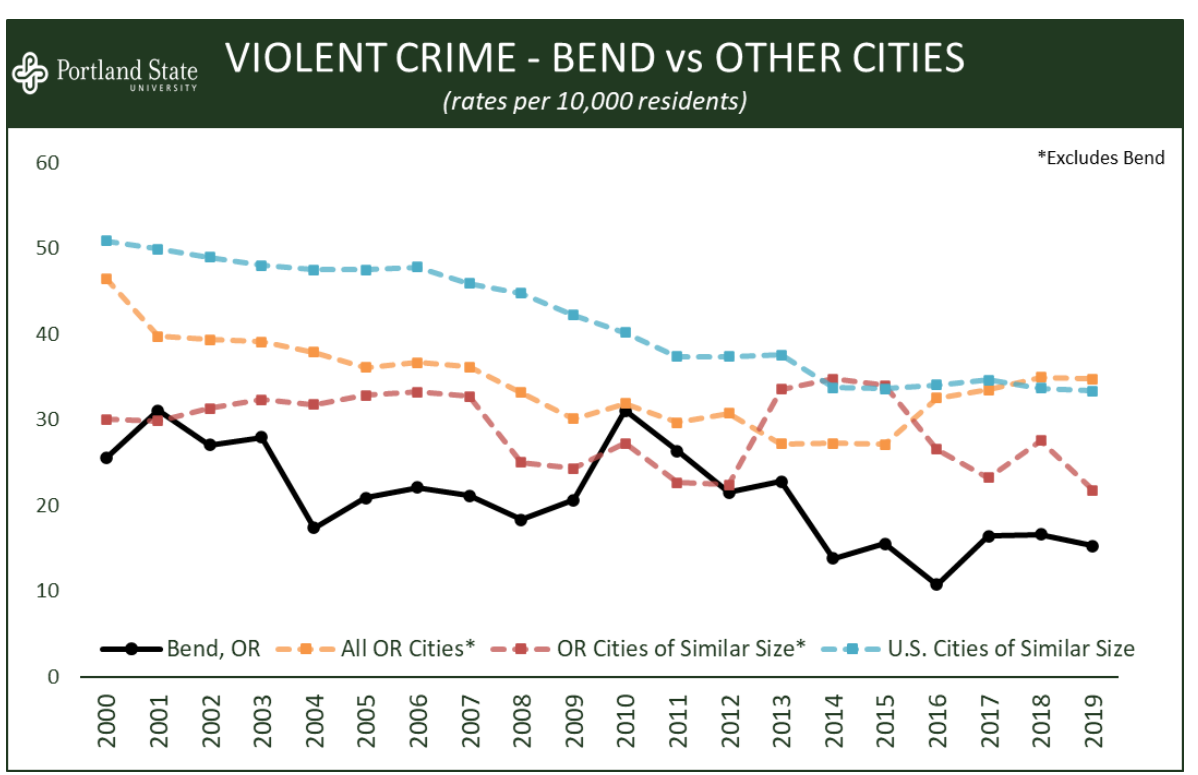

Figure 6

\section{Murder/ Non-Negligent Manslaughter}

We do not provide a summary of Bend's homicide rate in comparison to other cities due to the fact that so few homicides occur in Bend annually. The average number of homicides in Bend per year between 2000 and 2019 was 1.0 with little variance, despite the dramatic increase in population. See Figure 7 for the annual number of homicides in Bend between 2000 and 2019.

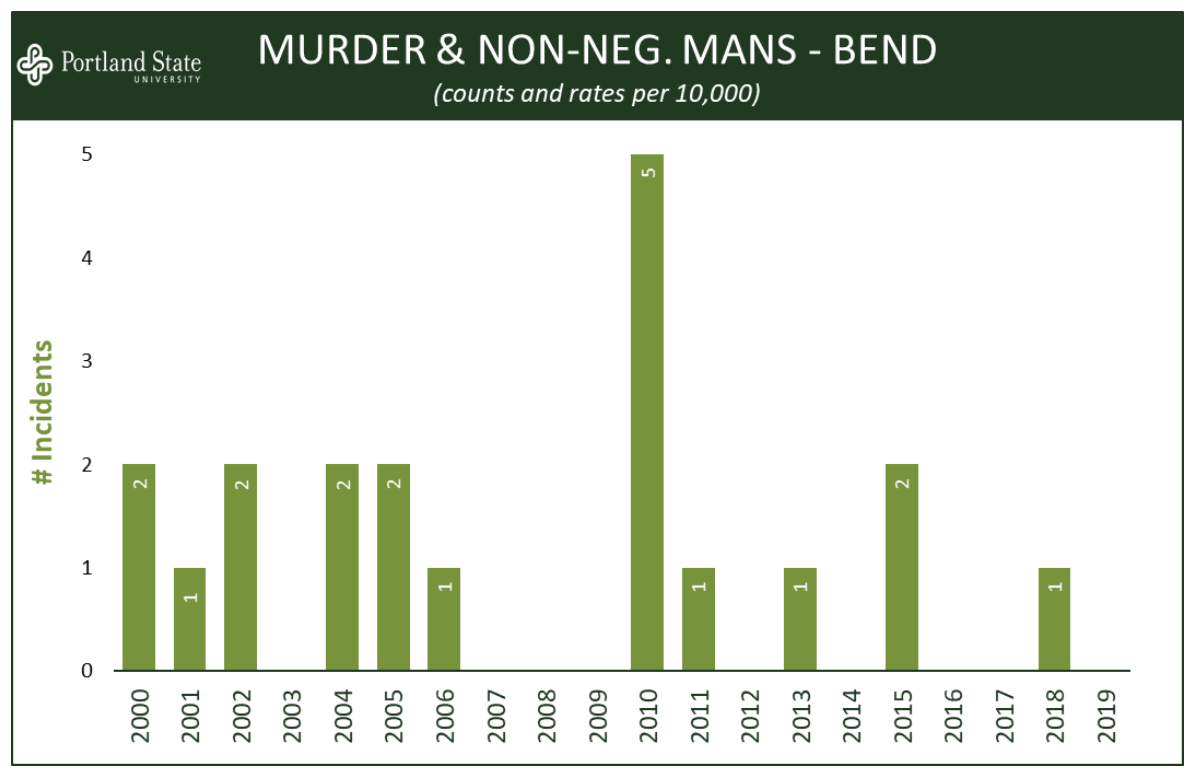

Figure 7 


\section{Aggravated Assault}

Between 2000 and 2009, Bend's aggravated assault incidents increased by $30.6 \%$ from 98 incidents in 2000 to 128 in 2009, with the average being 95.9 incidents per year. Due to the $54.8 \%$ population growth during this time, the rate for aggravated assault per 10,000 residents decreased from 18.8 in 2000 to 15.9 in 2009 ($15.6 \%)$. Oregon cities of a similar population size demonstrated a similar trend in aggravated assault rates, decreasing by $-5.6 \%$ between 2000 (16.7) and 2009 (15.7). U.S. cities of a similar size also demonstrated a negative trend in aggravated assault rates, decreasing by $-20.6 \%$ between 2000 (32.2) and 2009 (25.6), although the overall rate for these cities were higher than Bend's. Additionally, the total of all Oregon cities saw a larger and more steady decrease in aggravated assaults between 2000 (29.4) and 2009 (17.4), with an overall $-40.7 \%$ decrease.

In the next ten-year period, Bend's aggravated assaults decreased by $-47.7 \%$ between 2010 (197) and 2019 (103), with the average being 112.9 incidents per year. Bend's population continued to grow by $26.4 \%$, while the rate for aggravated assaults per 10,000 residents decreased significantly by $-58.6 \%$ from $2010(24.8)$ to 2019 (10.2). Oregon cities of a similar size also decreased in aggravated assault rates between 2010 (18.7) and 2019 (14.0) by $-25.5 \%$, in contrast to all Oregon cities as a whole, which saw a $15.4 \%$ increase between 2010 (18.9) and 2019 (21.8). U.S. cities of a similar size also continued to decrease in aggravated assault rates by $-11.3 \%$, from 24.1 incidents per 10,000 residents in 2010 to 21.4 incidents in 2019.

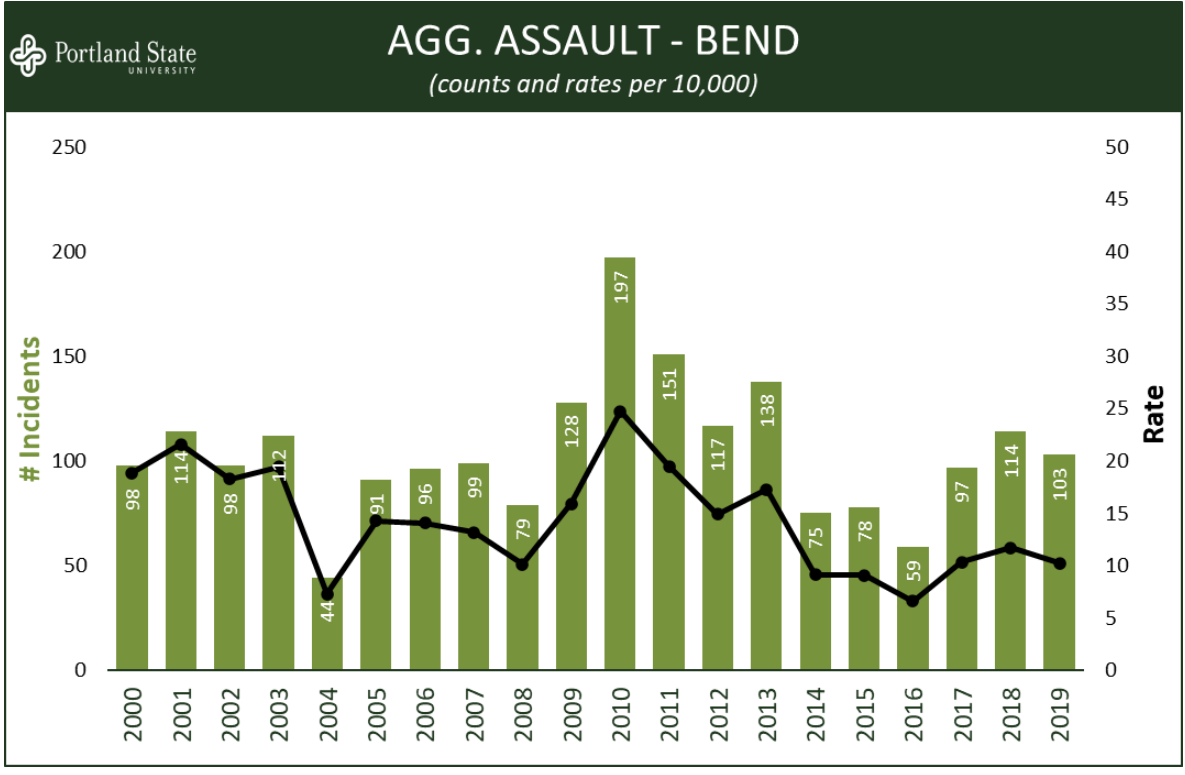

Figure 8

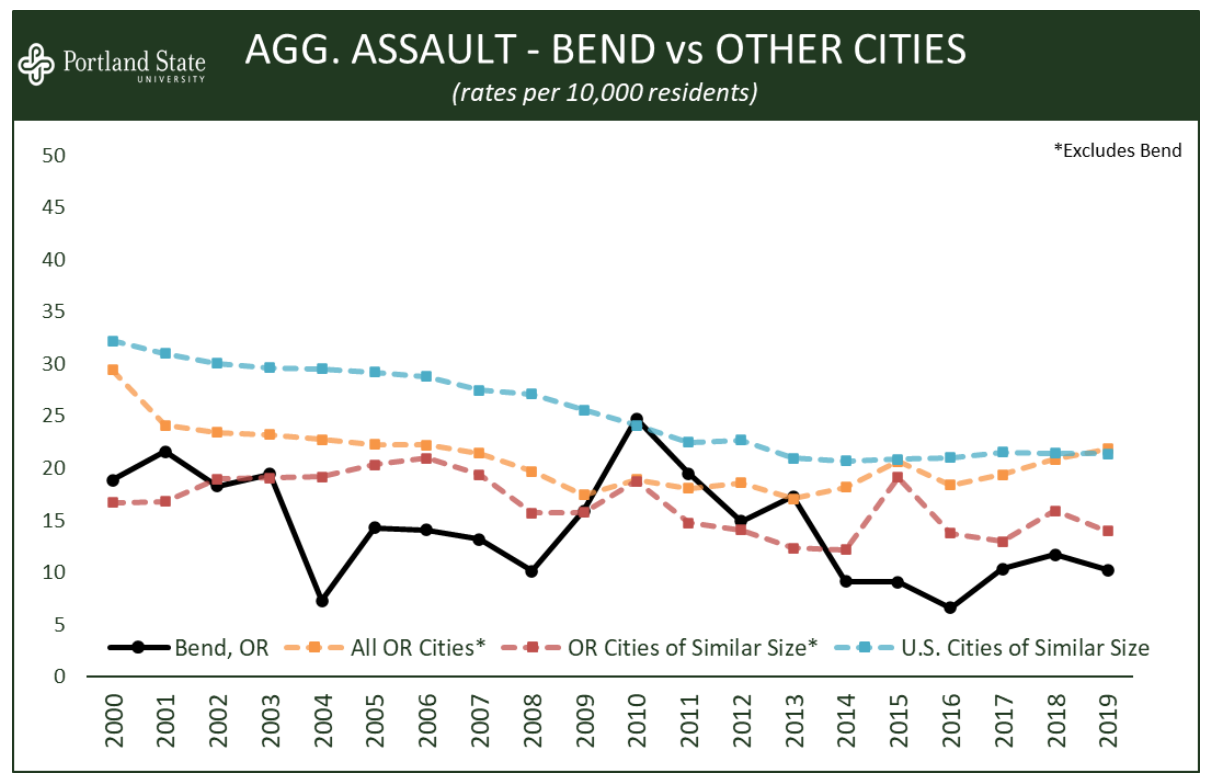

Figure 9 


\section{Robbery}

Between 2000 and 2009, Bend's robbery incidents increased slightly by $4.5 \%$ from 22 incidents in 2000 to 23 in 2009, with the average being 30.0 incidents per year. As Bend's population grew by $54.8 \%$ during this time, the rate for robbery per 10,000 residents decreased by almost a third from 4.2 in 2000 to 2.9 in 2009 (-32.5\%). Although their rates were almost twice as much, Oregon cities of a similar population size demonstrated a similar trend in robbery rates, decreasing by $-38.2 \%$ between 2000 (8.6) and 2009 (5.3). The state of Oregon as a whole also witnessed a decrease in robberies between 2000 (12.4) and 2009

(8.9), with an overall reduction of $28.2 \%$. U.S. cities of a similar size experienced a less significant decrease in robbery rates, decreasing by $-8.9 \%$ between 2000 (14.6) and 2009 (13.3).

Bend's robbery count then decreased by $-32.3 \%$ between 2010 (31) and 2019 (21), with the average being 23.4 incidents per year. Bend's population continued to grow by $26.4 \%$, while the rate for robbery per 10,000 residents decreased by $-46.4 \%$ from 2010 (3.9) to 2019 (2.1). In comparison, Oregon cities of a similar size experienced almost no change in robbery rates between $2010(4.4)$ and 2019 (4.4), decreasing by $0.2 \%$. All Oregon cities saw a higher decrease in robbery rates, with an overall $-13.7 \%$ change between 2010 (9.1) and 2019 (7.8). U.S. cities of a similar size decreased in robbery rates by over a third (-36.8\%), from 12.0 incidents per 10,000 residents in 2010 to 7.6 incidents in 2019.

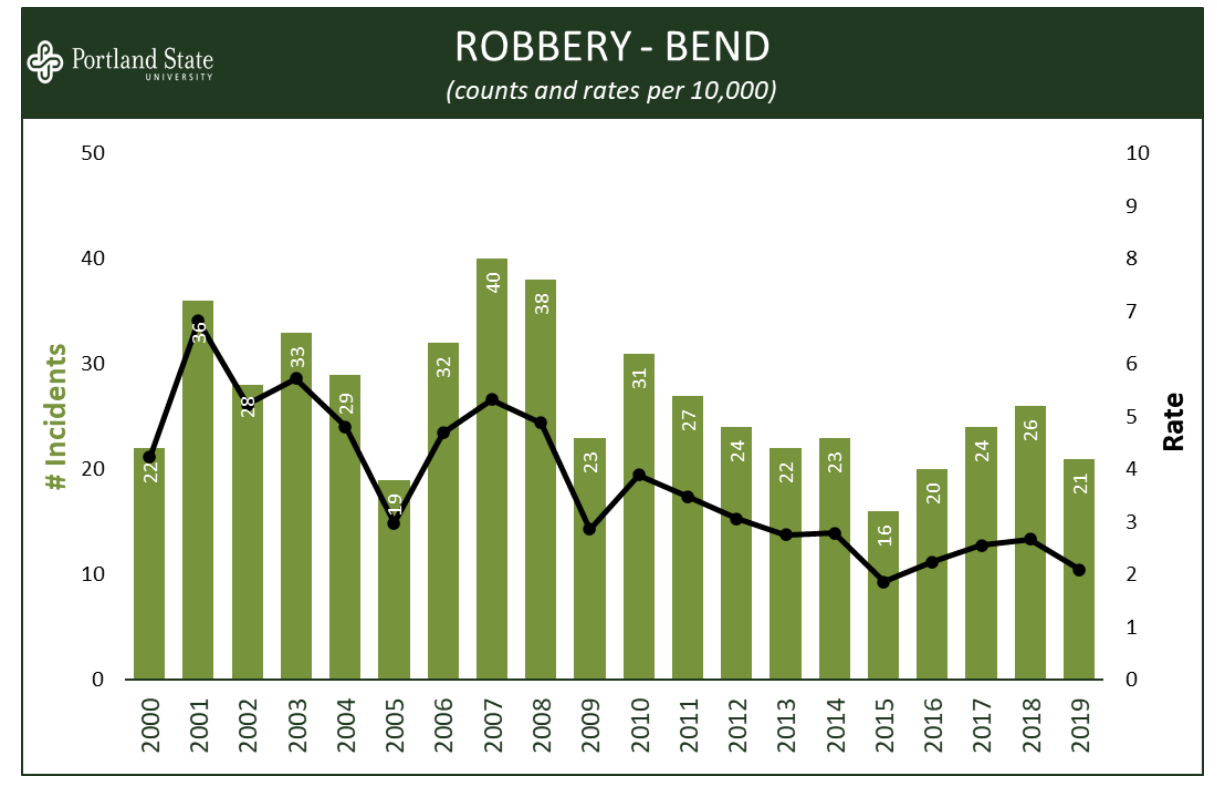

Figure 10

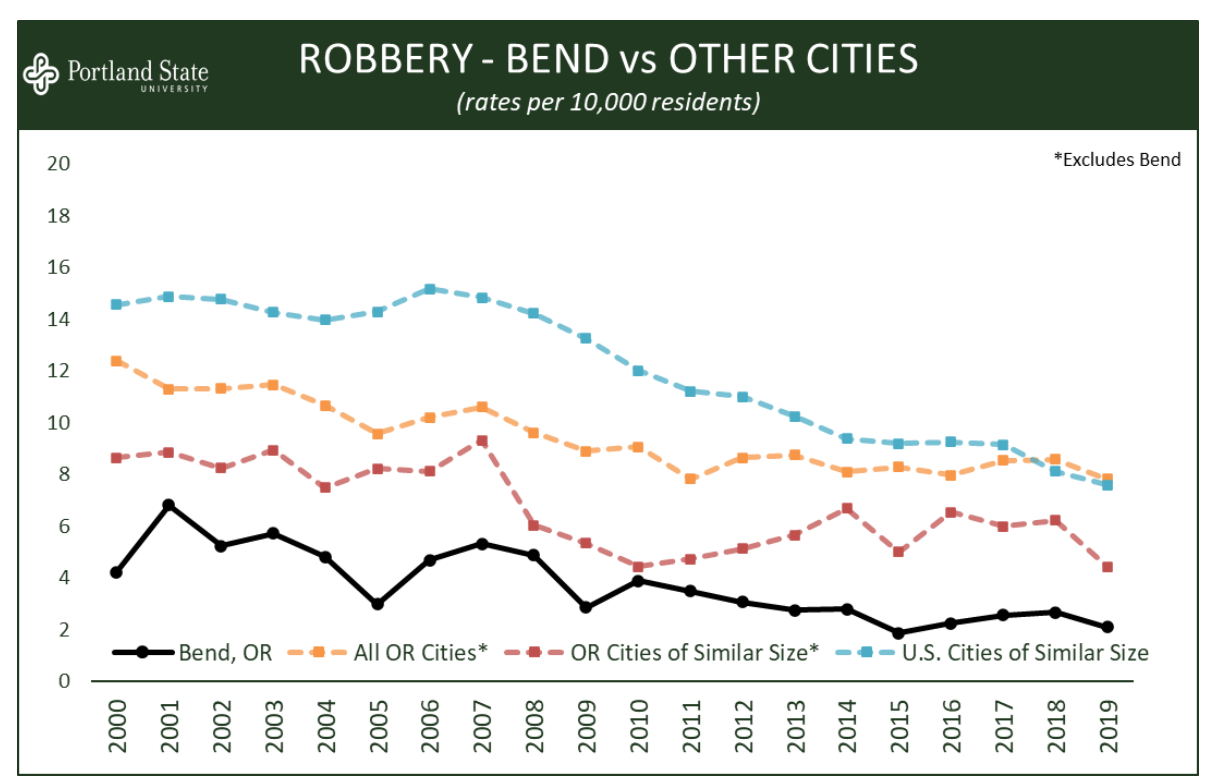

Figure 11 


\section{Rape}

Between 2000 and 2009, Bend's forcible rape incidents increased by $36.4 \%$ from 11 incidents in 2000 to 15 in 2009 , with the average being 19.1 incidents per year. As Bend's population grew by $54.8 \%$ during this time, the rate for forcible rape per 10,000 residents decreased by $11.9 \%$ from 2.1 in 2000 to 1.9 in 2009. Oregon cities of a similar population size also demonstrated a decrease in forcible rape rates, decreasing by $36.0 \%$ between 2000 (4.6) and 2009 (2.9). All cities in the state of Oregon demonstrated a similar trend in rape rates between 2000 (4.5) and 2009 (3.5), with an overall $-20.9 \%$ decrease. U.S. cities of a similar size

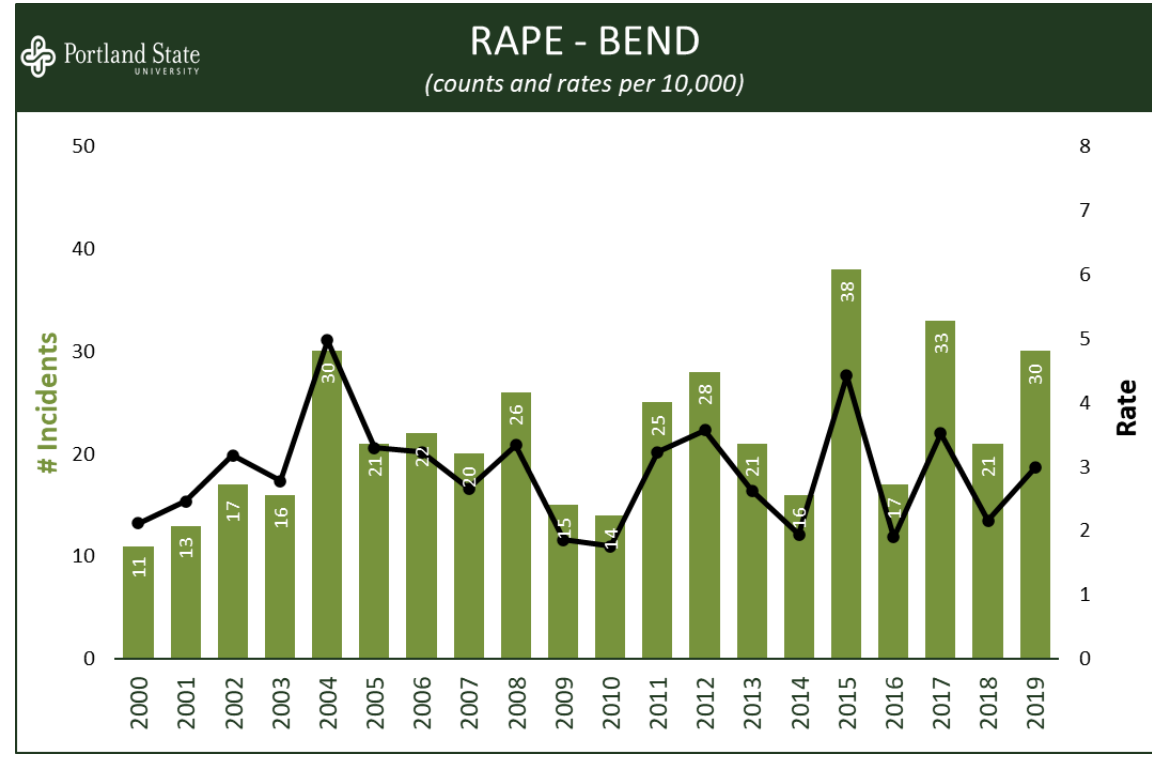

Figure 12 decreased similarly compared to Oregon in forcible rape rates, decreasing by $-19.3 \%$ between 2000 (3.6) and 2009 (2.9).

Bend's forcible rate count then increased by $114.3 \%$ between 2010 (14) and 2019 (30), with the average being 24.3 incidents per year. As Bend's population continued to grow by $26.4 \%$, the rate for forcible rape per 10,000 residents also increased by $69.5 \%$ from 2010 (1.8) to 2019 (3.0). In comparison, Oregon cities of a similar size continued to decrease in forcible rape rates between $2010(3.9)$ and 2019 (3.3) by $-16.7 \%$. However, the state of Oregon experienced an increase in rapes, with an overall $32.7 \%$ change between 2010 (3.7) and 2019 (4.9). U.S. cities of a similar size followed a similar trend, increasing in forcible rape rates by $39.3 \%$ from 2.8 incidents per 10,000 residents in 2010 to 4.0 incidents in 2019.

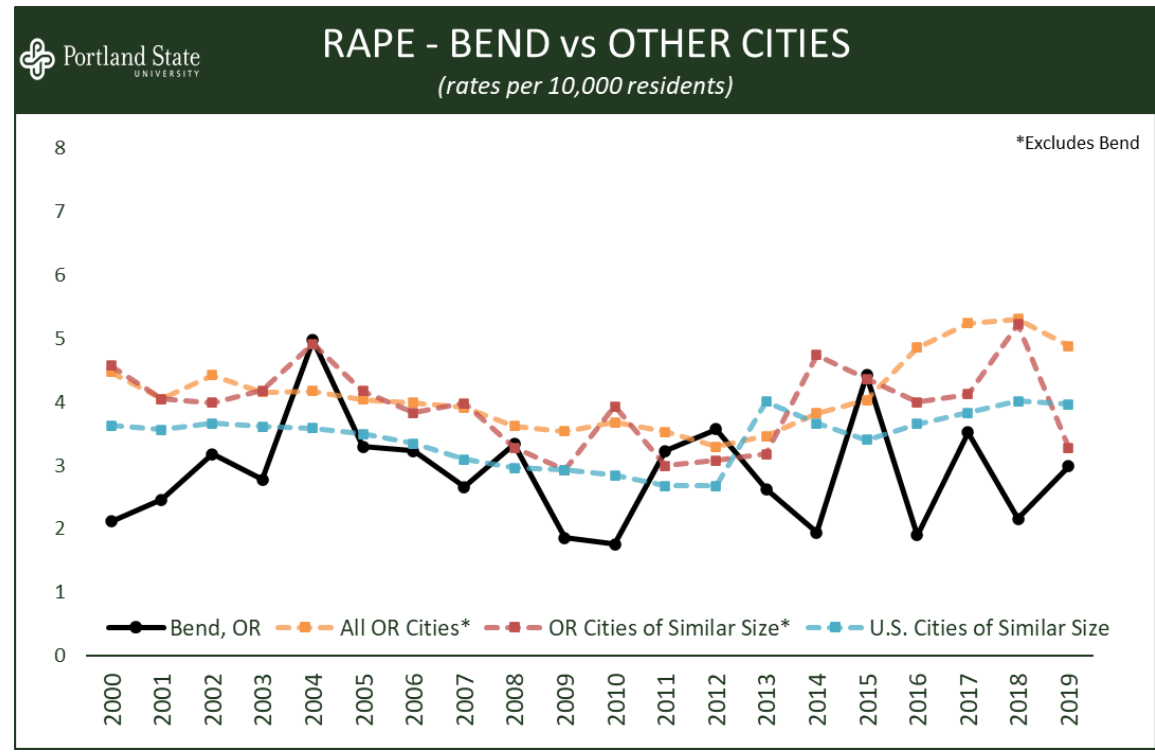

Figure 13 


\section{Property Crime}

Between 2000 and 2009, Bend's overall property crime incidents decreased by $-24.4 \%$ from 2,738 incidents in 2000 to 2,070 in 2009 , with the average being 2,958.7 incidents per year. As Bend's population grew by $54.8 \%$ during this time, the rate for property crime per 10,000 residents decreased by more than half $(-51.2 \%)$ from 526.2 in 2000 to 257.0 in 2009. Oregon cities of a similar population size demonstrated a similar trend in property crime rates, decreasing by $-47.7 \%$ between 2000 (570.1) and 2009 (298.4). The state of Oregon as a whole also witnessed a decrease in property crime between 2000 (566.9) and 2009 (405.1), with an overall -35.3\% decrease. U.S. cities an overall $-35.3 \%$ decrease. .S. cities of a similar population size saw a less significant negative trend in property crime rates, decreasing by $-19.1 \%$ between 2000 (412.6) and 2009 (333.9).

In the next ten-year period, Bend's property crime decreased by $-20.4 \%$ between $2010(2,410)$ and $2019(1,919)$, with the average being 2,185.8 incidents per year. Bend's population continued to grow by $26.4 \%$, while the rate for property crime per 10,000 residents decreased by $-37.0 \%$ from 2010 (302.9) to 2019 (190.8). Oregon cities of a similar size decreased less significantly in property crime rates between 2010 (291.1) and 2019 (278.9), with an overall $-4.2 \%$ change. All cities in the state of Oregon decreased similarly in property crime rates between 2010 (375.4) and 2019 (339.2), with an overall $-9.6 \%$ change. U.S. cities of a similar size continued to decrease in property crime rates by $-30.9 \%$, from 320.8 incidents per 10,000 residents in 2010 to 221.6 incidents in 2019.

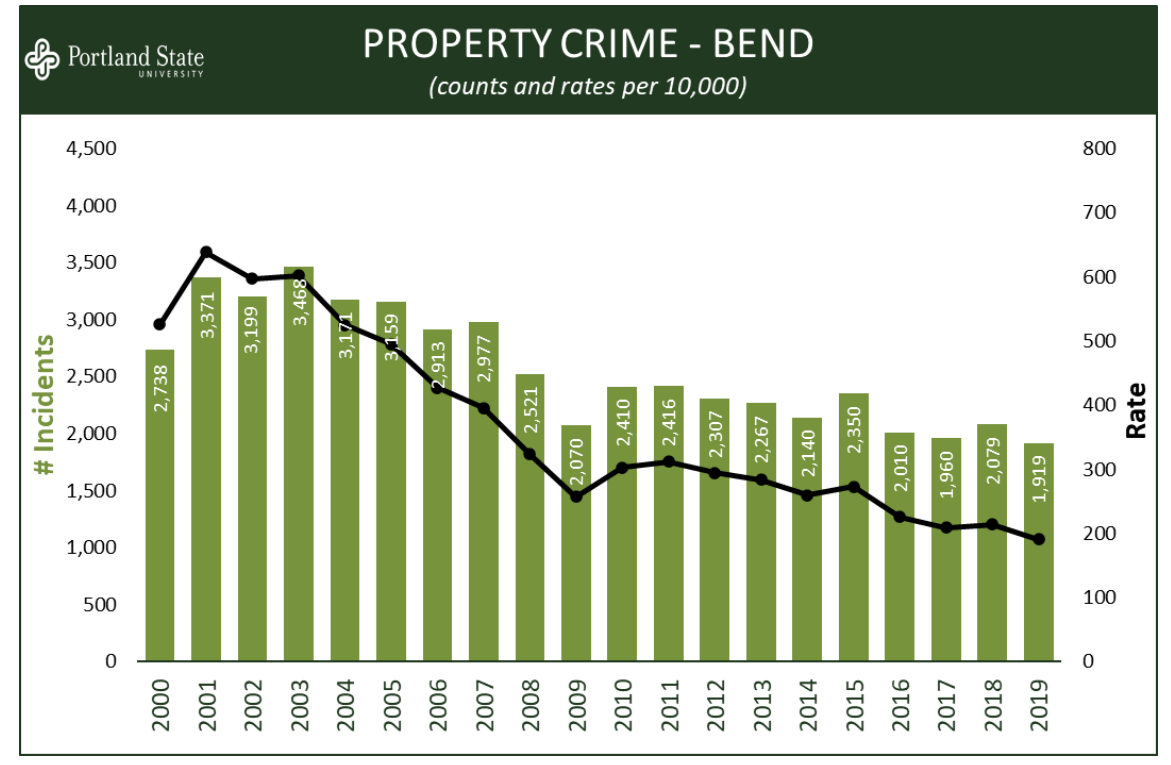

Figure 14

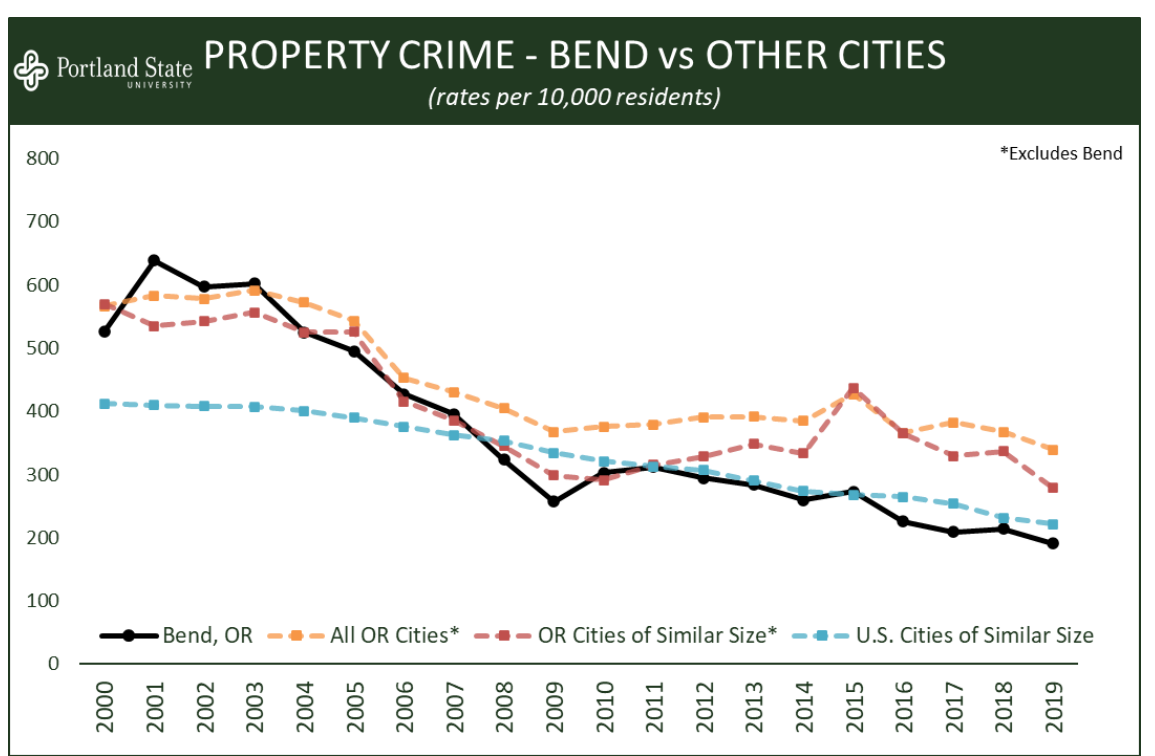

Figure 15 


\section{Larceny}

Between 2000 and 2009, Bend's larceny theft incidents decreased by $-22.5 \%$ from 2,157 incidents in 2000 to 1,672 in 2009 , with the average being 2,272.5 incidents per year. As Bend's population grew by $54.8 \%$ during this time, the rate for larceny theft per 10,000 residents decreased by almost half from 414.6 in 2000 to 207.6 in 2009 (-49.9\%). Oregon cities of a similar population size demonstrated a similar trend in larceny theft rates, decreasing by $44.7 \%$ between 2000 (428.3) and 2009 (236.9). The state of Oregon as a whole also demonstrated a steady decrease in larceny theft between 2000 (428.5) and 2009 (278.9), with an overall $-34.9 \%$ decrease. U.S. cities of a similar size also experienced a decrease in larceny theft rates, decreasing by $-19.1 \%$ between 2000 (288.9) and 2009 (233.7); although this decrease was not as significant as Bend's, the initial larceny theft rate for U.S. cities of a similar size was significantly lower.

Bend's larceny theft count continued to decrease by $-14.0 \%$ between $2010(1,951)$ and $2019(1,678)$, with the average being $1,851.8$ incidents per year. Bend's population continued to grow by $26.4 \%$, while the rate for larceny per 10,000 residents decreased by $-32.0 \%$ from 2010 (245.2) to 2019 (166.8). In comparison, Oregon cities of a similar size decreased slightly in larceny rates between 2010 (239.9) and 2019 (232.1) although not as significantly (-3.2\%). All Oregon cities saw a slightly higher decrease in larceny rates, with an overall $12.4 \%$ change between 2010 (286.6) and 2019 (251.0). U.S. cities of a similar size also decreased in larceny theft rates by about a quarter $(-25.2 \%)$, from 225.4 incidents per 10,000 residents in 2010 to 168.5 incidents in 2019.

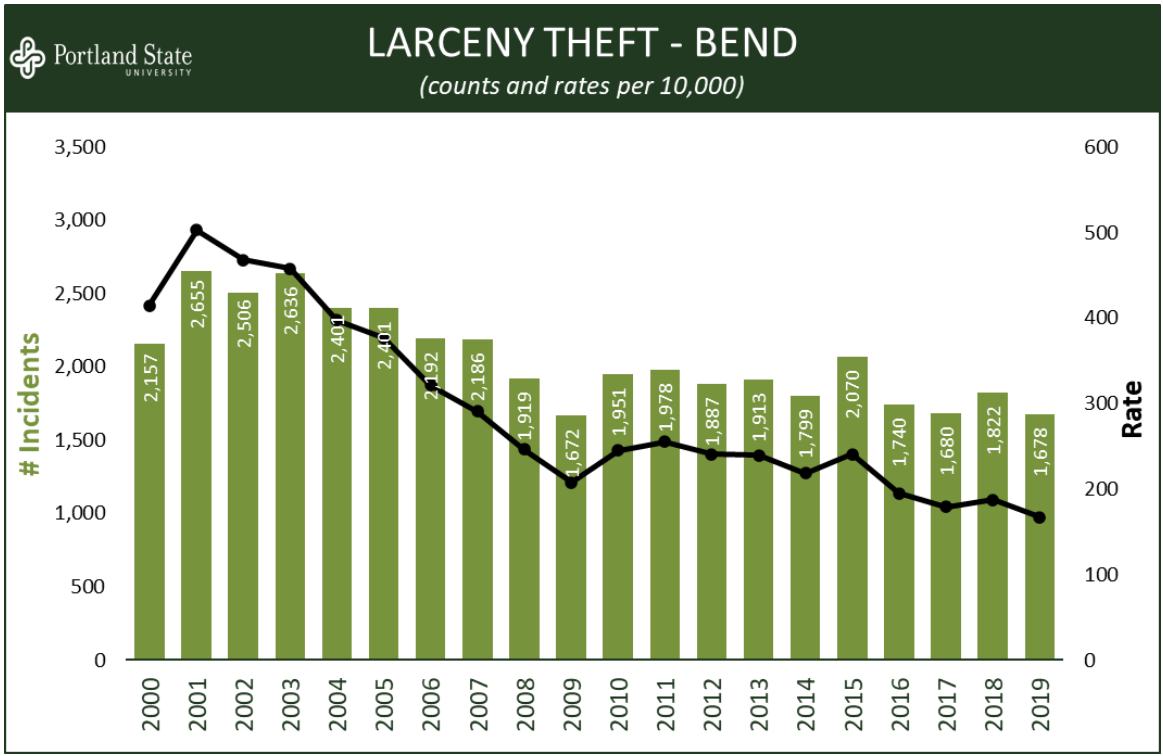

Figure 16

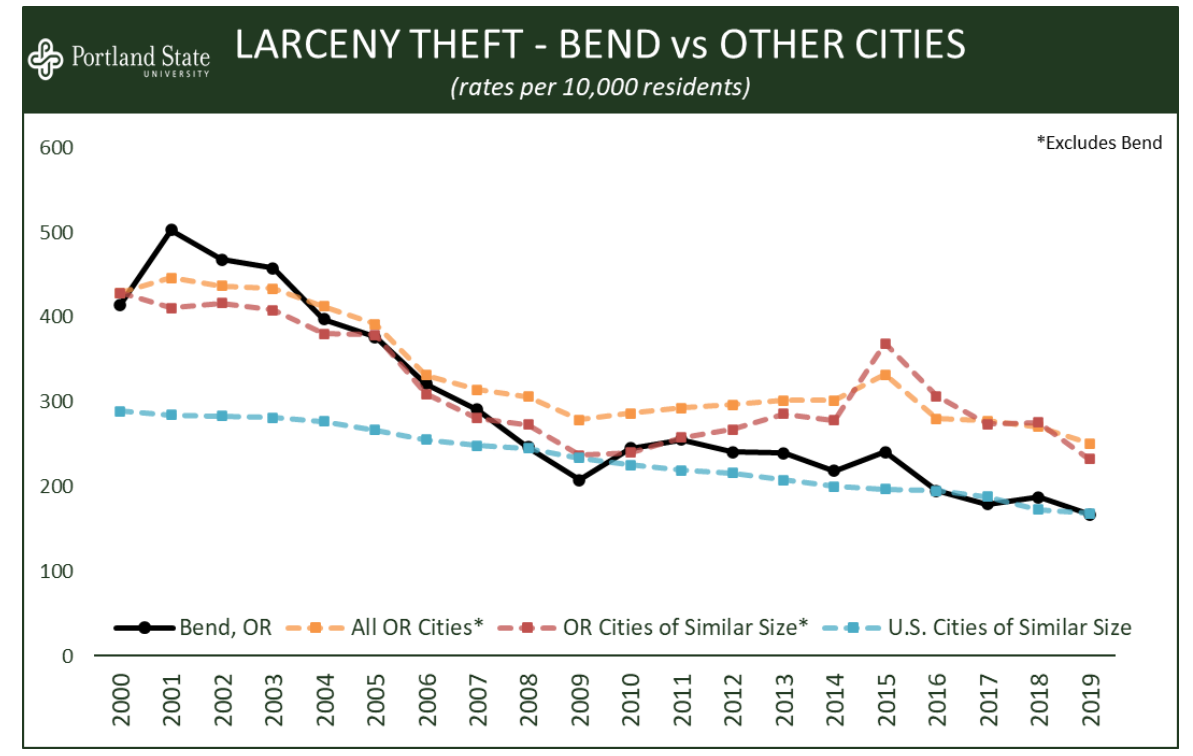

Figure 17 


\section{Motor Vehicle Theft}

Between 2000 and 2009, Bend's motor vehicle theft incidents decreased by almost half (-48.4\%) from 157 incidents in 2000 to 81 in 2009 , with the average being 183.7 incidents per year. As Bend's population grew by $54.8 \%$ during this time, the rate for motor vehicle theft per 10,000 residents decreased by $66.7 \%$ from 30.2 in 2000 to 10.1 in 2009. Oregon cities of a similar population size demonstrated a similar trend in motor vehicle theft rates, decreasing by $-67.7 \%$ between 2000 (60.4) and 2009 (19.5). All cities in the state of Oregon demonstrated a smaller decrease in motor vehicle theft between 2000 (52.3) and 2009

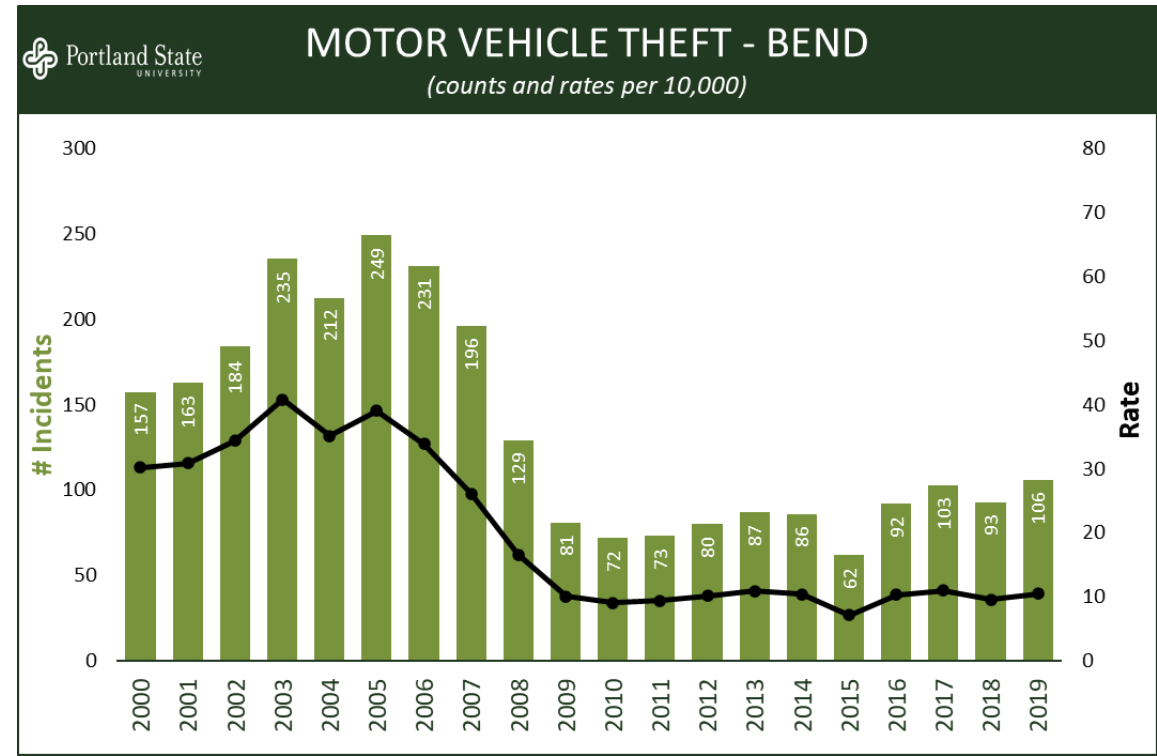

Figure 18

(32.1), with an overall $-38.6 \%$ decrease. U.S. cities of a similar size experienced a similar trend compared to Oregon in motor vehicle theft rates, decreasing by $-39.9 \%$ between $2000(45.0)$ and 2009 (27.0).

Bend's motor vehicle theft count then increased by $47.2 \%$ between 2010 (72) and 2019 (106), although the average incidents per year (85.4) was less than half of the previous ten-year period's average. As Bend's population continued to grow by $26.4 \%$, the rate for motor vehicle theft per 10,000 residents also increased by $16.4 \%$ from 2010 (9.1) to 2019 (10.5). In comparison, Oregon cities of a similar size increased more significantly $(43.4 \%)$ in motor vehicle theft rates between 2010 (15.3) and 2019 (21.9). The state of Oregon as a whole saw an even more dramatic increase in motor vehicle theft rates, with an overall $53.1 \%$ change

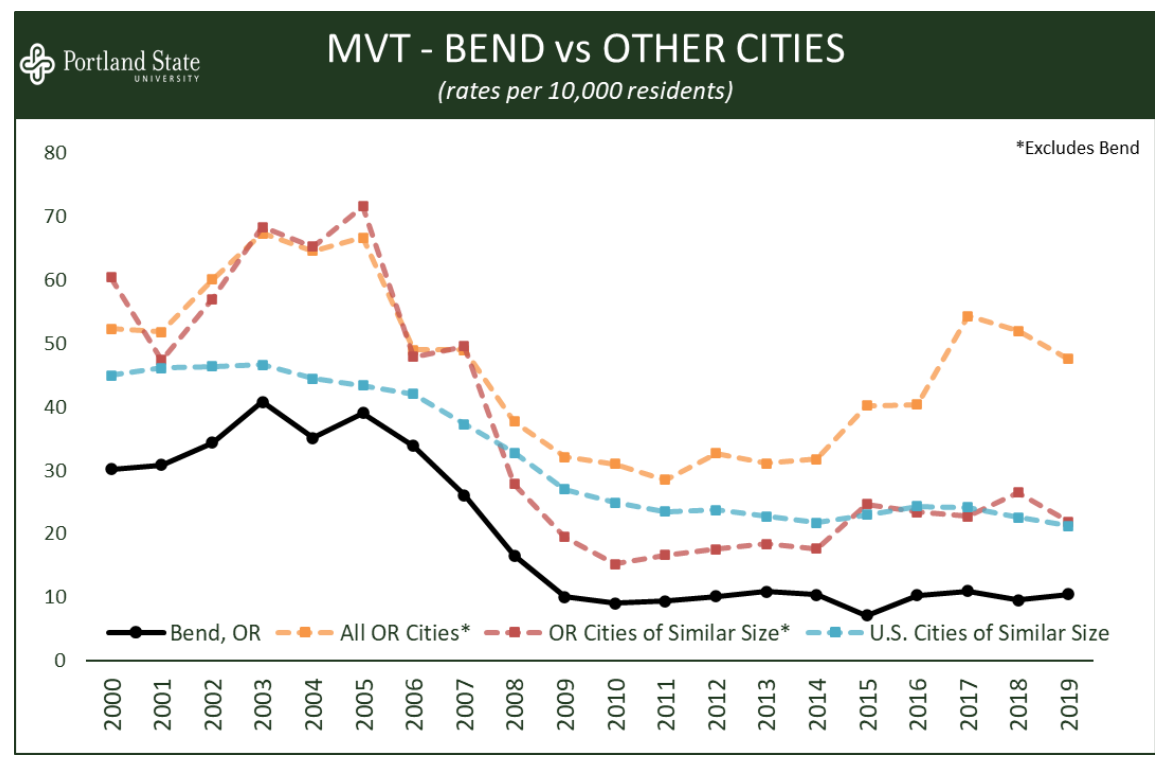

Figure 19 between 2010 (31.0) and 2019 (21.9). In contrast, U.S. cities of a similar size continued to decrease in motor vehicle theft rates by $-14.7 \%$, from 24.9 incidents per 10,000 residents in 2010 to 21.2 incidents in 2019. 


\section{Burglary}

Between 2000 and 2009, Bend's burglary incidents decreased by $25.2 \%$ from 424 incidents in 2000 to 317 in 2009 , with the average being 502.5 incidents per year. Due to the $54.8 \%$ population growth during this time, the rate for burglary per 10,000 residents decreased significantly from 81.5 in 2000 to 39.4 in 2009 (-51.7\%). Oregon cities of a similar population size demonstrated a similar trend in burglary rates, decreasing by $-48.5 \%$ between 2000 (81.5) and 2009 (42.0). Oregon cities also demonstrated a steady decrease in burglary rates between 2000 (86.1) and 2009 (56.0), with an overall $-30.5 \%$ decrease. Although not as significant as Bend and the state of Oregon as a whole, U.S. cities of a similar size experienced a slightly negative trend in burglary rates, decreasing by $-6.9 \%$ between 2000 (78.6) and 2009 (73.2).

Bend's burglaries continued to decrease by $-65.1 \%$ between 2010 (387) and 2019 (135), with the average being 248.6 incidents per year. Bend's population continued to grow by $26.4 \%$, while the rate for burglary per 10,000 residents decreased significantly by $-72.4 \%$ from 2010 (48.6) to 2019 (13.4). Oregon cities of a similar size also decreased in burglary rates between 2010 (18.7) and 2019 (14.0), although not as significantly ($30.6 \%)$. Oregon as a whole saw a similar decrease in burglary rates, with an overall $-30.8 \%$ change between 2010 (57.8) and 2019 (40.0). Cities of a similar size in the U.S. also decreased in burglary rates by more than half $(-55.3 \%)$, from 71.1 incidents per 10,000 residents in 2010 to 31.8 incidents in 2019.

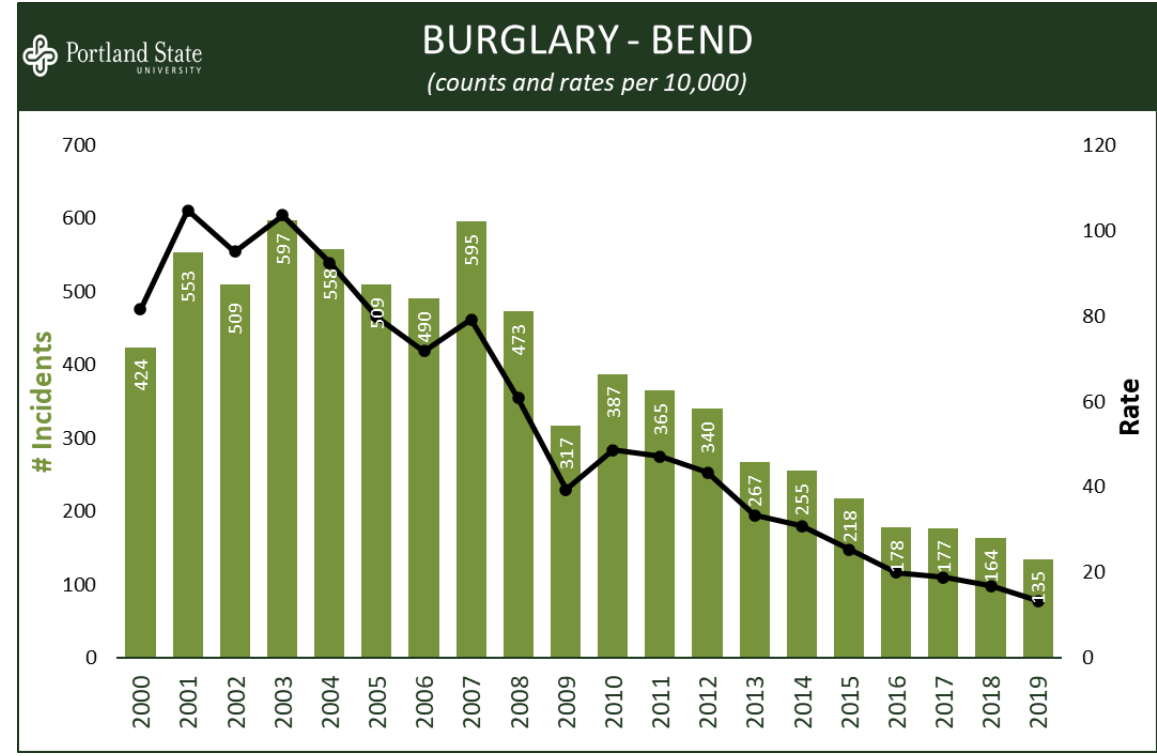

Figure 20

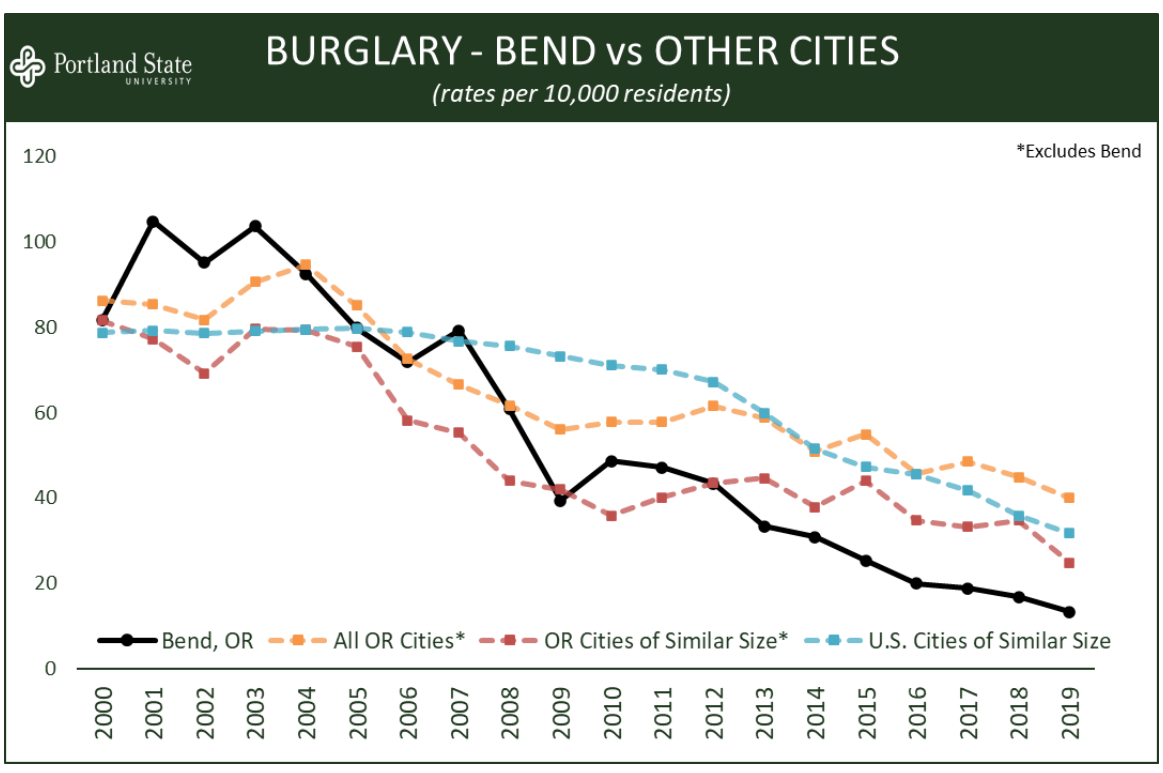

Figure 21 


\section{NIBRS Data (2010-2018)}

Now we will transition to analyzing NIBRS data between 2010 and 2018; while we do not have as much NIBRS data over time as UCR, NIBRS provides us with more detailed data on the nature of crime in Bend, Oregon. Between 2010 and 2018, Bend, Oregon experienced 37,048 total criminal incidents. Incidents decreased by $-12.9 \%$ overall, from 4,484 incidents in 2010 to 3,906 in 2018 . The average crime rate per 10,000 residents between 2010 and 2018 was 493.2. During this period, Bend's crime rate decreased by almost a third (-31.5\%) from 585.1 incidents per 10,000 residents to 401.0. The average number of offenses per incident in Bend between 2010 and 2018 was 1.1, ranging from one offense to seven in a single incident. However, most incidents only consisted of one $(32,613,88.0 \%)$, two $(3,880,10.5 \%)$, or three $(478,1.3 \%)$ offenses. The total number of offenses committed in Bend between 2010 and 2018 was 42,130.

\section{Temporal Trends}

Incidents in Bend, Oregon between 2010 and 2018 had a relatively stable monthly trend, with an average of 338.0 incidents per month and a standard deviation of 35.6. Bend experienced a slight increase in average incident counts during the months of June (366.1), July (416.1), and August (385.9); however, only July's increase was statistically significant. April demonstrated a slight decrease in average incident count (266.8), however it was not found to be statistically significant.

Incidents in Bend between 2010 and 2018 had a relatively stable pattern throughout the weekdays, with an average of 588.0 incidents per day of week and a standard deviation of 38.0. Fridays experienced a slight increase in average incident count (662.1); however, it was not found to be statistically significant. Additionally, there was a slight decrease in average incident counts on Sundays (523.8), although this change was not found to be statistically significant.

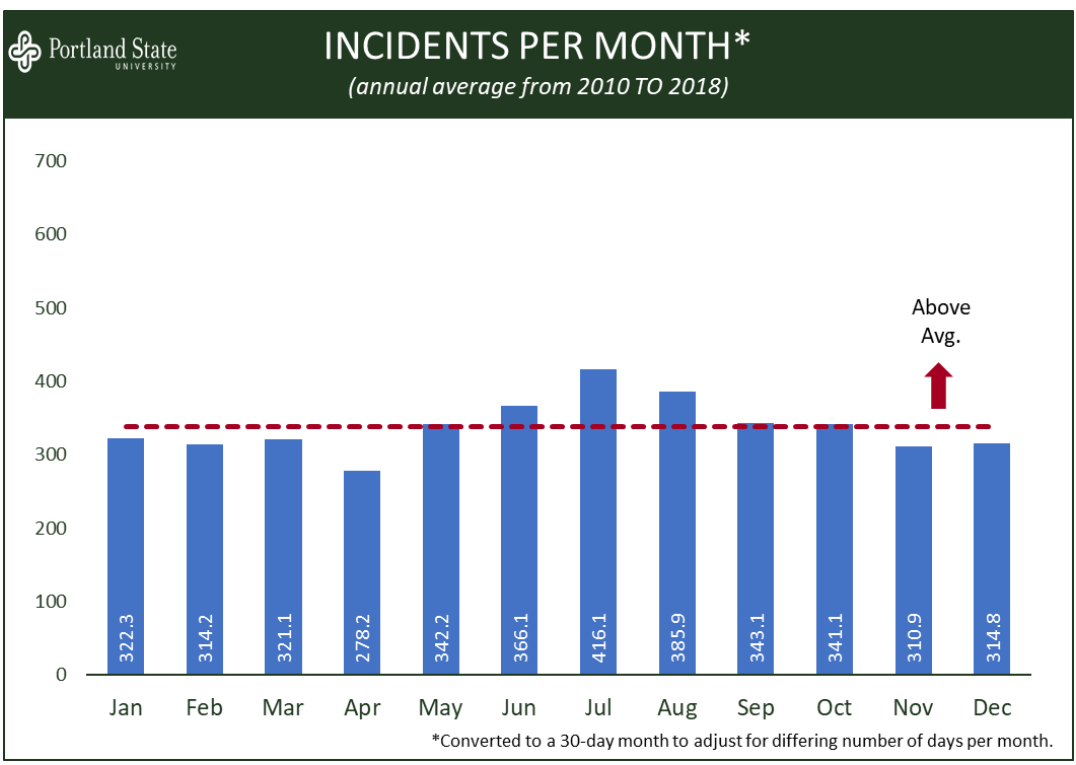

Figure 22

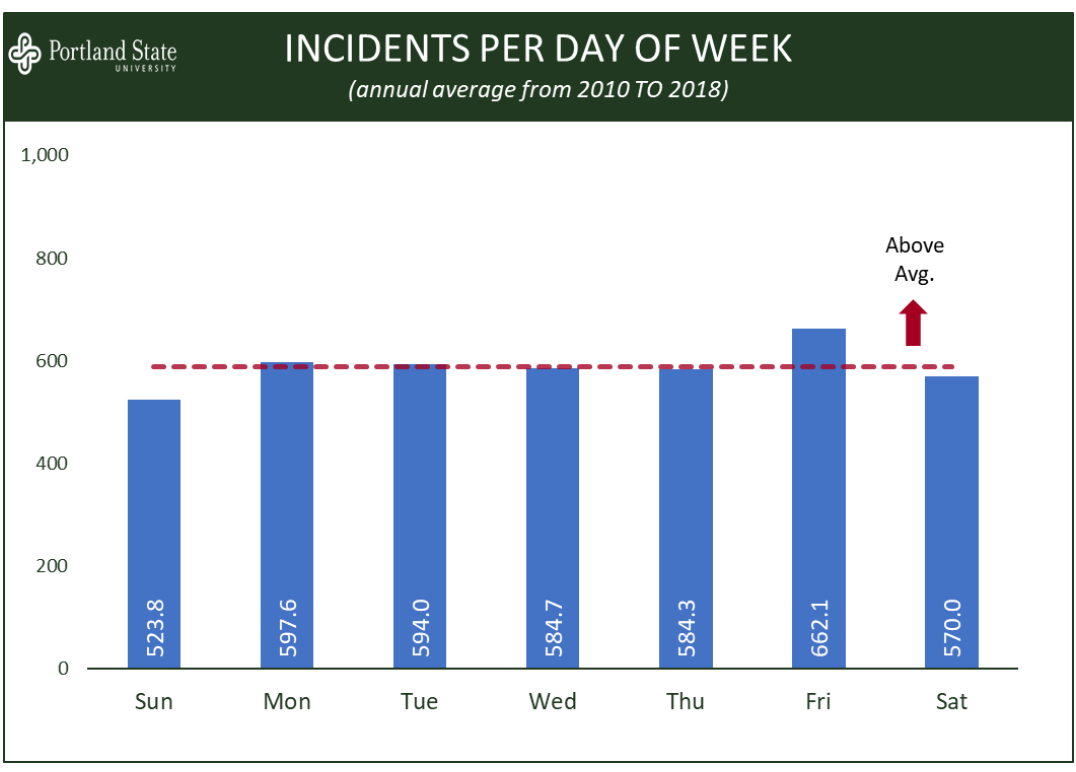

Figure 23 
Average incident counts for Bend between 2010 and 2018 experienced more temporal fluctuations depending on the hour of day, with incidents occurring more frequently between 11:00am and 12:00am. The average incident count during this period was 132.7 incidents per hour with a standard deviation of 56.8 . Incident counts tended to be above slightly above average between 11:00am (130.3) and midnight (131.0), and overall decreased between 1:00am (114.6) and 10:00am (120.8) Although there was slight variation in average incident counts throughout the day, there were no hours of the day that experienced a statistically significant increase or decrease in average number of incidents, with the exception of Saturdays at 5:00pm.

\section{Victim and Offender Statistics}

There were 27,643 total victims in Bend, Oregon between 2010 and 2018, with the average number of victims per incident being 0.7 . Most incidents involved only one victim $(23,329,63.0 \%)$; however, many incidents were victimless $(11,872$, $32.0 \%)$. Only $1,847(5.0 \%)$ incidents involved two victims or more, with the maximum being 20 in one incident. The number of victims decreased between $2010(3,675)$ and $2018(2,721)$ by $-26.0 \%$. The rate of victimization per 10,000 residents decreased from 479.5 in 2010 to 279.4 in 2018 , a $-41.7 \%$ change.

The three most common victim types in Bend, Oregon incidents were Individuals $(25,446,65.0 \%)$, Businesses $(7,623,19.5 \%)$, and Society/ Public $(5,334,13.6 \%)$. The remaining victim types included Government (426, 1.1\%), Law Enforcement Officer (111, 0.3\%), Financial Institution (111, 0.3\%), Religious Organization (37, 0.1\%), and Other/ Unknown (79, 0.2\%). There were 21,055 known offenders in Bend between 2010 and 2018. However, it should be noted that this statistic includes offenders identified in reports, therefore some of these offenders are likely the same person that reoffended and not 21,055 different people. In most incidents there were no known offenders $(20,073,54.2 \%)$, followed by one known offender per incident $(14,086,38.0 \%)$. Only 2,889 incidents $(7.8 \%)$ had two or more known offenders, with the maximum number being 11 in two incidents. The number of known offenders stayed relatively stable between $2010(2,671)$ and 2018 $(2,463)$, with a decrease of $-7.8 \%$.

The most common relationships found between victims and offenders were Acquaintance $(1,559$, $31.0 \%)$, Current/ Former Intimate Partner $(1,477,28.7 \%)$, Stranger $(1,005)$, and Family Member 
(845). The remaining relationships were Unknown (120), and in 29 incidents, the victim was also an offender. Cases in which a victim is also an offender include situations in which someone participates in an offense but is simultaneously victimized by other offenders, a common example is bar brawls.

\section{Clearance}

Of the 37,408 incidents in Bend between 2010 and 2018 , one third $(12,470,33.3 \%)$ of the incidents were Cleared by Arrest. The remaining incidents were either Not Cleared $(24,406,65.2 \%)$ or Cleared Exceptionally (172, $0.5 \%)$. Of the cases that were Cleared Exceptionally, 141 incidents were cleared because Prosecution Declined for a reason other than lack of probable cause $(0.4 \%), 27$ were cleared because the Victim Refused to Cooperate $(0.1 \%), 2$ were cleared due to the Death of Offender $(0.0 \%)$, and 2 were cleared by Juvenile/ No Custody $(0.0 \%)$. The latter refers to the handling of a juvenile without taking them into custody, but rather by oral or written notice given to the parents or legal guardian in a case involving a minor offense, such as petty larceny.

\section{Property Loss}

Between 2010 and 2018, Bend experienced 28,975 incidents involving property loss, with a total loss of $\$ 40,087,303$ reported. However, this total includes incidents in which the value of the property loss was not reported. To correct this, we substituted incidents missing values with the mean value of the property that was damaged. Including these mean substitutions, the total loss in Bend between 2010 and 2018 was found to be $\$ 42,019,175$. It is important to keep in mind that the actual property loss values are likely somewhere in between the reported cost and the mean substitution cost. The mean substitution values for each property loss category (Stolen, Burned, Counterfeited/ Forged) will be presented in Tables 3-5. Additionally, it should be noted that these values have

\begin{tabular}{|cccc|}
\hline 色 Portland State & \multicolumn{3}{c|}{$\begin{array}{c}\text { OFFENDERS } \\
(2010-2018)\end{array}$} \\
\hline Year & Offenders & Rate (per 10,000) & \% Change YTY \\
\hline 2010 & 2,671 & 348.5 & \\
2011 & 2,417 & 312.1 & $-10.5 \%$ \\
2012 & 2,383 & 303.7 & $-2.7 \%$ \\
2013 & 2,629 & 328.9 & $8.3 \%$ \\
2014 & 2,207 & 267.8 & $-18.6 \%$ \\
2015 & 2,142 & 248.9 & $-7.0 \%$ \\
2016 & 2,002 & 224.3 & $-9.9 \%$ \\
2017 & 2,141 & 228.3 & $1.8 \%$ \\
2018 & 2,463 & 252.9 & $10.8 \%$ \\
\hline Grand Total & $\mathbf{2 1 , 0 5 5}$ & & $-27.4 \%$ \\
Note: Percent change calculates change in rate rather than count. YTY = Year to Year. \\
\hline
\end{tabular}

Table 2

\begin{tabular}{|c|c|c|c|c|}
\hline \multicolumn{4}{|c|}{ 胥 Portland State } & \multirow[b]{2}{*}{ Total Costs (\$) } \\
\hline Year & Incidents & $\%$ Change & Avg. Cost (\$) & \\
\hline 2010 & 2,512 & & $2,389.56$ & $6,002,573$ \\
\hline 2011 & 2,942 & $17.1 \%$ & 939.03 & $2,762,633$ \\
\hline 2012 & 2,405 & $-18.3 \%$ & $1,784.98$ & $4,292,875$ \\
\hline 2013 & 2,348 & $-2.4 \%$ & $1,154.64$ & $2,711,102$ \\
\hline 2014 & 2,286 & $-2.6 \%$ & $1,368.14$ & $3,127,563$ \\
\hline 2015 & 2,456 & $7.4 \%$ & $1,651.66$ & $4,056,468$ \\
\hline 2016 & 2,137 & $-13.0 \%$ & $1,547.72$ & $3,307,484$ \\
\hline 2017 & 2,099 & $-1.8 \%$ & $1,637.38$ & $3,436,869$ \\
\hline 2018 & 2,208 & $5.2 \%$ & $2,125.37$ & $4,692,818$ \\
\hline Grand Total & 21,393 & $-12.1 \%$ & $1,607.55$ & $34,390,385$ \\
\hline \multicolumn{5}{|c|}{$\begin{array}{l}\text { Note: Percentage change describes changes in the number of incidents in which property was burned between each } \\
\text { year. For incidents in which the cost of property loss was not recorded, the mean value of the damaged property } \\
\text { was substituted. }\end{array}$} \\
\hline
\end{tabular}

Table 4

\begin{tabular}{|ccccc|}
\hline 色 Portland State & \multicolumn{5}{c|}{$\begin{array}{c}\text { PROPERTY BURNED } \\
\text { (2010-2018) }\end{array}$} \\
\hline Year & Incidents & \% Change & Avg. Cost (\$) & Total Costs (\$) \\
\hline 2010 & 976 & & $1,031.69$ & $1,006,931$ \\
2011 & 930 & $-4.7 \%$ & 632.22 & 587,962 \\
2012 & 1,026 & $10.3 \%$ & 612.29 & 628,207 \\
2013 & 857 & $-16.5 \%$ & $1,145.90$ & 982,033 \\
2014 & 715 & $-16.6 \%$ & 861.14 & 615,713 \\
2015 & 611 & $-14.5 \%$ & $1,398.52$ & 854,495 \\
2016 & 505 & $-17.3 \%$ & $1,335.36$ & 674,358 \\
2017 & 596 & $18.0 \%$ & $1,129.11$ & 672,951 \\
2018 & 595 & $-0.2 \%$ & $1,731.72$ & $1,030,375$ \\
\hline $\begin{array}{l}\text { Grand Total } \\
\text { Note: Percentage change describes changes in the number of incidents in which property was burned between each } \\
\text { year. For incidents in which the cost of property loss was not recorded, the mean value of the damaged property } \\
\text { was substituted. }\end{array}$ & $\mathbf{6}, \mathbf{4}$ &
\end{tabular}

Table 3 
not been adjusted for inflation between 2010 and 2018, and therefore the losses may be less significant as time goes on.

Property Stolen comprised most of Bend's property losses (73.8\%) between 2010 and 2018; there were 21,393 incidents involving stolen property with a total reported loss of $\$ 33,340,038$. During this nine-year period, incidents involving stolen property loss decreased overall by $-12.1 \%$ from 2,512 incidents in 2010 to 2,208 in 2018 . The average reported loss for stolen property per incident was $\$ 1,558.46$.

Property Burned accounted for almost a quarter of Bend's property losses (23.5\%) between 2010 and 2018; there were 6,811 incidents involving burned property with a total reported loss of $\$ 6,229,725$. During this nine-year period, incidents involving burned property decreased overall by $-39.0 \%$ from 976 incidents in 2010 to 595 in 2018 . The average reported loss for burned property per incident was $\$ 914$.

The remaining property loss in Bend between 2010 and 2018 was due to Property Counterfeited/ Forged (2.7\%); there were 771 incidents involving property loss due to counterfeiting or forging with a total reported loss of $\$ 517,540$. During this nine-year period, incidents involving counterfeited/ forged property resulting in a loss increased by $61.3 \%$ from 80 incidents in 2010 to 129 in 2018. The average reported loss for property that was counterfeited or forged per incident was \$671.26.

\begin{tabular}{|c|c|c|c|c|}
\hline \multicolumn{5}{|c|}{$\begin{array}{l}\text { PROPERTY COUNTERFEITED/FORGED } \\
\text { (2010-2018) }\end{array}$} \\
\hline Year & Incidents & $\%$ Change & Avg. Cost (\$) & Total Costs (\$) \\
\hline 2010 & 80 & & 599.99 & 47,999 \\
\hline 2011 & 118 & $47.5 \%$ & 645.00 & 76,110 \\
\hline 2012 & 58 & $-50.8 \%$ & $1,074.83$ & 62,340 \\
\hline 2013 & 74 & $27.6 \%$ & 861.99 & 63,787 \\
\hline 2014 & 53 & $-28.4 \%$ & $1,382.32$ & 73,263 \\
\hline 2015 & 65 & $22.6 \%$ & 518.78 & 33,721 \\
\hline 2016 & 70 & $7.7 \%$ & 365.74 & 25,602 \\
\hline 2017 & 124 & $77.1 \%$ & 354.49 & 43,957 \\
\hline 2018 & 129 & $4.0 \%$ & $1,154.93$ & 148,986 \\
\hline Grand Total & 771 & $61.3 \%$ & 746.78 & 575,765 \\
\hline $\begin{array}{l}\text { Note: Percentage ch } \\
\text { year. For incidents ir } \\
\text { was substituted. }\end{array}$ & $\begin{array}{l}\text { scribes } c \\
\text { the cost }\end{array}$ & 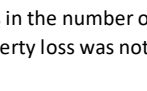 & ts in which prop & $\begin{array}{l}\text { burned between each } \\
\text { damaged property }\end{array}$ \\
\hline
\end{tabular}

Table 5 


\section{ASSAULT/INTIMIDATION OFFENSES}

\section{Introduction \& Offense Subtypes}

In this section we will be examining Assault/Intimidation offenses in Bend, Oregon between 2010 and 2018. This offense subgroup consists of Intimidation, Simple Assault, Aggravated Assault, and Murder/Nonnegligent Manslaughter. Our analysis excludes Negligent Manslaughter since there was only one instance of this offense in Bend during our nine-year period of study. It should be noted that these offenses are named and defined by the FBI. Oregon's Revised Statutes (ORS) addressing assaultive behaviors have different labels and have been cross-coded into the FBl's crime categories used in the present report. For example, the FBI's Aggravated Assault is equivalent to Oregon's Assault in the $1^{\text {st }}$ Degree, which is defined as "Intentionally causing serious physical injury to another by means of a deadly or dangerous weapon." "Provided below are the FBl's definitions for each offense subtype in this section of the report. ${ }^{5}$ We also provide the aggregate counts and rates for each offense in Bend between 2010 and 2018. The remainder of this section will analyze these Assault/Intimidation offenses collectively.

\section{Intimidation}

The FBI defines Intimidation as: "Unlawfully placing another person in reasonable fear of bodily harm through the use of threatening words and/or other conduct but without displaying a weapon or subjecting the victim to actual physical attack." Intimidation was the second most common subtype of Assault/Intimidation offense in Bend during the study period, accounting for $39.1 \%(1,844)$ of these crimes. The average number of offenses per year was 204.9 and the average annual rate was 2.4 per 1,000 residents.

\section{Simple Assault}

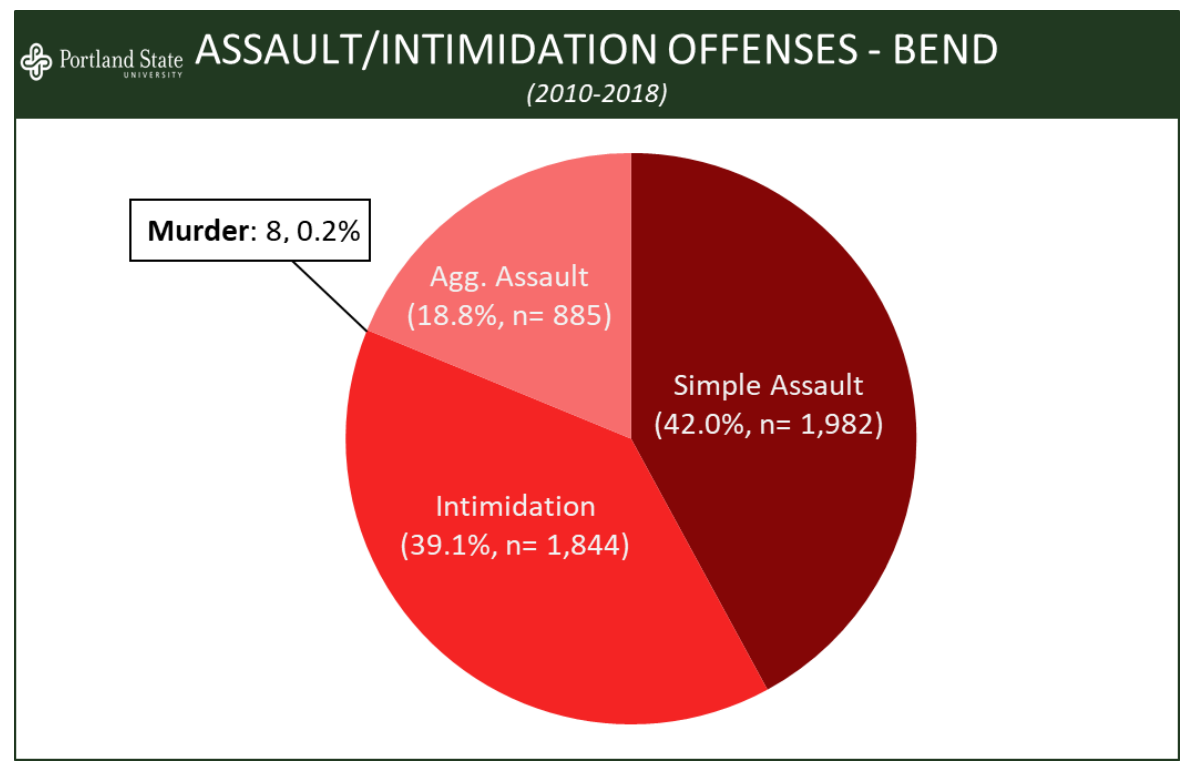

Figure 25

Simple Assault as defined by the FBI involves an, "Unlawful physical attack by one person upon another where neither the offender displays a weapon, nor the victim suffers obvious severe or aggravated bodily injury involving apparent broken bones, loss of teeth, possible internal injury, severe laceration, or loss of consciousness." This was the most common subtype of Assault/Intimidation offense in Bend during the years examined. There were 1,982 Simple Assaults, accounting for $42.0 \%$ of all Assault/Intimidation offenses. The average number of Simple Assaults per year was 220.2 and the average annual rate was 2.7 per 1,000 residents. 


\section{Aggravated Assault}

The FBI classifies Aggravated Assault as an "Unlawful attack by one person upon another wherein the offender uses a weapon or displays it in a threatening manner, or the victim suffers obvious severe or aggravated bodily injury involving apparent broken bones, loss of teeth, possible internal injury, severe laceration, or loss of consciousness." This was the third most common subtype of Assault/Intimidation offense in Bend, accounting for 885 offenses or $18.8 \%$ of the total. The average number of Aggravated Assaults per year in the city was 98.3 and the average annual rate was 1.2 per 1,000 residents.

\section{Murder}

Murder/Nonnegligent Manslaughter 6 is defined by the FBI as, "The willful (non-negligent) killing of one human being by another." Non-negligent in this context means that the victim did not die as a result of unintentional, albeit risky, actions of the suspect. Murder was the least common subtype of Assault/Intimidation offense in Bend between 2010 and 2018. There was a total of eight murders, accounting for $0.2 \%$ of all Assault/Intimidation offenses.

\section{Annual Trend}

There was a total of 4,719

Assault/Intimidation offenses in Bend during the 9-year study period, or an average of 524.3 offenses per year. The number of offenses per year declined $15.5 \%$ from 2010 to 2018. As show in Figure 26, this does not represent a singular downward trend. The lowest number of offenses $(n=396)$ happened in 2016. From there to 2018 this category of crime rose $38.6 \%$. However, offense counts like these fail to consider changes in the underlying population, so we also calculated the annual rate of Assault/Intimidation offenses per 1,000 residents using U.S. Census

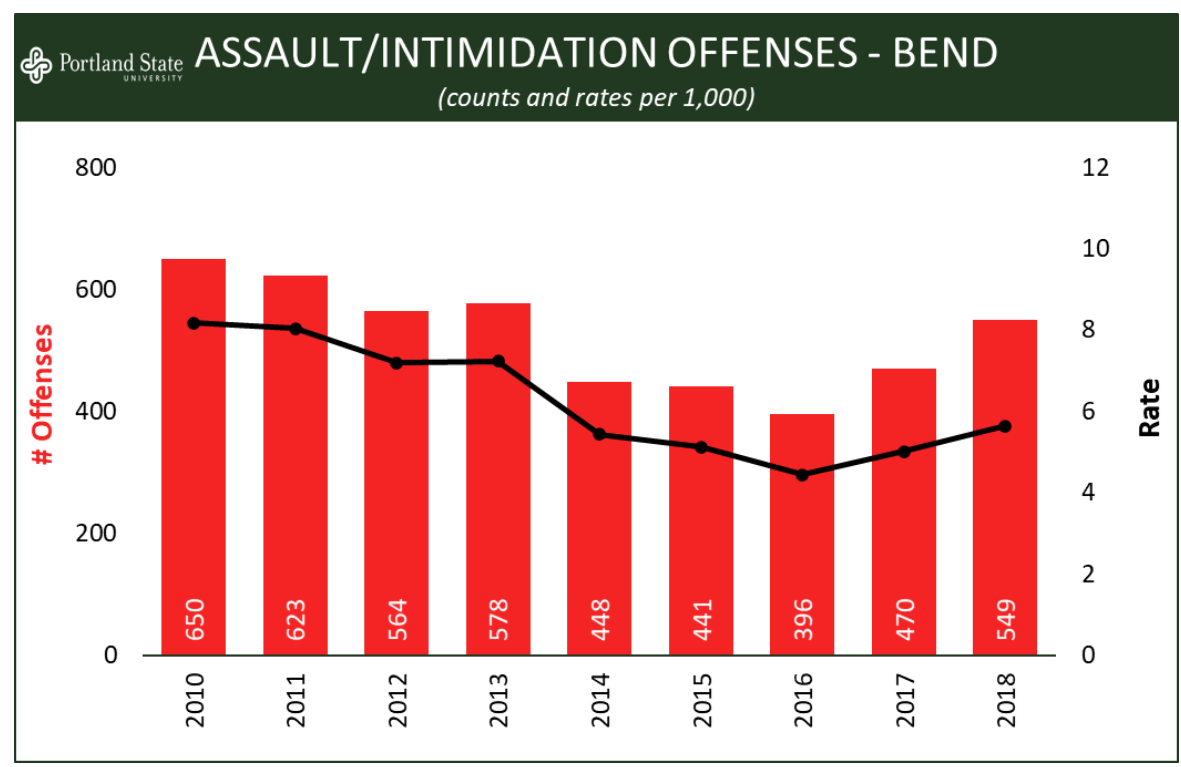

Figure 26 estimates for Bend. The rate for these offenses decreased $-31.0 \%$ from $2010(8.2$ per 1,000) to 2018 $(5.6$ per 1,000$)$. Consistent with the finding for counts, the rate of Assault/Intimidation offenses for 2018 was $27.0 \%$ higher than 2016.

\section{Temporal Patterns}

We assessed monthly or seasonal patterns in Assault/Intimidation offenses by calculating the average number of offenses per month across the 9 -year study period. ${ }^{7}$ Bend averaged 43.1 offenses per month during this period of time. Higher monthly averages were found for May, June, July, August, and October. The only month that was well above average (i.e., 2+ standard deviations above average) was July, with an average number of 52.4 offenses. April was the only month that was well

\footnotetext{
${ }^{6}$ We refer to this offense as Murder throughout the rest of our analyses for the sake of brevity.

${ }^{7}$ Monthly counts were standardized to a 30-day month to control for the fact that some months have more days than others.
} 
below average (i.e., 2+ standard deviations below average), with an average of 34.2 offenses.

With regard to the distribution of Assault/Intimidation offenses by day of week, we found that slightly higher proportions of these offenses happened on Fridays (15.0\%), Saturdays (16.6\%), and Sundays (16.3\%). None of these days exceeded our threshold for being well above average (i.e., 2+ standard deviations above the mean).

Figure 29 documents the distribution of Assault/Intimidation offenses in Bend by time of day across the 9year study period. Offenses were above average between 3:00pm and 2:00am, with the highest peak occurring between 8:00pm (6.7\%) and $9: 00 \mathrm{pm}(6.8 \%)$. Although there were also notable increases at $12: 00 \mathrm{pm}(4.8 \%)$ and $12: 00 \mathrm{am}$ $(7.0 \%)$, this could potentially be due to reporting estimates. This is because if the exact time of an offense is unknown, agencies will often estimate noon or midnight as the time of occurrence when reporting the incident. Although no specific hour of day was found to be well above average, the percentage of offenses that occurred at $8: 00 \mathrm{pm}$ (6.7\%), 9:00pm (6.8\%), 10:00pm $(6.3 \%)$, and $12: 00 \mathrm{pm}(7.0 \%)$ were above the average number of offenses.

When analyzing Assault/Intimidation offenses by the hour per day of week, it becomes apparent that the number of offenses increases on Friday and Saturday nights between 10:00pm and 2:00am. On Friday nights at 11:00pm (1.3\%), 12:00am $(1.3 \%)$, and $1: 00 \mathrm{am}(1.5 \%)$, the number of offenses were well above the average $(0.6 \%)$. Saturday nights at $10: 00 \mathrm{pm}(1.3 \%), 12: 00 \mathrm{am}(1.7 \%)$,

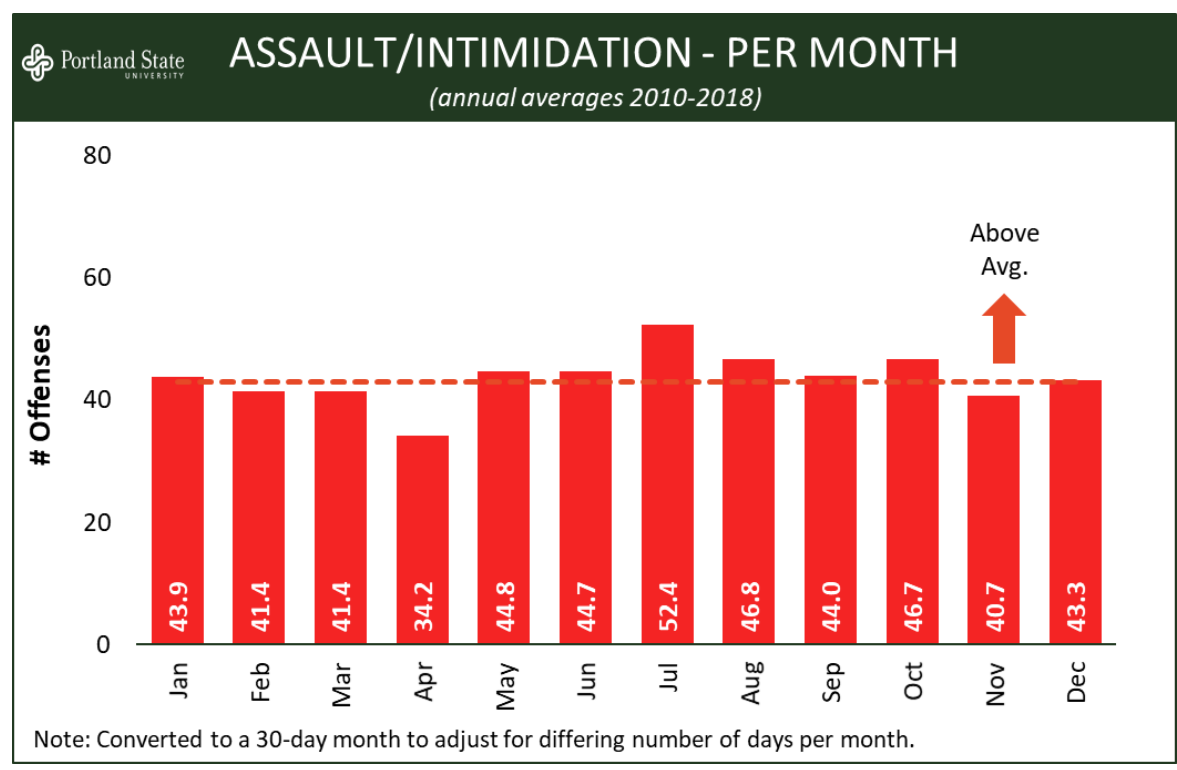

Figure 27

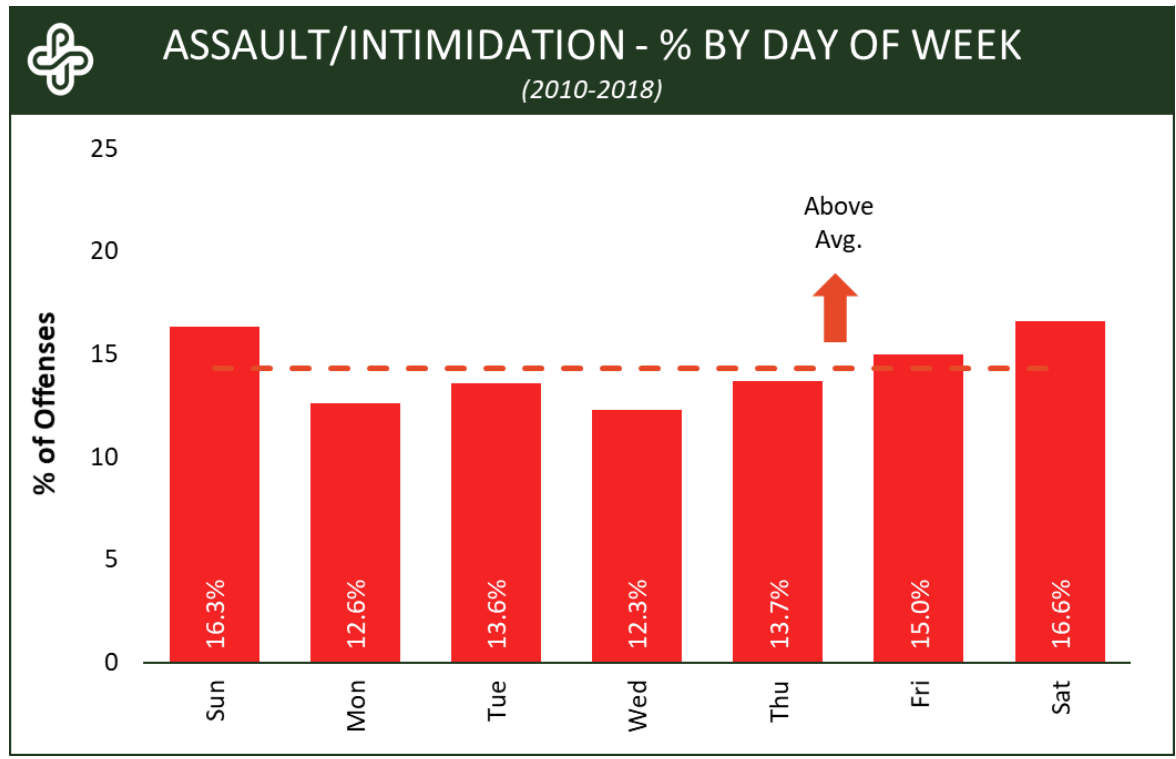

Figure 27

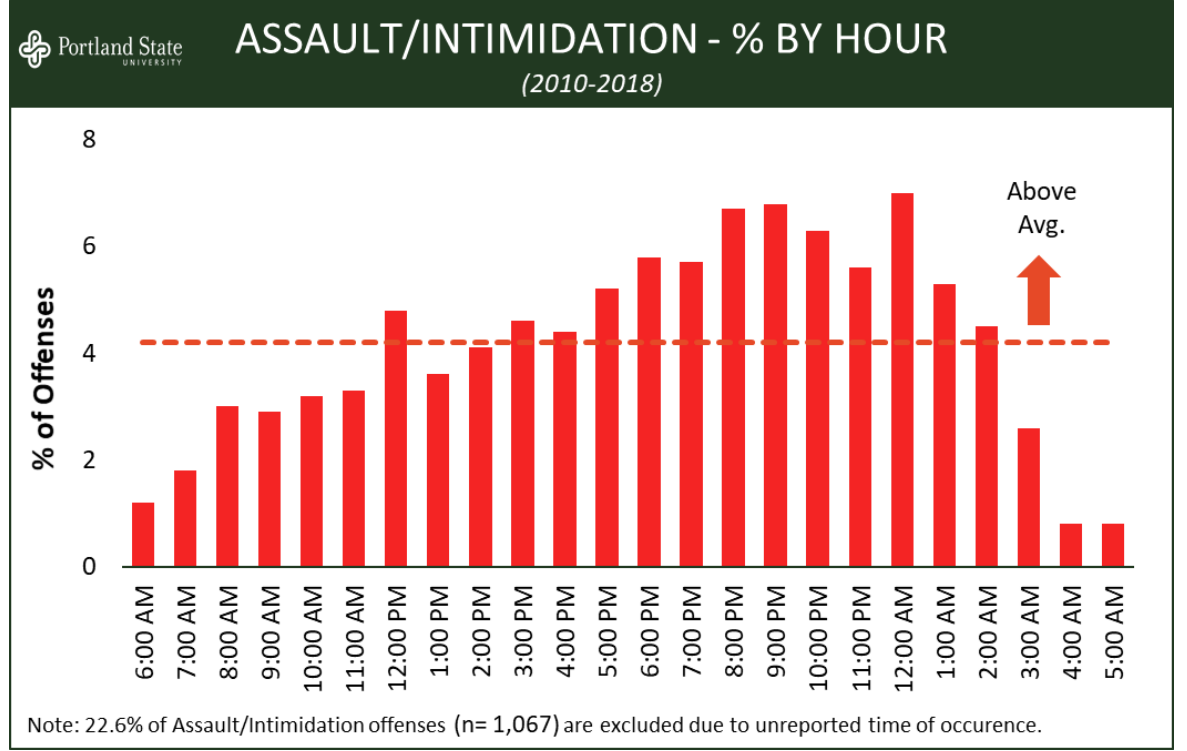

Figure 29 
and 2:00am (1.5\%) were also well above the average percentage of

Assault/Intimidation offenses. See Figure 30 for a more detailed breakdown; keep in mind that although it appears that Saturday and Sunday morning experience a significant increase, this is actually Friday and Saturday night spilling into the early morning hours.

\section{Geographic Pattern}

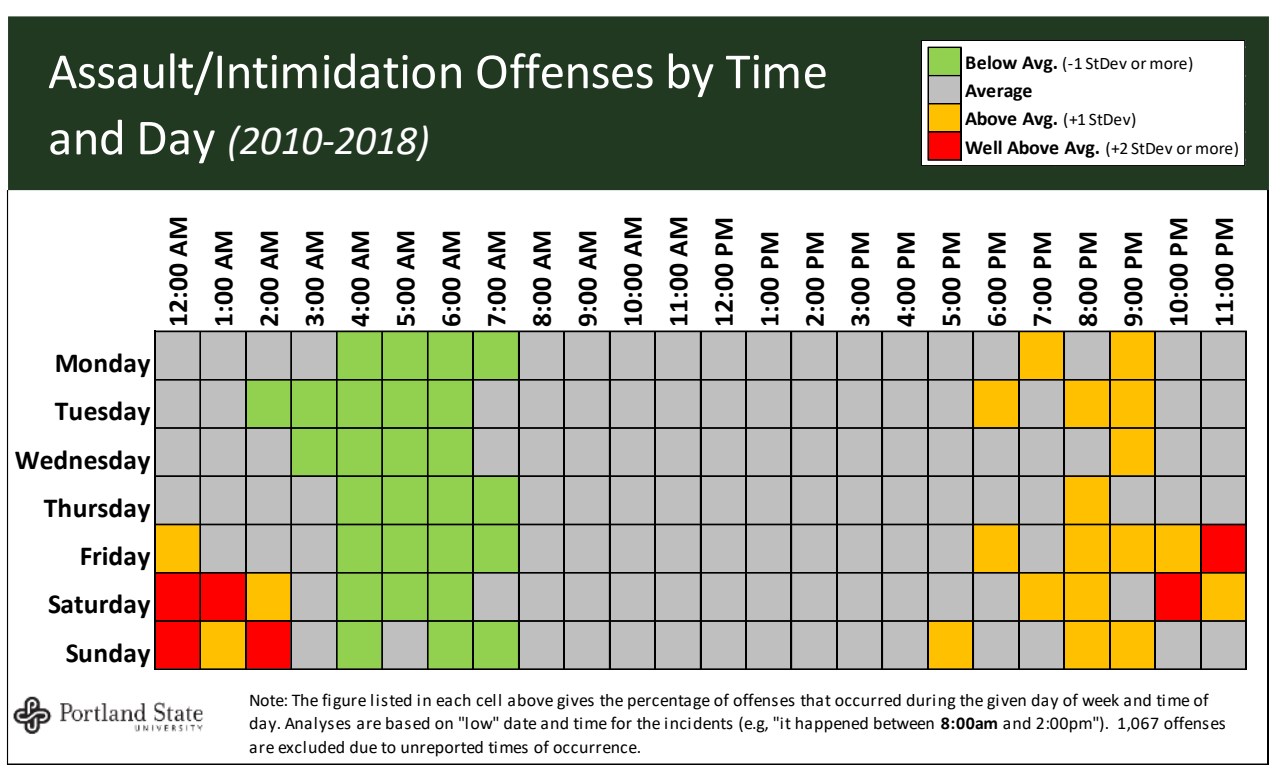

Figure 30

Although NIBRS does not provide exact location information such as latitude and longitude for where crimes occur, NIBRS does group offenses into location categories. The most common location type for Assault/Intimidation offenses during the study period was Residence/Home, with almost half $(47.2 \%, 2,228)$ of all offenses occurring at someone's residence. The second most common location type reported was a Roadway, ${ }^{8}$ which comprised about of fifth $(19.3 \%, 912)$ of all offenses. The third most common location for instances of Assault/ Intimidation was a Bar/Nightclub, in which $6.2 \%$ (293) of the offenses took place. Together, these three locations alone account for almost three

\begin{tabular}{|c|c|c|}
\hline ASSA & CATIC & \\
\hline Location Type & $f$ & $\%$ \\
\hline Residence/Home & 2,228 & $47.2 \%$ \\
\hline Roadway & 912 & $19.3 \%$ \\
\hline Bar/Nightclub & 293 & $6.2 \%$ \\
\hline Parking Area & 280 & $5.9 \%$ \\
\hline Other/Unknown & 207 & $4.4 \%$ \\
\hline Hotel/Motel/Etc. & 129 & $2.7 \%$ \\
\hline School & 112 & $2.4 \%$ \\
\hline Medical Building & 87 & $1.8 \%$ \\
\hline Park/Playground & 70 & $1.5 \%$ \\
\hline Restaurant & 62 & $1.3 \%$ \\
\hline All Other Locations & 339 & $7.2 \%$ \\
\hline Total & 4,719 & $100.0 \%$ \\
\hline
\end{tabular}

Table 6

quarters $(72.7 \%, 3,433)$ of all Assault/ Intimidation offenses. See Table 6 for the top ten most common location types.

\section{Victim \& Arrestee Demographic Profile}

\section{Age}

The average age for victims of Assault/Intimidation offenses during the 9-year study period was 32.3 years old. The most common age group for victims of this type of crime was people between the age of 25 and 34 , which made up about a quarter $(1,350)$ of all victims. The second most common age group for victims was people between the age of 18 and $24(1,009)$, followed by people between the

\footnotetext{
8 This is typically coded as Highway/Road/Alley/Street/Sidewalk, but we have condensed the title for the sake of brevity.
} 
age of 35 and 44 (944). As demonstrated in Figure 31, victims were more likely than arrestees to be either particularly young ( 0 to 12 years old) or particularly old (55 and older).

The average age for arrestees of Assault/Intimidation offenses was 32.5 years old. Like victims, the most common age group for arrestees was people between the age of 25 and 34 (951), followed by 18 to 24 (707), and 35 to 44 (663). See Figure 31 for a more detailed age breakdown for both victims and arrestees.

\section{Sex}

Of the victims of an Assault/Intimidation offense whose sex was known ( $\mathrm{n}=$ 5,232 ), slightly over half were female $(50.7 \%)$. In contrast, the majority of arrestees for this type of offense were Male (73.1\%). See Table 7 more detailed statistics.

\section{Race \& Ethnicity}

Among victims where race was documented $(n=5,127)$, the vast majority $(97.4 \%)$ were White, followed by Black or African American (1.8\%). American Indian, Alaska Native and Asian ${ }^{10}$ people accounted for less than one percent of victims. With regard to ethnicity $(n=1,568), 6.4 \%$ of victims were identified as Hispanic or Latino.

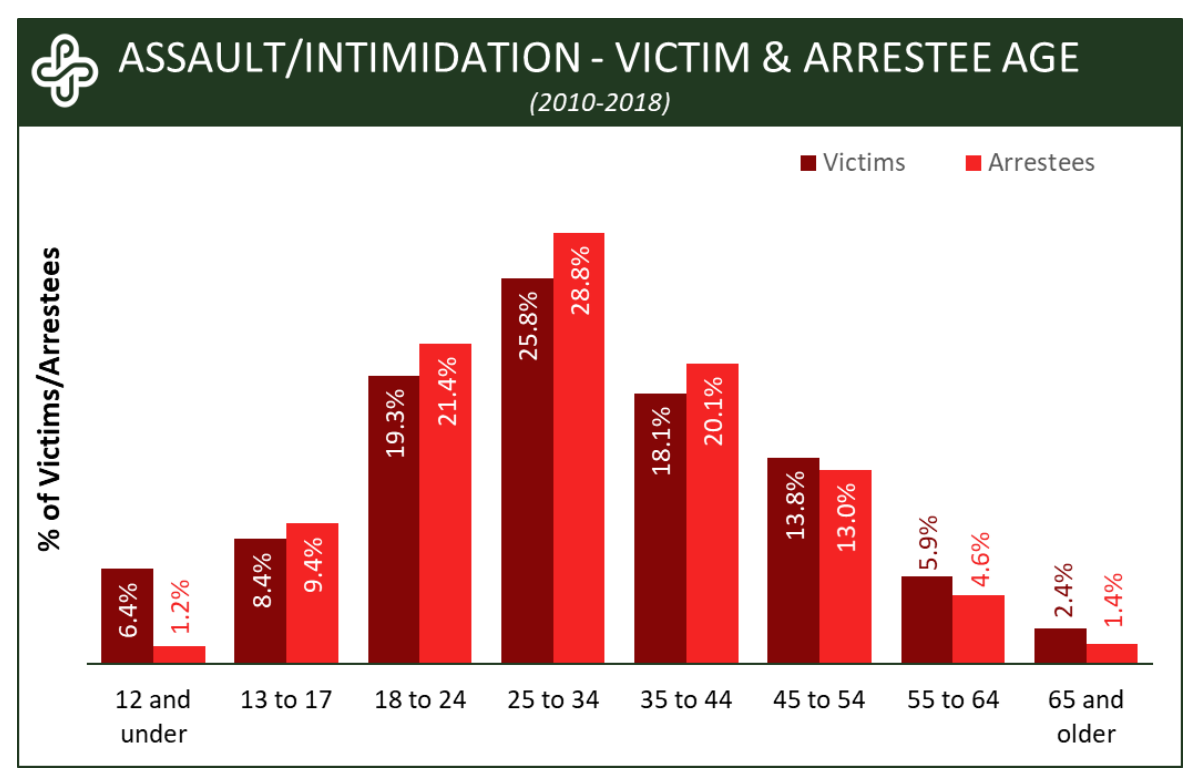

Figure 31

\begin{tabular}{|c|c|c|c|c|}
\hline \multicolumn{5}{|c|}{$\begin{array}{l}\text { ASSAULT/INTIMIDATION - DEMOGRAPHICS } \\
\qquad(2010-2018)\end{array}$} \\
\hline Demographic & \multicolumn{2}{|c|}{ Victims } & \multicolumn{2}{|c|}{ Arrestees } \\
\hline Sex* & $f$ & $\%$ & $f$ & $\%$ \\
\hline Male & 2,578 & $49.3 \%$ & 2,412 & $73.1 \%$ \\
\hline Female & 2,653 & $50.7 \%$ & 888 & $26.9 \%$ \\
\hline \multicolumn{5}{|l|}{ Race* } \\
\hline White & 4,992 & $97.4 \%$ & 3,095 & $95.3 \%$ \\
\hline Black or African American & 90 & $1.8 \%$ & 111 & $3.4 \%$ \\
\hline All Others Combined & 45 & $0.9 \%$ & 43 & $1.3 \%$ \\
\hline \multicolumn{5}{|l|}{ Ethnicity* } \\
\hline Not Hispanic or Latino & 1,468 & $93.6 \%$ & 1,174 & $90.7 \%$ \\
\hline Hispanic or Latino & 100 & $6.4 \%$ & 121 & $9.3 \%$ \\
\hline \multicolumn{5}{|l|}{ Residency* } \\
\hline Resident & 3,393 & $92.2 \%$ & 2,301 & $91.8 \%$ \\
\hline Nonresident & 289 & $7.8 \%$ & 206 & $8.2 \%$ \\
\hline
\end{tabular}

Table 7

Comparable to victims, $95.3 \%$ of arrestees $(n=3,249)$ were White, followed by Black or African American (3.4\%). People who identified as American Indian, Alaska Native, Asian, and Native Hawaiian/Other Pacific Islander ${ }^{9}$ comprised $1.3 \%$ of the arrestees. Regarding those with reported ethnicity $(n=1,295), 9.3 \%$ of arrestees were Hispanic or Latino. See Table 7 for a more detailed breakdown of race and ethnicity for both victims and arrestees.

\section{Residency}

In NIBRS reporting, Residency refers to whether a person is a resident of the jurisdiction that the offense took place in; in this case, Residency refers to whether an involved person lives in Bend. Of the Assault/Intimidation victims whose Residency status was known $(n=3,682), 92.2 \%$ were

\footnotetext{
${ }^{9}$ Referred to as "All Others Combined" in demographic tables for brevity.
} 
residents of Bend. Likewise, out of the arrestees with known Residency status ( $n=2,507), 91.8 \%$ of arrestees were residents of Bend. See Table 7 for more information.

\section{Offense Characteristics}

\section{Victim-Offender Relationship}

The victim's relationship to their offender in Assault/Intimidation offenses has important implications for crime prevention. Among those cases where the relationship was known $(n=4,851)$, roughly three quarters $(75.5 \%)$ of victims knew their offender to some degree. About a third of victims were an Acquaintance or Otherwise Known to the offender $(30.2 \%)$ and similar percentage of victims were a Current or Former Intimate Partner (29.2\%). The next most common Victim-Offender Relationship was Stranger (23.4\%), followed by Family Member (16.2\%) and Victim Was Offender (1.1\%) which is not

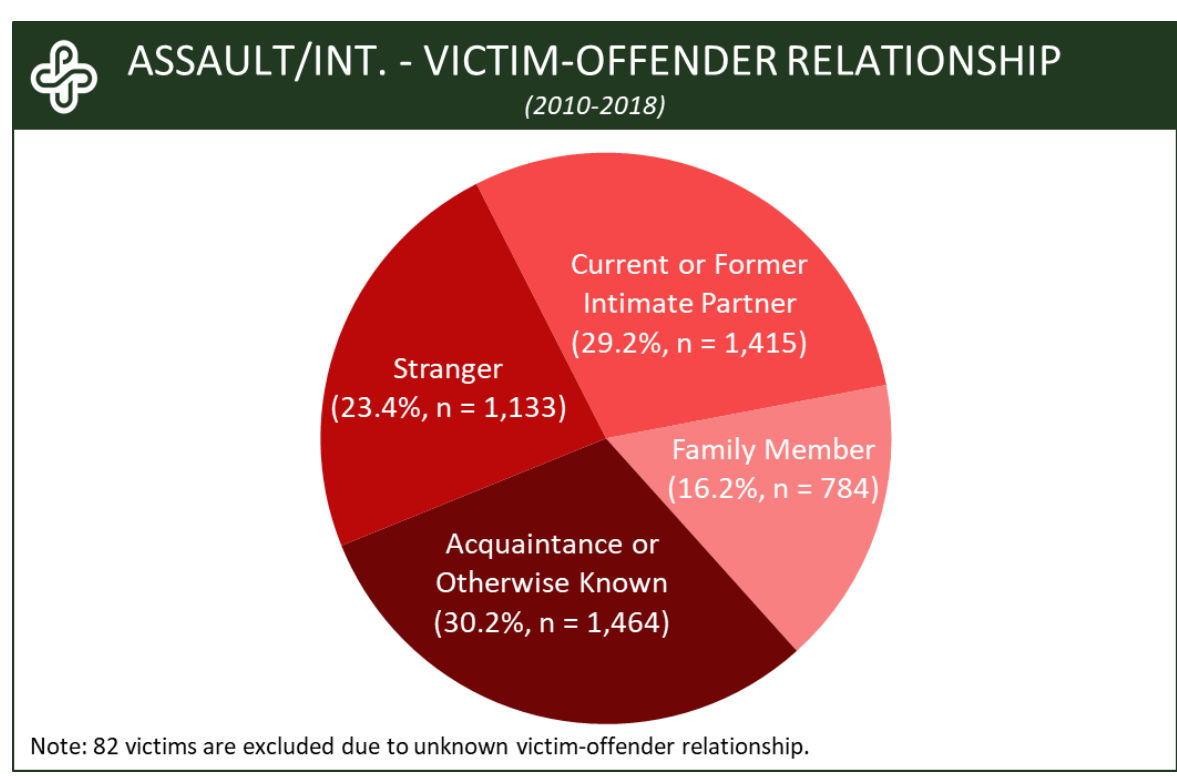

Figure 32 included in Figure 32 due to low rate of occurrence. Cases in which a victim is also an offender include situations in which someone participates in an offense but is simultaneously victimized by other offenders, a common example is a fight that breaks out in a bar or nightclub.

\section{Victim Injuries}

In this section we discuss injuries sustained by victims involved in an Assault/Intimidation offense. We should also note that victim injuries are not recorded in NIBRS for Intimidation or Homicide offenses. Hence, the results presented below are only attributable to Simple and Aggravated Assaults.

Of the instances involving an Assault/Intimidation offense in which an Injury was reported $(n=3,117)$, $16.5 \%$ (515) of victims had No Injury. Out of the remaining victims, $72.2 \%(2,251)$ sustained a Minor Injury and $11.3 \%$ (351) experienced a Major Injury.

\section{Number of Victims}

Most Assault/Intimidation offenses during the 9-year study period involved a single victim (86.0\%, $3,889)$. During this time, $10.9 \%$ (492) of offenses involved two victims, $2.9 \%$ (133) involved three to five victims, and $0.1 \%$ (6) involved six or more victims. The largest number of victims involved in an offense was 20 , which only occurred once. ${ }^{10}$

4520

\section{Number of Known Offenders (Co-Offending)}

The NIBRS reporting system makes a distinction between suspects, or people identified to some degree in association with a crime, and people arrested for a given offense. The demographic

\footnotetext{
10 There were 122 offenses in which there were no reported victims, however this is excluded due to probable reporting error.
} 
characteristics reported previously are based on the latter. In this section we address the issue of cooffending by analyzing the number of suspects identified per criminal offense. We exclude cases where no information (e.g., age, sex, race) was available. Most Assault/Intimidation offenses over the 9 -year study period had only one known offender $(92.3 \%, 3,951)$. During this time, $5.8 \%(273)$ of offenses involved two known offenders and $1.2 \%$ (57) involved three to six known offenders. ${ }^{11}$

\section{Weapon Involvement}

In this section we discuss types of weapons used in Assault/Intimidation offenses. It should be noted that certain weapons (Firearm, Knife/Cutting Instrument, and Blunt Object ${ }^{12}$ ) are not recorded in NIBRS for Simple Assault or Intimidation, since weapons are typically the deciding factor between these offense subtypes (see definitions above in "Introduction \& Offense Subtypes" section).

Therefore, the results for the aforementioned weapons only include Aggravated Assault and Murder.

Among the Assault/Intimidation offenses with a reported weapon $(n=2,786)$ the most common weapon reported for Assault/Intimidation offenses was Personal Weapon, or a bodily object $(81.1 \%$, $2,260)$. This was followed by Other (10.3\%), Blunt Object $(3.3 \%, 91)$, and Knife/Cutting Instrument $(3.2 \%, 90)$. Roughly one percent of these offenses involved a Firearm $(1.2 \%, 33)$. The remaining offenses involved an Unknown weapon $(0.9 \%, 24)$.

\section{Clearance Rate}

An agency's clearance rate is based on the number of offenses that result in the arrest or citation of at least one suspect associated with a given crime. Offenses can also be cleared by exceptional means. It should be noted that NIBRS codes cases as "Cleared by Arrest" when a single suspect is arrested, even if there may be multiple suspects involved that are not arrested.

Of the 4,719 Assault/Intimidation offenses between 2010 and 2018, $67.8 \%(3,199)$ were Cleared either by Arrest/Citation or Exceptionally. The average clearance rate for was $69.7 \%$, or 365.7 offenses per year. There were no dramatic changes in clearance rates during this study period (see Figure 33). Of the offense subtypes, Murder had the highest clearance rate $(75.0 \%, 6)$, however Murder only accounts for a very slight portion of these offenses $(0.2 \%)$. Simple Assault had the second highest clearance rate, with $73.2 \%$ of offenses $(1,450)$ being cleared between 2010 and 2018. This was followed by Aggravated

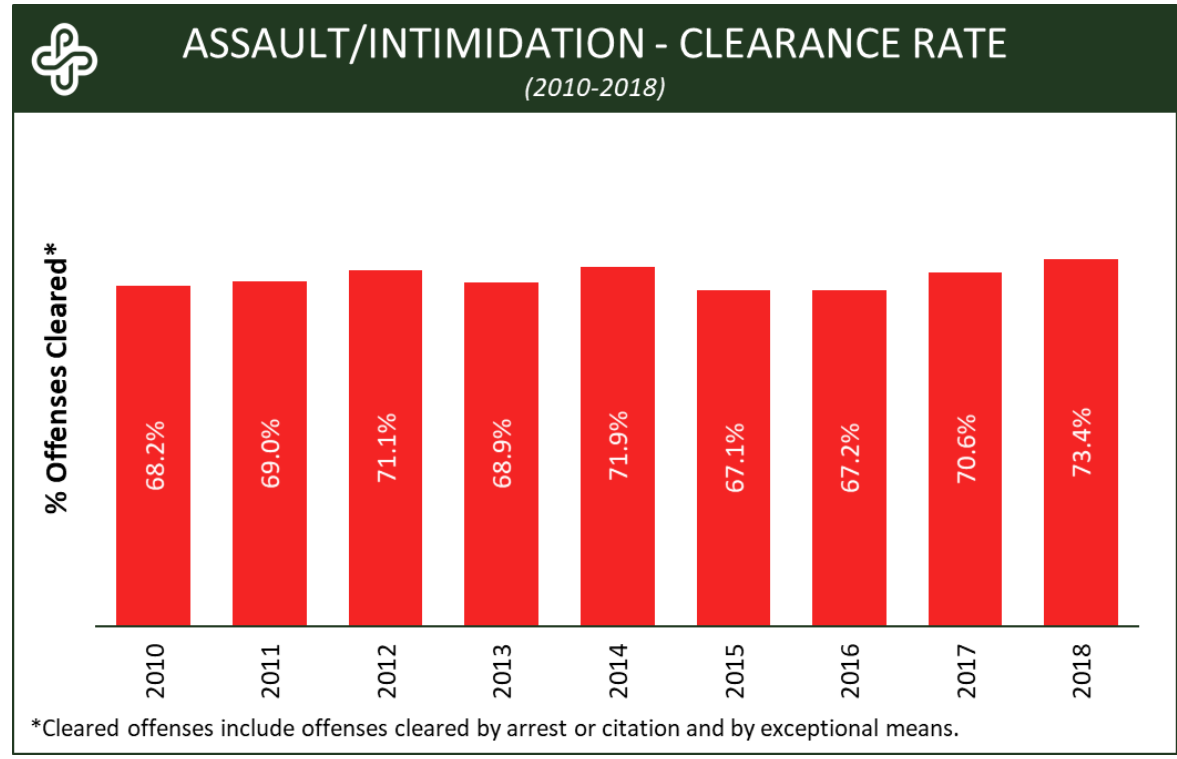

Figure 33

Assaults which were cleared $73.0 \%$ of the time (646), while Intimidation was cleared at the lowest rate $(64.5 \%, 1,189)$.

\footnotetext{
11 There were 438 offenses in which there were no known offenders, however this is excluded due to probable reporting error.

${ }^{12}$ Firearms include handgun, rifle, shotgun, and other firearm. Knife/Cutting Instrument includes knives, razors, hatchets, axes, cleavers, scissors, glass, broken bottles, ice picks, etc. Blunt Object includes baseball bats, butt of handgun, clubs, bricks, jack handles, tire irons, bottles, etc.
} 


\section{BURGLARY}

\section{Introduction \& Offense Definition}

In this section we will be analyzing burglary in Bend between 2010 and 2019. ${ }^{13}$ Burglary, also referred to in NIBRS as Breaking \& Entering, is defined by the FBI as, "The unlawful entry into a building or other structure with the intent to commit a felony or a theft." This is most consistent with Oregon's Burglary in the $2^{\text {nd }}$ degree (ORS 164.215).

\section{Annual Trend}

There was a total of 2,515 Burglary offenses in Bend during the 10-year study period, or an average of 251.5 offenses per year. As shown in Figure 34, burglaries steadily declined between 2010 to 2019, an overall reduction of $64.2 \%$. To account for changes in the underlying population, we calculated the annual rate of Burglary per 1,000 residents using U.S. Census estimates. The burglary rate decreased $71.7 \%$ from 2010 (4.8 per $1,000)$ to 2019 (1.4 per 1,000).

These findings indicate that burglaries in Bend have declined significantly despite a growing population. Efforts should be taken to study this notable decline and determine the potential causes. For example, the BPD ran several crime prevention initiatives during this period that might have contributed to the decline in burglary.

\section{Temporal Patterns}

We analyzed monthly/seasonal patterns in Burglary offenses by calculating the average number of offenses per month across the 10year study period. ${ }^{14}$ Bend averaged 20.7 burglaries per month during this period of time. Higher monthly

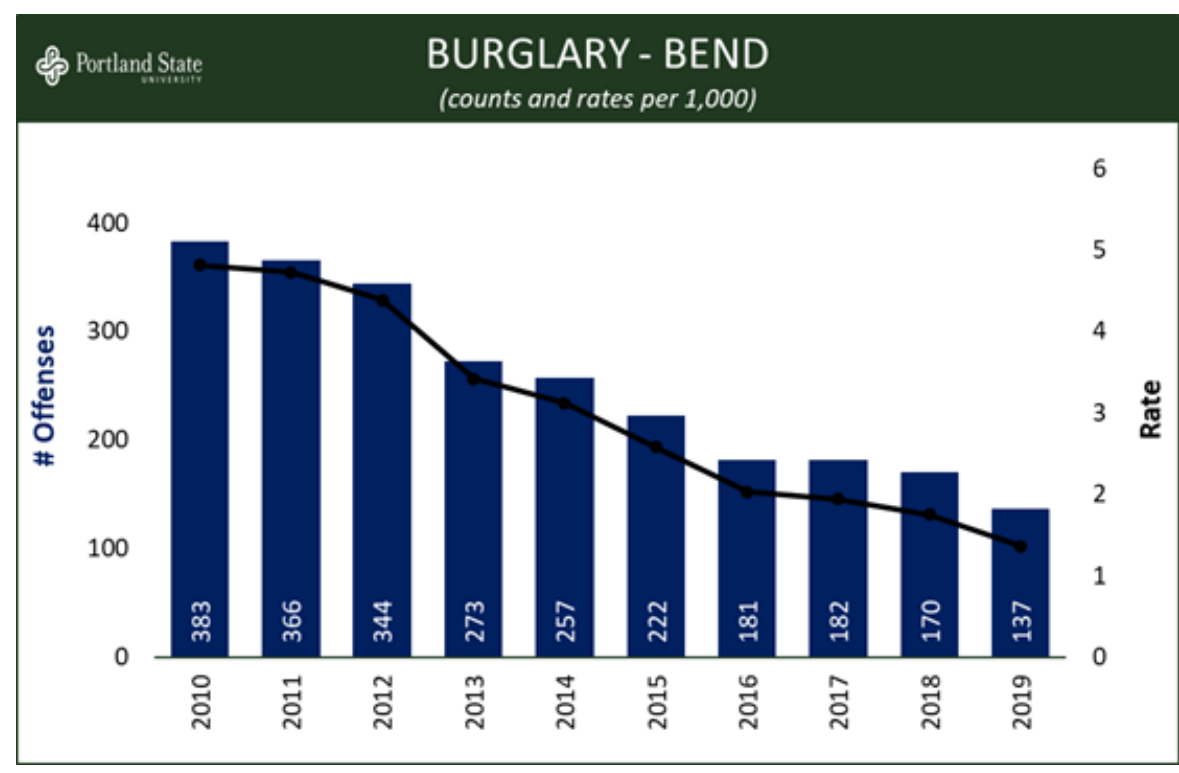

Figure 34

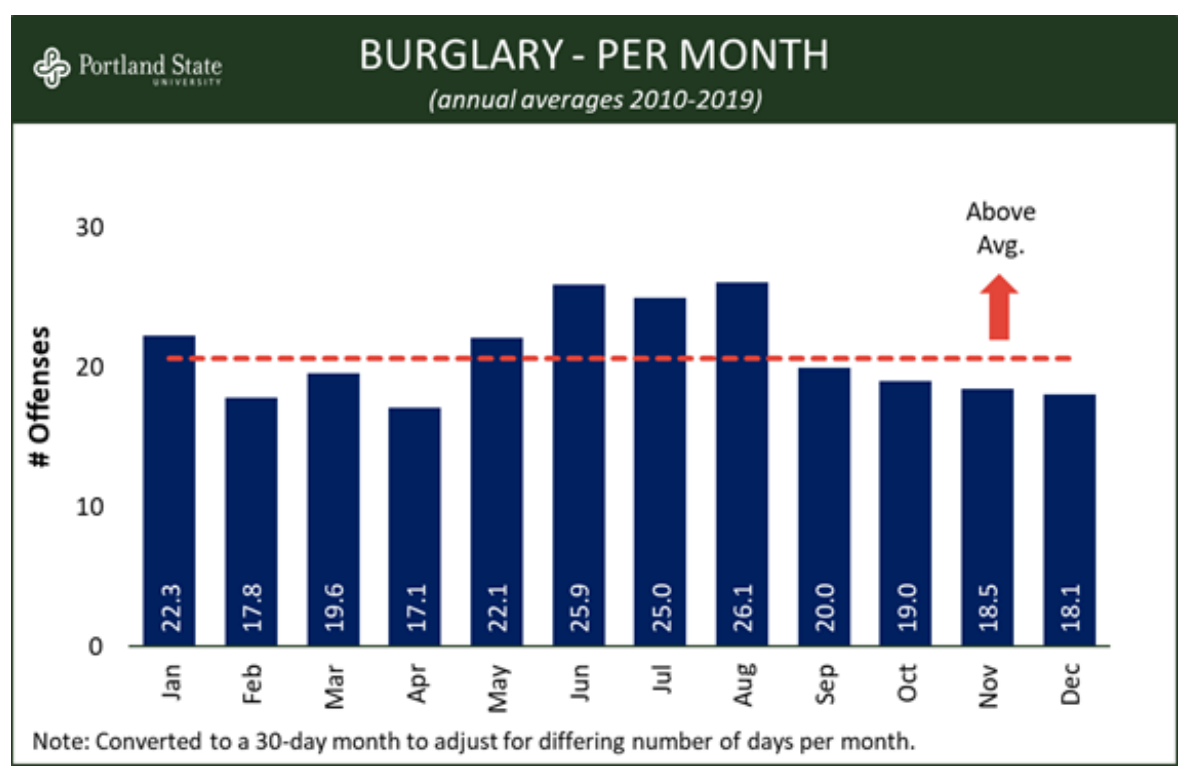

Figure 35

\footnotetext{
13 We were able to obtain the 2019 NIBRS data after completing our Incident and Assault/Intimidation section, which only examined offenses through 2018. The remainder of this report will include the 2019 data.

14 Monthly counts were standardized to a 30-day month to control for the fact that some months have more days than others.
} 
averages were found for January, May, June, July, and August. While above average, none of these months met our threshold for well above average (i.e., 2+ StDev). Similarly, none of the months would be considered well below average (i.e., 2+ standard deviations below average). In short, seasonal fluctuations in burglary seem to be limited.

Regarding the distribution of Burglary offenses by day of week, we found that Friday was the only day that exceed our definition for well above average (i.e., 2+ StDev), accounting for $18.2 \%$ of the incidents. Otherwise, there was relatively limited fluctuation in this offense by day.

Our efforts to analyze the distribution of burglary by time of day ran into problems. Due to the nature of burglary, victims will often not know the exact time when the incident occurred. A victim might leave home at 8:00 am in the morning and not return until $4: 00 \mathrm{pm}$ in the afternoon, at which time they discover the offense. NIBRS allows the agency to document this in two ways. First, they can report the time of occurrence using the starting point for the given time span (8:00 am in the example above; often referred to as the low time). Second, they can flag the incident as missing and leave the occurred hour field blank. In the case of Bend's burglaries, we found that 665 incidents (26.4\%) were missing the time of day. While the remaining 1,850 incidents listed an occurred hour, we noted anomalies when we analyzed these data. Disproportionate numbers of these offenses were reported to have started at midnight, noon, and 5:00pm. This is inconsistent with research on burglary done in other jurisdictions and suggests to us that officers are defaulting to these times when victims are unable to accurately pinpoint when their burglary happened. Lacking more accurate data, we opted to skip the analysis of time of day in this section of the report.

\section{Geographic Pattern}

The most common location type for Burglary offenses during the study period was Residence/Home, with more than half $(60.1 \%, 1,512)$ of all offenses occurring at someone's residence. The second most common location type reported was a Commercial/Office Building, which comprised about a tenth $(9.5 \%, 239)$ of all offenses. Together, these two locations alone account for almost three quarters $(69.6 \%, 1,751)$ of all Burglary offenses in Bend. See Table 8 for the top ten most common location types.

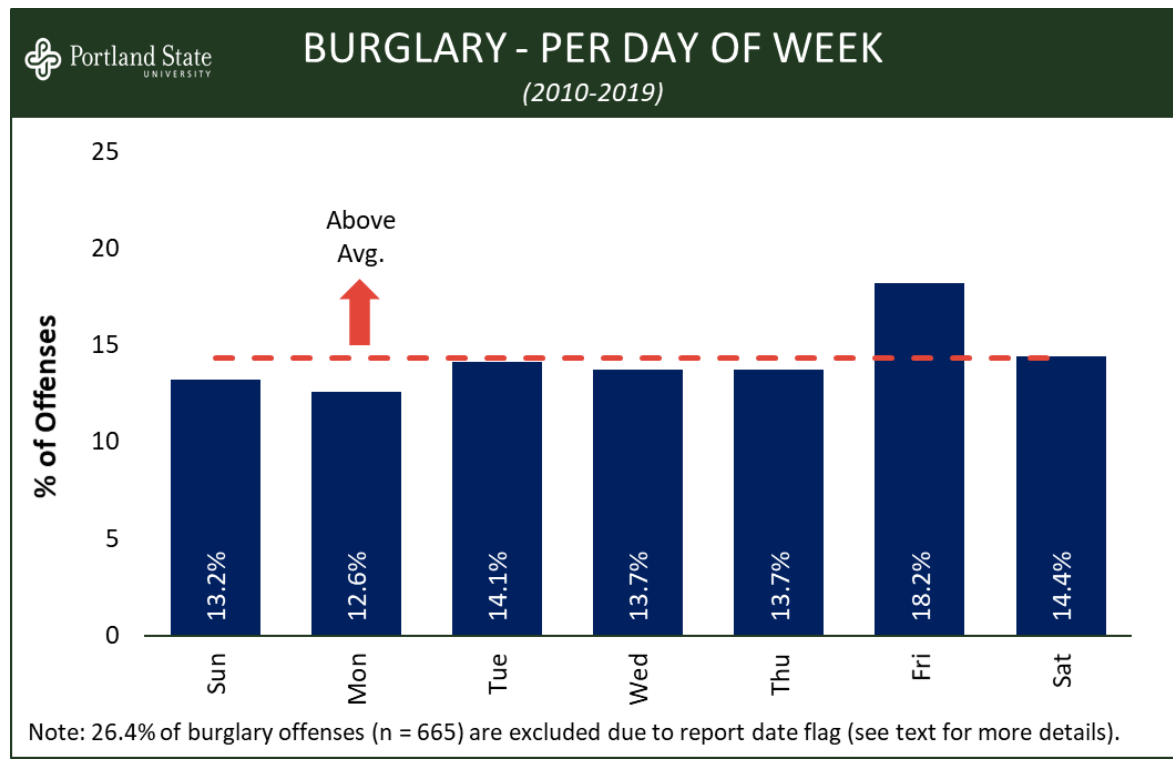

Figure 36 


\section{Victim \& Arrestee Information}

\section{Victim Type}

The most common victim type for Burglary offenses during the study period was an Individual, with almost three quarters $(71.4 \%, 1,951)$ of all victims falling into this category. The second most common victim type reported was a Business, which comprised about a quarter $(24.9 \%$, 679 ) of all victims. These two victim types combined account for almost all $(96.3 \%, 2,630)$ of the Burglary victims in Bend. See Table 9 for a more detailed breakdown of victim types involved in Burglary offenses.

\section{Arrestee Demographic Profile}

\begin{tabular}{|lrc|} 
胥 Portland State & $\begin{array}{c}\text { BURGLARY - VICTIM TYPE } \\
(2010-2019)\end{array}$ & \\
\hline Victim Type & $f$ & $\%$ \\
\hline Individual & 1,951 & $71.4 \%$ \\
Business & 679 & $24.9 \%$ \\
Society/Public & 65 & $2.4 \%$ \\
Religious Organization & 12 & $0.4 \%$ \\
Government & 8 & $0.3 \%$ \\
Financial Institution & 7 & $0.3 \%$ \\
Other & 10 & $0.4 \%$ \\
\hline Total & $\mathbf{2 , 7 3 2}$ & $\mathbf{1 0 0 . 0 \%}$ \\
\hline
\end{tabular}

Table 9

For more a detailed analysis, we separated burglary arrestees into two different categories: residential and commercial. While residential burglaries only include burglaries that occurred at a Residence/Home, commercial burglaries include all location types that consist of buildings or establishments that are normally occupied during business hours and left vacant otherwise. Additionally, we decided to make this distinction since prior research has suggested that the suspects involved in a burglary case may vary based on the type of burglary committed, which we will show is consistent with our findings.

Overall, the average age for arrestees of Burglary offenses $(\mathrm{N}=$ $695)$ was 28.2 years old. The most common age group for arrestees was people between the age of 25 and $34(29.8 \%)$, followed by 18 to 24 $(27.8 \%)$, and 13 to $17(16.0 \%)$.

However, when we differentiate between residential and commercial burglaries, trends in arrestee ages shift slightly. There were more teenage arrestees involved in residential burglaries (18.5\%) than commercial burglaries (12.4\%).

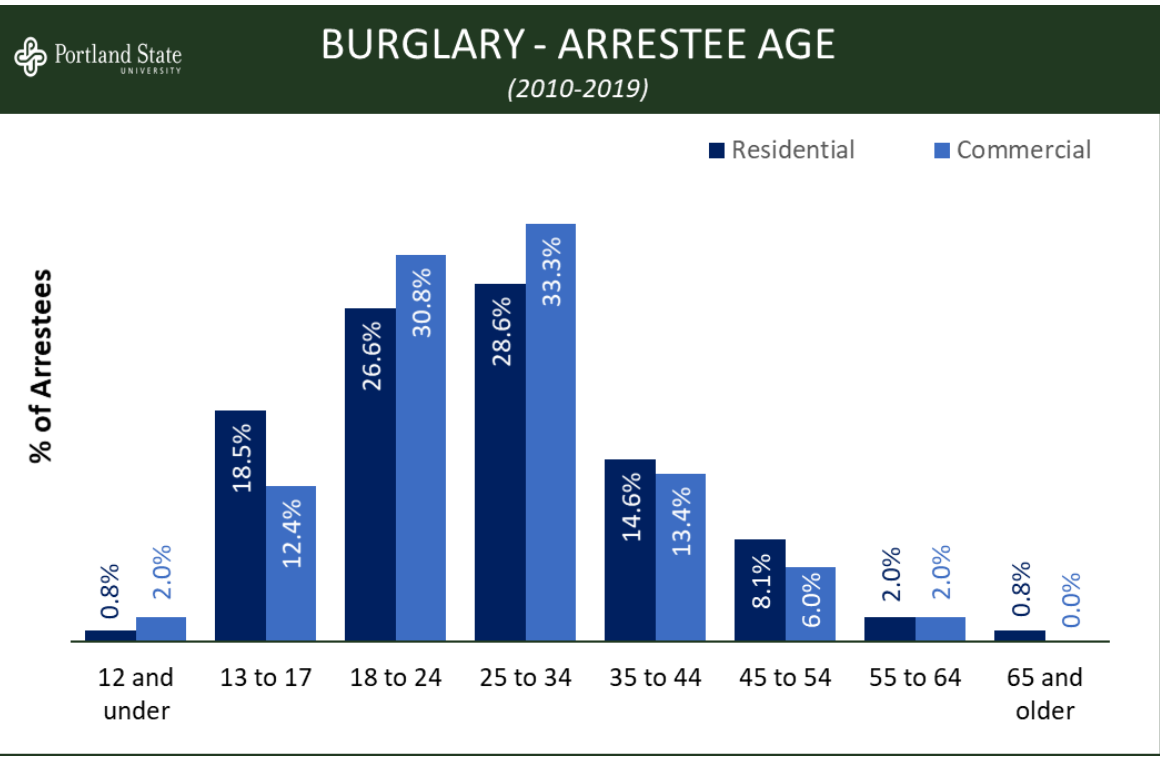

Figure 37

Additionally, there were slightly more arrestees that were 35 and older involved in residential burglaries. Most arrestees involved in commercial burglaries were between the ages of 18 and 34 (64.1\%). See Figure 37 for a more detailed depiction of age distribution for burglary arrestees in Bend.

The majority of commercial burglary arrestees during the study period were Male (94.0\%). Residential burglary arrestees demonstrated slightly more variability in reported sex, with $83.5 \%$ being Male. 
Among residential arrestees, the vast majority (95.1\%) were White, followed by Black or African American (2.3\%). Asian (6), Native Hawaiian or Other Pacific Islander (2), and American Indian or Alaska Native (1) represented 2.6\% of residential arrestees. ${ }^{15}$ Although most of the commercial arrestees were also White $(88.1 \%)$, there was slightly more variability in race for commercial burglaries. Black or African American arrestees represented $8.8 \%$ of commercial arrestees, with the remaining 3.1\% being Native Hawaiian or Other Pacific Islander (3), American Indian or Alaska Native (2), and Asian (1). ${ }^{15}$

\begin{tabular}{|c|c|c|c|c|}
\hline \multicolumn{5}{|c|}{$\begin{array}{l}\text { BURGLARY - ARRESTEE DEMOGRAPHICS } \\
(2010-2019)\end{array}$} \\
\hline \multirow{2}{*}{$\frac{\text { Demographic* }}{\text { Sex }}$} & \multicolumn{2}{|c|}{ Residential } & \multicolumn{2}{|c|}{ Commercial } \\
\hline & $f$ & $\%$ & $f$ & $\%$ \\
\hline Male & 298 & $83.5 \%$ & 189 & $94.0 \%$ \\
\hline Female & 59 & $16.5 \%$ & 12 & $6.0 \%$ \\
\hline \multicolumn{5}{|l|}{ Race } \\
\hline White & 328 & $95.1 \%$ & 170 & $88.1 \%$ \\
\hline Black or African American & 8 & $2.3 \%$ & 17 & $8.8 \%$ \\
\hline $\begin{array}{l}\text { All Others Combined } \\
\text { Ethnicity }\end{array}$ & \multicolumn{3}{|c|}{ Ethnicity } & $3.1 \%$ \\
\hline Not Hispanic or Latino & 163 & $95.9 \%$ & 88 & $89.8 \%$ \\
\hline Hispanic or Latino & 7 & $4.1 \%$ & 10 & $10.2 \%$ \\
\hline \multicolumn{5}{|l|}{ Residency } \\
\hline Resident & 238 & $94.4 \%$ & 117 & $91.4 \%$ \\
\hline Nonresident & 14 & $5.6 \%$ & 11 & $8.6 \%$ \\
\hline
\end{tabular}

Table 10

With regard to ethnicity, $4.1 \%$ of residential arrestees were reported as Hispanic or Latino. A higher percentage of arrestees were reported as Hispanic or Latino (10.2\%) when the burglary took place at a commercial location.

Of the residential burglary arrestees whose Residency status was known, $94.4 \%$ were residents of Bend. In comparison, a slightly lower percentage of commercial burglary arrestees were found to be a resident $(91.4 \%)$. See Table 10 for more detailed demographic information about Burglary arrestees in Bend.

\section{Offense Characteristics}

\section{Method of Entry}

In this section we touch on the method of entry for Burglary offenses during the 10-year study period, in other words how many burglaries were forced versus non-forced. According to the FBI, "A forced entry occurs when the offender(s) uses force of any degree or a mechanical contrivance of any kind (e.g., a passkey or skeleton key) to unlawfully enter a building or other structure. An unforced entry occurs when the offender(s) achieves unlawful entry without force through an unlocked door or window." If a burglary involves both forced and non-forced entry, it is reported to NIBRS as forced. ${ }^{5}$

Slightly over half of all burglaries $(\mathrm{N}=2,515)$ during the study period were accomplished through nonforced entry $(60.1 \%, 1,512)$. However, this trend changes when these offenses are divided into residential and commercial ${ }^{16}$ burglaries. Over half $(63.6 \%, 418)$ of the burglaries that occurred at commercial locations $(n=657)$ involved forced entry. In contrast, most $(72.0 \%, 1,088)$ of residential burglaries $(n=1,088)$ were non-forced.

\section{Number of Known Offenders (Co-Offending)}

Most residential burglaries in Bend between 2010 and 2018 had no known offenders $(69.2 \%, 1,047)$. However, of the residential burglaries in which there was at least one known offender $(n=465)$, $71.4 \%$ (332) involved a single offender. During this time, $17.4 \%(81)$ of residential burglaries involved

\footnotetext{
${ }^{15}$ Referred to as "All Others Combined" in table for brevity.

${ }^{16}$ Commercial, as we have defined it, refers to buildings that are normally occupied during business hours and left vacant otherwise.
} 
two known offenders and $10.5 \%$ (49) involved three to five offenders. There were three $(0.6 \%)$ residential burglaries that involved six or more offenders, with the highest number of offenders being eleven on one occasion.

Similarly, many commercial burglaries in Bend had no known offenders (66.8\%, 439). However, of the commercial burglaries in which the number of offenders were known $(n=218), 71.1 \%(155)$ involved only one offender. In comparison to residential burglaries, a slightly higher percentage of commercial burglaries involved two offenders $(21.1 \%, 46)$ and a lower percentage $(7.3 \%, 16)$ involved three to five known offenders. There was only one $(0.5 \%)$ commercial burglary that involved six offenders over the ten-year study period.

\section{Property Stolen}

In this section we analyze the items that were stolen, damaged, or counterfeited as a result of burglaries in Bend between 2010 and 2019. It should be noted that the sample sizes in this section refer to the number of items stolen, damaged, or counterfeited, rather than the number of burglary offenses.

Overall, the most common property that was Stolen in a burglary offense during the 10-year study period was Money (11.8\%). This was followed by Other (10.3\%), Computer Hard/Software (8.8\%), and Tools (7.1\%). However, when we

\begin{tabular}{|lcc|}
\hline \multicolumn{3}{|c|}{$\begin{array}{c}\text { BURGLARY - PROPERTY STOLEN DESCRIPTIONS } \\
(2010-2019)\end{array}$} \\
\hline Property Description & $f$ & $\%$ \\
\hline Money & 440 & $11.8 \%$ \\
Other & 396 & $10.6 \%$ \\
Computer Hard/Software & 327 & $8.8 \%$ \\
Tools & 265 & $7.1 \%$ \\
Bicycles & 231 & $6.2 \%$ \\
Radio/TV/VCR & 212 & $5.7 \%$ \\
Jewelry/Precious Metals & 184 & $4.9 \%$ \\
Household Goods & 146 & $3.9 \%$ \\
Purse/Wallet & 134 & $3.6 \%$ \\
Clothes/Furs & 122 & $3.3 \%$ \\
All Other Items & 1,272 & $34.1 \%$ \\
\hline Total & 3,729 & $100.0 \%$ \\
\hline
\end{tabular}

Table 11 differentiate between residential and commercial burglaries, certain items are more commonly stolen. For example, Jewelry/Precious Metals $(6.4 \%, 150)$ are ranked within the top ten for residential burglaries $(n=2,338)$ but not for commercial burglaries. Similarly, in commercial burglaries $(n=731)$ Consumable Goods $(5.6 \%, 41)$ and Office Equipment $(4.1 \%, 30)$ were ranked within the top ten stolen property items, which is less common in residential burglaries.

\section{Costs Associated with Burglary}

In this section we estimate the direct costs associated with burglaries in Bend during the 10-year study period. If the value of a property loss was unknown at the time of the initial report, we replaced these missing values with the statewide mean value for a given item and year. For example, if a stolen bicycle was reported in 2019 with a value of $\$ 1$ (i.e., missing), we replaced the value with $\$ 936$, the average cost for bikes stolen that year. Also, by "direct costs" we mean only the value for property items involved. Criminal offenses come with additional direct (e.g., police response, prosecution, jails, prisons) and indirect costs (e.g., emotional impact, lost productivity, investment in security systems) that are not considered in this report.

It should also be noted that outliers, or single property losses that were significantly higher than the rest, were removed from the data so that patterns in property loss over time can be depicted more clearly. There were two instances in which we removed the value of a property loss; the first involved a $\$ 500,000$ Damaged property loss in 2010 , resulting from a burglary in which the perpetrator burned down the building. The second outlier involved a $\$ 726,000$ Stolen property loss in 2015 , due to the 
theft of Jewelry/Precious Metals at multiple locations. These values have been removed from the data below.

Between 2010 and 2019, Bend experienced $\$ 6,316,382$ in property losses resulting from burglaries. The average loss per burglary during this time was $\$ 2,511$. Most financial losses resulted from property being stolen; the total cost of stolen property over the ten-year study period was $\$ 5,271,737$ and the average cost of stolen property was $\$ 1,414$ per loss. The total cost of damaged property resulting from burglaries during this time was $\$ 1,035,392$, with the average cost being $\$ 1,224$ per loss. Property loss resulting from counterfeited/forged property represented a very small amount of Bend's losses, with the

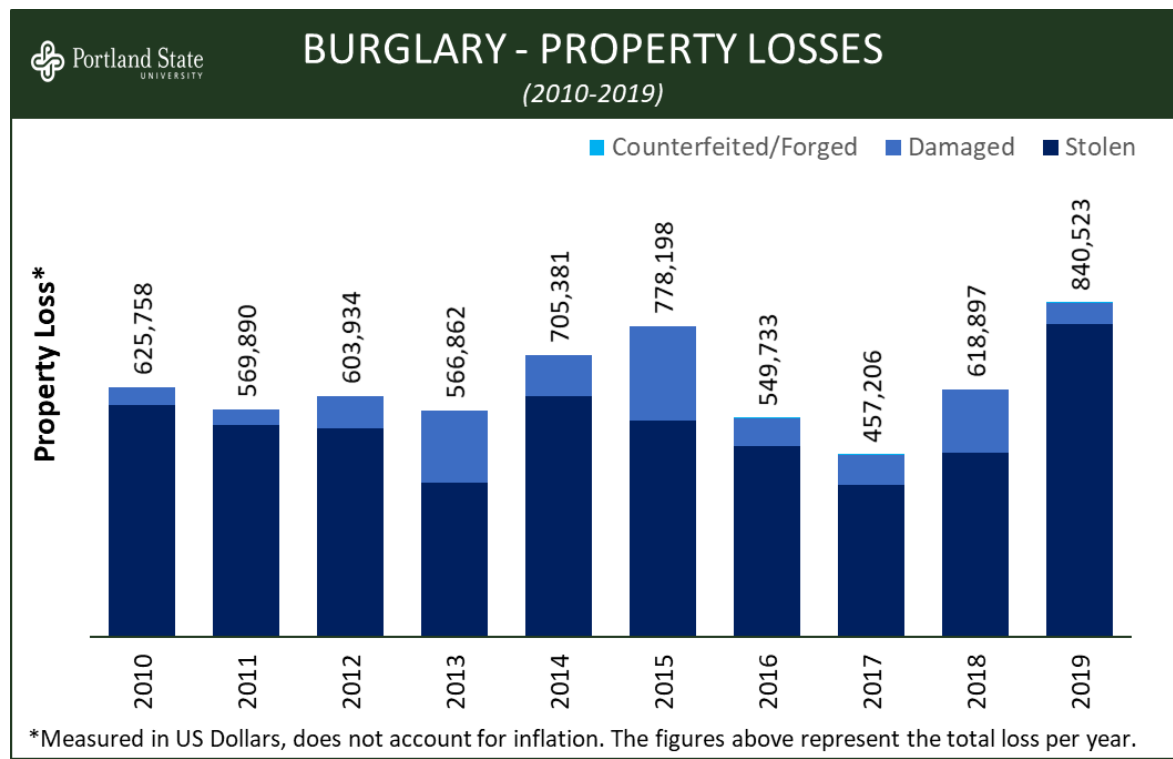

Figure 38

total cost being $\$ 9,253$. When this type of property loss did occur, the average cost per loss was $\$ 1,850$. See Figure 38 for a yearly breakdown of Bend's property losses resulting from burglaries.

\section{Property Stolen}

Between 2010 and 2019, the cost of stolen property represented $83.5 \%$ of all property losses resulting from a burglary. There were 3,728 stolen property losses resulting from a burglary, with the yearly average loss being $\$ 527,174$. Bend experienced the lowest total cost of stolen property in 2017 , with the yearly total being $\$ 381,625$. Since then, the annual cost of stolen property has increased by $105.3 \%$, with 2019 's total being $\$ 783,633$. This contradicts the steadily decreasing rate of burglaries in Bend over the past decade, however as previously mentioned, this analysis does not take inflation into account.

\section{Other Property Loss}

Between 2010 and 2019, the cost of Damaged/Vandalized/Destroyed property represented $16.4 \%$ of all property losses resulting from a burglary. There were 846 damaged property losses resulting from a burglary, with the yearly average loss being $\$ 103,539$.

Property loss that was Counterfeited/Forged represented $0.1 \%$ of all property loss resulting from a burglary during the study period. There were 5 property losses in this category, with the yearly average loss being $\$ 923$. 


\section{Clearance Rate}

Of the 2,515 Burglary offenses between 2010 and 2019, 22.2\% (558) were Cleared by Arrest/Citation. There were no burglaries that were Cleared Exceptionally. The average annual clearance rate during this time was $24.0 \%$, or 55.8 offenses per year. The clearance rate for Burglary in Bend has steadily increased over the past decade, and as of 2019 , the clearance rate has more than doubled $(+111.0 \%)$ the rate in 2010 . Considering the low national average for burglaries, this is a very interesting finding, and more efforts should be made to analyze why the clearance rate for burglaries is so

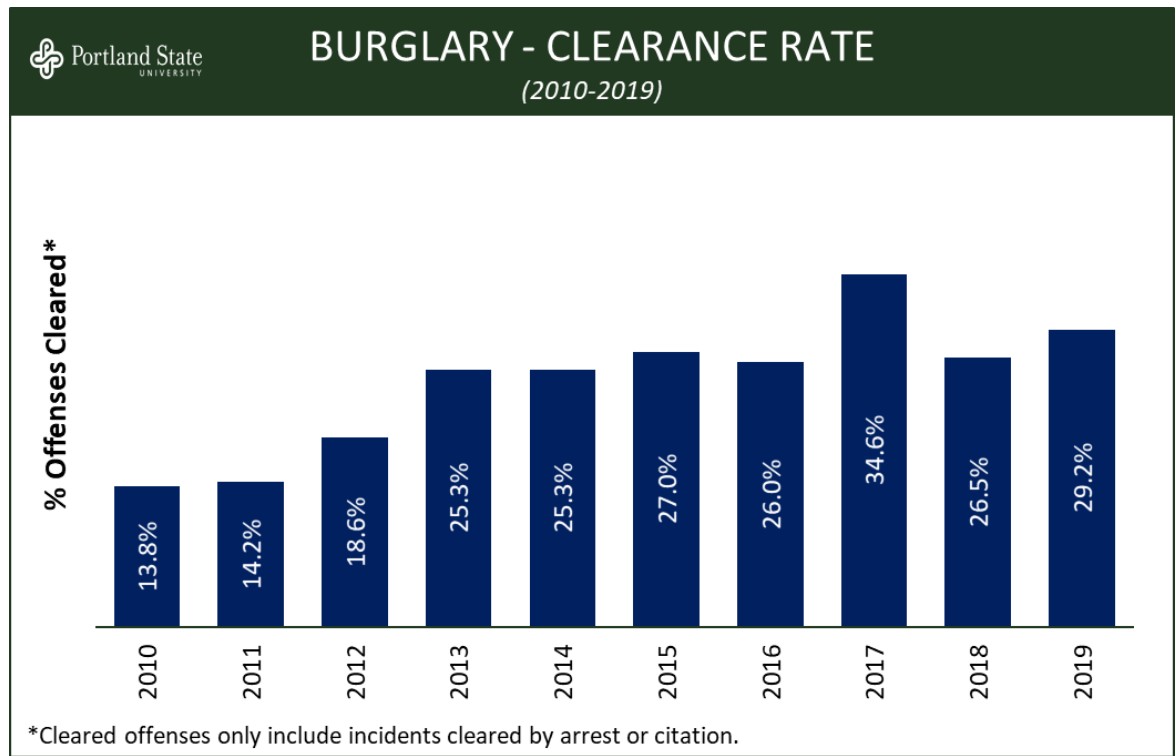

Figure 39

high in Bend. See Figure 39 for an annual breakdown of burglary clearance rates over the study period in Bend.

When Bend's clearance rate is divided into residential and commercial burglaries, the clearance rate for commercial burglaries has increased slightly more than residential. The overall clearance rate for commercial burglaries between 2010 and 2019 was $28.0 \%$, while the rate for residential burglaries was $21.2 \%$. The clearance rate for commercial burglaries increased by $94.4 \%$ over this ten-year period, while the residential rate increased by $82.9 \%$. 


\section{DRUG OFFENSES}

\section{Introduction \& Offense Definition}

In this section we will be analyzing drug offenses in Bend between 2010 and 2019. Drug offenses encompass both Drug/Narcotic Violations and Drug Equipment Violations, although there was only one incident of the latter offense in Bend over the study period. Drug/Narcotic Violations as defined by the FBI include, "The unlawful cultivation, manufacture, distribution, sale, purchase, use, possession, transportation, or importation of any controlled drug or narcotic substance." There are many Oregon Revised Statutes that fall under this NIBRS offense depending on the drug activity involved. The Oregon statutes regarding selling/distributing and possession include, "it is unlawful for any person to manufacture or deliver a controlled substance" and "it is unlawful for any person knowingly or intentionally to possess a controlled substance" (ORS 475.752).

\section{Annual Trend}

There was a total of 5,167 drug offenses in Bend during the 10-year study period, or an average of 516.7 offenses per year. As shown in Figure 40, drug offenses have remained relatively stable between 2010 to 2019. Drug offense counts increased by $32.3 \%$ between 2010 and 2014, however over the next five years, offenses only increased slightly by $2.6 \%$. To account for changes in the underlying population, we calculated the annual rate of drug offense per 1,000 residents using U.S. Census estimates. While the rate for drug offenses increased by $27.7 \%$ from (5.0 per 1,000$)$ to $2014(6.4$ per

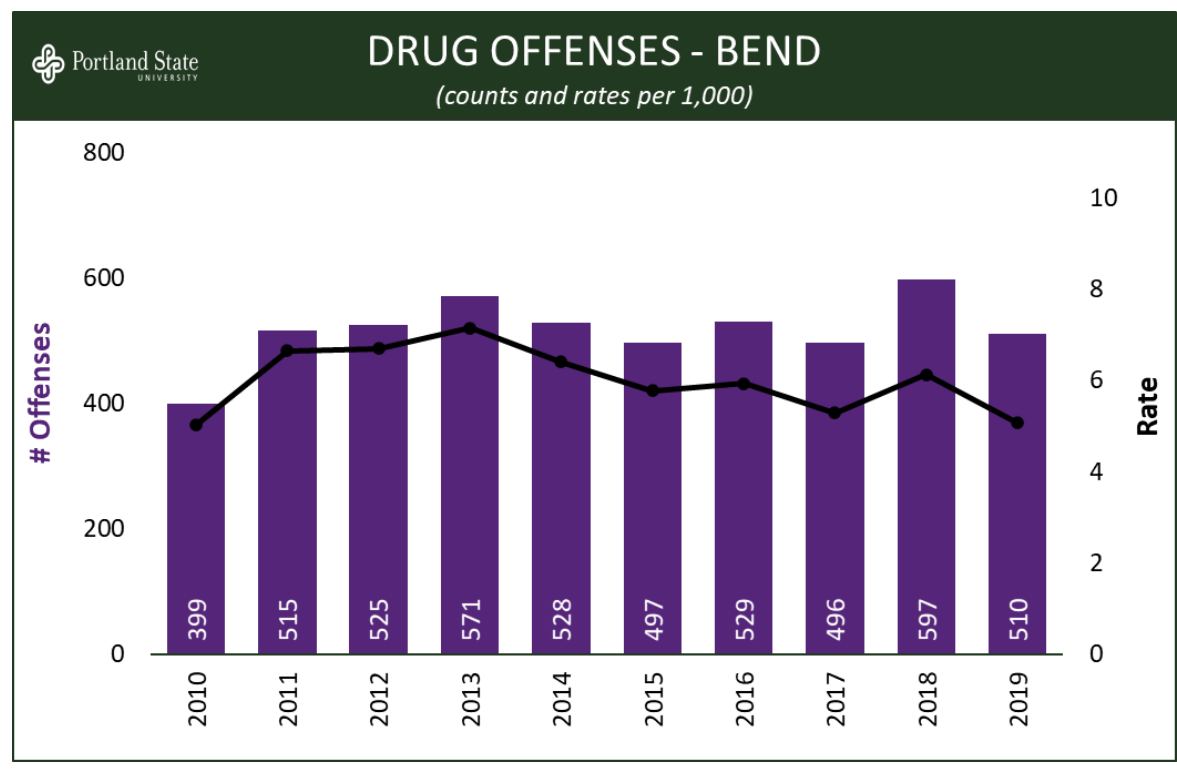

Figure 40 $1,000)$, the rate has since dropped by $-12.2 \%$ as of $2019(5.1$ per 1,000$)$. It should be noted that marijuana was legalized for recreational use in Oregon as of 2014, which may have contributed to this slight reduction of drug offenses in Bend. 


\section{Temporal Patterns}

We analyzed monthly/seasonal patterns in drug offenses by calculating the average number of offenses per month across the 10year study period. ${ }^{17}$ Bend averaged 42.5 drug offenses per month during this period of time. Although many months were found to be slightly above average, none of these months met our threshold for well above average (i.e., 2+ StDev). Similarly, none of the months would be considered well below average (i.e., 2+ standard deviations below average). This indicates that there is little to no seasonal patterns for drug offenses.

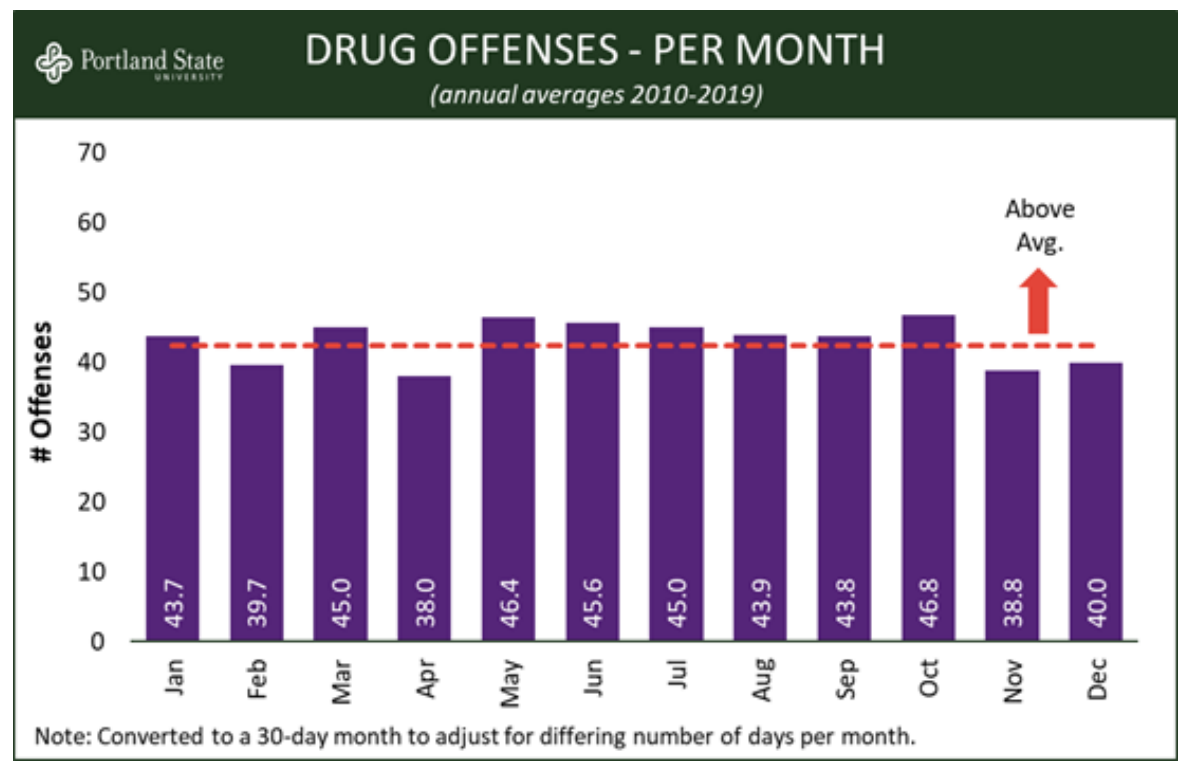

Figure 41

Regarding the distribution of drug offenses by day of week, we found that weekdays were slightly above average while Saturdays and Sundays were below average. However, there were no days of the week that met our threshold for well above average (i.e., 2+ StDev) or well below average (i.e., 2+

\section{\& Portland State DRUG OFFENSES - PER DAY OF WEEK (2010-2019)}

standard deviations below average). This reduction in drug offenses over the weekend could be due to the fact that drug offenses are primarily motivated by police proactivity. In other words, people committing a drug offense are most often caught when law enforcement officers deliberately investigate suspected drug offenders. Therefore, if officers are more preoccupied with other offenses over the weekend, they may not have the time or resources to make as many drug-related arrests.

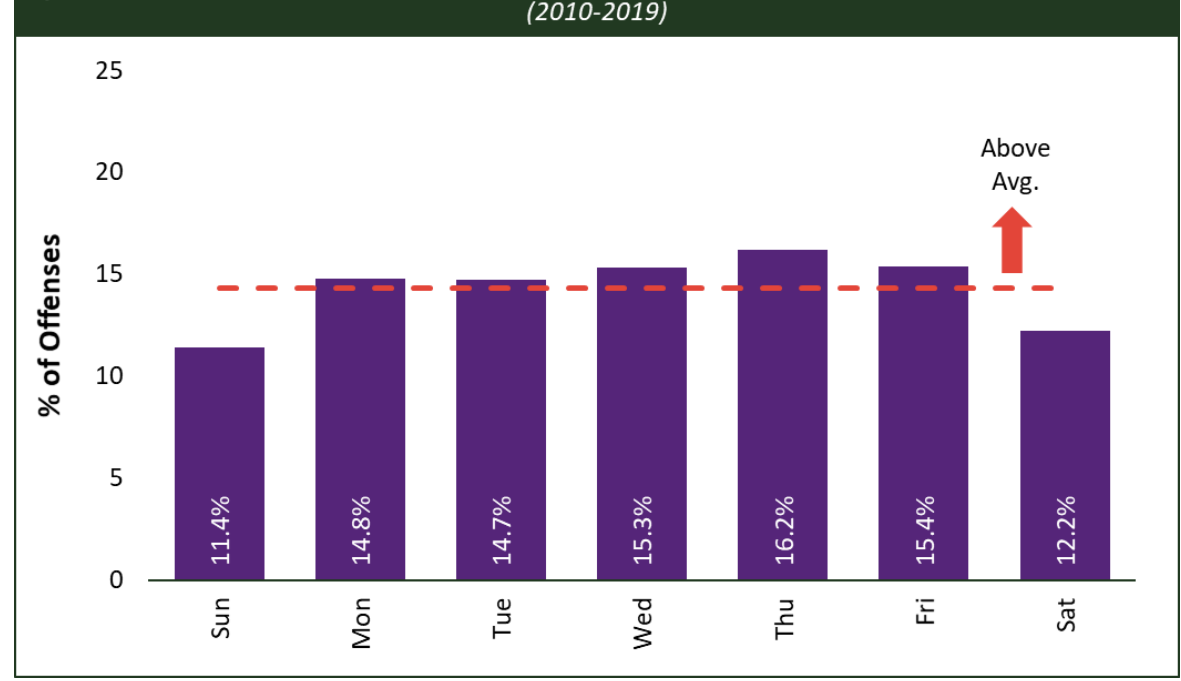

Figure 42

Figure 43 documents the distribution of drug offenses in Bend by time of day across the 10-year study period. Offenses were above average between 10:00am and 5:00pm, as well as between 7:00pm and 12:00am, other than a decrease at 11:00pm which is likely due to reporting estimates (i.e. when reporting an offense, an officer may round up to midnight if it happened between 11:00pm and 12:00am). The highest peak occurred at 12:00pm (6.6\%), however there was no specific hour of day was found to be well above average (i.e., 2+ StDev). The only time of day that was found to be well below average (i.e., 2+ standard deviations below average) was 5:00am (0.5\%). It should be noted that as mentioned previously, drug offenses are largely motivated by police proactivity, therefore any

\footnotetext{
17 Monthly counts were standardized to a 30-day month to control for the fact that some months have more days than others.
} 
hourly trends are more likely based on when officers have time to further investigate suspected drug users rather than when people actually use or distribute drugs.

\section{Geographic Pattern}

The most common location type for drug offenses during the study period was a Roadway ${ }^{18}$, with almost half $(43.4 \%, 2,241)$ of all offenses occurring on a public roadway. The second most common location type reported was Residence/Home, which comprised about a tenth $(12.2 \%, 632)$ of all offenses. This was followed by a Parking Area ${ }^{19}$ $(11.8 \%, 608)$, in which a similar percentage of drug offenses were reported to have taken place.

Together, these three locations alone account for over half $(67.4 \%, 3,481)$ of all drug offenses in Bend. See Table 12 for the top ten most common location types.

\section{Arrestee Demographic Information}

The average age for arrestees of Assault/Intimidation offenses was 28.3 years old. The most common age group for arrestees was people between the age of 25 and $34(27.9 \%)$, followed by 18 to 24 (23.5\%), and 13 to 17 (20.5\%). These three age groups comprise almost three quarters of all drug offense arrestees $(71.9 \%, 3,725)$. As demonstrated in Figure 44 , the number of arrestees increased dramatically after the age of twelve, indicating that teenagers account for a sizable percentage of drug offense arrestees. See Figure 44 for a more detailed age breakdown of drug offense arrestees.

Compared to other NIBRS offenses, there appears to be more variability in reported sex for drug offenses, with almost a third of arrestees being reported as Female (30.7\%).

\footnotetext{
18 Coded in NIBRS as Highway/Road/Alley/Street/Sidewalk, however we have changed it to Roadway for brevity.

${ }^{19}$ Coded in NIBRS as Parking/Drop Lot/Garage, however we have changed it to Parking Area for brevity.
} 
The majority of arrestees were White $(96.3 \%)$, followed by Black or African American (2.7\%). People who identified as American Indian or Alaska Native (33), Asian (14), and Native Hawaiian or Other Pacific Islander (6) comprised $1.0 \%$ of the arrestees. Regarding those with reported ethnicity $(n=2,493), 6.2 \%$ of arrestees were Hispanic or Latino.

Drug offenses also appeared to experience more variability in Residency status than other NIBRS offenses, with $12.6 \%$ of arrestees being nonresidents of Bend. This is potentially due to the fact that recreational use of marijuana is legal in Bend, which may attract visitors from other jurisdictions in which marijuana is still illegal. Between 2010 and 2019 , the percentage of nonresident drug offense arrestees increased overall by $45.2 \%$. The percentage of nonresident arrestees peaked in 2016 (17.1\%) and 2017 (18.1\%), however it has since decreased by $-26.9 \%$ as of 2019 . See Figure 45 for a more detailed depiction of nonresident drug offense arrestees in Bend over time.

\section{Offense Characteristics}

\section{Drug Offense Activities}

In this section we will analyze the different drug offense activities in Bend between 2010 and 2019. For each drug offense committed, law enforcement agencies can enter up to three types of activities. For example, if a law enforcement officer arrests someone for selling methamphetamine and they have it in their possession, although this is counted as one offense, the activities that would be reported include Possessing/Concealing and Distributing/Selling. We analyzed drug offense activities by calculating what percentage of the 5,167 drug offenses involved each activity.

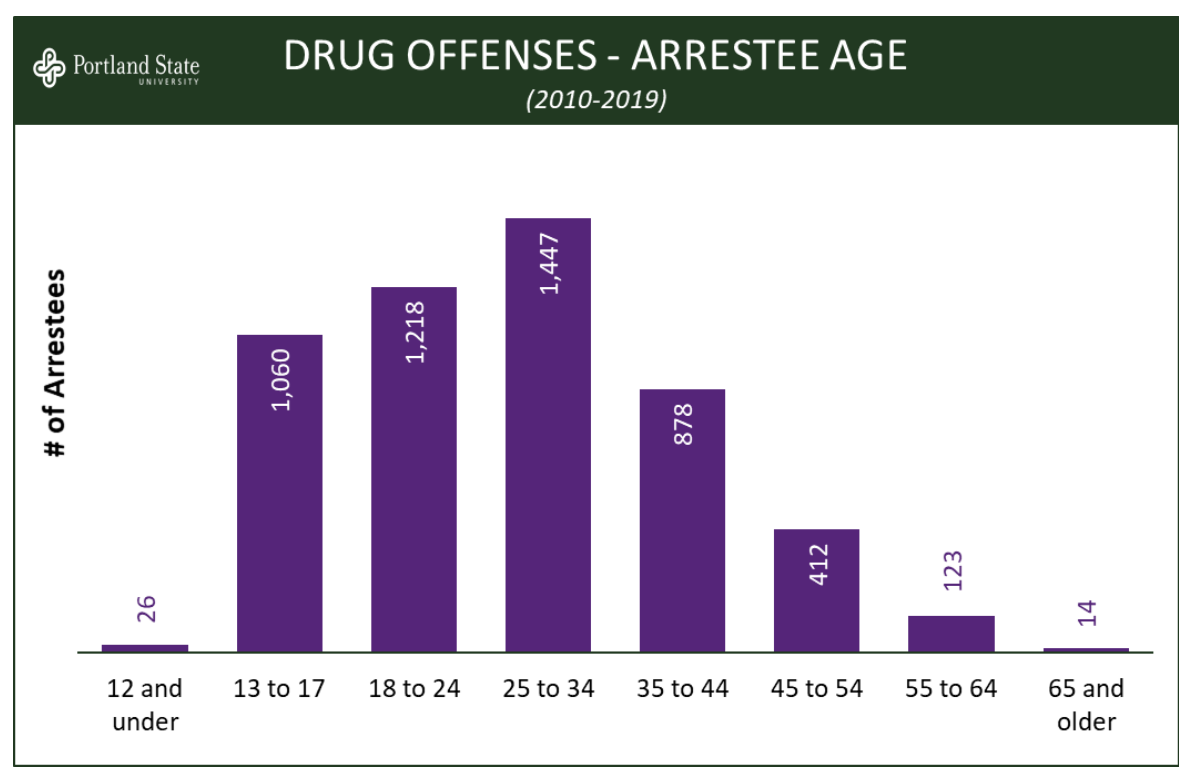

Figure 44

\begin{tabular}{|c|c|c|}
\hline \multicolumn{3}{|c|}{$\stackrel{\int}{\int}$ DRUG OFFENSES - $\underset{(2010-2019)}{\text { ARRESTEE DEMOGRAPHICS }}$} \\
\hline \multirow{2}{*}{$\frac{\text { Demographic* }}{\text { Sex }}$} & \multicolumn{2}{|c|}{ Arrestees } \\
\hline & $f$ & $\%$ \\
\hline Male & 3,586 & $69.3 \%$ \\
\hline Female & 1,592 & $30.7 \%$ \\
\hline \multicolumn{3}{|l|}{ Race } \\
\hline White & 4,905 & $96.3 \%$ \\
\hline Black or African American & 138 & $2.7 \%$ \\
\hline All Others Combined & 53 & $1.0 \%$ \\
\hline \multicolumn{3}{|l|}{ Ethnicity } \\
\hline Not Hispanic or Latino & 2,338 & $93.8 \%$ \\
\hline Hispanic or Latino & 155 & $6.2 \%$ \\
\hline \multicolumn{3}{|l|}{ Residency } \\
\hline Resident & 3,519 & $87.4 \%$ \\
\hline Nonresident & 508 & $12.6 \%$ \\
\hline
\end{tabular}

Table 13

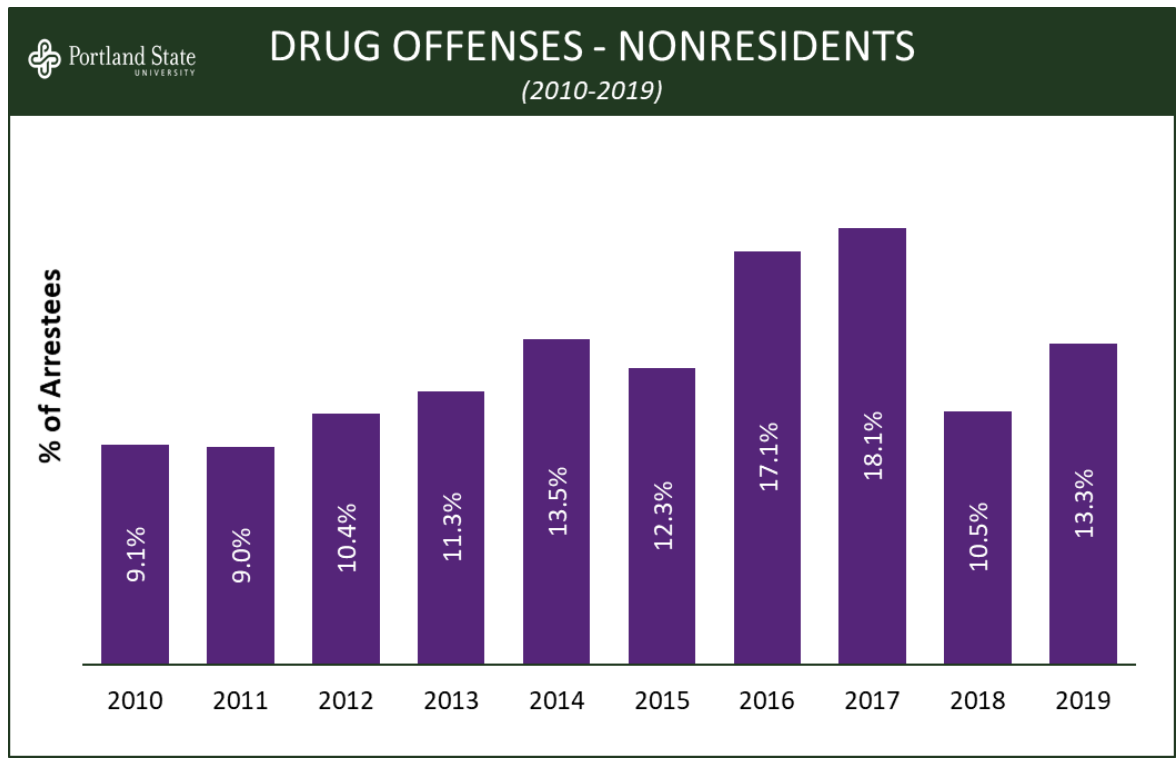

Figure 45 
The most common drug offense activity in Bend over the 10-year study period was Possessing/Concealing (74.6\%), which was involved in about three quarters of all drug violations. This was followed by

Buying/Receiving (18.7\%) and Distributing/Selling (10.5\%). See Table 14 for a more detailed breakdown of drug offenses in Bend.

\section{Drugs Seized}

The most common drug seized as a result of a drug offense in Bend between 2010 and 2019 was Marijuana $(35.0 \%, 1,838)$, with a little over 11,000 pounds of marijuana being seized during this ten-year period. This was followed by Meth/Amphetamines, which was seized at a similar rate $(34.4 \%, 1,809)$ and resulted in about 200 pounds of seized substance. The third most common drug was Heroin, which represented about $12.8 \%$ of all seizures, and totaled 80 pounds of seized substances during this period. These three substances accounted for $82.2 \%$ of all drug seizures in Bend over the study period. See Table 15 for more details about the types and quantities of drugs seized in Bend.

To provide a more in-depth analysis of drug offenses in Bend over the past ten years, we analyzed the three most common substances over time based on how many times they were seized in comparison to the quantity seized over time.

As depicted in Figure 46, the number of marijuana seizures has dramatically decreased over time from 227 seizures in 2010 to 68 in 2019 , an overall $-70.0 \%$ decrease. The number of marijuana seizures drops off dramatically after 2014 , due to the legalization of recreational marijuana. However, the quantity of marijuana seized spiked dramatically in 2018. Between 2010 and 2017, the average quantity of marijuana seized per year was $156.0 \mathrm{lbs}$. In 2018, Bend law enforcement seized 3,989.2 lbs. of marijuana, followed by $5,894.8 \mathrm{lbs}$. in 2019 . This indicates that although the number of seizures 
have decreased over time, Bend law enforcement has been making fewer but significantly larger marijuana busts.

In contrast to marijuana seizures, the number of meth/amphetamine seizures have steadily increased over the past ten years, from 90 meth/amphetamine seizures in 2010 to 289 seizures in 2019 , an overall $221.1 \%$ increase. As demonstrated in Figure 47, the quantity of meth/amphetamines seized seems to be relatively stable, aside from the large busts that occurred in 2015 and 2019. Excluding the spike in the quantity of meth/amphetamines seized in 2015 (60.7 lbs.), the average quantity seized per year before 2019 was $3.3 \mathrm{lbs}$. In 2019, Bend law enforcement seized 125.7 lbs. of meth/amphetamines, which represents about $59.8 \%$ of all of the quantity seized over the past ten years.

Similarly to meth/amphetamines, the number of heroin seizures have steadily increased over the study period, from 20 heroin seizures in 2010 to 122 seizures in 2019, an overall $510.0 \%$ increase. As depicted in Figure 48, the quantity of heroin seized seems to be consistent, excluding larger busts that occurred in 2015 and 2016. Not including the quantities seized in 2015 (50.6 lbs.) and 2016 (24.1 lbs), the average quantity of heroin seized per year was $0.8 \mathrm{lbs}$.

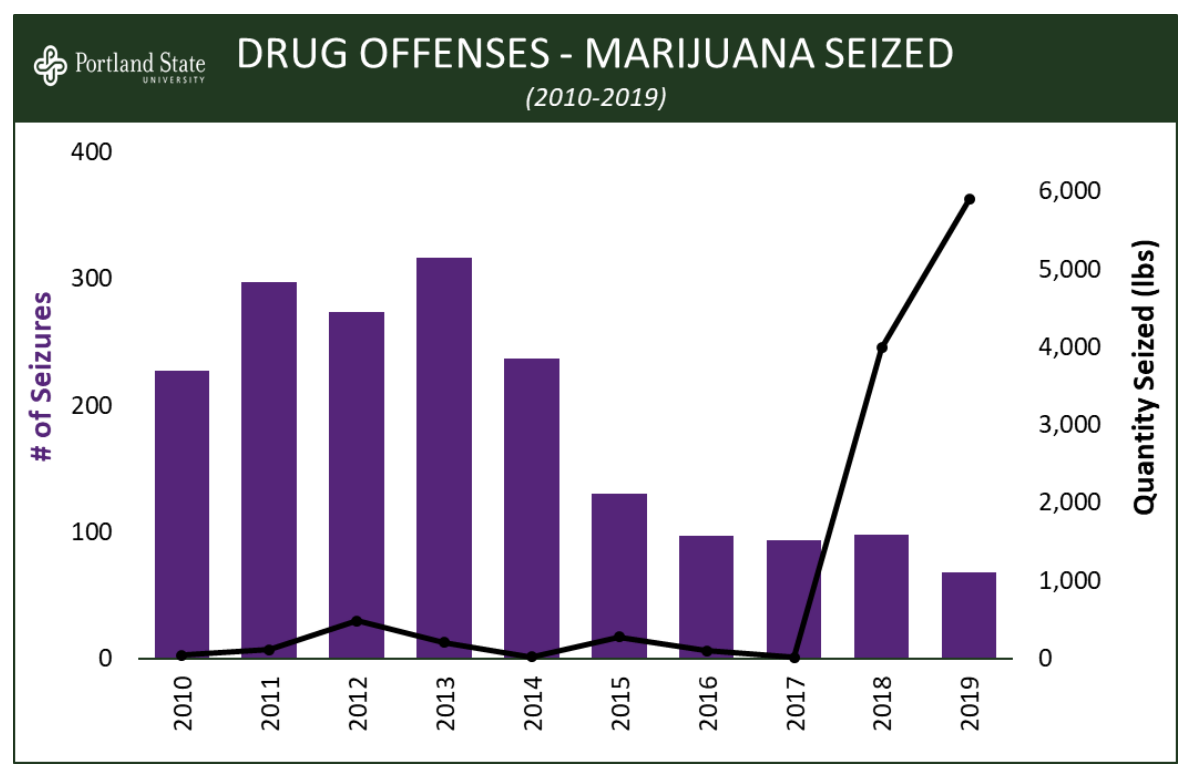

Figure 46

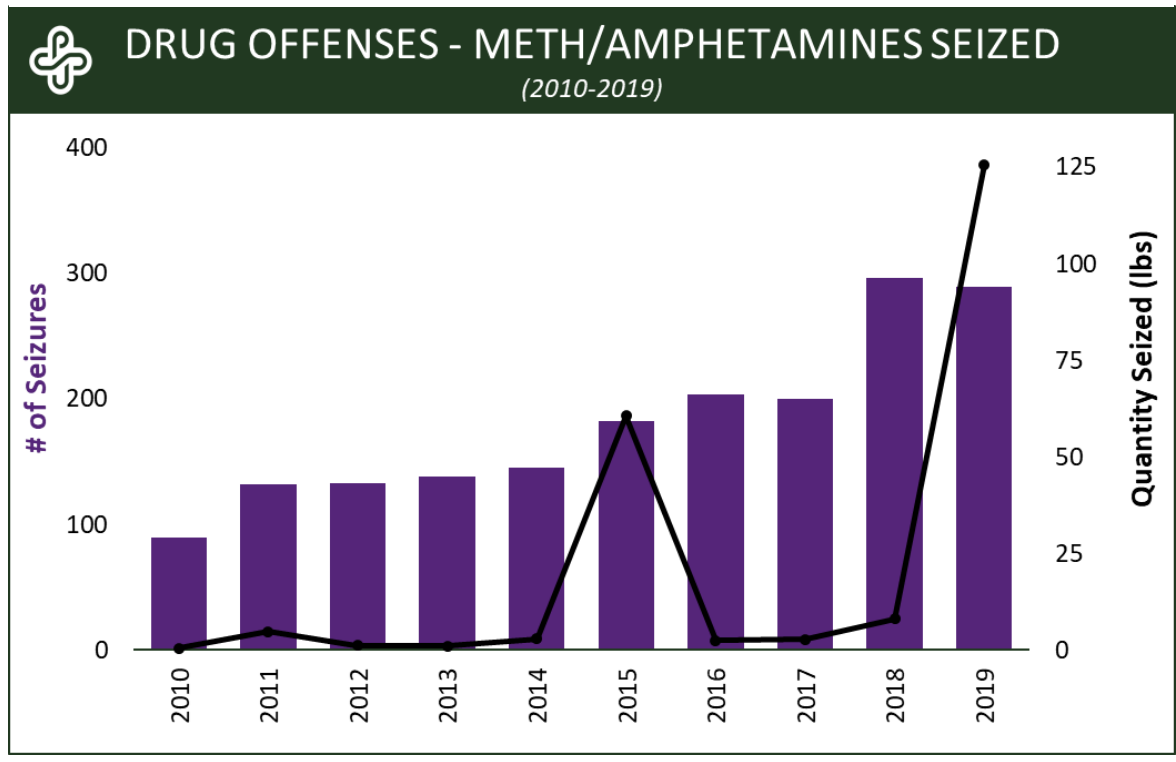

Figure 47
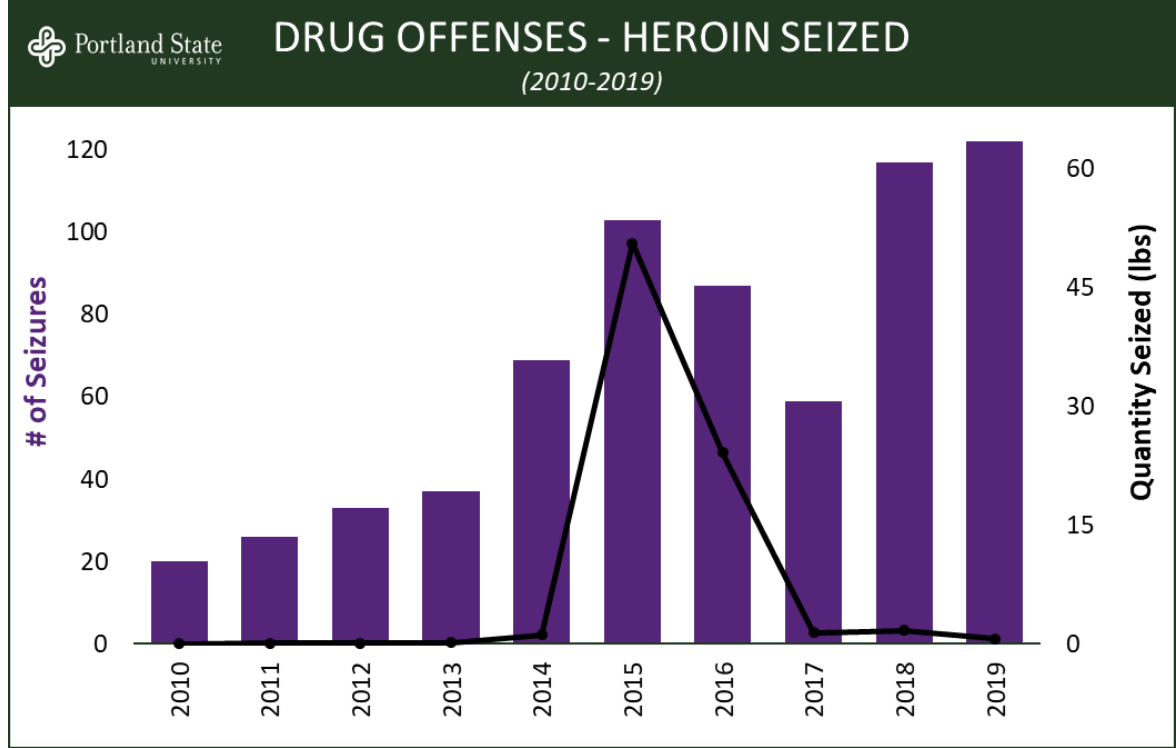

Figure 48 


\section{LARCENY/THEFT OFFENSES}

\section{Introduction \& Offense Subtypes}

In this section we will be examining Larceny/Theft offenses in Bend, Oregon between 2010 and 2019. It should be noted that although both Larceny/Theft and Burglary involve stealing property from someone else, the key distinction between the two offenses is that Burglary involves "the unlawful entry into a building or other structure," whereas Larceny/Theft does not. This offense subgroup consists of All Other Larceny, Shoplifting, Theft from Building, Pocket-picking, Purse-snatching, and Theft from Coin-Operated Machine or Device. The definition of Larceny/Theft provided by the FBI is, "The unlawful taking, carrying, leading, or riding away of property from the possession or constructive possession of another person." While Oregon has three varying degrees of theft depending on the cost of the stolen property, this is most consistent with ORS 165.015 Theft described, "A person commits a theft, when with intent to deprive another property or to appropriate property to the person or to a third person, the person takes, appropriates, obtains or withholds such property from an owner thereof." Provided below are the FBl's definitions for each offense subtype in this section of the report. We also provide the aggregate counts and rates for each offense in Bend between 2010 and 2019. The remainder of this section will analyze All Other Larceny offenses in comparison to Shoplifting over the study period since Shoplifting offenses often have distinct characteristics in comparison to general theft offenses.

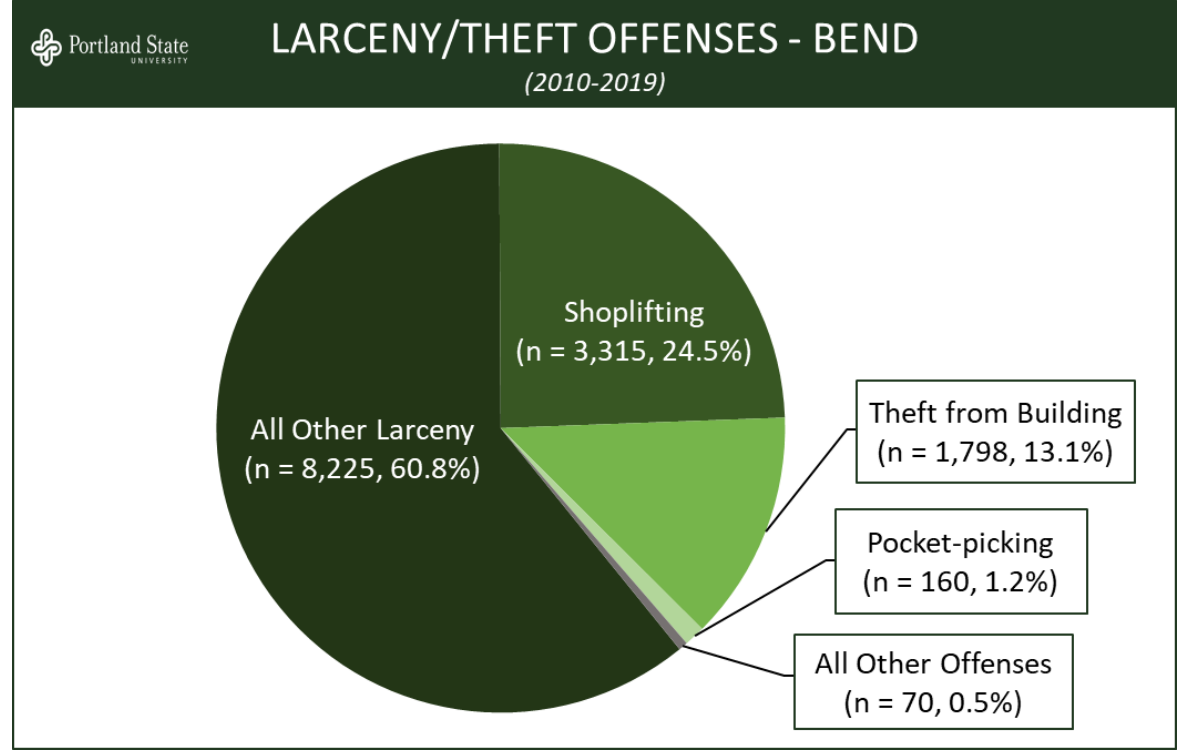

Figure 49

\section{All Other Larceny}

The FBI defines All Other Larceny as, "All thefts that do not fit any of the definitions of the specific subcategories of Larceny/Theft listed [below]." According to the NIBRS User Manual, some examples of offenses within the subtype include, "thefts from fenced enclosures, boats (houseboats if used for recreational purposes), and airplanes. It also includes the illegal entry of a tent, tent trailer, or travel trailer used for recreational purposes, followed by a theft or attempted theft. Examples of items stolen from areas in which the offender did not break into a structure are thefts of animals, lawnmowers, lawn furniture, hand tools, and farm and construction equipment." This was the most common subtype of Larceny offenses in Bend during the years examined. There were 8,225 instances of All Other Larceny, accounting for $60.8 \%$ of all Larceny offenses. The average number of All Other Larceny offenses per year was 822.5 and the average annual rate was 9.6 per 1,000 residents.

\section{Shoplifting}

Shoplifting as defined by the FBI, is "The theft by someone other than an employee of the victim of goods or merchandise exposed for sale." Shoplifting was the second most common subtype of Larceny offenses in Bend during the study period, accounting for $24.5 \%(3,315)$ of these crimes. The average number of offenses per year was 331.5 and the average annual rate was 3.9 per 1,000 residents. 


\section{Theft from Building}

The FBI classifies Theft from Building as, "A theft from within a building which is either open to the general public or to which the offender has legal access." This was the third most common subtype of Larceny offenses in Bend, accounting for $13.1 \%(1,768)$ of offenses. The average number of Thefts from Building per year in the city was 176.8 and the average annual rate was 2.1 per 1,000 residents.

\section{Pocket-picking}

Pocket-picking is defined by the FBI as, "The theft of articles from another person's physical possession by stealth where the victim usually does not become immediately aware of the theft." Pocket-picking was the fourth most common subtype of Larceny offenses between 2010 and 2019, representing $1.2 \%$ (160) of Larceny offenses. The average number of Pocket-picking offenses per year was 16.0 and the average annual rate was 0.2 per 1,000 residents.

\section{Purse-snatching}

The FBI defines Purse-snatching as, "The grabbing or snatching of a purse, handbag, etc., from the physical possession of another person." The fifth most common Larceny offense was Pursesnatching, which accounted for $0.4 \%$ (48) of theft offenses during the ten-year study period. The average number of Purse-snatching offenses per year was 4.8 and the average annual rate was 0.1 per 1,000 residents.

\section{Theft from Coin-Operated Machine or Device}

The FBI classifies Theft from Coin-Operated Machine or Device as, "A theft from a machine or device that is operated or activated by the use of coins." The least most common Larceny/Theft offense during the study period was Theft from Coin-Operated Machine or Device, which accounted for $0.2 \%$ (22) of all larceny offenses. The average number of these offenses per year was 2.2 and the average annual rate was 0.0 per 1,000 residents. For the remainder of the report, the latter four offenses will be combined with All Other Larceny due to the low rate of occurrence for each.

\section{Annual Trend}

There was a total of 13,538 Larceny/Theft offenses in Bend during the 10-year study period, or an average of $1,353.8$ offenses per year. As shown in Figure 50, the number larcenies have remained relatively stable between 2010 to 2019 , with a slight reduction of $9.8 \%$. To account for changes in the underlying population, we calculated the annual rate of Larceny Theft per 1,000 residents using U.S. Census estimates. After calculating for this, the theft rate demonstrates a decreased of $28.6 \%$ from 2010 (16.9 per 1,000$)$ to $2019(12.0$ per 1,000$)$.

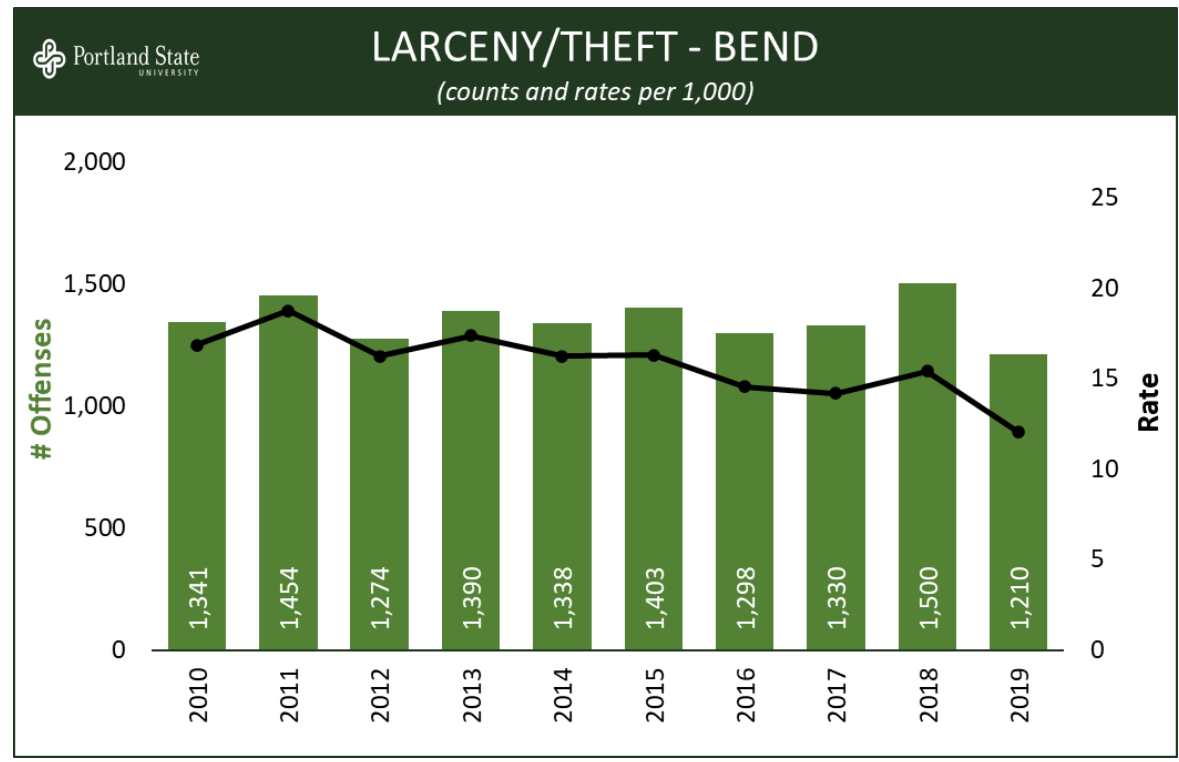

Figure 50

See Figure 50 for a more detailed annual breakdown of Larceny/Theft offenses in Bend. 


\section{Temporal Patterns}

We analyzed monthly/seasonal patterns in Larceny/Theft offenses by calculating the average number of offenses per month across the 10year study period. ${ }^{20}$ For All Other Larceny offenses, Bend averaged 83.9 thefts per month during this period of time. Higher monthly averages were found during May, June, July, August, September, and October. The highest monthly averages occurred during the summer months. While these were above average, the only month that met our threshold for well above average (i.e., 2+ StDev) was July, with an average of 108.0 monthly offenses. None of the months would be considered well below average (i.e., 2+ standard deviations below average).

While there appears to be a seasonal increase in All Other Larceny offenses during the summer, Shoplifting demonstrated a relatively stable pattern of offenses throughout the year. Between 2010 and 2019 , there was an average 27.4 shoplifting offenses per month. Higher monthly averages were found during January, May, and December. However, none of these months met our threshold for well above average. The only month that was found to be well below average was April, with an average of 21.0 shoplifting offenses per month.

For our analysis regarding the

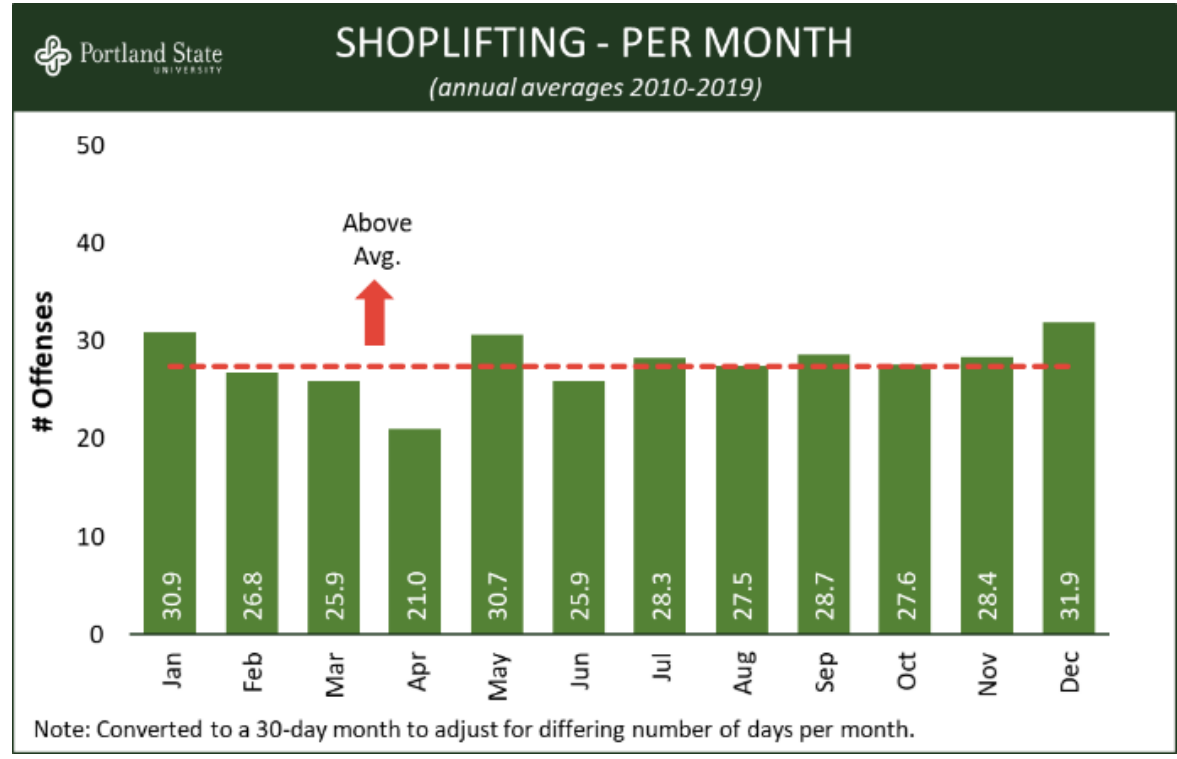

Figure 52

distribution of Larceny/Theft offenses by day of week, we decided to analyze all theft offenses collectively due to the similarity in distribution we found for All Other Larceny and Shoplifting.

Although the percentage of offenses that occurred on Friday was above average, there were no days that exceeded our definition for well above average (i.e., 2+ StDev). Otherwise, there was relatively limited fluctuation in this theft offenses by day.

Figure 54 documents the distribution of Larceny/Theft offenses in Bend by time of day across the 9year study period. All Other Larceny offenses were above average between 10:00am and 6:00pm, with the highest peaks occurring at 3:00pm (5.8\%) and 5:00pm (5.8\%). It should be noted that 
averages of the preceding and following hour (i.e. to smooth the curve for 8:00am, we took the average of 7:00am and 9:00am) were taken for 8:00am, 12:00pm, and 12:00am to control for spikes likely resulting from reporting inaccuracies. There was no specific hour of day was found to be well above average (i.e., 2+ StDev) for All Other Larceny offenses. The only hours of day that were found to be well below average (i.e., 2+ standard deviations below average) were 4:00am and 5:00am, accounting for $0.8 \%$ of offenses.

Shoplifting offenses demonstrated a much more significant hourly pattern in comparison to All Other Larceny. Shoplifting offenses were above average between 11:00am and 8:00pm, with the highest peak occurring at $3: 00 \mathrm{pm}(10.6 \%)$. None of these hours were found to be well above average (i.e., 2+ StDev), however this pattern is indicative of an increase in Shoplifting offenses during typical business hours. There were no hours of day that were found to be well below average, however as demonstrated in Figure 54 , shoplifting offenses dramatically decreased between 9:00pm and 9:00am.

For our analysis regarding Larceny/Theft offenses by time of day and day of week, we decided to analyze all theft offenses collectively due to the similarities between All Other Larceny offenses and Shoplifting. It should also be noted that averages of the preceding and following hour were taken for 8:00am, $12: 00 \mathrm{pm}$, and 12:00am to control for outliers likely resulting from reporting estimates. When analyzing Larceny/Theft offenses by the hour per day of week, it

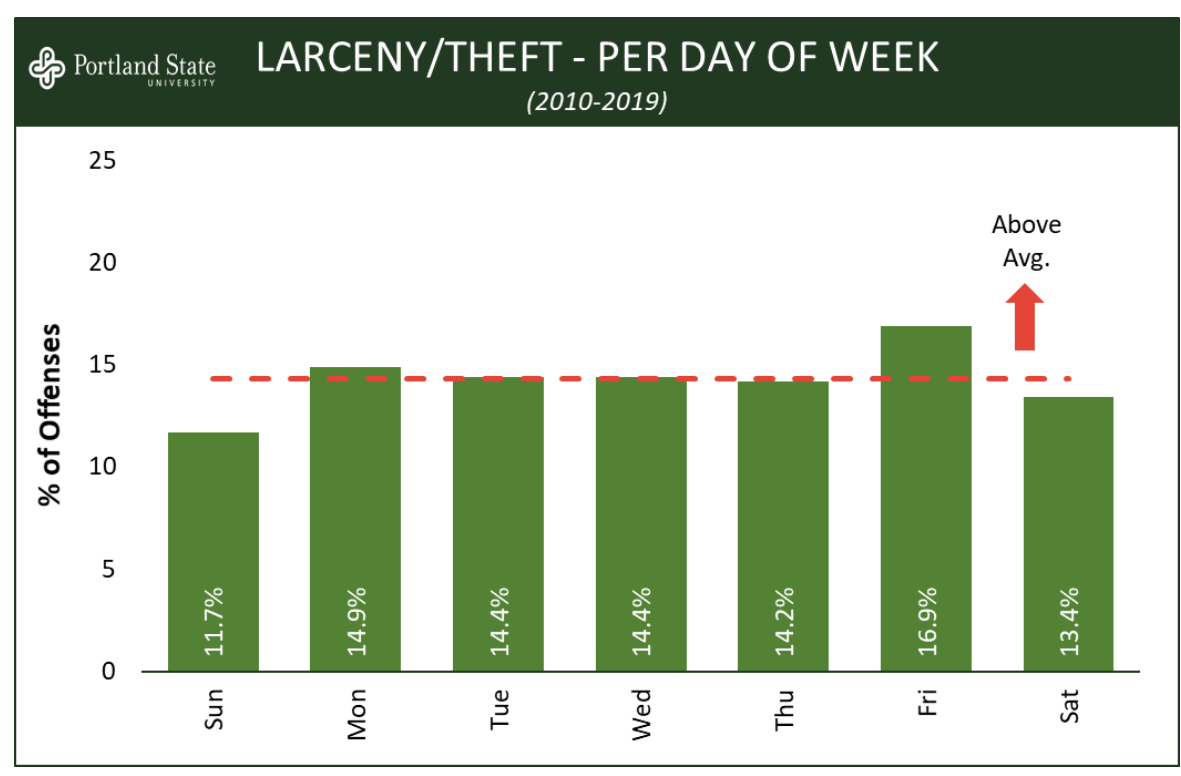

Figure 53

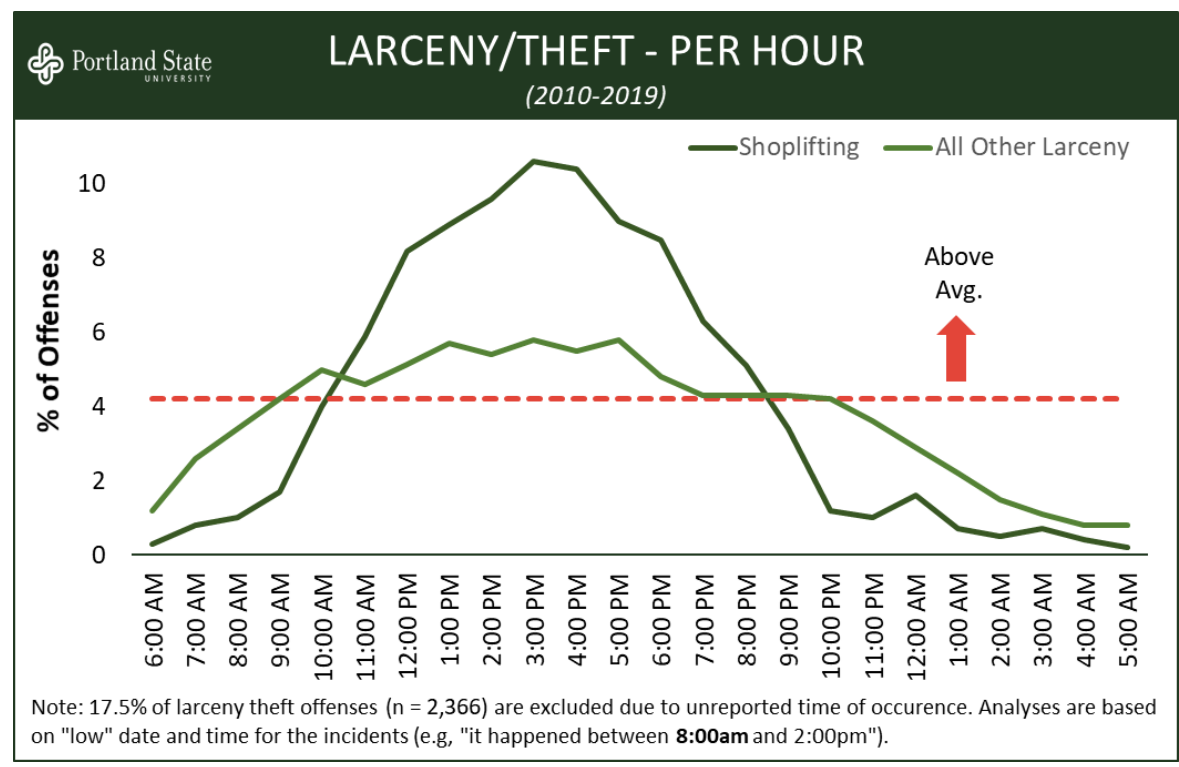

Figure 54

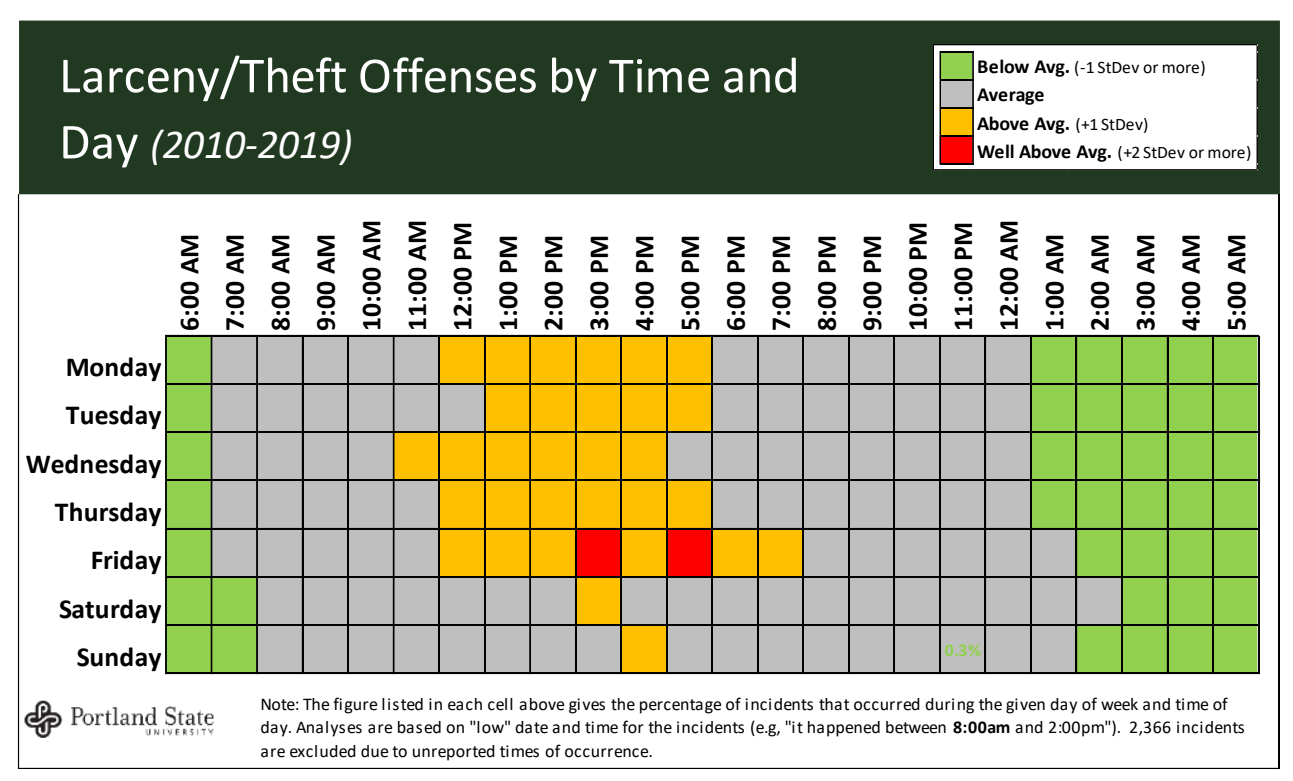

Figure 55 
becomes apparent that the number of offenses increases during the weekdays between 12:00pm and 5:00pm. Although this period of time during the weekday was found to be above average, the only weekday that experienced hours that were well above the average was Friday. On Fridays at 3:00pm $(1.3 \%)$ and $5: 00 \mathrm{pm}(1.2 \%)$, the number of offenses were well above the average. See Figure 55 for a more detailed breakdown of Larceny/Theft offenses by hour per day of week.

\section{Geographic Pattern}

The most common location type for All Other Larceny offenses during the study period was Residence/Home, with about a quarter $(24.1 \%, 2,467)$ of all offenses occurring at someone's residence. The second most common location type reported was a Roadway, which comprised $16.5 \%(1,690)$ of all offenses. Other public locations such as Parking Area, Commercial/Office Building, and Bar/Nightclub were common in All Other Larceny offenses. See Table 16 for the top ten most common location types for All Other Larceny.

Naturally, the most common location type for Shoplifting offenses during the study period was a Department/Discount Store, which accounted for almost half $(41.2 \%$, $1,366)$ of all offenses. The second most common location type was found to be Grocery/Supermarket, which comprised almost a quarter $(23.4 \%$, 777) of Shoplifting offenses. The third most common location for Shoplifting to occur was a Shopping Mall, which represented $9.7 \%$ (322) of offenses during the study period. See Table 17 for the top ten most common Shoplifting location types.

\begin{tabular}{|lcc|}
$\begin{array}{l}\text { 色 Portland State } \\
\text { Location Type }\end{array}$ & \multicolumn{1}{c|}{$\begin{array}{l}\text { AL OTHER LARCEN - LOCATION TYPE } \\
(2010-2019)\end{array}$} & $\%$ \\
\hline Residence/Home & 2,467 & $24.1 \%$ \\
Roadway & 1,690 & $16.5 \%$ \\
Other/Unknown & 1,360 & $13.3 \%$ \\
Parking Area & 589 & $5.8 \%$ \\
Commercial/Office Building & 507 & $5.0 \%$ \\
Bar/Nightclub & 410 & $4.0 \%$ \\
Restaurant & 381 & $3.7 \%$ \\
School & 317 & $3.1 \%$ \\
Grocery/Supermarket & 308 & $3.0 \%$ \\
Department/Discount Store & 275 & $2.7 \%$ \\
All Other Locations & 1,919 & $18.8 \%$ \\
\hline Total & 10,223 & $100.0 \%$ \\
\hline
\end{tabular}

Table 16

\begin{tabular}{|lrc|}
$\begin{array}{l}\text { S PHOPLIFTING - LOCATION TYPE } \\
\text { (2010-2019) }\end{array}$ & \\
\hline Location Type & $f$ & $\%$ \\
\hline Department/Discount Store & 1,366 & $41.2 \%$ \\
Grocery/Supermarket & 777 & $23.4 \%$ \\
Shopping Mall & 322 & $9.7 \%$ \\
Specialty Store & 208 & $6.3 \%$ \\
Convenience Store & 161 & $4.9 \%$ \\
Commercial/Office Building & 155 & $4.7 \%$ \\
Roadway & 121 & $3.7 \%$ \\
Other/Unknown & 89 & $2.7 \%$ \\
Liquor Store & 33 & $1.0 \%$ \\
Parking Area & 23 & $0.7 \%$ \\
All Other Locations & 60 & $1.8 \%$ \\
\hline Total & 3,315 & $100.0 \%$ \\
\hline
\end{tabular}

Table 17

\section{Victim \& Arrestee Information}

\section{Victim Type}

In this section we will analyze the types of victims that were affected by a Larceny/Theft offense during the 10-year study period. Since theft is not a person crime and victims are normally targeted based on other factors such as how secure the location is or whether someone is present, we will only assess theft victims based on what NIBRS category they were reported as. It should also be noted 
that victims can be double coded for victim categories, which can result in the total number of victim types exceeding the actual number of offenses.

The most common victim type for All Other Larceny offenses during the study period was an Individual, with more than three quarters $(82.0 \%, 8,910)$ of all victims falling into this category. The second most common victim type reported was a Business, which comprised $15.3 \%(1,662)$ of all victims. These two victim types combined account for almost all $(97.3 \%, 10,872)$ of the All Other Larceny victims in Bend.

\begin{tabular}{|c|c|c|c|c|}
\hline \multicolumn{5}{|c|}{ 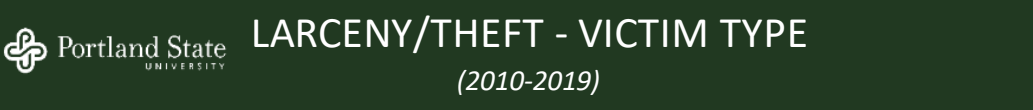 } \\
\hline \multirow[b]{2}{*}{ Victim Type } & \multicolumn{2}{|c|}{ All Other Larceny } & \multicolumn{2}{|c|}{$\underline{\text { Shoplifting }}$} \\
\hline & $f$ & $\%$ & $f$ & $\%$ \\
\hline Individual & 8,910 & $82.0 \%$ & 155 & $4.3 \%$ \\
\hline Business & 1,662 & $15.3 \%$ & 3,239 & $89.0 \%$ \\
\hline Society/Public & 164 & $1.5 \%$ & 239 & $6.6 \%$ \\
\hline Government & 63 & $0.6 \%$ & 2 & $0.1 \%$ \\
\hline Financial Insitution & 43 & $0.4 \%$ & 2 & $0.1 \%$ \\
\hline Other & 16 & $0.1 \%$ & 1 & $0.0 \%$ \\
\hline Religious Organization & 9 & $0.1 \%$ & 0 & $0.0 \%$ \\
\hline Total & 10,867 & $100.0 \%$ & 3,638 & $100.0 \%$ \\
\hline
\end{tabular}

Table 18

The most common victim type for Shoplifting offenses over the ten-year study period was a Business, with $89.0 \%(3,239)$ of all victims being reported in this category. The second most common victim type was found to be Society/Public, which accounted for $6.6 \%$ (239) of victims. These two victim types combined represent almost all $(95.6 \%, 3,478)$ of the Shoplifting victims in Bend. See Table 18 for a more detailed breakdown of victim types involved in Larceny/Theft offenses.

\section{Arrestee Demographic Profile}

Overall, the average age for arrestees of Larceny/Theft offenses $(\mathrm{N}=4,634)$ was 29.3 years old. The most common age group for arrestees was people between the age of 25 and $34(26.2 \%)$, followed by 18 to $24(23.2 \%)$, and 13 to 17 (19.4\%).

There were more teenage arrestees involved in Shoplifting offenses $(22.1 \%)$ than All Other Larceny offenses (16.9\%). Additionally, there were slightly more Shoplifting arrestees that were between the ages of 18 and 34 (48.9\%) compared to All Other Larceny arrestees $(47.1 \%)$. There were more

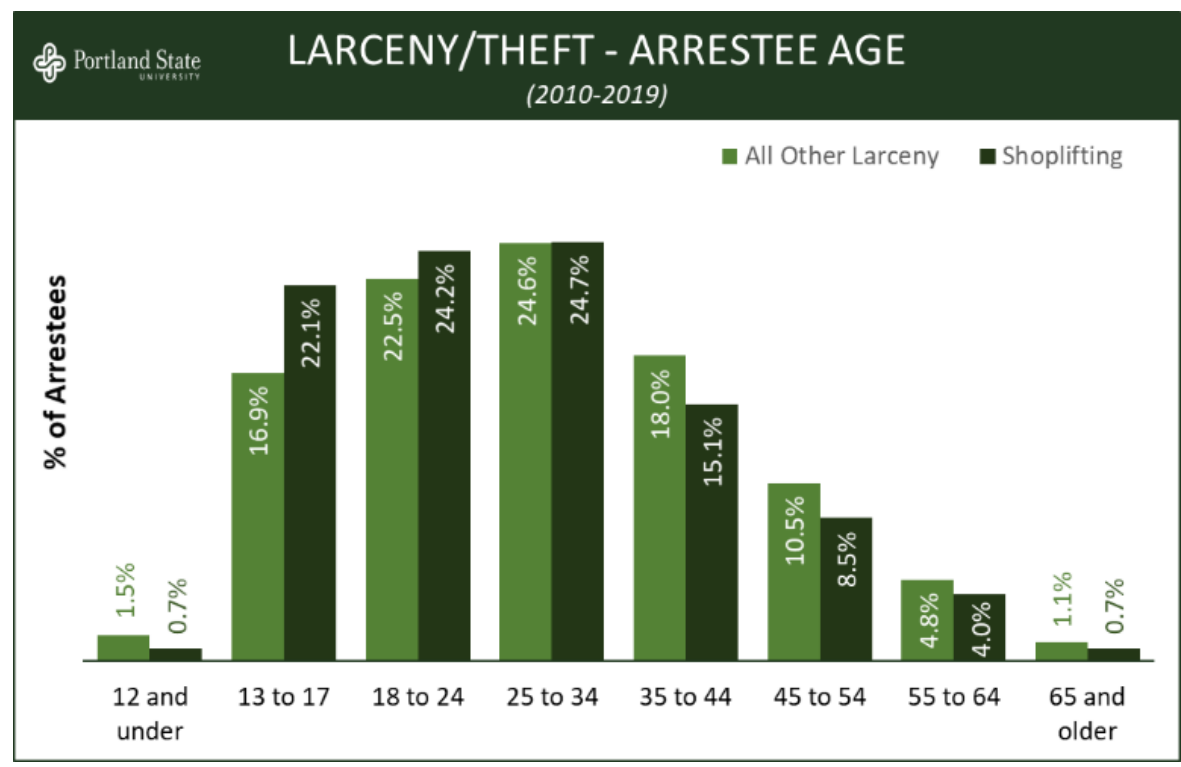

Figure 56

arrestees that were 35 and older involved in an All Other Larceny offense (34.4\%) compared to Shoplifting arrestees (28.3\%). See Figure 56 for a more detailed breakdown of age distribution for Larceny/Theft arrestees.

A large percentage of All Other Larceny arrestees during the study period were Male $(67.2 \%)$. Shoplifting arrestees, however, were split more evenly in reported sex with $50.2 \%$ being Male. Among All Other Larceny arrestees, the vast majority (95.5\%) were White, followed by Black or African American (3.1\%). Asian (9), American Indian or Alaska Native (5), and Native Hawaiian or 
Other Pacific Islander (2) represented $1.4 \%$ of All Other Larceny arrestees. ${ }^{21}$ Although the same percentage of Shoplifting arrestees were White $(95.5 \%)$, there was slightly higher percentage of arrestees categorized in "All Others Combined." Black or African American arrestees represented 2.1\% of Shoplifting arrestees, with the remaining $2.4 \%$ being American Indian or Alaska Native (43), Asian (13), and Native Hawaiian or Other Pacific Islander (8). ${ }^{15}$

With regard to ethnicity, $4.9 \%$ of All Other Larceny arrestees were reported as Hispanic or Latino. A similar percentage of Shoplifting arrestees were reported as Hispanic or Latino $(4.6 \%)$.

\begin{tabular}{|c|c|c|c|c|}
\hline LARCENY/THEF & $\begin{array}{l}\text { ARR } \\
(2010\end{array}$ & DEN & RAP & \\
\hline \multirow[b]{2}{*}{ Demographic* } & \multicolumn{2}{|c|}{ All Other Larceny } & \multicolumn{2}{|c|}{ Shoplifting } \\
\hline & $f$ & $\%$ & $f$ & $\%$ \\
\hline \multicolumn{5}{|l|}{ Sex } \\
\hline Male & 781 & $67.2 \%$ & 1,347 & $50.2 \%$ \\
\hline Female & 382 & $32.8 \%$ & 1,335 & $49.8 \%$ \\
\hline \multicolumn{5}{|l|}{ Race } \\
\hline White & 1,078 & $95.5 \%$ & 2,512 & $95.5 \%$ \\
\hline Black or African American & 35 & $3.1 \%$ & 55 & $2.1 \%$ \\
\hline All Others Combined & 16 & $1.4 \%$ & 64 & $2.4 \%$ \\
\hline \multicolumn{5}{|l|}{ Ethnicity } \\
\hline Not Hispanic or Latino & 506 & $95.1 \%$ & 1,178 & $95.4 \%$ \\
\hline $\begin{array}{l}\text { Hispanic or Latino } \\
\text { Residency }\end{array}$ & 26 & $4.9 \%$ & 57 & $4.6 \%$ \\
\hline Resident & 770 & $90.2 \%$ & 1,676 & $82.6 \%$ \\
\hline Nonresident & 84 & $9.8 \%$ & 354 & $17.4 \%$ \\
\hline
\end{tabular}

Table 19

Of the All Other Larceny arrestees whose Residency status was known, 90.2\% were residents of Bend. In comparison, a lower percentage of Shoplifting arrestees were found to be a resident (82.6\%). See Table 19 for more detailed demographic information about Larceny/Theft arrestees in Bend.

\section{Property Stolen Losses}

\section{Property Descriptions}

Overall, the most common property that was stolen in a Larceny/Theft offense during the 10-year study period was Bicycles (11.8\%). This was followed by Money (10.9\%), Purse/Wallet (6.8\%), and Clothes/Furs (6.2\%). Unfortunately, we were unable to distinguish between the most common items stolen in All Other Larceny offenses versus Shoplifting due to the layout of NIBRS reporting. See Table 20 for the top ten most common descriptions of property stolen in Larceny/Theft offenses over the study period.

\begin{tabular}{|lrc|}
\hline \multicolumn{1}{|c|}{$\begin{array}{c}\text { (2010-2019) } \\
\text { Property Description }\end{array}$} & $\boldsymbol{f}$ & $\%$ \\
\hline Bicycles & 2,103 & $11.2 \%$ \\
Money & 2,053 & $10.9 \%$ \\
Purse/Wallet & 1,281 & $6.8 \%$ \\
Clothes/Furs & 1,173 & $6.2 \%$ \\
Portable Electronic Communications & 848 & $4.5 \%$ \\
Consumable Goods & 819 & $4.3 \%$ \\
Credit/Debit cards & 730 & $3.9 \%$ \\
Tools & 664 & $3.5 \%$ \\
Identity Documents & 580 & $3.1 \%$ \\
Computer Hard/Software & 551 & $2.9 \%$ \\
All Other Items & 8,048 & $42.7 \%$ \\
\hline Total & 18,850 & $100.0 \%$ \\
\hline
\end{tabular}

Table 20

\section{Costs of Stolen Property}

In this section we estimate the direct costs associated with Larceny/Theft offenses in Bend during the 10 -year study period. Due to the nature of Larceny/Theft we will only be analyzing the costs resulting from stolen property. In other words, since larceny by definition does not involve breaking and entering and rarely involves counterfeiting, we will only analyze the values of losses that were

${ }^{21}$ Referred to as "All Others Combined" in table for brevity. 
reported to NIBRS as "Stolen." In order to estimate the total financial losses attributable to larceny, we replaced any missing values with the statewide mean value for a given item and year. Additionally, it should be noted that one incident in 2010 resulting in a property loss worth \$1,069,554 was removed from the data so that patterns in property loss over time can be depicted more clearly.

Between 2010 and 2019, Bend experienced $\$ 20,481,517$ in stolen property losses resulting from Larceny/Theft offenses. This means that there was an average loss of $\$ 2,048,151$ per year as a result of stolen property. The average loss per theft during this time was $\$ 1,119$. Although the total cost of stolen property has varied considerably per year, the yearly loss has decreased overall by 10.9\% between 2010 and 2019. In recent years, it appears that the yearly costs associated with Larceny/Theft offenses have increased. As of 2019, the yearly cost of stolen property has increased by $53.1 \%$ since 2015 . See Figure 57 for a yearly breakdown of Bend's property losses resulting from Larceny/Theft offenses.

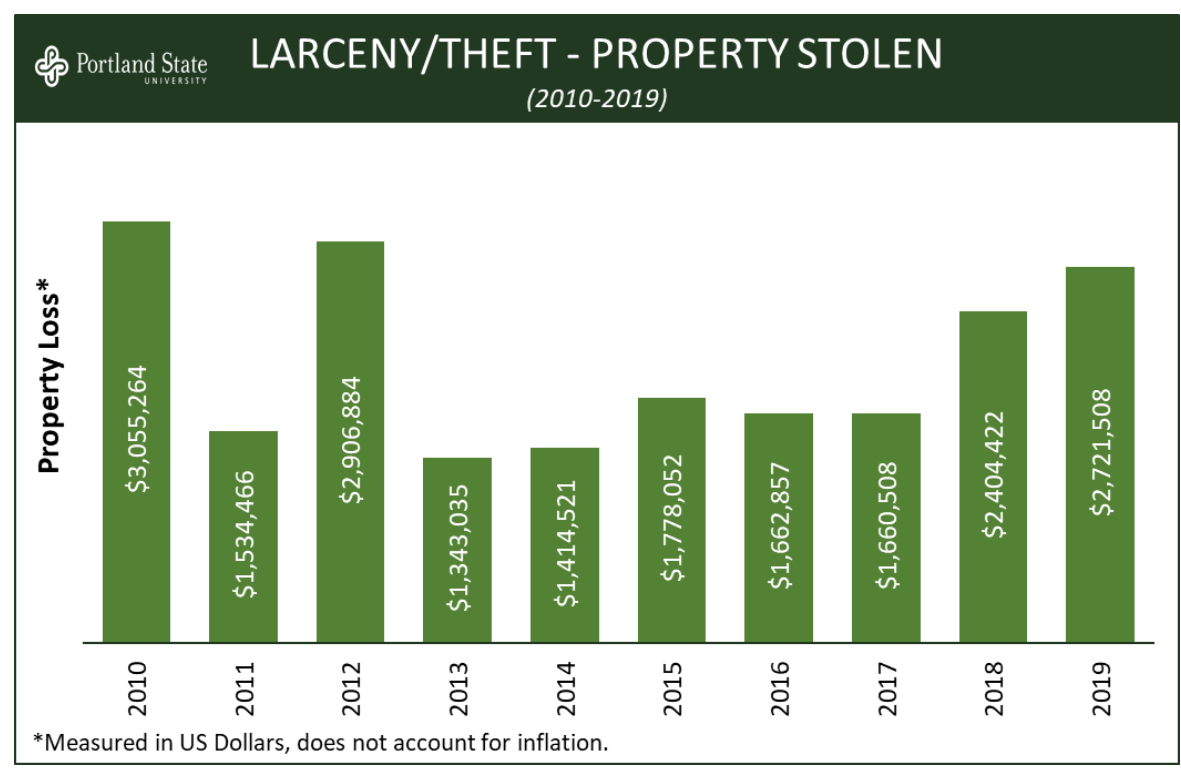

Figure 57

\section{Clearance Rate}

Of the 13,538 Larceny/Theft offenses between 2010 and 2019, $29.2 \%(3,957)$ were Cleared by Arrest/Citation or Exceptionally. The average annual clearance rate during this time was $29.2 \%$, or 395.7 offenses per year. The overall clearance rate for Larceny/Theft in Bend has remained relatively stable over the past decade, with a slight increase of $17.9 \%$ between 2010 and 2019. See Figure 58 for an annual breakdown of Larceny/Theft clearance rates over the study period in Bend.

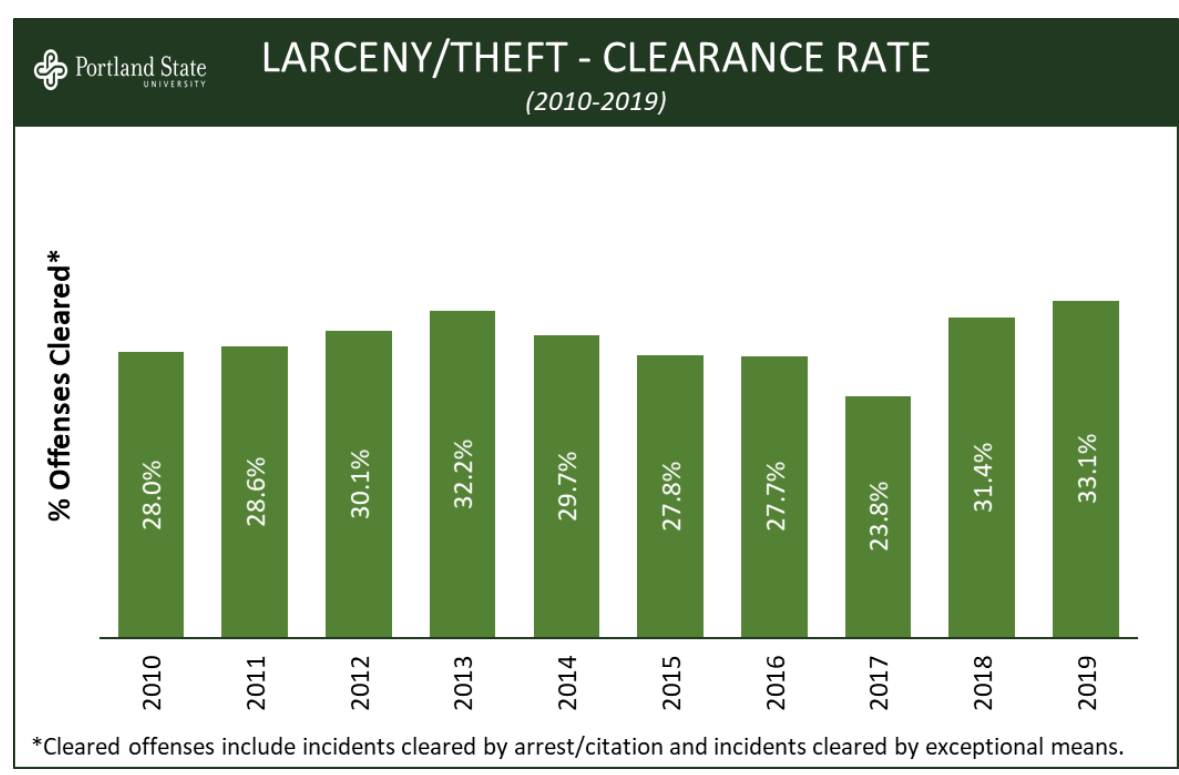

Figure 58

When we analyze clearance rates for All Other Larceny and Shoplifting offenses, it becomes apparent that the Shoplifting clearance rate dominates all other forms of larceny. Of the 3,315 Shoplifting offenses over the study period, $74.8 \%(2,481)$ were Cleared by Arrest/Citation or Exceptionally. In contrast, of the 10,223 All Other Larceny offenses over the study period, only $14.4 \%(1,472)$ of offenses were Cleared. This stark difference in clearance rates is likely due to the nature of each 
crime; shoplifters are normally identified as they commit the crime, whereas many victims of larceny do not realize they have been stolen from until after the fact. Although both clearance rates appear to be relatively stable over time, there does seem to be a slight decrease in clearance rates for Shoplifting while the All Other Larceny clearance rate seems to be increasing slightly. Since 2015, the clearance rate for Shoplifting has decreased by $12.2 \%$, while the clearance rate for All Other Larceny has increased by $28.0 \%$. See Figure 59 for an annual breakdown of both clearance rates over the study period in Bend.

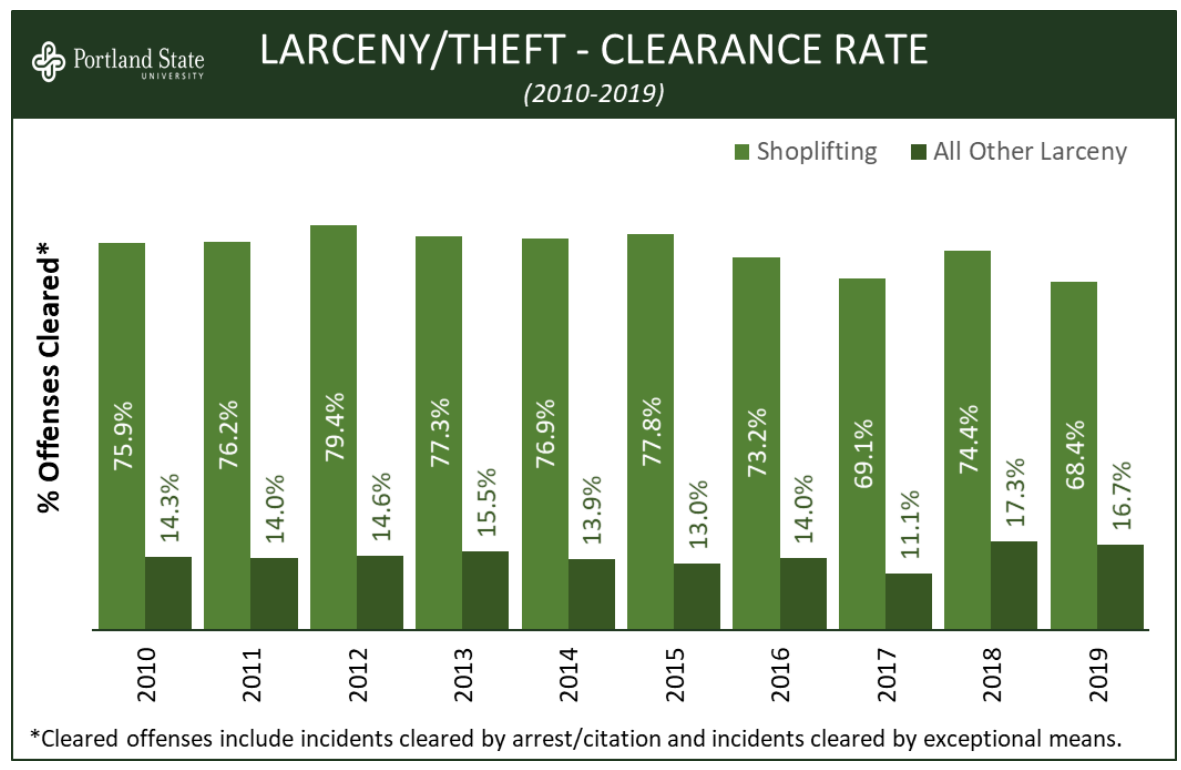

Figure 59 


\section{THEFT OF/FROM A MOTOR VEHICLE}

\section{Introduction \& Offense Subtypes}

In this section we will be examining offenses involving Theft of/from a Motor Vehicle in Bend, Oregon between 2010 and 2019. This offense subgroup consists Theft from a Motor Vehicle, Theft of a Motor Vehicle, and Theft of Motor Vehicle Parts or Accessories. Oregon has three varying degrees of theft based on the cost of the stolen property, all of which can be applied to this offense group depending on whether the theft is of or from a motor vehicle. This is most consistent with ORS 165.015 Theft described, "A person commits a theft, when with intent to deprive another property or to appropriate property to the person or to a third person, the person takes, appropriates, obtains or withholds such property from an owner thereof." Additionally, Theft of a Motor Vehicle is most similar to ORS 164.135 Unauthorized use of a vehicle, "A person commits the crime of unauthorized use of a vehicle when the person knowingly takes, operates, exercises control over or otherwise uses another's vehicle boat or aircraft." Provided below are the FBI's definitions for each offense subtype in this section of the report, as well as the aggregate counts and rates for each offense type. The remainder of this section analyzes Theft of/from a Motor Vehicle offenses collectively in Bend between 2010 and 2019.

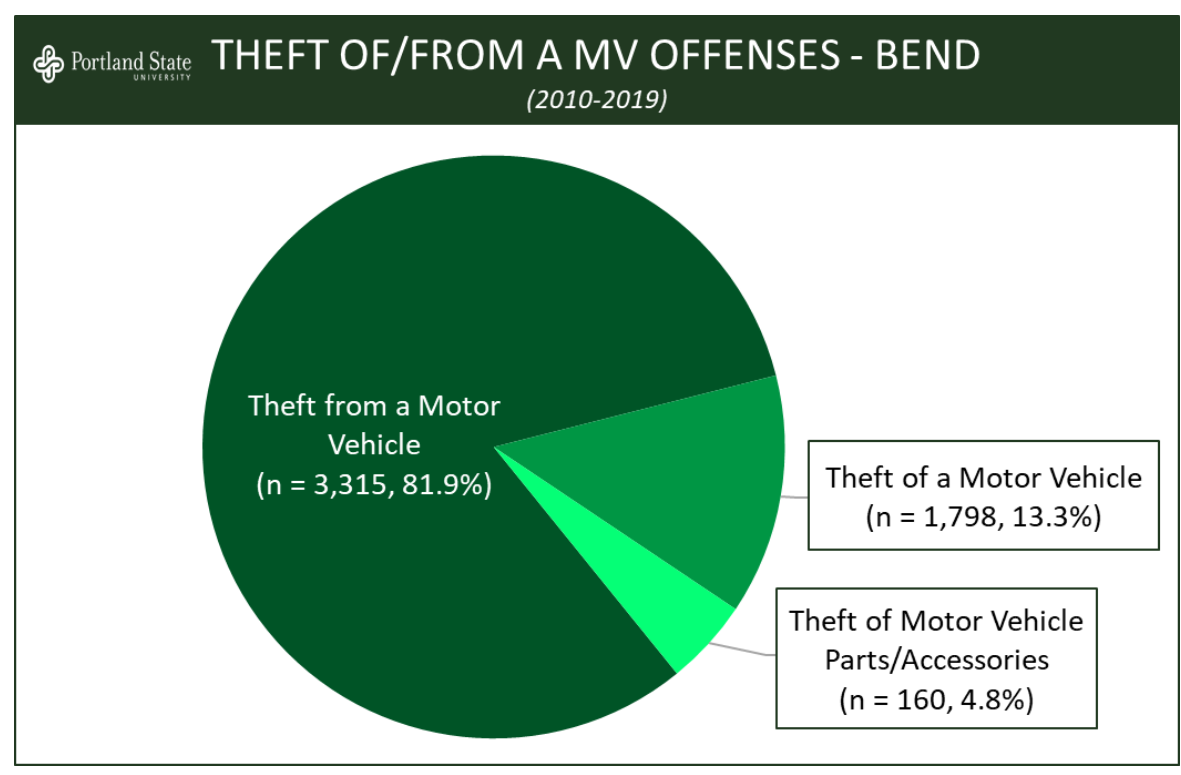

Figure 60

\section{Theft from a Motor Vehicle}

The FBI defines Theft from a Motor Vehicle as, "The theft of articles from a motor vehicle, locked or unlocked." This was the most common subtype of Theft of/from a Motor Vehicle offenses in Bend during the years examined. There were 5,352 instances of Theft from a Motor Vehicle, accounting for $81.9 \%$ of these offenses. The average number of All Other Larceny offenses per year was 535.2 and the average annual rate was 6.3 per 1,000 residents.

\section{Theft of a Motor Vehicle}

Motor Vehicle Theft as defined by the FBI, is simply "The theft of a motor vehicle." Theft of a Motor Vehicle was the second most common subtype of these offenses in Bend during the study period, accounting for $13.3 \%$ (872) of these crimes. The average number of offenses per year was 87.2 and the average annual rate was 1.0 per 1,000 residents.

\section{Theft of Motor Vehicle Parts or Accessories}

The FBI classifies Theft of Motor Vehicle Parts or Accessories as, "The theft of any part or accessory affixed to the interior or exterior of a motor vehicle in a manner which would make the item an attachment of the vehicle or necessary for its operation." This was the least common subtype of Thefts of/from a Motor Vehicle in Bend, accounting for $4.8 \%$ (312) of offenses. The average number 
of Thefts of Motor Vehicle Parts or Accessories per year in the city was 3.1 and the average annual rate was 0.4 per 1,000 residents.

\section{Annual Trend}

There was a total of 6,536 Thefts of/from a Motor Vehicle in Bend during the 10-year study period, or an average of 653.6 offenses per year. As shown in Figure 61, the number of Thefts of/from a Motor Vehicle have decreased overall between 2010 to 2019 despite a few spikes, with a slight reduction of $6.8 \%$. To account for changes in the underlying population, we calculated the annual rate of thefts per 1,000 residents using U.S. Census estimates. After calculating for this, the theft of/from a motor vehicle rate demonstrates a decrease of almost a third (-26.3\%) from 2010 (8.8 per $1,000)$ to 2019 (6.5 per 1,000). See Figure 61 for a more detailed annual breakdown of Thefts of/from a Motor Vehicle in Bend.

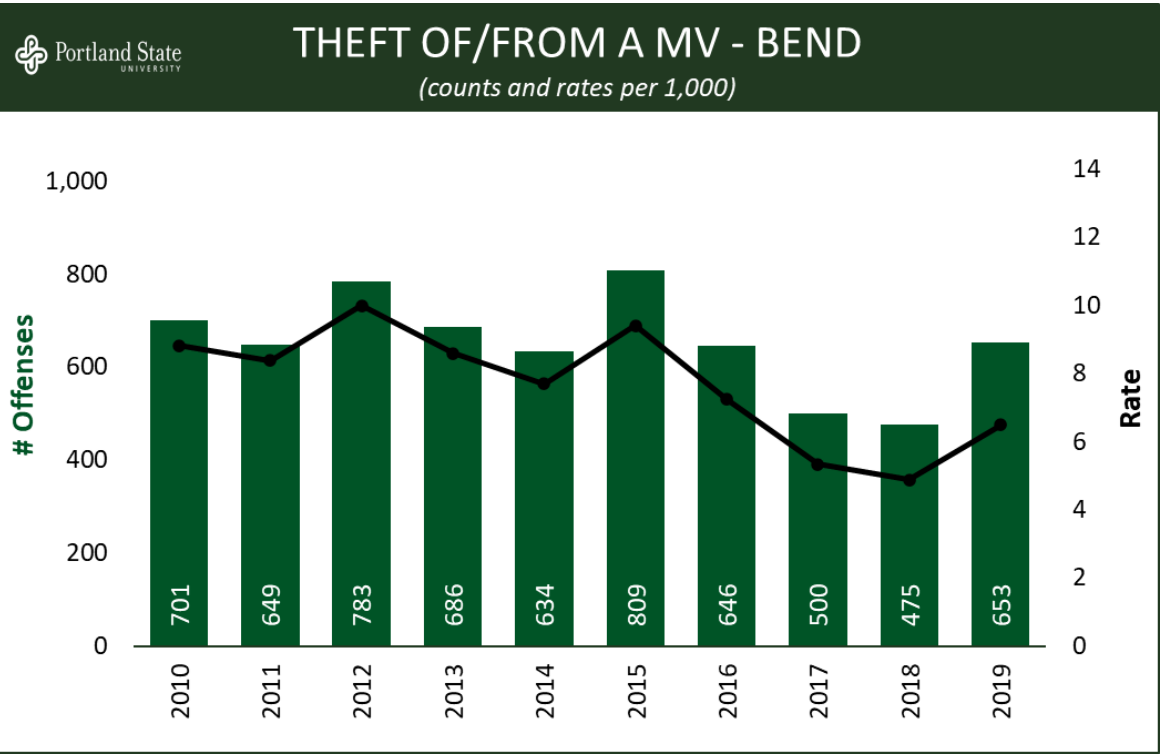

\section{Temporal Patterns}

Figure 61

We analyzed monthly/seasonal patterns in Thefts of/from a Motor Vehicle by calculating the average number of offenses per month across the 10-year study period. ${ }^{22}$ Bend averaged 53.7 thefts per month during this period of time. Higher monthly averages were found between the months of May and November. While above average, the only month that met our threshold for well above average (i.e., 2+ StDev) was August (72.6). This is potentially because there may be more targets available during summer vacation and because Bend is popular travel destination during this time. None of the months would be considered well below average (i.e., 2+ standard deviations below average).

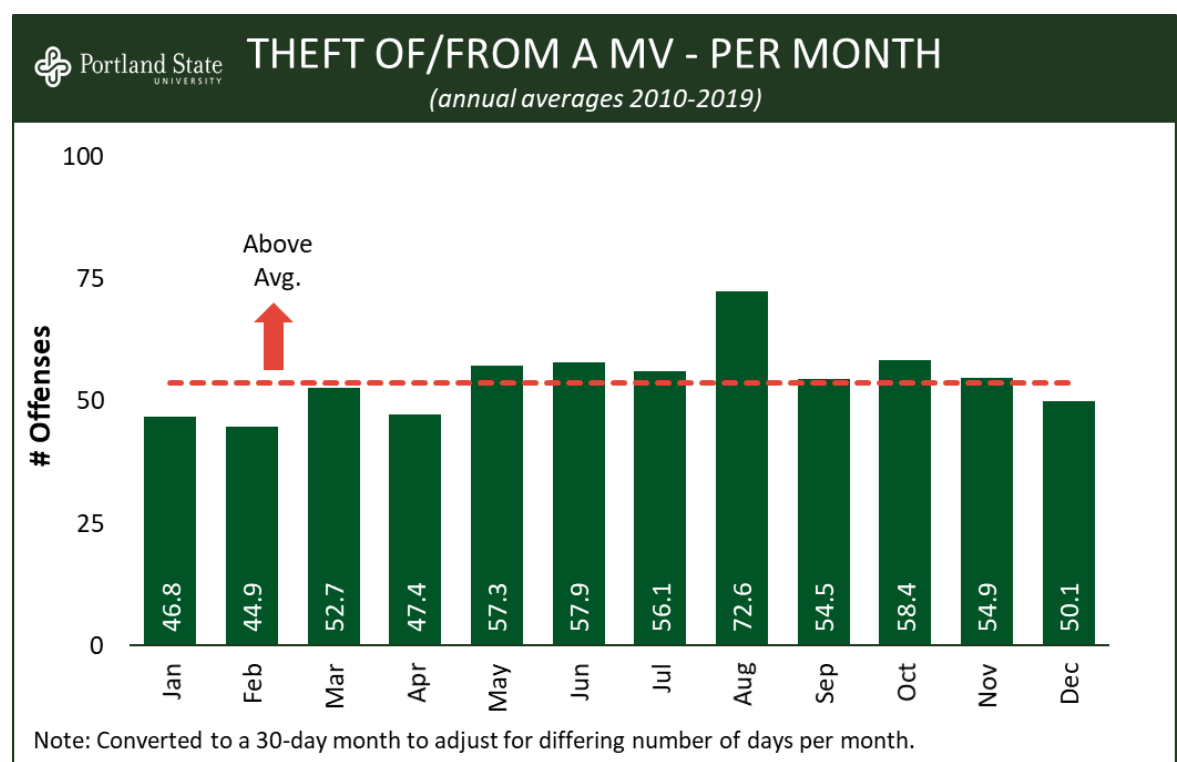

Figure 62

Regarding the distribution of Theft of/from a Motor Vehicle by day of week, we found very limited fluctuations in this offense by day. While four of the weekdays were very slightly above average, none of these days met our threshold for well above average (i.e., 2+ StDev). Similarly, none would be

\footnotetext{
22 Monthly counts were standardized to a 30-day month to control for the fact that some months have more days than others.
} 
considered well below average (i.e., $2+$ standard deviations below average). See Figure 63 for a more detailed depiction of Theft of/from a Motor Vehicle by day of week in Bend during the study period.

Figure 64 documents the distribution of Thefts of/from a Motor Vehicle in Bend by time of day across the 10year study period. Offenses were above average between 5:00pm and 1:00am, with the highest peaks occurring at $10: 00 \mathrm{pm}(10.0 \%)$ and 12:00am (8.5\%). Although many evening hours were above average, the only hour of day was found to be well above average (i.e., 2+ StDev) was $10: 00 \mathrm{pm}$. There were no hours of day that were found to be well below average (i.e., 2+ standard deviations below average). It should be noted that because the reported incident hour is based on the "low" time of the incidents (e.g. "it happened between 10:00pm and 8:00am"), the actual time that Thefts of/from a Motor Vehicle occurred is likely later than reported. Overall, our analyses demonstrate a tendency for Thefts of/from a Motor Vehicle to be committed in the nighttime through the early morning.

When analyzing Thefts of/from a Motor Vehicle by the hour per day of week, it becomes apparent that the number of offenses increases on most days of the week between 10:00pm and 12:00am. At 10:00pm on Tuesday (1.5\%), Wednesday (1.4\%), Thursday $(1.5 \%)$, Friday $(1.4 \%)$, and Sunday $(1.6 \%)$, the number of offenses were well above the average. Friday nights at $11: 00 \mathrm{pm}(1.5 \%)$ and Sunday nights at $12: 00$ am (1.5\%) were also well above the average percentage of Thefts of/from a Motor Vehicle. See Figure 65

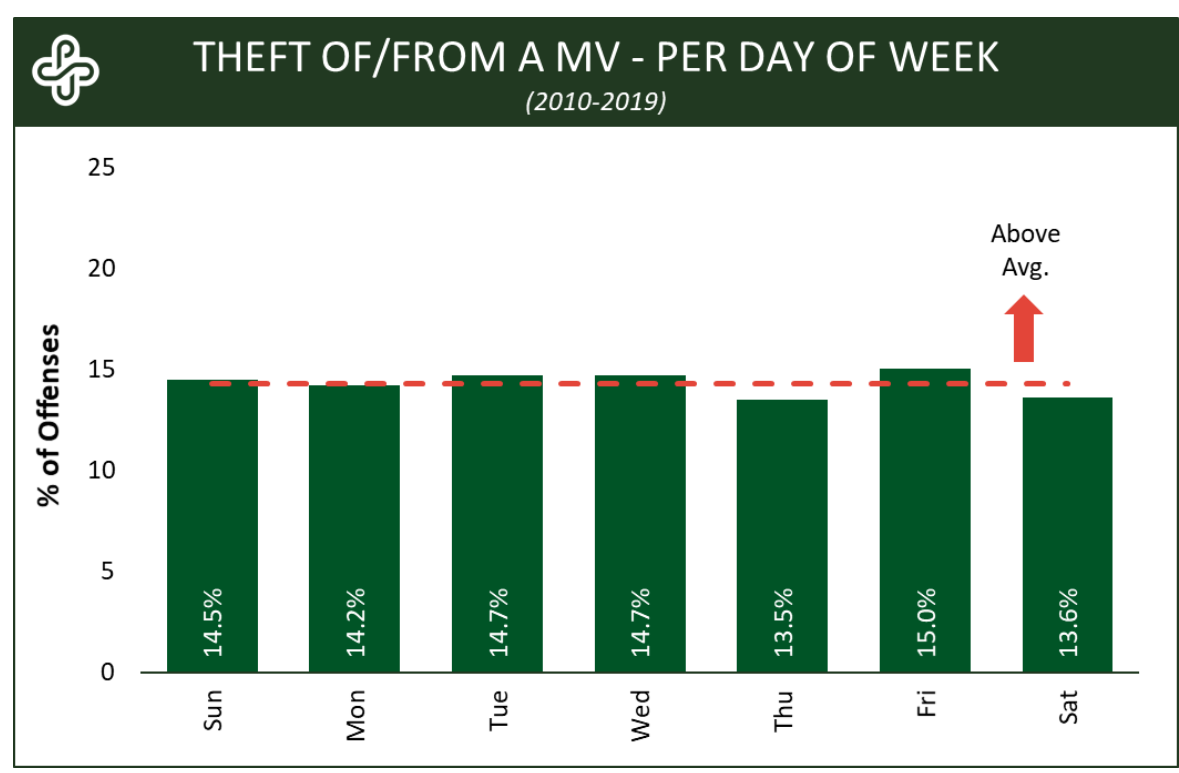

Figure 63

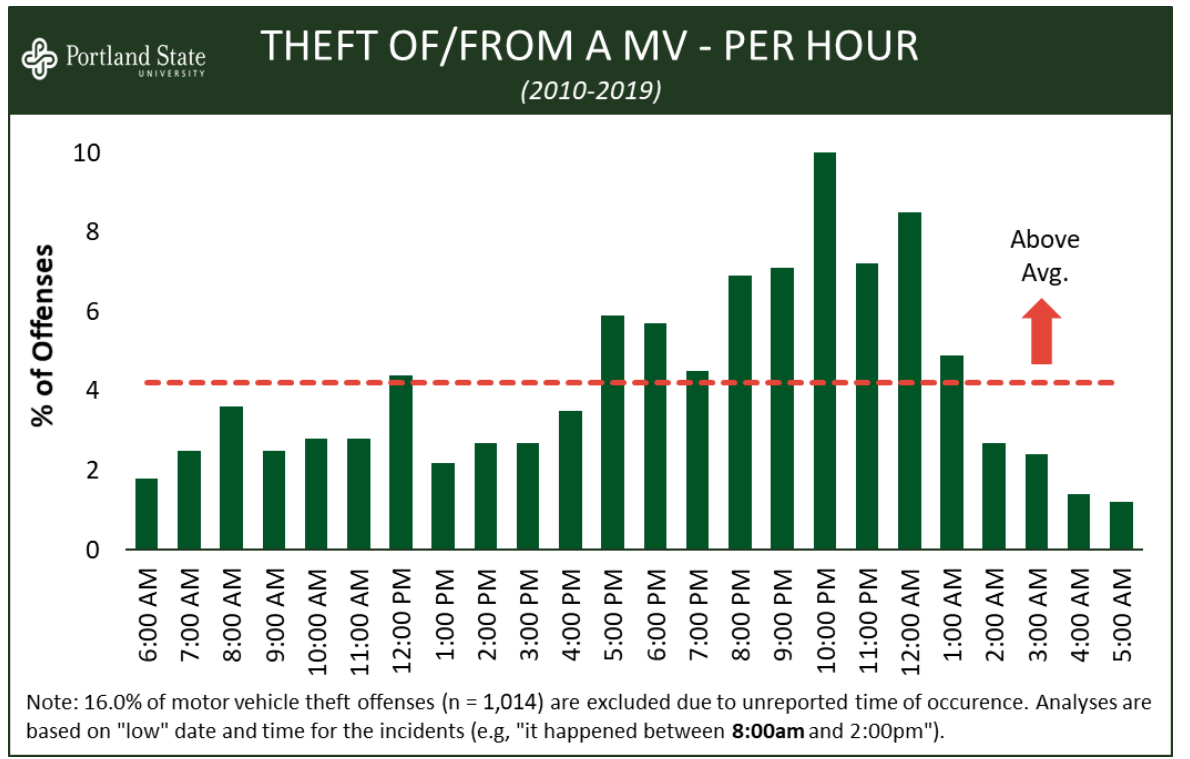

Figure 64

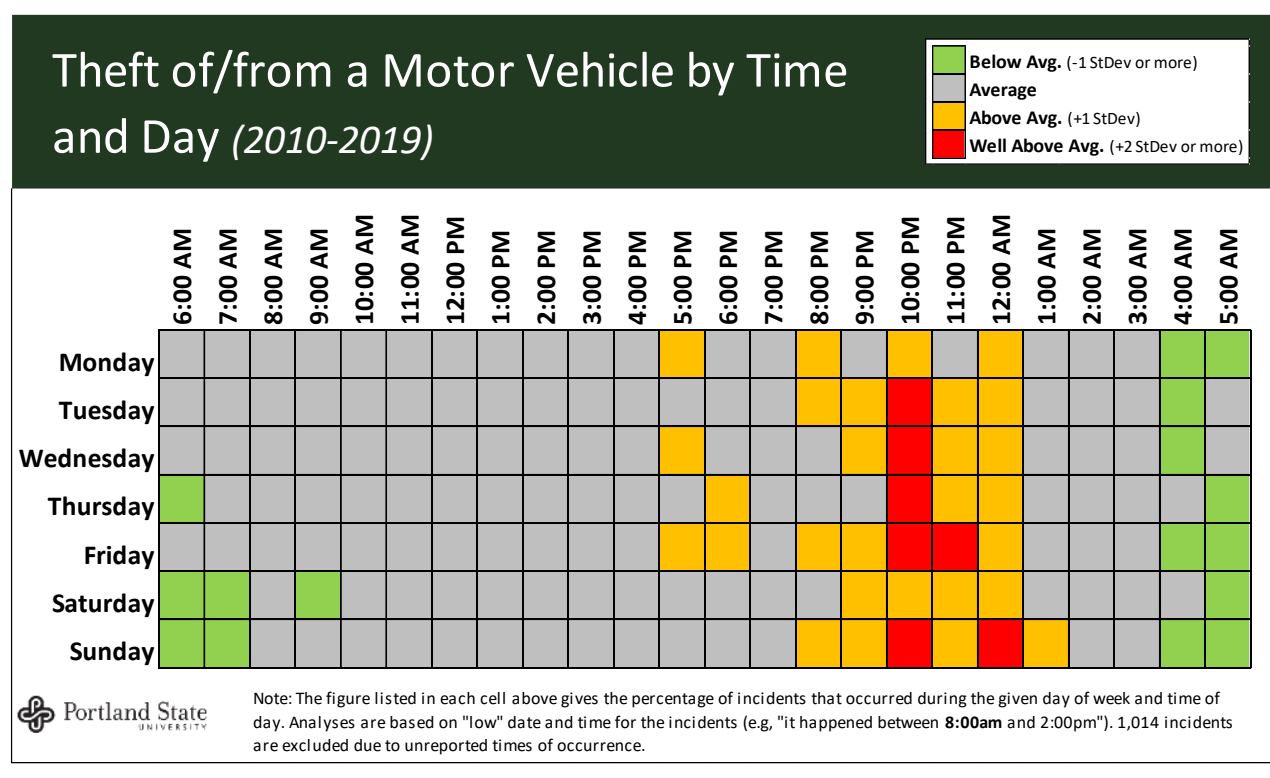

Figure 65 
for a more detailed breakdown of Thefts of/from a Motor Vehicle by the hour per day of week in Bend during the study period.

\section{Geographic Pattern}

The most common location type for Theft of/from a Motor Vehicle during the study period was a Roadway, with more than half $(56.6 \%, 3,702)$ of all offenses occurring at a location within this category. The second most common location type reported was a Parking Area, which comprised about a fifth $(18.6 \%, 1,214)$ of all offenses. Together, these two locations alone account for almost three quarters $(75.2 \%, 4,916)$ of all offenses in Bend, which indicates that Thefts of/from a Motor Vehicle often occur public areas. See Table 21 for the top ten most common location types.

\begin{tabular}{|lrc|}
\hline \multicolumn{2}{|c}{ THEFT OF/FROM A MV - LOCATION TYPE } \\
Location Type & \multicolumn{1}{c|}{} \\
\hline Roadway & 3,702 & $\%$ \\
Parking Area & 1,214 & $56.6 \%$ \\
Residence/Home & 743 & $18.6 \%$ \\
Other/Unknown & 245 & $11.4 \%$ \\
Hotel/Motel/Etc. & 95 & $3.7 \%$ \\
Commercial/Office Building & 93 & $1.5 \%$ \\
Auto Dealership New/Used & 51 & $1.4 \%$ \\
Service/Gas Station & 46 & $0.8 \%$ \\
Bar/Nightclub & 37 & $0.7 \%$ \\
Park/Playground & 33 & $0.6 \%$ \\
All Other Locations & 277 & $0.5 \%$ \\
\hline Total & 6,536 & $4.2 \%$ \\
\hline
\end{tabular}

Table 21

\section{Victim \& Arrestee Information}

\section{Victim Type}

In this section we will analyze the types of victims that were affected by Thefts of/from a Motor Vehicle during the 10year study period. We will only assess victims based on what NIBRS category they were reported as since Theft of/from a Motor Vehicle is not a person crime, similarly to Burglary and Larceny/Theft. It should also be noted that victims can be double coded for victim categories, which can result in the total number of victim types exceeding the actual number of offenses.

The most common victim type for Thefts of/from a Motor Vehicle during

\begin{tabular}{|c|c|c|}
\hline THEFT OF/ & - VICT & \\
\hline Victim Type & $f$ & $\%$ \\
\hline Individual & 6,223 & $91.5 \%$ \\
\hline Business & 479 & $7.0 \%$ \\
\hline Society/Public & 63 & $0.9 \%$ \\
\hline Government & 29 & $0.4 \%$ \\
\hline Other & 4 & $0.1 \%$ \\
\hline Financial Institution & 2 & $0.0 \%$ \\
\hline Law Enforcement Officer & 1 & $0.0 \%$ \\
\hline Total & 6,801 & $100.0 \%$ \\
\hline
\end{tabular}

Table 22 the study period was an Individual, with $91.5 \%(6,223)$ of all victims falling into this category. The second most common victim type reported was a Business, which comprised $7.0 \%$ (479) of all victims. These two victim types combined account for almost all $(98.5 \%, 6,702)$ of the victims during the study period. See Table 22 for a more detailed breakdown of victim types involved in Thefts of/from a Motor Vehicle in Bend.

\section{Arrestee Demographic Profile}

The average age for arrestees of Thefts of/from a Motor Vehicle was 25.3 years old, with the most common age group being 18 to 24 (36.8\%). The second most common age group for arrestees was 
25 to $34(23.4 \%)$, followed by 13 to $17(22.2 \%)$. In short, these findings indicate that the age of arrestees involved in this type of offense tend to demonstrate a younger curve compared to other offenses. See Figure 66 for a more detailed age breakdown for Theft of/from a Motor Vehicle arrestees in Bend during the study period.

The majority of Theft of/from a Motor Vehicle arrestees were reported as Male $(87.6 \%, 831)$.

Most arrestees with documented race $(n=914)$ were White $(96.7 \%)$, followed by Black or African

American (2.2\%). People who identified as American Indian or Alaska Native (4), Asian (3), and Native Hawaiian or Other Pacific Islander (3) comprised $1.1 \%$ of the arrestees. Regarding those with reported ethnicity $(n=335), 16.1 \%$ of arrestees were Hispanic or Latino, which is a slightly higher percentage compared to previous sections in this report.

Of the Theft of/from a Motor Vehicle arrestees whose Residency status was known, $91.1 \%$ were residents of Bend.

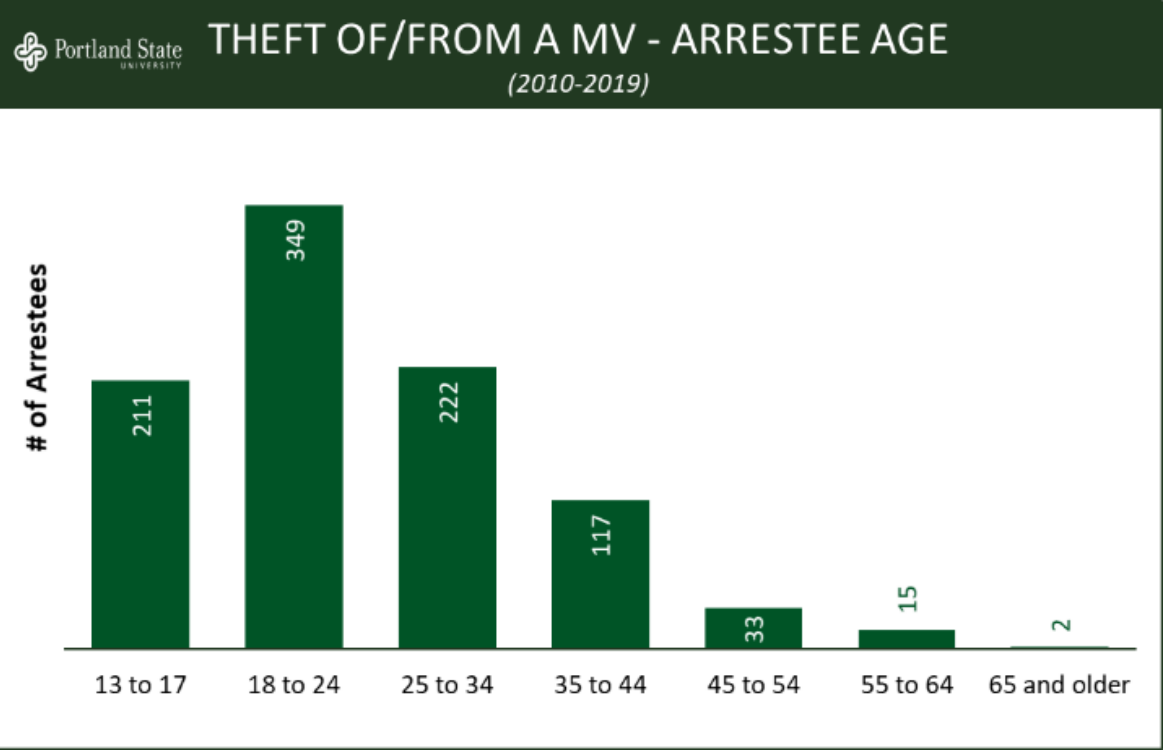

Figure 66

\begin{tabular}{|c|c|c|}
\hline \multirow{2}{*}{$\begin{array}{c}\text { Demographic* } \\
\text { Sex }\end{array}$} & \multicolumn{2}{|c|}{ Arrestees } \\
\hline & $f$ & $\%$ \\
\hline Male & 831 & $87.6 \%$ \\
\hline Female & 118 & $12.4 \%$ \\
\hline \multicolumn{3}{|l|}{ Race } \\
\hline White & 884 & $96.7 \%$ \\
\hline Black or African American & 20 & $2.2 \%$ \\
\hline All Others Combined & 10 & $1.1 \%$ \\
\hline \multicolumn{3}{|l|}{ Ethnicity } \\
\hline Not Hispanic or Latino & 281 & $83.9 \%$ \\
\hline Hispanic or Latino & 54 & $16.1 \%$ \\
\hline \multicolumn{3}{|l|}{ Residency } \\
\hline Resident & 658 & $91.1 \%$ \\
\hline Nonresident & 64 & $8.9 \%$ \\
\hline
\end{tabular}

Table 23 


\section{Property Loss}

\section{Property Descriptions}

Overall, the most common property that was stolen in a Theft of/from a Motor Vehicle during the 10-year study period was a Purse/Wallet $(9.8 \%)$. This was followed by Money (8.2\%), Radio/TV/VCR (7.0\%), Vehicle Parts (5.8\%), and Automobile (5.5\%). This demonstrates that items in the vehicle were more likely to be stolen than the vehicle itself. See Table 24 for the top ten most common descriptions of property stolen in Thefts of/from a Motor Vehicle over the study period.

\section{Costs of Stolen Property}

In this section we estimate the direct

costs associated with Theft of/from a Motor Vehicle in Bend during the 10-year study period. Although Theft of/from a Motor Vehicle sometimes involves breaking and entering, which can lead to "Damaged" property losses, only a small proportion of damaged losses comprise the total cost associated with this offense. Therefore, we will only analyze the values of losses that were reported to NIBRS as "Stolen." In order to estimate the total financial losses attributable to Thefts of/from a Motor Vehicle we replaced any missing values with the statewide mean value for a given item and year.

Between 2010 and 2019, Bend experienced $\$ 11,771,612$ in stolen property losses resulting from Theft of/from a Motor Vehicle. This means that there was an average loss of $\$ 1,177,161$ per year as a result of stolen property. The average loss per Theft from a Motor Vehicle or Theft of Motor Vehicle

Parts/Accessories was $\$ 466$. In contrast, the average loss per Theft of a Motor Vehicle was $\$ 6,354$. As demonstrated in Figure 67, the yearly losses resulting from Theft of/from a Motor Vehicle has steadily increased over time. Over the past ten years, the yearly cost of Theft of/from a Motor Vehicle has increased overall by $62.8 \%$. We attempted to determine why the cost of Thefts of/from a Motor Vehicle have steadily increased over time by analyzing whether the number of items stolen from vehicles have increased, however this was not indicated in our analysis. Although our analysis does not account for inflation, further efforts should be made to determine why the costs are increasing so steadily. See Figure 67 for a yearly breakdown of Bend's property losses resulting from Theft of/from a Motor Vehicle.

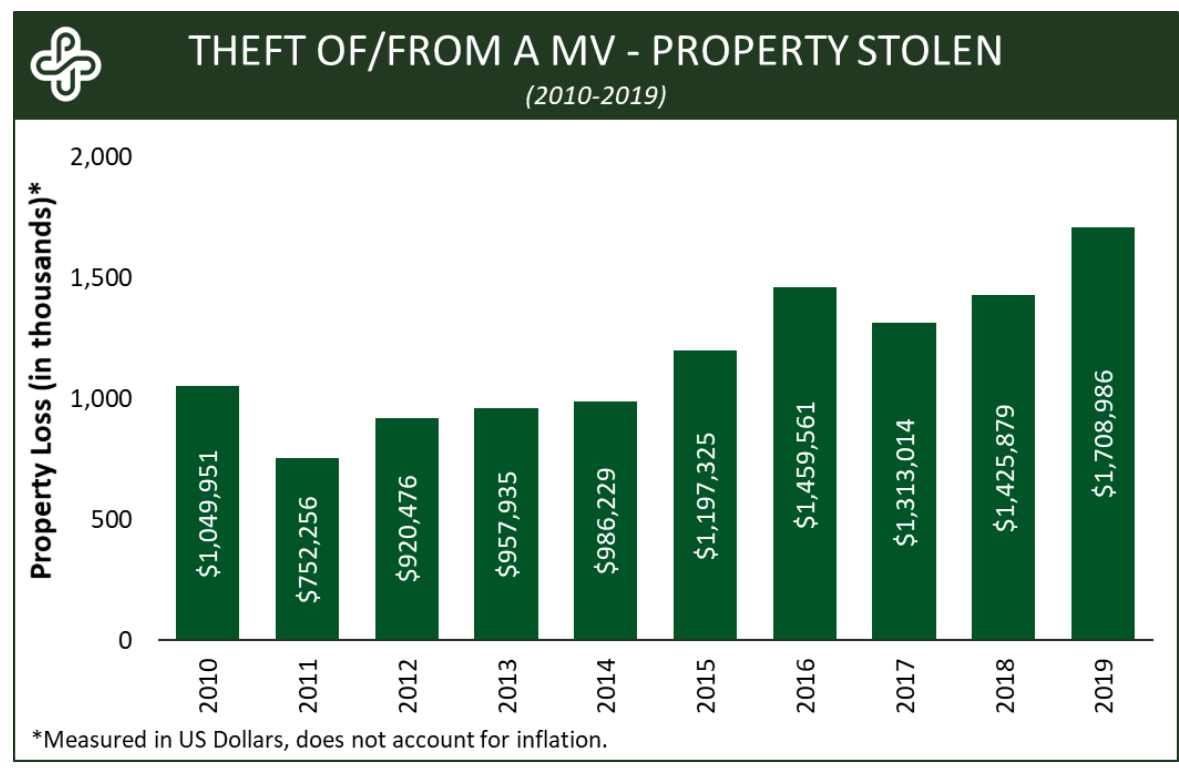

Figure 67 


\section{Clearance Rate}

Of the 6,536 Thefts of/from a Motor Vehicle between 2010 and 2019, $10.1 \%$ (659) were Cleared by Arrest/Citation or Exceptionally. The overall clearance rate for Theft of/from a Motor Vehicle in Bend has fluctuated somewhat over the past ten years. However, as of 2019 $(14.2 \%)$ the clearance rate has increased by $60.0 \%$ since 2015 (8.9\%). See Figure 68 for an annual breakdown of clearance rates over the study period in Bend.

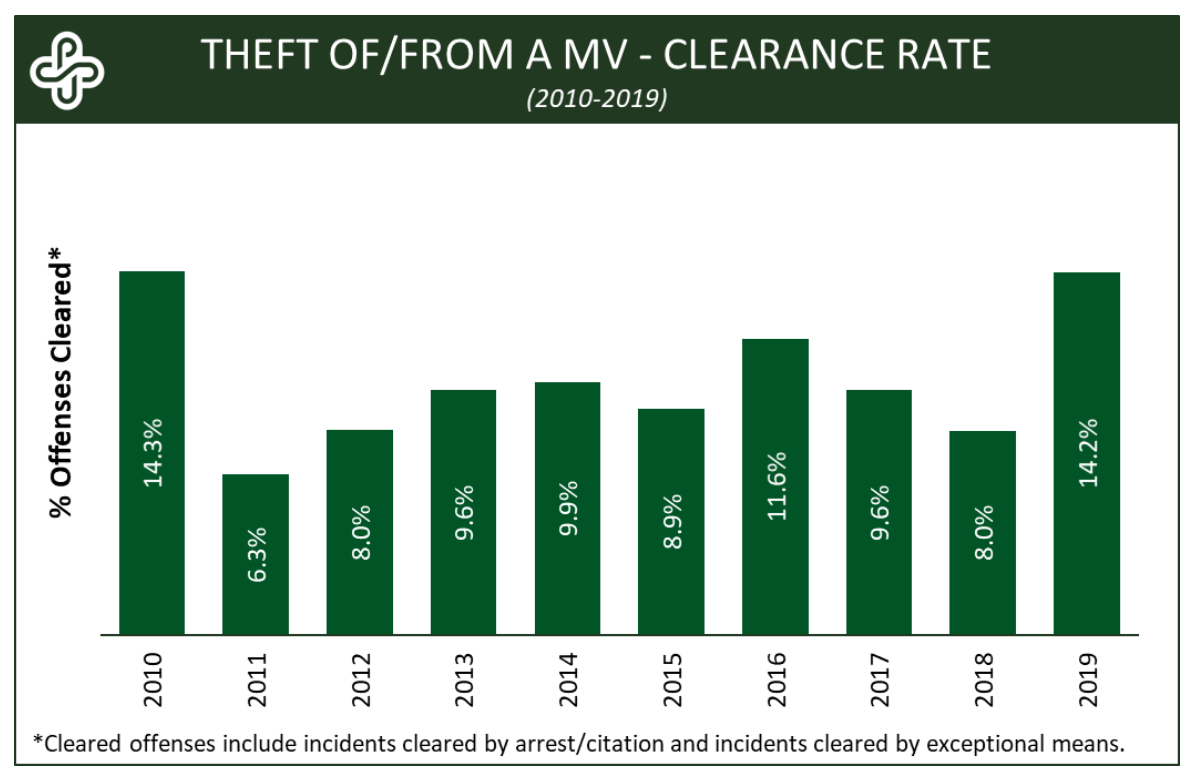

Figure 68 


\section{ROBBERY}

\section{Introduction \& Offense Definition}

In this section we will be analyzing robbery in Bend between 2010 and 2019. Robbery is defined by the FBI as, "The taking or attempting to take anything of value under confrontational circumstances from the control, custody, or care of another person by force or threat of force or violence and/or by putting the victim in fear of immediate harm." This definition is most consistent with Oregon's Robbery in the $1 s t, 2^{\text {nd }}$, or $3^{\text {rd }}$ degree depending on the level of threat to the victim (i.e. weapon involvement versus verbal threat, etc.).

\section{Annual Trend}

There was a total of 234 Robbery offenses in Bend during the 10-year study period, or an average of 23.4 offenses per year. To account for changes in the underlying population, we calculated the annual rate of Robbery per 1,000 residents using U.S. Census estimates. The robbery rate decreased $-46.4 \%$ from $2010(0.4$ per 1,000$)$ to $2019(0.2$ per 1,000$)$. As demonstrated in Figure 69, counts and rate for robberies have decreased overall in Bend over the past ten years.

\section{Temporal Patterns}

We analyzed monthly/seasonal patterns in Robbery offenses by calculating the average number of offenses per month across the 10year study period. ${ }^{23}$ Bend averaged 2.3 robberies per month during this period of time. Higher monthly averages were found for January, August, September, November, and December. While above average, the only month that met our threshold for well above average (i.e., 2+ StDev) was January (3.5). None of the months were found to be well below average (i.e., 2+ standard deviations below average).

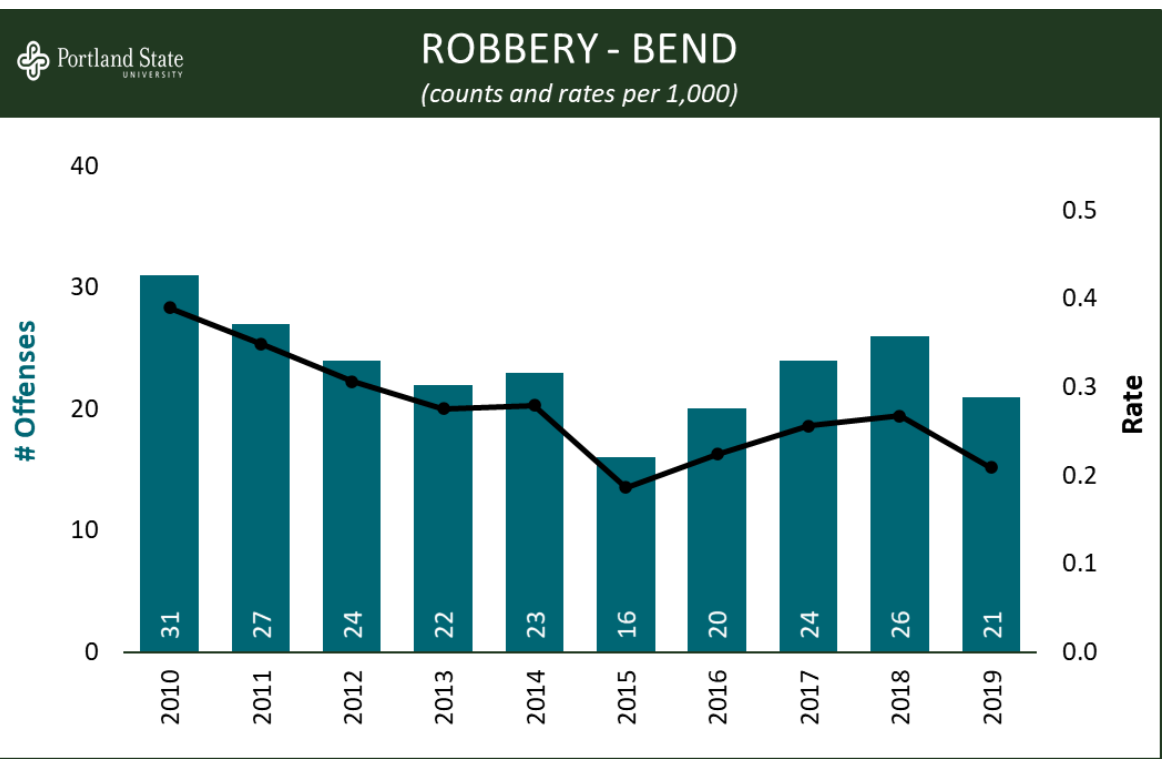

Figure 69

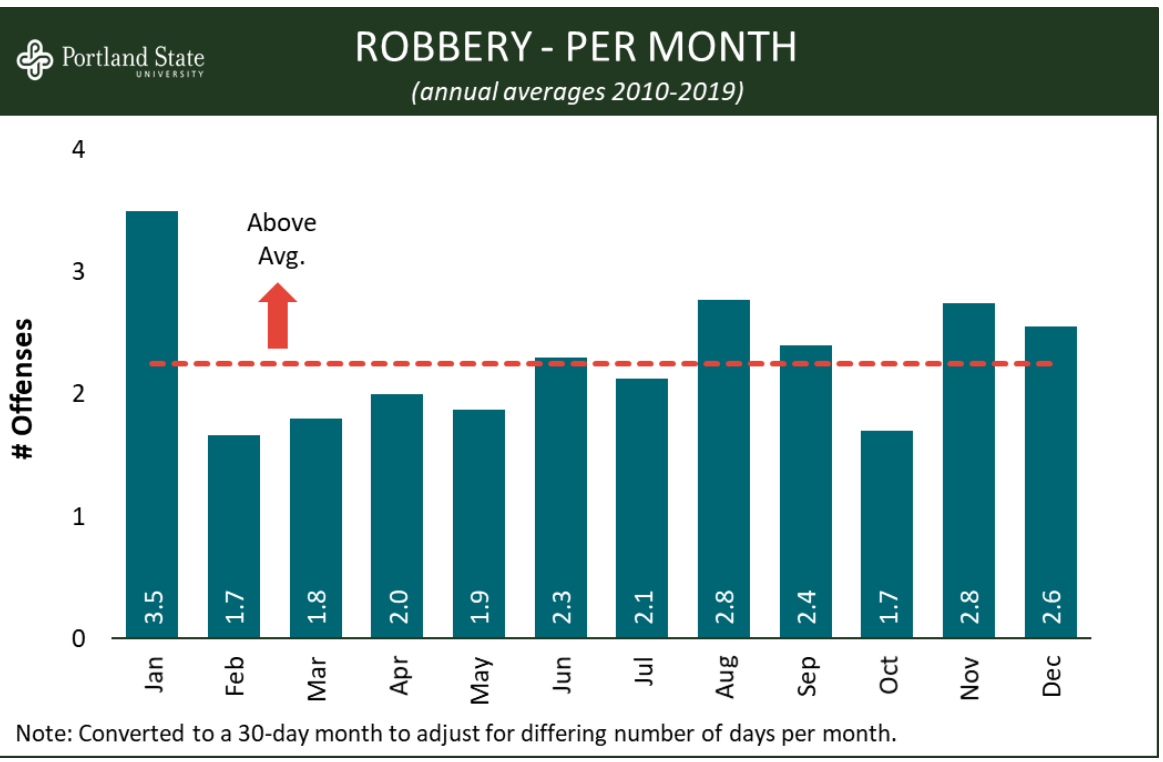

Figure 70

\footnotetext{
${ }^{23}$ Monthly counts were standardized to a 30-day month to control for the fact that some months have more days than others.
} 
Regarding the distribution of Robbery offenses by day of week, we found that Tuesday and Thursday above average. However, there was no day that exceeded our definition for well above average (i.e., 2+ StDev). Similarly, there was no day that was found to be well below average (i.e., 2+ standard deviations below average). In short, temporal fluctuations by day seem to be limited for robberies.

Figure 72 documents the distribution of Robbery offenses in Bend by time of day across the 10-year study period. It should be noted that due to missing reported times, the sample size for our hourly analysis is very small, which decreases our confidence in any patterns present in the data. Offenses were above average at 9:00am, 11:00am, 1:00pm, and between 4:00pm and 9:00pm. The highest peak occurred at $4: 00 \mathrm{pm}(10.9 \%)$, which was the only hour of day that was found to be well above average (i.e., 2+ StDev). There were no hours of day that were found to be well below average (i.e., 2+ standard deviations below average). Overall, our analysis demonstrates that robberies tend to occur during the active hours of the day.

\section{Geographic Pattern}

The most common location type for Robbery offenses during the study period was a Roadway, with about a fifth $(20.1 \%, 47)$ of all offenses occurring at a location within this category. The second most common location type reported was a Grocery/Supermarket, which comprised about a tenth $(12.8 \%, 30)$ of all offenses. The third most common location type for robberies was a Department/Discount Store $(11.5 \%, 27)$. Together, these three locations account for almost half $(44.4 \%$, $104)$ of all Robbery offenses in Bend.

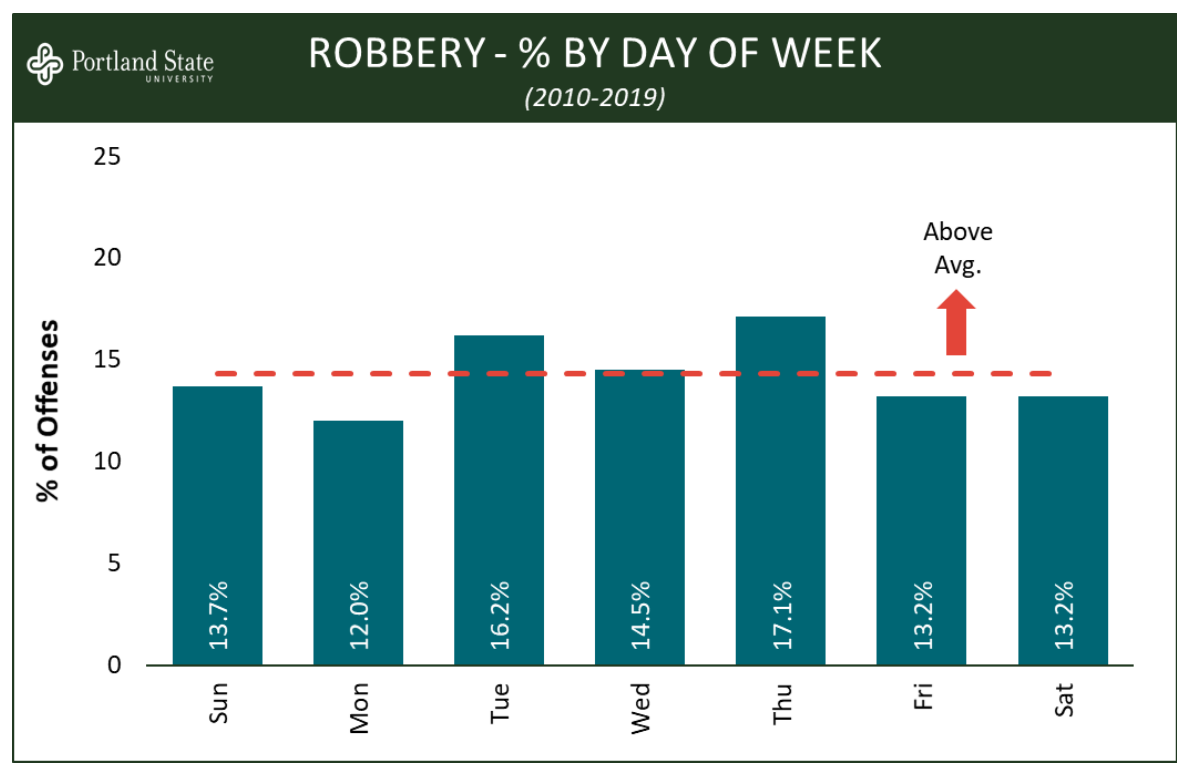

Figure 71

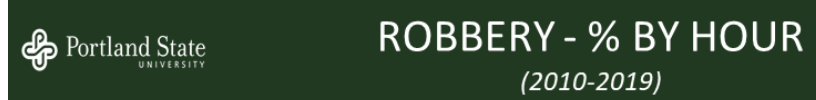

10

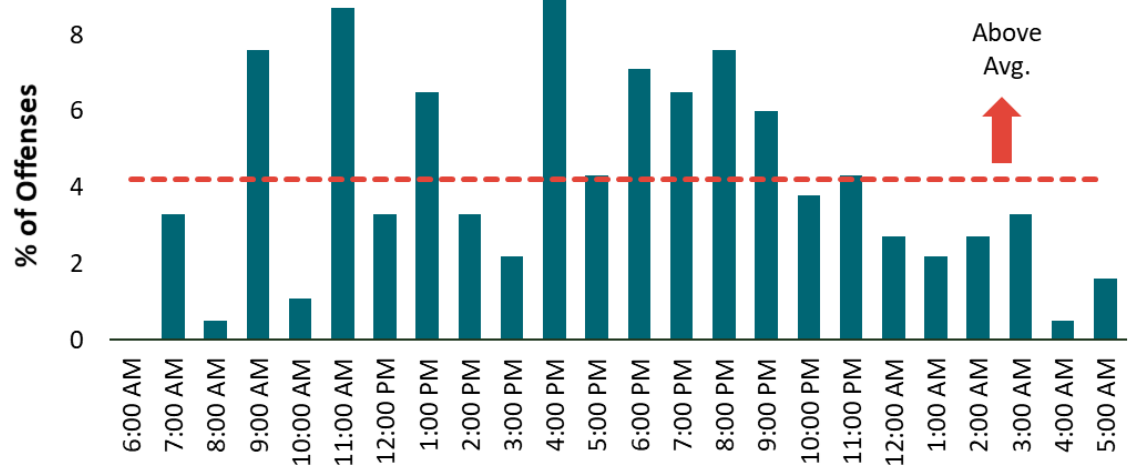

Note: $21.4 \%$ of robbery offenses $(n=50)$ are excluded due to unreported time of occurence. Analyses are based on "low" date and time for the incidents (e.g, "it happened between 8:00am and 2:00pm").

Figure 72

\begin{tabular}{|lcc|} 
色 Portland State & $\begin{array}{c}\text { ROBBERY - LOCATION TYPE } \\
(2010-2019)\end{array}$ & \\
\hline Location Type & $f$ & $\%$ \\
\hline Roadway & 47 & $20.1 \%$ \\
Grocery/Supermarket & 30 & $12.8 \%$ \\
Department/Discount Store & 27 & $11.5 \%$ \\
Residence/Home & 23 & $9.8 \%$ \\
Parking Area & 18 & $7.7 \%$ \\
Convenience Store & 17 & $7.3 \%$ \\
Bank/Savings and Loan & 14 & $6.0 \%$ \\
Other/Unknown & 9 & $3.8 \%$ \\
Shopping Mall & 8 & $3.4 \%$ \\
Service/Gas Station & 7 & $3.0 \%$ \\
All Other Locations & 34 & $14.5 \%$ \\
\hline Total & $\mathbf{2 3 4}$ & $\mathbf{1 0 0 . 0 \%}$ \\
\hline
\end{tabular}

Table 25 


\section{Victim \& Arrestee Demographic Profiles}

\section{Age}

The average age for victims of Robbery offenses during the 10-year study period was 33.1 years old. The most common age group for victims of this type of crime was people between the age of 18 and 24 , which made up about a third (67) of all victims. The second most common age group for victims was people between the age of 25 and 34 (59), followed by people between the age of 45 and 54 (39).

The average age for arrestees of Robbery offenses was 29.0 years old. The most common age group for arrestees was people between the age of 25 and 34 (69), followed by 18 to 24

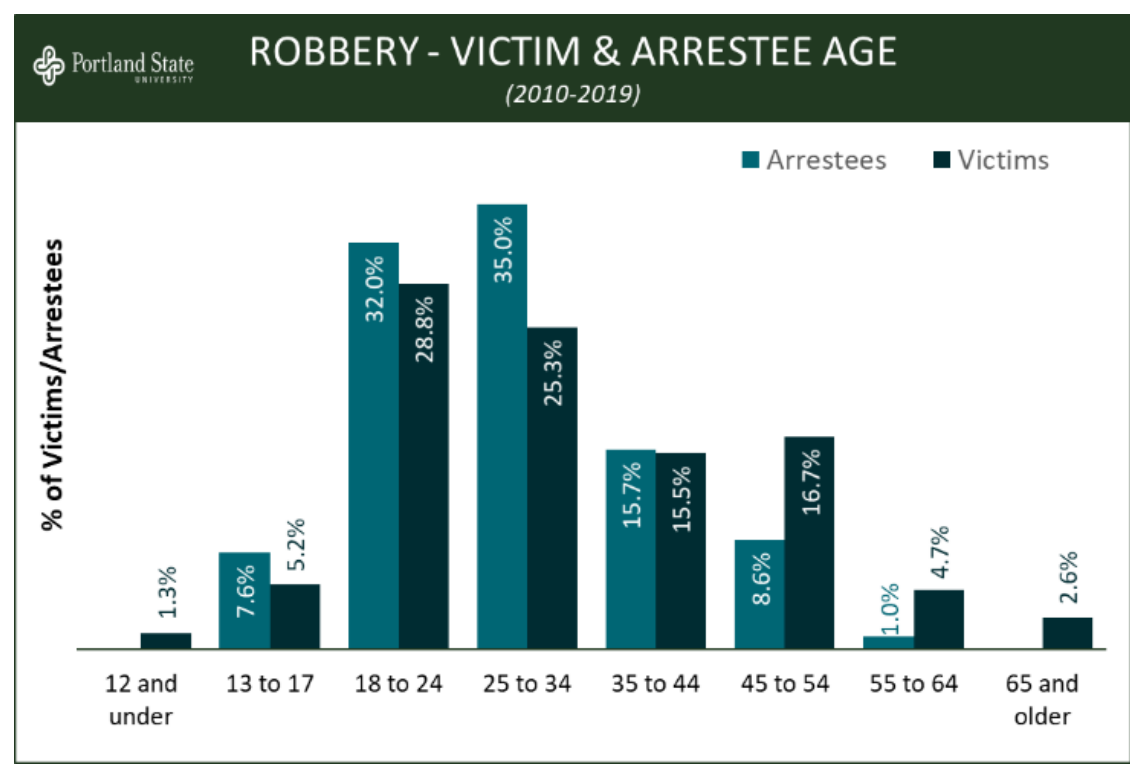

Figure 73

(67). These two age groups represent $67.0 \%$ (126) of all robbery arrestees in Bend during the study period. See Figure 73 for a more detailed age breakdown for both victims and arrestees.

Sex

Of the victims of a Robbery offense whose sex was known, over half were female $(66.5 \%)$. In contrast, the majority of arrestees for this type of offense were Male (81.7\%).

\section{Race \& Ethnicity}

Among victims where race was documented, the vast majority $(96.5 \%)$ were White, followed by Black or African American (1.3\%). Asian (3), American Indian or Alaska Native (1), and Native Hawaiian or Other Pacific Islander people accounted for $2.2 \%$ of victims. With regard to ethnicity, $7.5 \%$ of victims were identified as Hispanic or Latino.

\section{ROBBERY - VICTIM \& ARRESTEE DEMOGRAPHICS} (2010-2019)

\begin{tabular}{|c|c|c|c|c|}
\hline \multirow{2}{*}{$\frac{\text { Demographic* }}{\text { Sex }}$} & \multicolumn{2}{|c|}{ Victims } & \multicolumn{2}{|c|}{ Arrestees } \\
\hline & $f$ & $\%$ & $f$ & $\%$ \\
\hline Male & 155 & $66.5 \%$ & 161 & $81.7 \%$ \\
\hline Female & 78 & $33.5 \%$ & 36 & $18.3 \%$ \\
\hline \multicolumn{5}{|l|}{ Race } \\
\hline White & 220 & $96.5 \%$ & 189 & $97.4 \%$ \\
\hline Black or African American & 3 & $1.3 \%$ & 5 & $2.6 \%$ \\
\hline All Others Combined & 5 & $2.2 \%$ & 0 & $0.0 \%$ \\
\hline \multicolumn{5}{|l|}{ Ethnicity } \\
\hline Not Hispanic or Latino & 74 & $92.5 \%$ & 92 & $93.9 \%$ \\
\hline Hispanic or Latino & 6 & $7.5 \%$ & 6 & $6.1 \%$ \\
\hline \multicolumn{5}{|l|}{ Residency } \\
\hline Resident & 143 & $89.9 \%$ & 103 & $84.4 \%$ \\
\hline Nonresident & 16 & $10.1 \%$ & 19 & $15.6 \%$ \\
\hline
\end{tabular}

Table 26

Comparable to victims, $97.4 \%$ of arrestees were White, followed by Black or African American (2.6\%). See Table 26 for a more detailed breakdown of race and ethnicity for both victims and arrestees. 


\section{Residency}

Of the Robbery victims whose Residency status was known, $89.9 \%$ were residents of Bend. Likewise, out of the arrestees with known Residency status, $84.4 \%$ of robbery arrestees were residents of Bend.

See Table 26 for more information.

\section{Offense Characteristics}

\section{Victim Type}

The most common victim type for Robbery offenses during the study period was an Individual, with almost two thirds $(62.8 \%)$ of all victims falling into this category. The second most common victim type reported was a Business, which comprised about a fifth $(21.4 \%)$ of all victims. These two victim types combined account for more than three quarters (84.2\%) of the Robbery victims in Bend. See Table 27 for a more detailed breakdown of victim types involved in Robbery offenses.

\section{Victim-Offender Relationship}

In most Robbery offenses over the 10-year study period, the offender was a Stranger (72.6\%) while roughly a third $(27.4 \%, 43)$ of victims knew their offender to some degree. The most common victim-offender relationship was an Acquaintance or Otherwise Known (21.0\%), followed by Current or Former Intimate Partner (4.5\%), and Family Member (1.9\%).

\section{Victim Injuries}

Of the Robbery offenses that occurred in Bend over the study period, $67.9 \%$ (159) of victims had no

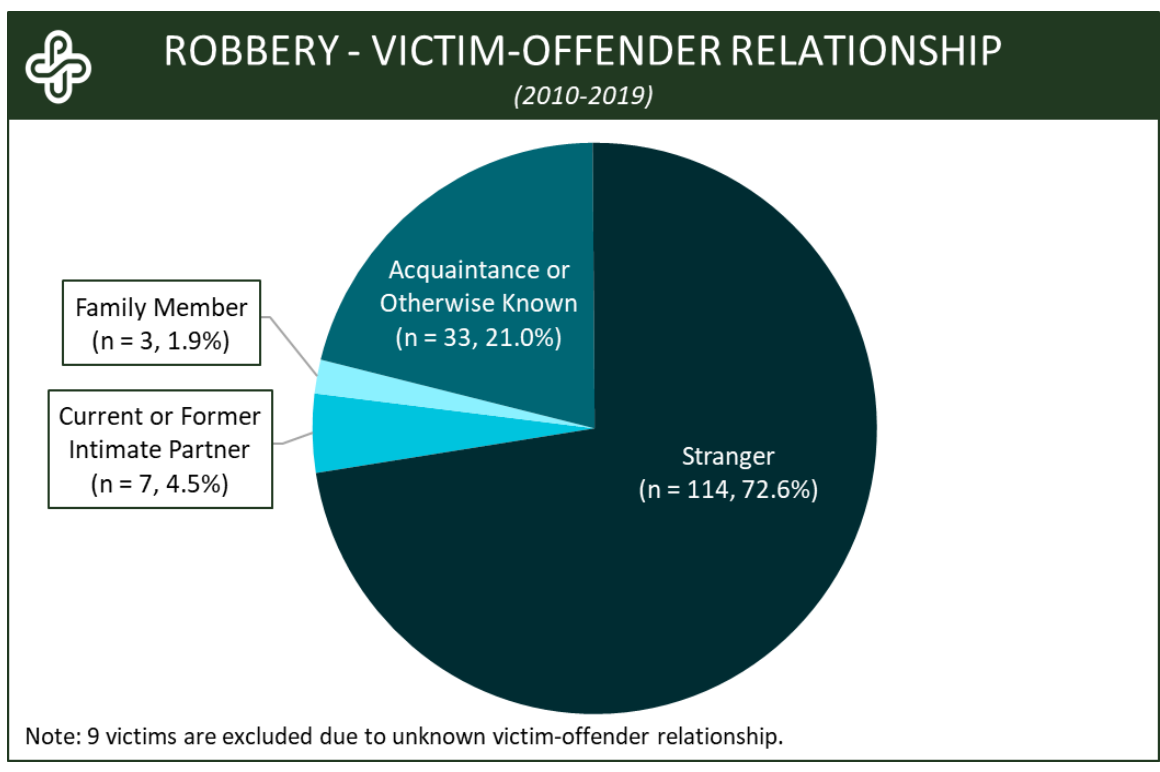

Figure 74

\begin{tabular}{|c|c|c|}
\hline 串 Portland State & & \\
\hline Victim Type & $f$ & $\%$ \\
\hline Individual & 211 & $62.8 \%$ \\
\hline Business & 72 & $21.4 \%$ \\
\hline Society/Public & 44 & $13.1 \%$ \\
\hline Financial Institution & 8 & $2.4 \%$ \\
\hline Law Enforcement Officer & 1 & $0.3 \%$ \\
\hline Total & 336 & $100.0 \%$ \\
\hline
\end{tabular}

Table 27

injuries. Out of the remaining victims, 27.4\% (64) experienced a Minor Injury and 4.7\% (11) suffered from a Major Injury.

\section{Number of Victims}

Most Robbery offenses during the 10 -year study period involved a single victim $(80.8 \%, 173)$. During this time, $15.0 \%$ (32) of offenses involved two victims, $3.7 \%$ (8) involved three to five victims, and $0.5 \%$ (1) involved six or more victims. The largest number of victims involved in a robbery was 7 , which only occurred once. 


\section{Number of Known Offenders}

Of the Robbery offenses in Bend in which at least one offender was known, 71.4\% (120) of robberies involved a single offender. During this time, $18.4 \%$ (31) of offenses involved two known offenders and $10.1 \%$ (17) involved three to six known offenders.

\section{Weapon Involvement}

Among the Robbery offenses with a known weapon $(n=222)$ the most common weapon was a hand, foot, or other body part $(42.0 \%, 93)$. This was followed by Knife/Cutting Instrument $(17.6 \%, 39)$, Firearm $(15.3 \%, 34)$, and No Weapon $(15.3 \%, 34)$. The remaining offenses involved either Blunt Object $(5.4 \%, 12)$ or a weapon that was reported as Other $(4.5 \%, 10)$.

\section{Property Stolen Losses}

\section{Property Descriptions}

The most common property that was stolen during a Robbery over the 10year study period was Money (25.2\%). This was followed by Consumable Goods (9.8\%), Purse/Wallet (7.6\%), Alcohol (6.9\%), and Clothes/Furs (6.9\%). See Table 28 for the top ten most common descriptions of property stolen as a result of a robbery in Bend.

\section{Costs of Stolen Property}

In this section we estimate the direct costs associated with stolen property as a result of Robbery in Bend during the 10-year study period. In order to estimate the total financial losses attributable to Robbery, we replaced any missing values with the statewide mean value for a given item and year. Additionally, it should be noted that one incident in 2018 resulting in a property loss worth $\$ 87,587$ was removed from the data so that patterns in property loss over time can be depicted more clearly.

Between 2010 and 2019, Bend experienced $\$ 173,159$ in stolen property losses resulting from Robbery offenses. This means that there was an average loss of $\$ 17,315$ per year as a result of

\begin{tabular}{|c|c|c|}
\hline ROBBERY - PROF & SCRI & \\
\hline Property Description & $f$ & $\%$ \\
\hline Money & 80 & $25.2 \%$ \\
\hline Consumable Goods & 31 & $9.8 \%$ \\
\hline Purse/ Wallet & 24 & $7.6 \%$ \\
\hline Alcohol & 22 & $6.9 \%$ \\
\hline Clothes/ Furs & 22 & $6.9 \%$ \\
\hline Portable Electronic Communications & 18 & $5.7 \%$ \\
\hline Radio/TV/ VCR & 8 & $2.5 \%$ \\
\hline Bicycles & 7 & $2.2 \%$ \\
\hline Credit/ Debit cards & 7 & $2.2 \%$ \\
\hline Automobile & 6 & $1.9 \%$ \\
\hline All Other Property & 92 & $29.0 \%$ \\
\hline Total & 317 & $100.0 \%$ \\
\hline
\end{tabular}

Table 28
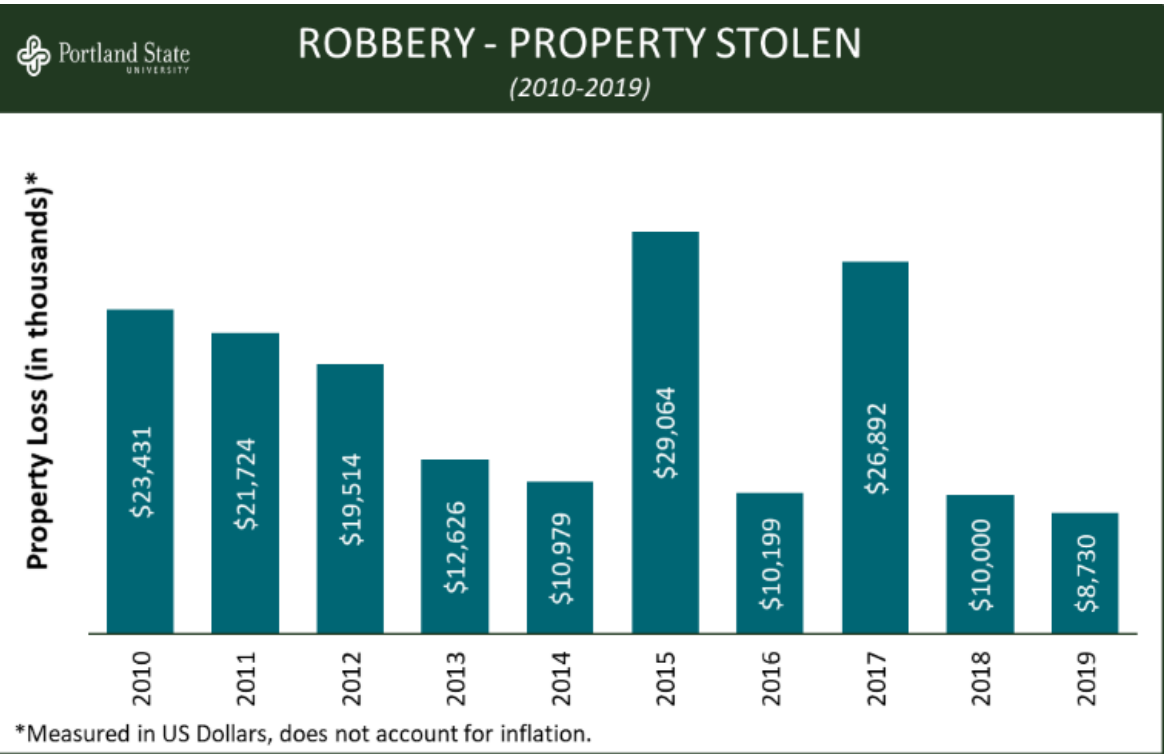

Figure 75 stolen property. The average loss per robbery during this time was $\$ 548$. Although the annual costs of stolen property spiked during 2015 and 2017, the yearly loss has decreased overall by $62.7 \%$ between 2010 and 2019. This is consistent with the overall decrease in the robbery rate over the past 
ten years. See Figure 75 for a yearly breakdown of Bend's property losses resulting from Robbery offenses.

\section{Clearance Rate}

Of the 234 Robbery offenses between 2010 and 2019, 64.1\% (150) were Cleared by Arrest/Citation. The average annual clearance rate during this time was $65.1 \%$, or 15 offenses per year. According to the FBI's UCR data, the national clearance rate for Robbery was $30.4 \%$ as of 2018 . This means that Bend's annual clearance rate for Robbery offenses was more than double the national average. See Figure 76 for an annual breakdown of Robbery clearance rates over the study period in Bend.

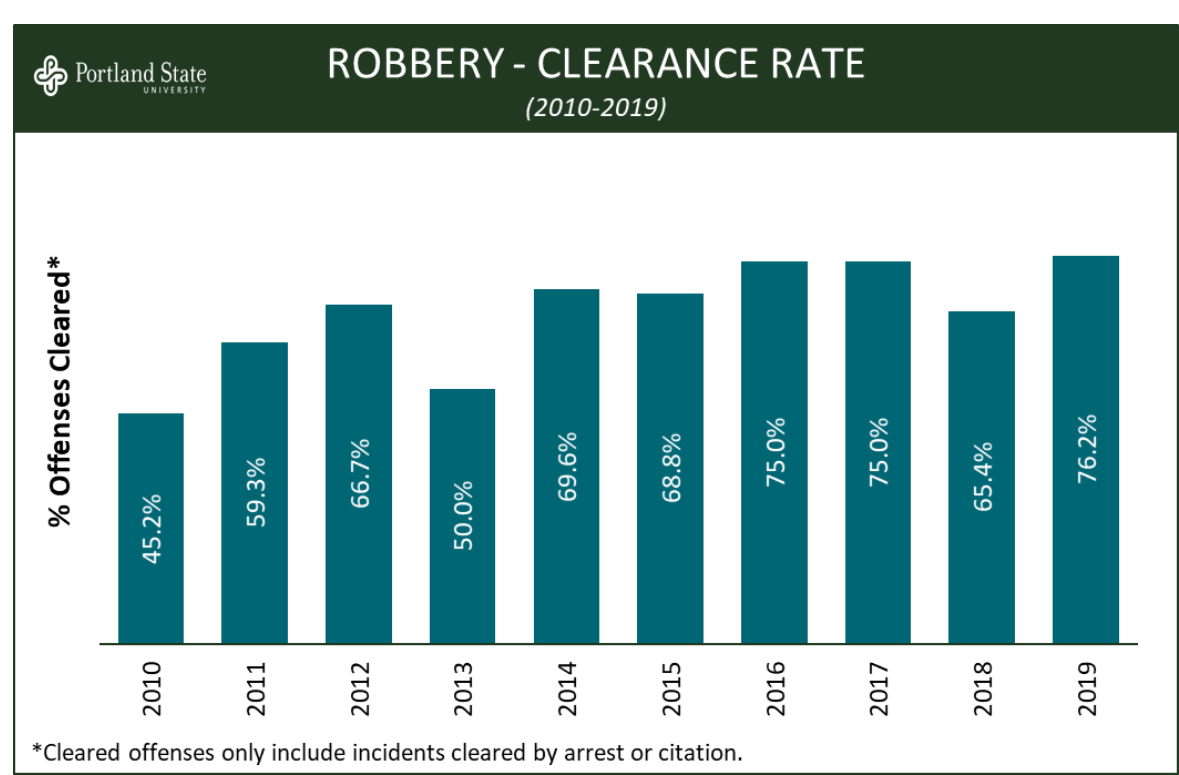

Figure 76 


\section{SEXUAL OFFENSES}

\section{Introduction \& Offense Subtypes}

In this section we will be examining Sexual Offenses in Bend, Oregon between 2010 and 2019. This offense subgroup consists of Fondling, Incest, Rape, Sexual Assault with an Object, Sodomy, and Statutory Rape. The FBI defines Sexual Offenses as, "Any sexual act directed against another person, without the consent of the victim, including instances where the victim is incapable of giving consent." While each of the subtypes in this offense category have different corresponding Oregon Revised Statutes, some examples of ORS codes within this category include Rape (three varying degrees), Sodomy (three varying degrees), Sexual abuse (three varying degrees), and Contributing to the sexual delinquency of a minor. Provided below are the FBl's definitions for each offense subtype in this section of the report. We also provide the aggregate counts and rates for each offense in Bend between 2010 and 2019. The remainder of this section will analyze Sexual Offenses based on whether they involved a juvenile or adult victim, when appropriate.

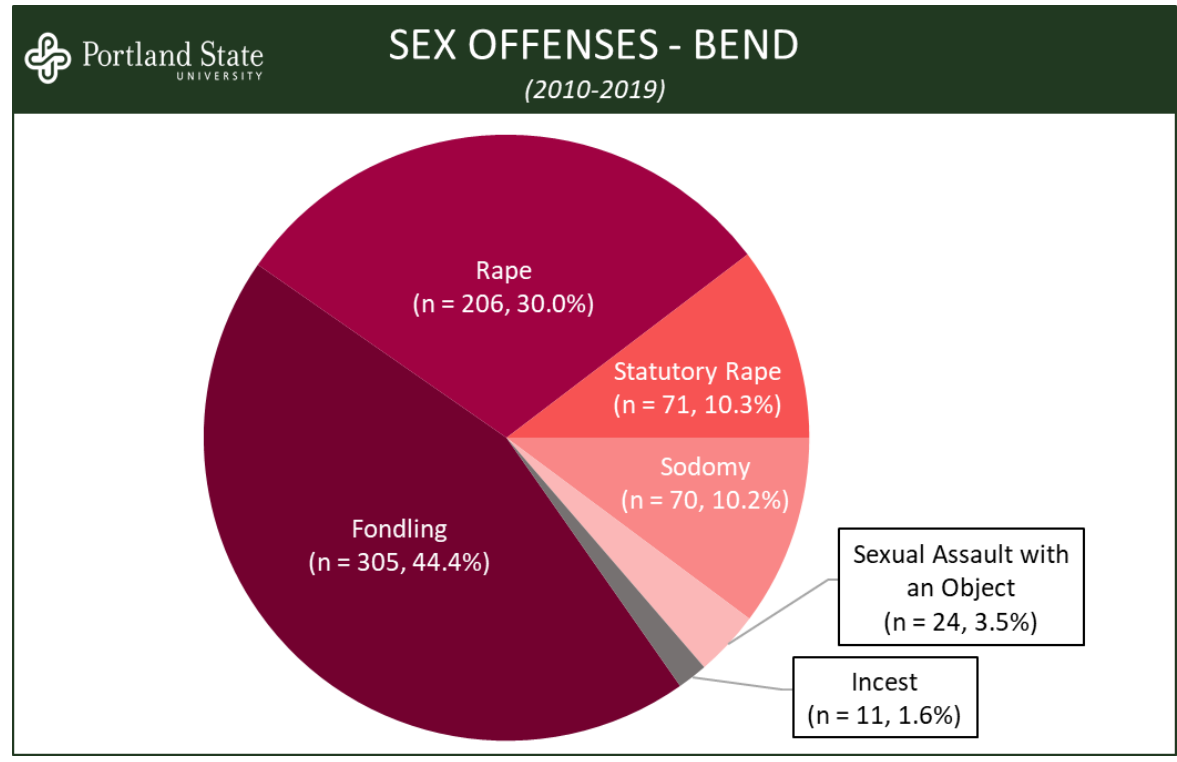

Figure 77

\section{Fondling}

The FBI defines Fondling as, "The touching of the private body parts of another person for the purpose of sexual gratification, without the consent of the victim, including instances where the victim is incapable of giving consent because of his/her age or because of his/her temporary or permanent mental or physical incapacity." Fondling was the most common subtype of Sexual offenses in Bend during the study period, accounting for $44.4 \%$ (305) of these crimes. The average number of offenses per year was 68.7 and the average annual rate was 0.4 per 1,000 residents.

\section{Rape}

Rape as defined by the FBI is, "The carnal knowledge of a person, without the consent of the victim, including instances where the victim is incapable of giving consent because of his/her age or because of his/her temporary or permanent mental or physical incapacity." This was the second most common subtype of sexual offenses in Bend during the study period, representing about a third $(30.0 \%, 206)$ of these crimes. There was an average of 20.6 offenses per year, with an average annual rate of 0.2 per 1,000 residents.

\section{Statutory Rape}

The FBI classifies Statutory Rape as, "Sexual intercourse with a person who is under the statutory age of consent." This was the third most common subtype of sexual offenses in Bend, accounting for 71 offenses or $10.3 \%$ of the total. The average number of Statutory Rape offenses per year in the city was 7.1 and the average annual rate was 0.1 per 1,000 residents. 


\section{Sodomy}

The FBI defines Sodomy as, "Oral or anal sexual intercourse with another person, without the consent of the victim, including instances where the victim is incapable of giving consent because of his/her age or because of his/her temporary or permanent mental or physical incapacity." Sodomy was the fourth most common subtype of sexual offenses in Bend during the study period, accounting for $10.2 \%$ (70) of these crimes. The average number of offenses per year was 7.0 and the average annual rate was 0.1 per 1,000 residents.

\section{Sexual Assault with an Object}

Sexual Assault with an Object as defined by the FBI is, "To use an object or instrument to unlawfully penetrate, however slightly, the genital or anal opening of the body of another person, without the consent of the victim, including instances where the victim is incapable of giving consent because of his/her age or because of his/her temporary or permanent mental or physical incapacity." This was the one of the least common subtypes of sexual offenses in Bend during the study period, representing about a third $(3.5 \%, 24)$ of these crimes. There was an average of 2.4 offenses per year, with an average annual rate of 0.0 per 1,000 residents.

\section{Incest}

Incest is defined by the FBI as, "Sexual intercourse between persons who are related to each other within the degrees wherein marriage is prohibited by law." Incest was the least common subtype of sexual offense in Bend between 2010 and 2019. There were 11 incidents involving Incest, accounting for $1.6 \%$ of all sexual offenses.

\section{Annual Trend}

There was a total of 327 Sexual Offenses involving a juvenile victim in Bend during the 10-year study period, or an average of 32.7 offenses per year. To account for changes in the underlying population, we calculated the annual rate of sexual offenses per 1,000 residents using U.S. Census estimates. The rate for sexual offenses committed against a juvenile decreased $-28.6 \%$ from $2010(0.4$ per 1,000$)$ to $2019(0.2$ per 1,000$)$. As demonstrated in Figure 78, counts and rates for sexual offenses involving a juvenile have decreased overall in Bend over the past ten years, aside from a slight increase in recent years.

Regarding sexual offenses committed against adult victims, there was a total of 262 offenses in Bend over the study period, or an average of 26.2 yearly offenses. After controlling for changes in the population, the rate for sexual offenses committed against adults was found to have increased overall

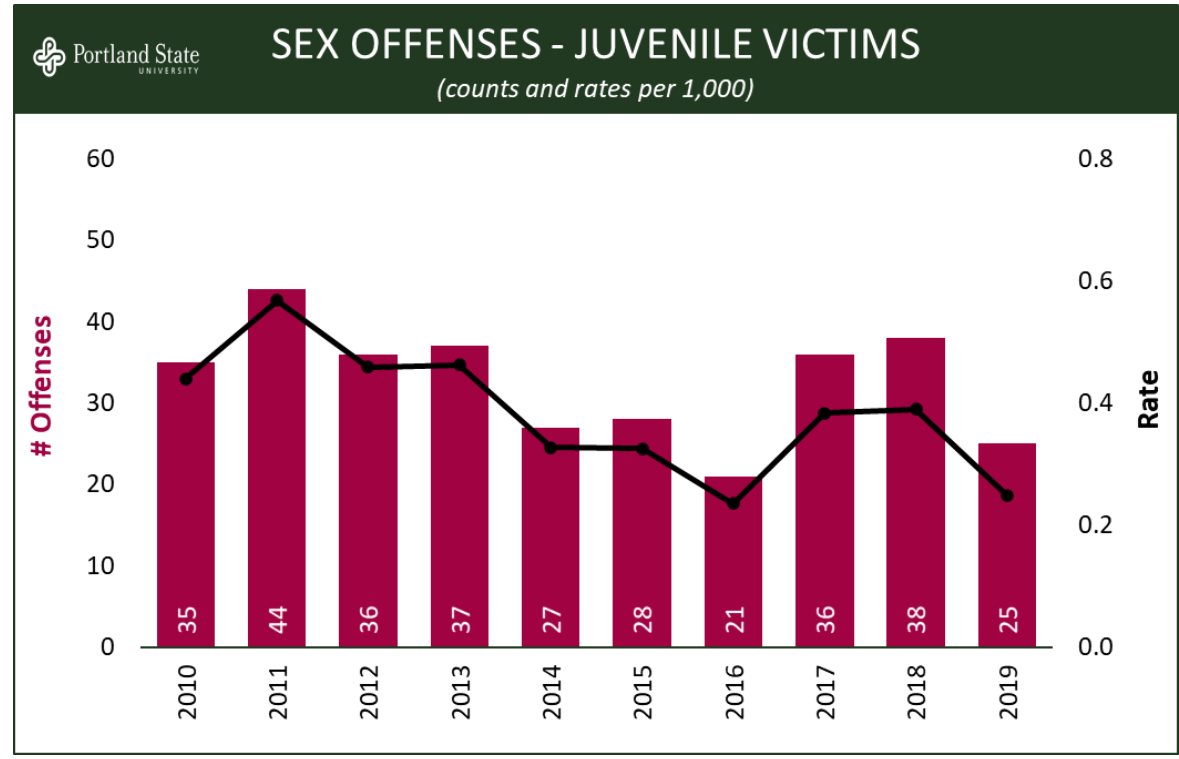

Figure 78 
by $49.9 \%$ from $2010(0.2$ per 1,000$)$ to 2019 (0.4 per 1,000). However, as demonstrated in Figure 79, sexual offenses involving adult victims have fluctuated considerably on a yearly basis over the past ten years.

\section{Temporal Patterns}

We analyzed monthly/seasonal patterns in Sexual Offenses by calculating the average number of offenses per month across the 10year study period. ${ }^{24}$ Bend averaged 3.0 sexual offenses committed against a juvenile per month during this period of time. Higher monthly averages were found for January, June, July, September, October, and December. While above average, the only month that met our threshold for well above average (i.e., 2+ StDev) was January (4.6). None of the months were found to be well below average (i.e., 2+ standard deviations below average).

There was a monthly average of 2.4 sexual offenses committed against an adult over the study period.

Sexual offenses involving an adult victim were above average

February, April, May, June, July, and October. While above average, there was no month that met our threshold for well above average.

Similarly, none of the months were found to be well below average.

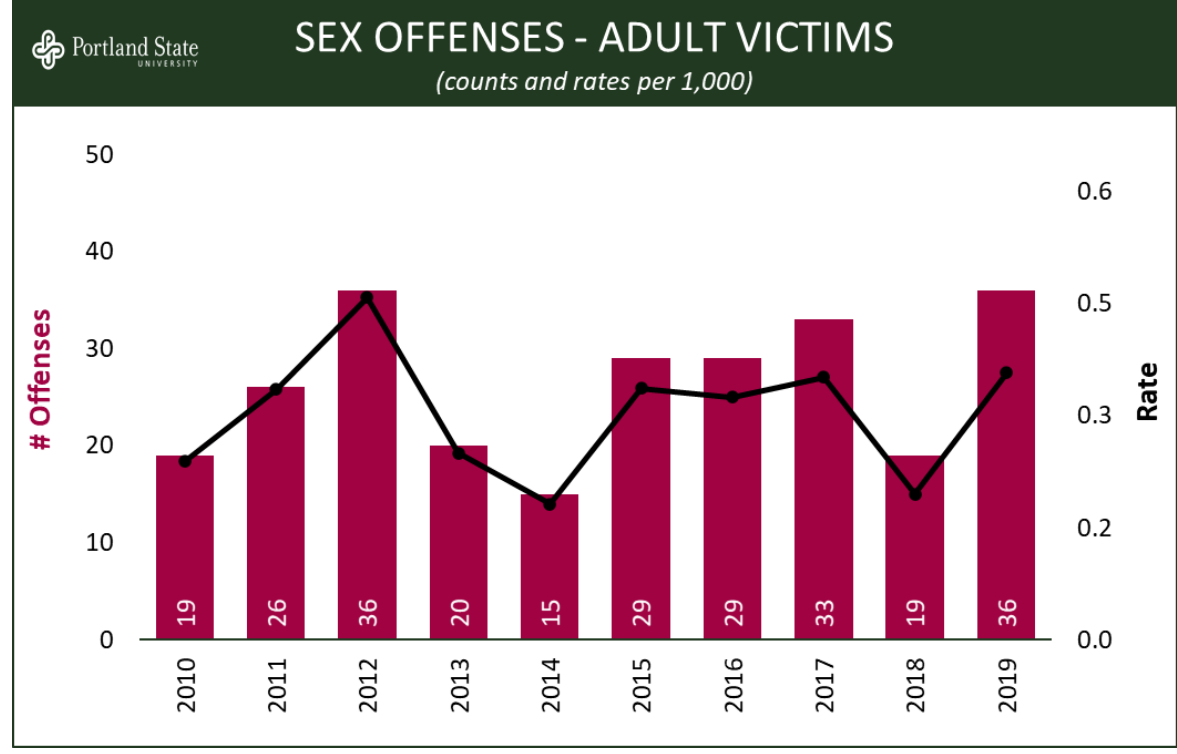

Figure 79

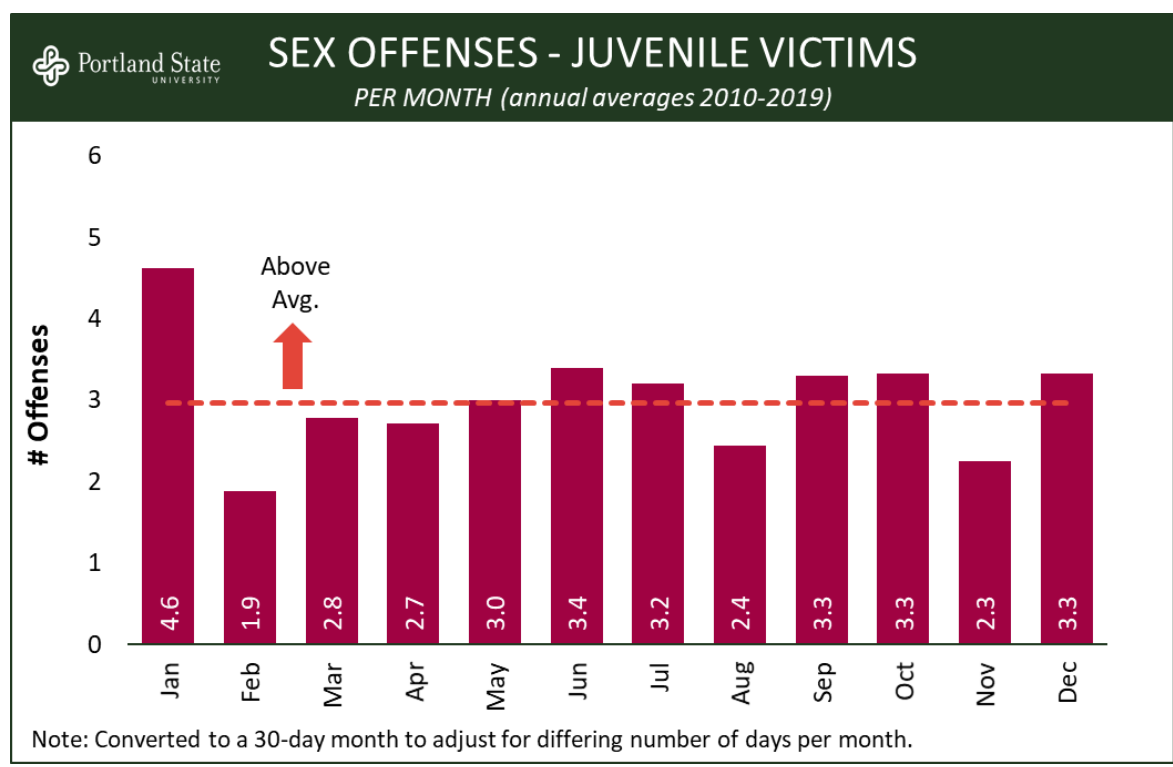

Figure 80

\footnotetext{
${ }^{24}$ Monthly counts were standardized to a 30-day month to control for the fact that some months have more days than others.
} 
Regarding the distribution of Sexual Offenses by day of week, we found that offenses committed against a juvenile were above average on Thursday and Friday. However, there was no day that exceeded our definition for well above average (i.e., 2+ StDev). Similarly, there was no day that was found to be well below average (i.e., 2+ standard deviations below average). In short, temporal fluctuations by day seem to be limited for sexual offenses involving a juvenile victim.

As demonstrated in Figure 83, sexual offenses committed against adults were above average on Friday, Saturday, and Sunday likely due to increased nightlife activity on the weekends. While this pattern is apparent, there was no day that exceeded our definition for well above average or well below average.

The hourly patterns observed for sexual offenses involving juvenile victims demonstrated inconsistencies, likely due to reporting methods. In many sexual offenses involving a juvenile, the crime is not reported until much later, which often results in time estimates rather than reporting the actual time of occurrence. Because this does not produce valid or accurate depictions of temporal fluctuations, we will only analyze the hourly pattern for sexual offenses committed against adults.

Figure 84 documents the distribution of Sexual Offenses in Bend by time of day across the 10-year study period. Offenses committed against an adult were above average at $12: 00 \mathrm{pm}$ and between $8: 00 \mathrm{pm}$ and 3:00am. The highest peaks occurred at $10: 00 \mathrm{pm}(12.8 \%)$ and $12: 00 \mathrm{am}$ (15.1\%), which were both found to be well above average (i.e., 2+ StDev). There were no hours of day

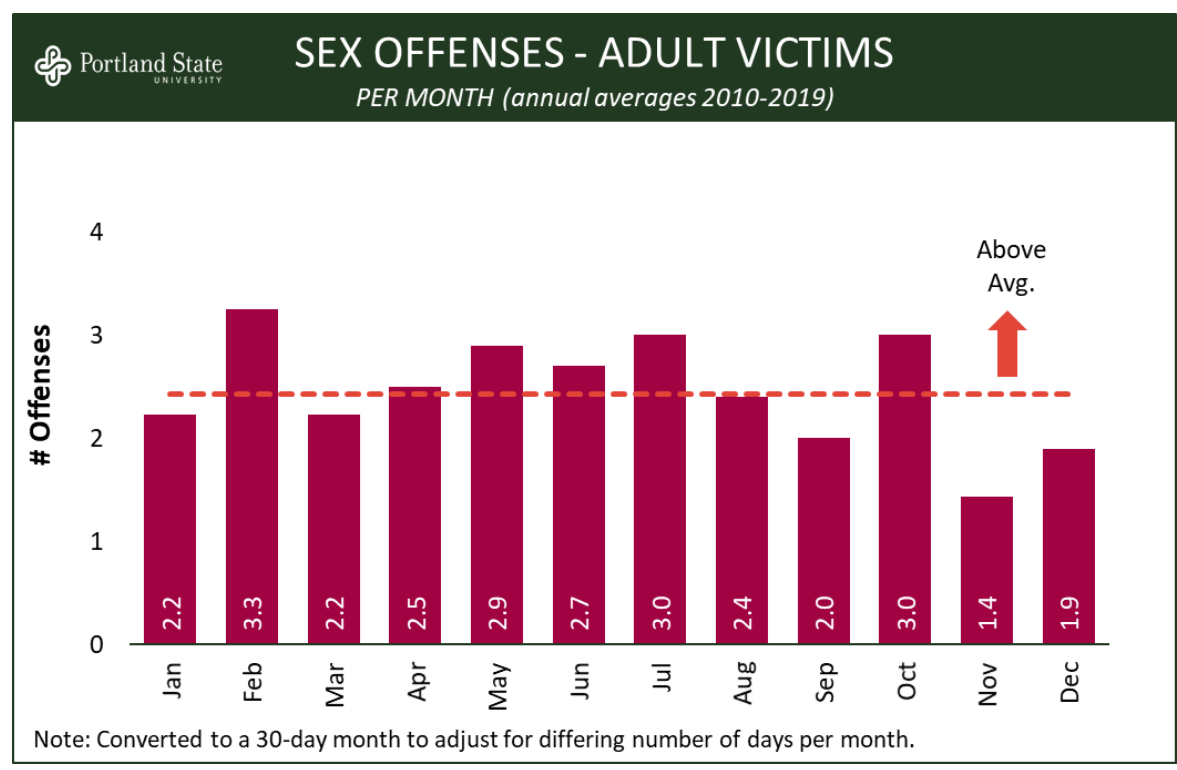

Figure 81

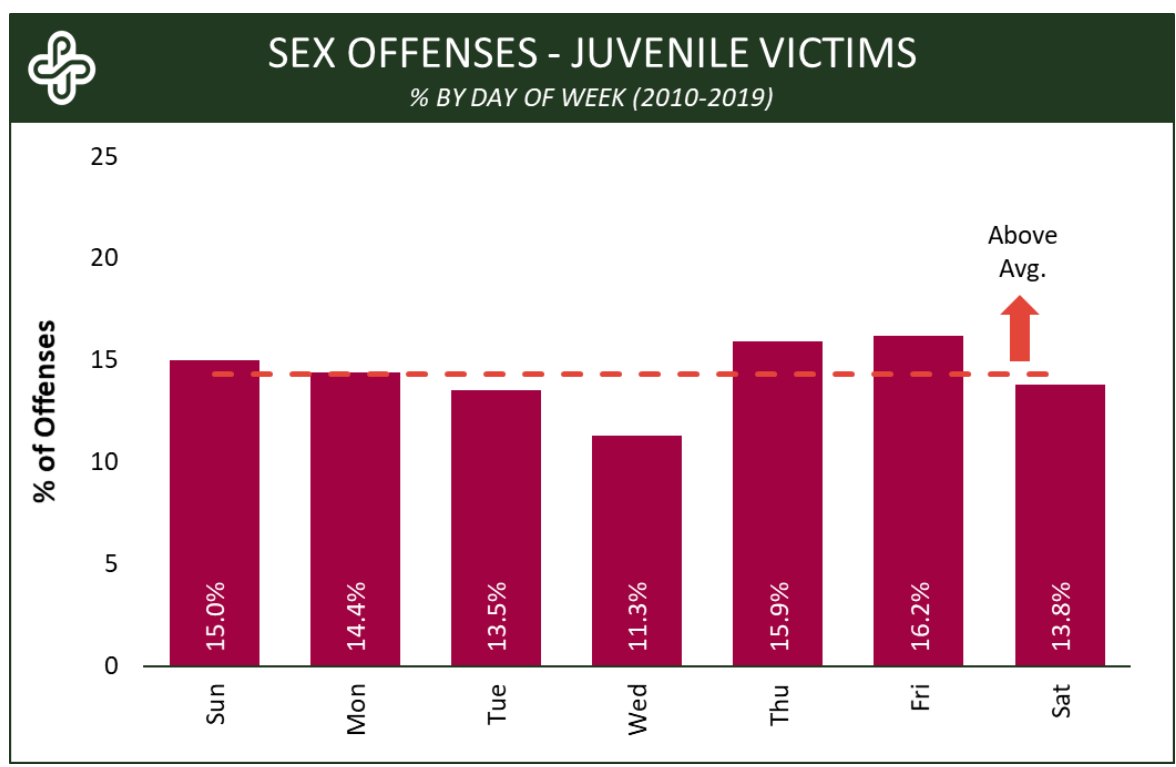

Figure 82

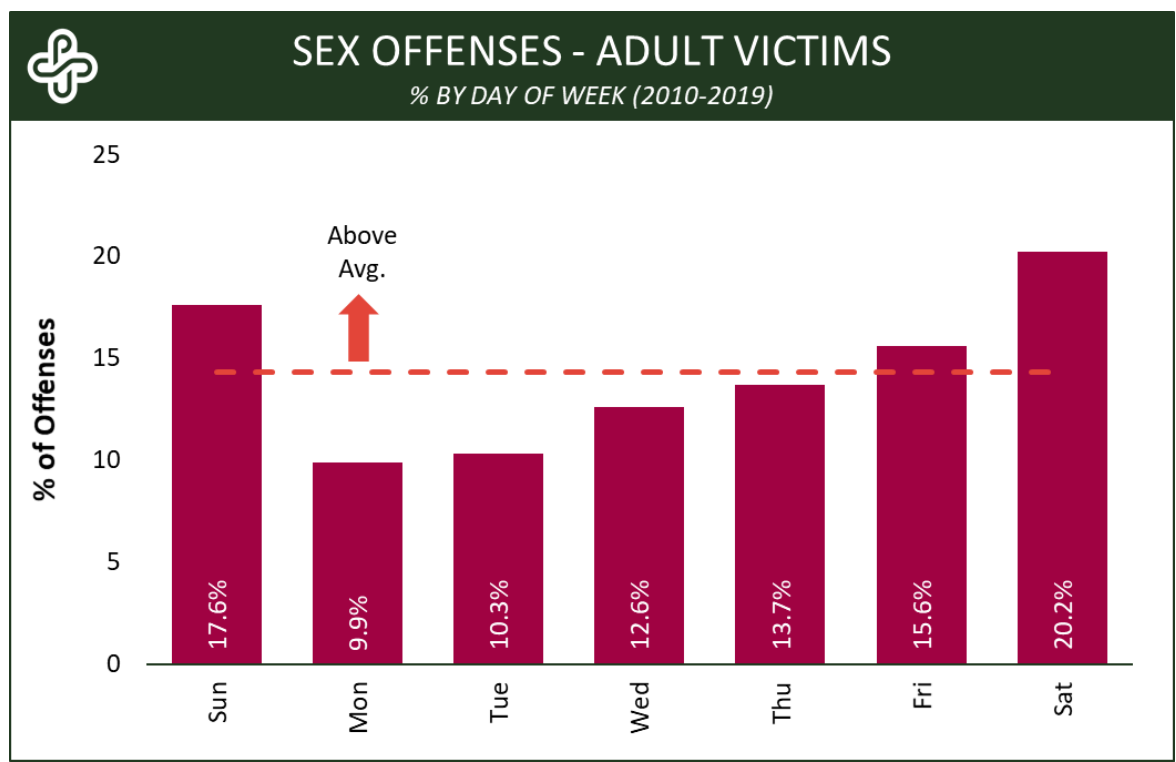

Figure 83 
that were found to be well below average (i.e., 2+ standard deviations below average). Overall, this suggests that sexual offenses involving an adult victim generally occur during the late nighttime to early morning hours.

When analyzing Sexual Offenses involving an adult victim by the hour per day of week, it becomes apparent that the number of offenses increases on Friday, Saturday, and Sunday nights between 8:00pm and 3:00am. The number of offenses were well above the average (i.e., 2+ StDev) on Friday nights between $11: 00 \mathrm{pm}$ $(2.3 \%)$ and $12: 00 \mathrm{pm}(3.7 \%)$, Saturday nights between $8: 00 \mathrm{pm}(3.7 \%)$ and $10: 00 \mathrm{pm}$ (3.2\%) and at 2:00am (3.7\%), and Sunday nights at $10: 00 \mathrm{pm}$ $(2.8 \%)$ and $12: 00 \mathrm{am}(2.8 \%)$. See Figure 85 for a more detailed breakdown; keep in mind that although it appears that Saturday, Sunday, and Monday morning experience a significant increase, this is actually the weekend nights spilling into the early morning hours.

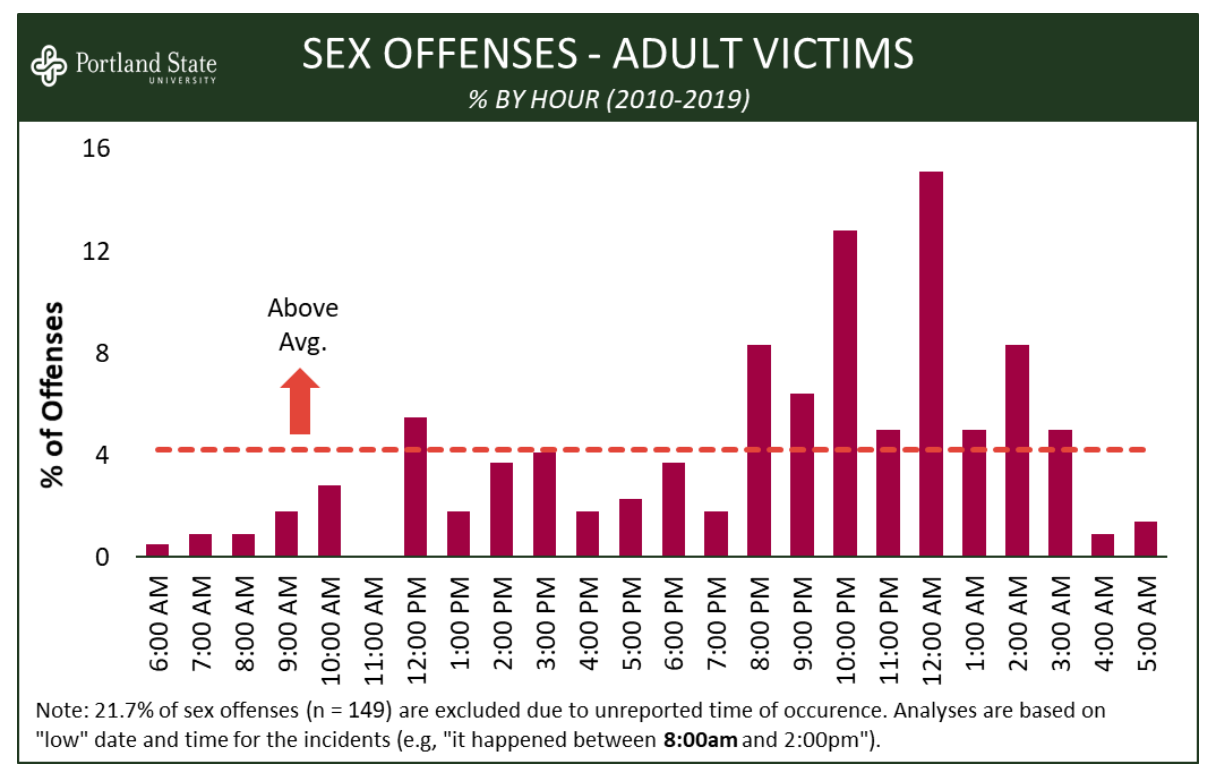

Figure 84

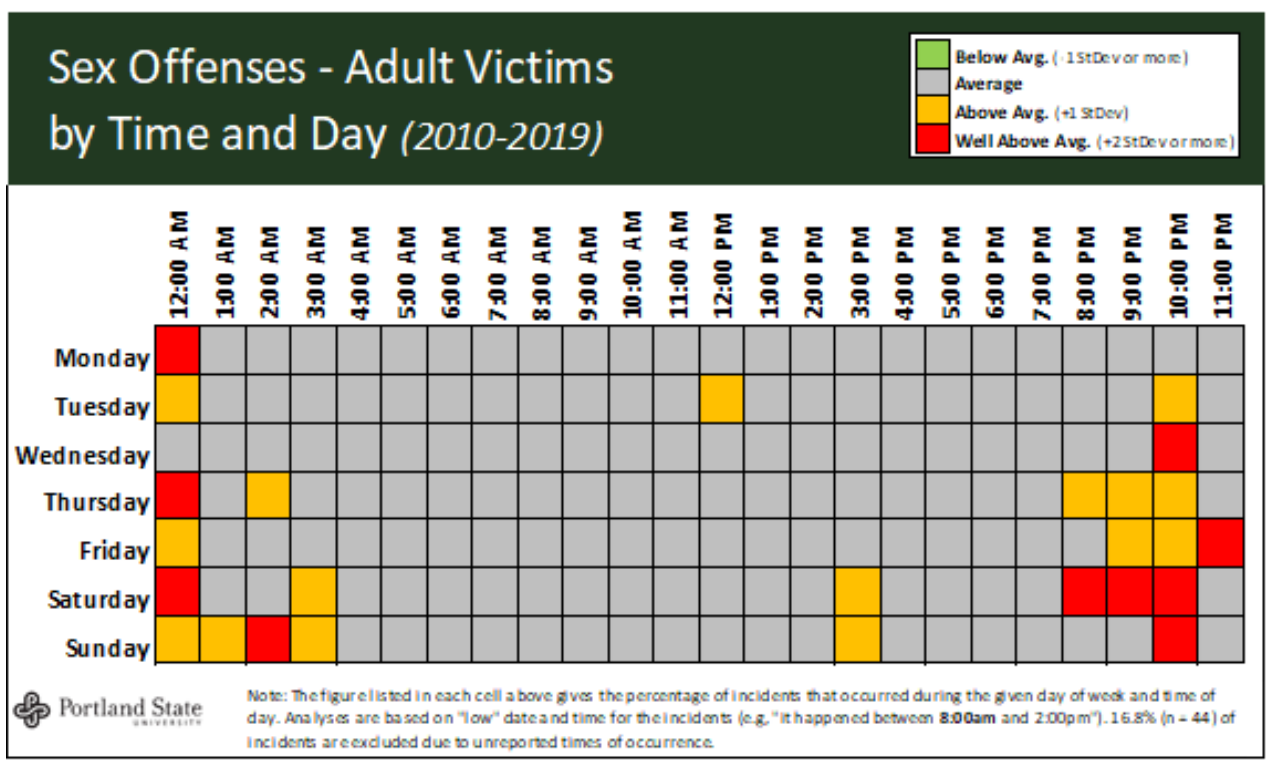

Figure 85 


\section{Geographic Pattern}

The most common location type for sexual offenses committed against a juvenile during the study period was a Residence/Home, with over half $(67.3 \%, 220)$ of all offenses occurring at someone's home. The second most common location type reported was a Roadway, which comprised less than a tenth $(7.0 \%, 23)$ of all offenses. The third most common location type for sexual offenses involving a juvenile victim was a Park/Playground $(4.6 \%$, 15). Together, these three locations account for $78.9 \%$ (258) of all sexual offenses involving a juvenile in Bend. See Table 29 for the top ten most common location types.

\begin{tabular}{|c|c|c|c|c|}
\hline \multicolumn{5}{|c|}{$\begin{array}{c}\stackrel{P}{P} \text { Portland State } \\
\text { SEX OFFENSES - LOCATION TYPE } \\
(2010-2019)\end{array}$} \\
\hline \multirow[b]{2}{*}{ Location Type } & \multicolumn{2}{|c|}{ Juvenile Victim } & \multicolumn{2}{|c|}{ Adult Victim } \\
\hline & $f$ & $\%$ & $f$ & $\%$ \\
\hline Residence/Home & 220 & $67.3 \%$ & 160 & $61.1 \%$ \\
\hline Roadway & 23 & $7.0 \%$ & 24 & $9.2 \%$ \\
\hline Park/Playground & 15 & $4.6 \%$ & 7 & $2.7 \%$ \\
\hline Other/Unknown & 15 & $4.6 \%$ & 17 & $6.5 \%$ \\
\hline Parking Area & 11 & $3.4 \%$ & 11 & $4.2 \%$ \\
\hline Hotel/Motel/Etc. & 11 & $3.4 \%$ & 16 & $6.1 \%$ \\
\hline School & 5 & $1.5 \%$ & 1 & $0.4 \%$ \\
\hline Daycare Facility & 5 & $1.5 \%$ & 0 & $0.0 \%$ \\
\hline Field/Woods & 4 & $1.2 \%$ & 0 & $0.0 \%$ \\
\hline Camp/Campground & 4 & $1.2 \%$ & 3 & $1.1 \%$ \\
\hline All Other Locations & 14 & $4.3 \%$ & 23 & $8.8 \%$ \\
\hline
\end{tabular}

Table 29

For sexual offenses involving an adult victim, the most common location type reported was also Residence/Home $(61.1 \%, 160)$. The second most common location was a Roadway $(9.2 \%, 24)$, followed by Other/Unknown $(6.5 \%, 17)$ and Hotel/Motel $(2.3 \%, 16)$. See Table 29 for how sexual offenses involving an adult victim compare to offenses involving a juvenile by location type. Overall, our analysis suggests that most sexual offenses occur within someone's residence, rather than in public spaces.

\section{Victim \& Arrestee Demographic Profiles}

\section{Age}

The average age for victims of a Sexual Offense during the 10-year study period was 19.4 years old. The most common age group for victims of this type of crime was teenagers, who made up about a third (182) of all victims. The second most common age group for victims were juveniles 12 and under (171), followed by people between the age of 18 and 24 (108). This analysis demonstrates that sexual offense victims tend to be younger than victims involved in previous offenses analyzed in this report.

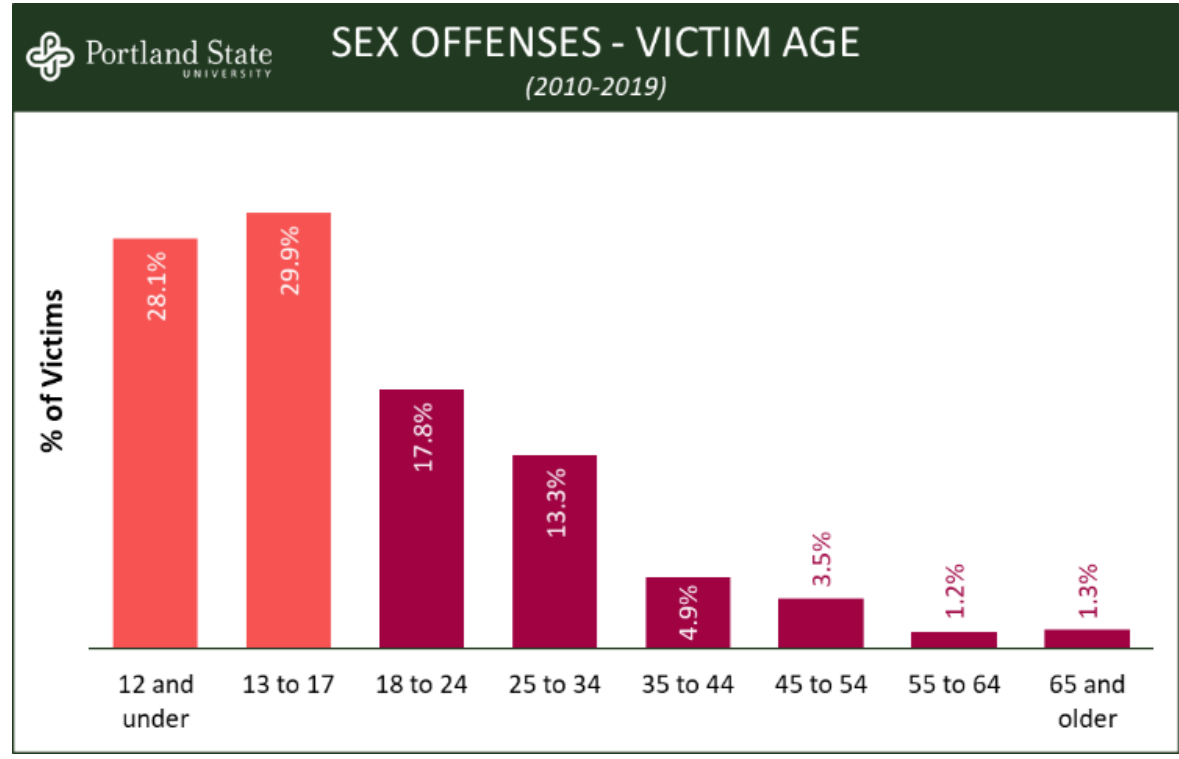

Figure 86 
The average age for arrestees of sexual offenses involving a juvenile victim was 28.4 years old. The most common age group for these arrestees was people between the age of 18 and 24 (32), followed by 25 to 34 (23). Regarding arrestees of sexual offenses involving an adult victim, the average age was 34.9 years old. The most common age group for these arrestees was people between 35 to 44 (17), followed by 25 to 34 (16). These findings indicate that arrestees who committed an offense against a juvenile tend to be younger, while arrestees who committed an offense against an adult tend to be older.

See Figure 87 for a more detailed age breakdown for both victims and arrestees.

\section{Sex}

Of the victims under the age of 18 , most were female $(85.2 \%)$. In comparison, a slightly higher percentage of adult victims were female $(92.6 \%)$.

In contrast, the majority of arrestees were Male for both offenses involving a juvenile victim (91.2\%) and offenses involving an adult victim (96.5\%). See Table 30 for a more detailed breakdown of reported sex for both victims and arrestees.

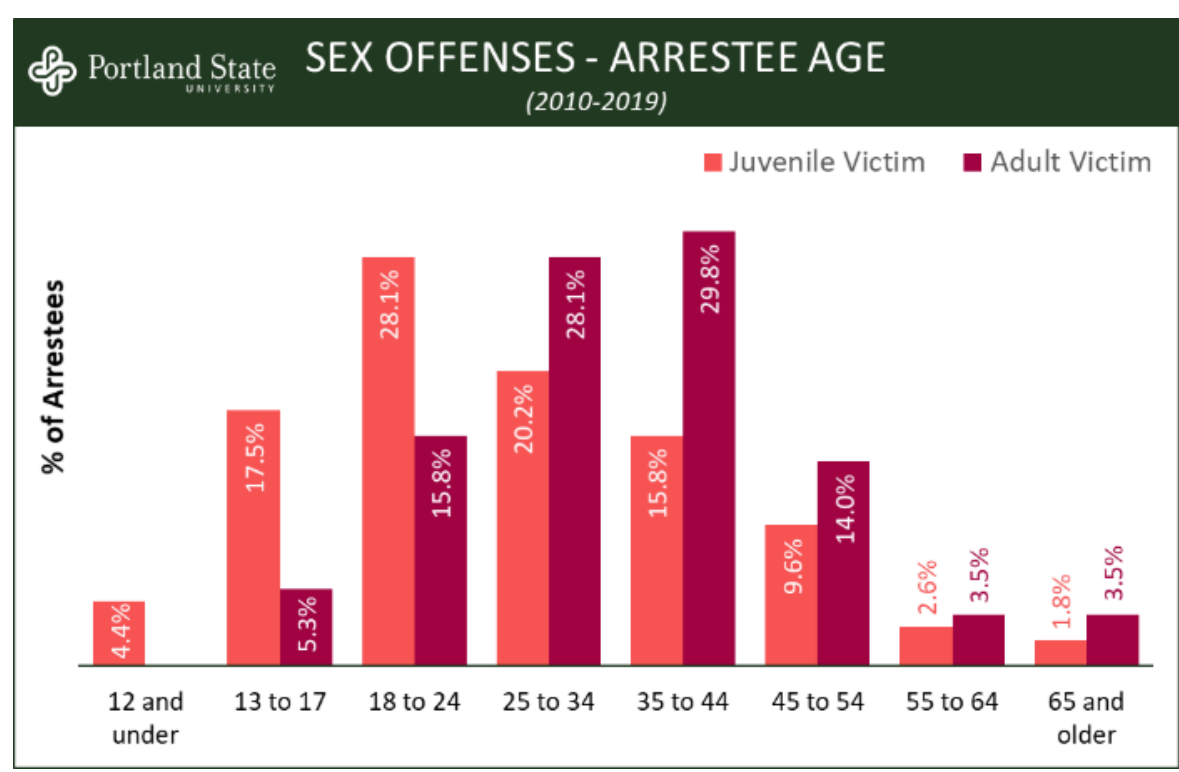

Figure 87

\begin{tabular}{|c|c|c|c|c|}
\hline \multicolumn{5}{|c|}{$\begin{array}{l}\text { SEX OFFENSES - VICTIM DEMOGRAPHICS } \\
\qquad \begin{array}{l}(2010-2019) \\
\text { (2019) }\end{array}\end{array}$} \\
\hline Demographic* & \multicolumn{2}{|c|}{ Juvenile Victim } & \multicolumn{2}{|c|}{ Adult Victim } \\
\hline Sex & $f$ & $\%$ & $f$ & $\%$ \\
\hline Female & 300 & $85.2 \%$ & 237 & $92.6 \%$ \\
\hline Male & 52 & $14.8 \%$ & 19 & $7.4 \%$ \\
\hline \multicolumn{5}{|l|}{ Race } \\
\hline White & 319 & $96.7 \%$ & 234 & $95.1 \%$ \\
\hline Black or African American & 7 & $2.1 \%$ & 9 & $3.7 \%$ \\
\hline All Others Combined & 4 & $1.2 \%$ & 3 & $1.2 \%$ \\
\hline \multicolumn{5}{|l|}{ Ethnicity } \\
\hline Not Hispanic or Latino & 112 & $90.3 \%$ & 106 & $96.4 \%$ \\
\hline Hispanic or Latino & 12 & $9.7 \%$ & 4 & $3.6 \%$ \\
\hline \multicolumn{5}{|l|}{ Residency } \\
\hline Resident & 223 & $86.4 \%$ & 155 & $83.8 \%$ \\
\hline Nonresident & 35 & $13.6 \%$ & 30 & $16.2 \%$ \\
\hline
\end{tabular}

Table 30

\section{Race \& Ethnicity}

Among juvenile victims where race was documented, the majority $(96.7 \%)$ were White, followed by Black or African American (2.1\%). Asian (2) and Native Hawaiian or Other Pacific Islander (2) people accounted for $1.2 \%$ of juvenile victims. With regard to ethnicity, $9.7 \%$ of juvenile victims were identified as Hispanic or Latino. Similarly, most adult victims were White $(95.1 \%)$ followed by Black or African American (3.7\%). American Indian or Alaska Native (3) people represented $1.2 \%$ of adult victims. Only $3.6 \%$ of adult victims were reported to be Hispanic or Latino.

Of the arrestees in offenses involving a juvenile victim, $90.3 \%$ of arrestees were White followed by Black or African American (8.0\%). Asian (1) and Native Hawaiian or Other Pacific Islander (1) people represented $1.8 \%$ of arrestees involved in an offense with a juvenile victim. About a sixth of all arrestees involved in an offense committed against a juvenile were Hispanic or Latino (15.1\%). Of the arrestees in offenses involving an adult victim, $86.0 \%$ were White, followed by Black or African American (7.0\%). American Indian or Alaska Native (2), Asian (1), and Native Hawaiian or Other 
Pacific Islander (1) people represented the remaining arrestees. Regarding ethnicity, $3.6 \%$ of arrestees in an offense involving an adult victim were identified as Hispanic or Latino. See Table 31 for a more detailed breakdown of race and ethnicity for both victims and arrestees.

\section{Residency}

Of the juvenile sexual offense victims whose Residency status was known, $86.4 \%$ were residents of Bend.

Likewise, $83.8 \%$ of adult sexual offense victims were residents. Regarding arrestees of offenses involving a juvenile victim, $90.7 \%$ were residents of Bend. Of the arrestees in sexual

offenses involving an adult victim, $87.2 \%$ were residents. See Table 31 above for more information.
SEX OFFENSES - ARRESTEE DEMOGRAPHICS (2010-2019)

\begin{tabular}{|c|c|c|c|c|}
\hline \multirow{2}{*}{$\begin{array}{l}\text { Arrestee Demographic* } \\
\text { Sex }\end{array}$} & \multicolumn{2}{|c|}{ Juvenile Victim } & \multicolumn{2}{|c|}{ Adult Victim } \\
\hline & $f$ & $\%$ & $f$ & $\%$ \\
\hline Male & 104 & $91.2 \%$ & 55 & $96.5 \%$ \\
\hline Female & 10 & $8.8 \%$ & 2 & $3.5 \%$ \\
\hline \multicolumn{5}{|l|}{ Race } \\
\hline White & 102 & $90.3 \%$ & 49 & $86.0 \%$ \\
\hline Black or African American & 9 & $8.0 \%$ & 4 & $7.0 \%$ \\
\hline All Others Combined & 2 & $1.8 \%$ & 4 & $7.0 \%$ \\
\hline \multicolumn{5}{|l|}{ Ethnicity } \\
\hline Not Hispanic or Latino & 45 & $84.9 \%$ & 21 & $91.3 \%$ \\
\hline Hispanic or Latino & 8 & $15.1 \%$ & 2 & $8.7 \%$ \\
\hline \multicolumn{5}{|l|}{ Residency } \\
\hline Resident & 78 & $90.7 \%$ & 34 & $87.2 \%$ \\
\hline Nonresident & 8 & $9.3 \%$ & 5 & $12.8 \%$ \\
\hline
\end{tabular}

Table 31

\section{Offense Characteristics}

\section{Victim-Offender Relationship}

Among sexual offenses involving a juvenile victim where the relationship was known, almost all $(95.8 \%)$ of the victims knew their offender to some degree. Slightly less than half of juvenile victims were an Acquaintance or Otherwise Known to the offender (43.5\%) and the same percentage of offenders were a Family Member (43.5\%). The next most common Victim-Offender Relationship was Current or Former Intimate Partner (8.8\%), with only $4.2 \%$ of offenders being a Stranger.

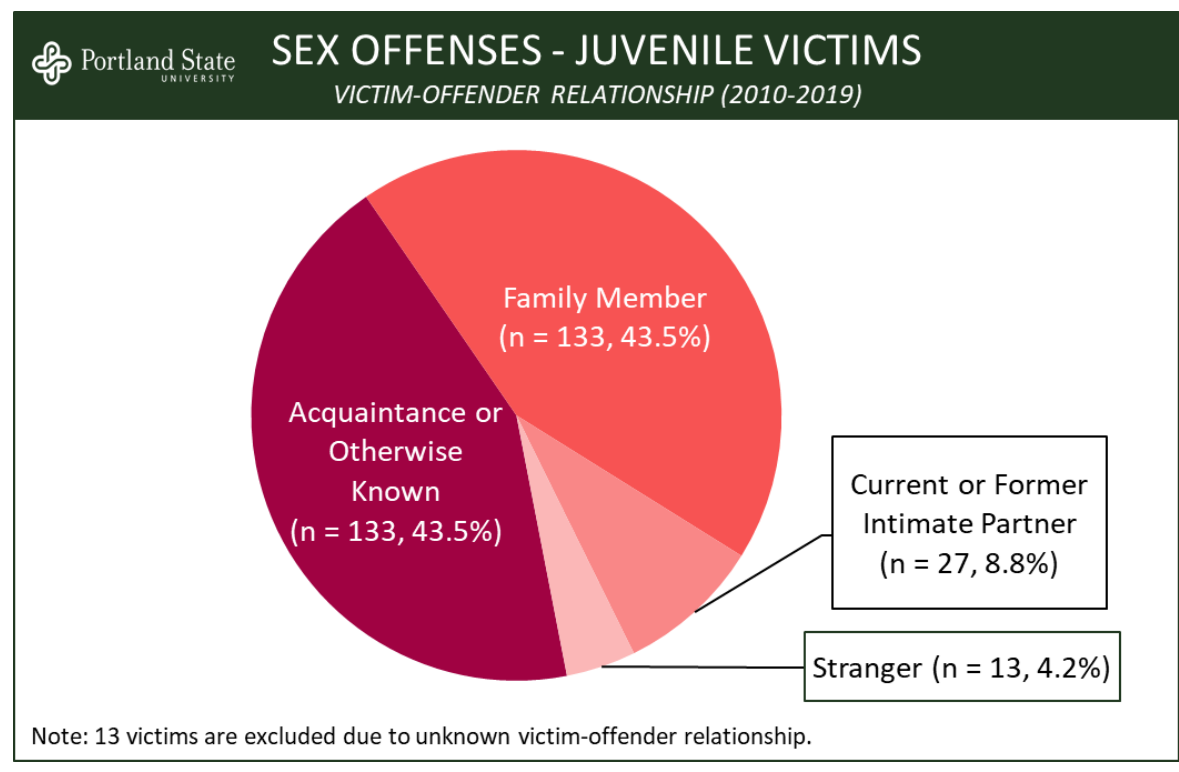

Figure 88 
A slightly lower percentage of adult victims knew their offender to some degree $(87.1 \%)$, with the most common relationship being Acquaintance or Otherwise Known (67.2\%). Current or Former Intimate Partners represented $13.4 \%$ of victim-offender relationships where the victim was an adult. The next most common adult victim-offender relationship was a Stranger (12.9\%), followed by a Family Member (6.5\%). Overall, our analysis demonstrates that although victims of a sexual offense were most likely to know their offender to some degree, adults were more likely to be victimized by a stranger than juveniles.

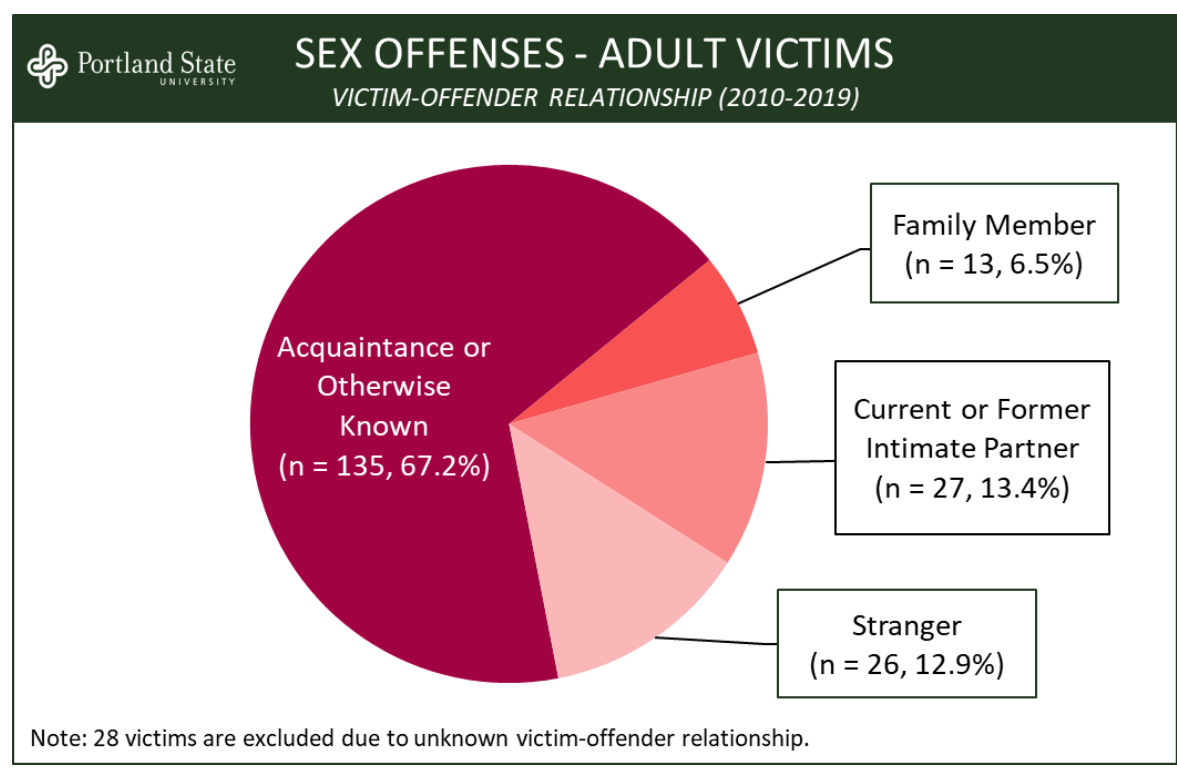

Figure 89

\section{Victim Injuries}

Of the sexual offenses committed against a juvenile that occurred in Bend over the study period, $85.1 \%$ (291) of victims had no injuries. Out of the remaining juvenile victims, $14.0 \%$ (48) experienced a Minor Injury and $0.9 \%$ (3) suffered from a Major Injury.

Out of the adult victims of a sexual offense in Bend, $71.5 \%$ (181) experienced no injuries. About a quarter $(25.3 \%, 64)$ of adult victims reported a Minor Injury and $3.2 \%$ (8) suffered from a Major Injury as a result of the offense.

\section{Number of Victims}

Most sexual offenses committed against a juvenile during the 10 -year study period involved a single victim $(89.7 \%, 287)$. During this time, $7.8 \%(25)$ of offenses involved two victims, $2.2 \%(7)$ involved three victims, and only one incident $(0.3 \%)$ involved four victims.

Similarly, most sexual offenses committed against an adult involved a single victim $(94.8 \%, 236)$. Over the study period, $4.0 \%$ (10) of offenses involved two victims and $1.2 \%$ (3) involved three victims, which was the highest number of adult victims involved in a sexual offense.

\section{Number of Known Offenders}

Of the sexual offenses involving a juvenile victim in Bend in which at least one offender was known, $94.3 \%$ (248) involved a single offender. During this time, $4.2 \%$ (11) of offenses involved two known offenders and $1.5 \%(4)$ involved three known offenders.

Sexual offenses involving an adult victim also involved a single offender $(94.6 \%, 175)$ the majority of the time. The remaining offenses committed against an adult reported two known offenders $(5.4 \%$, 10).

\section{Weapon Involvement}

Among the sexual offenses committed against a juvenile with a known weapon, the most common weapon was a hand, foot, or other body part $(64.7 \%, 196)$. This was followed by No Weapon $(31.4 \%$, $95)$ and Other $(3.6 \%, 11)$. There was one offense against a juvenile involved a Firearm $(0.3 \%)$. 
Similarly, the most common weapon involved in a sexual offense committed against an adult was a hand, foot, or other body part $(59.8 \%, 140)$. This was followed by No Weapon $(31.6 \%, 74)$ and Other $(4.7 \%, 11)$. The remaining weapons included a Knife/Cutting Instrument $(2.6 \%, 6)$, Firearm $(0.9 \%, 2)$, and a Blunt Object $(0.4 \%, 1)$.

\section{Clearance Rate}

Due to the similarities in clearance rates for sexual offenses committed against a juvenile versus an adult, we will analyze sexual offense clearance rates collectively. Of the 687 Sexual Offenses between 2010 and $2019,34.1 \%$ (234) were Cleared by Arrest/Citation or by Exceptional Means. The average annual clearance rate during this time was $34.3 \%$, or 23.4 offenses per year. Over the past ten years, the clearance rate for sexual offenses has fluctuated slightly, although it appears to be relatively stable overall. See Figure 90 for an annual breakdown of Sexual

Offense clearance rates over the study period in Bend.

Figure 90

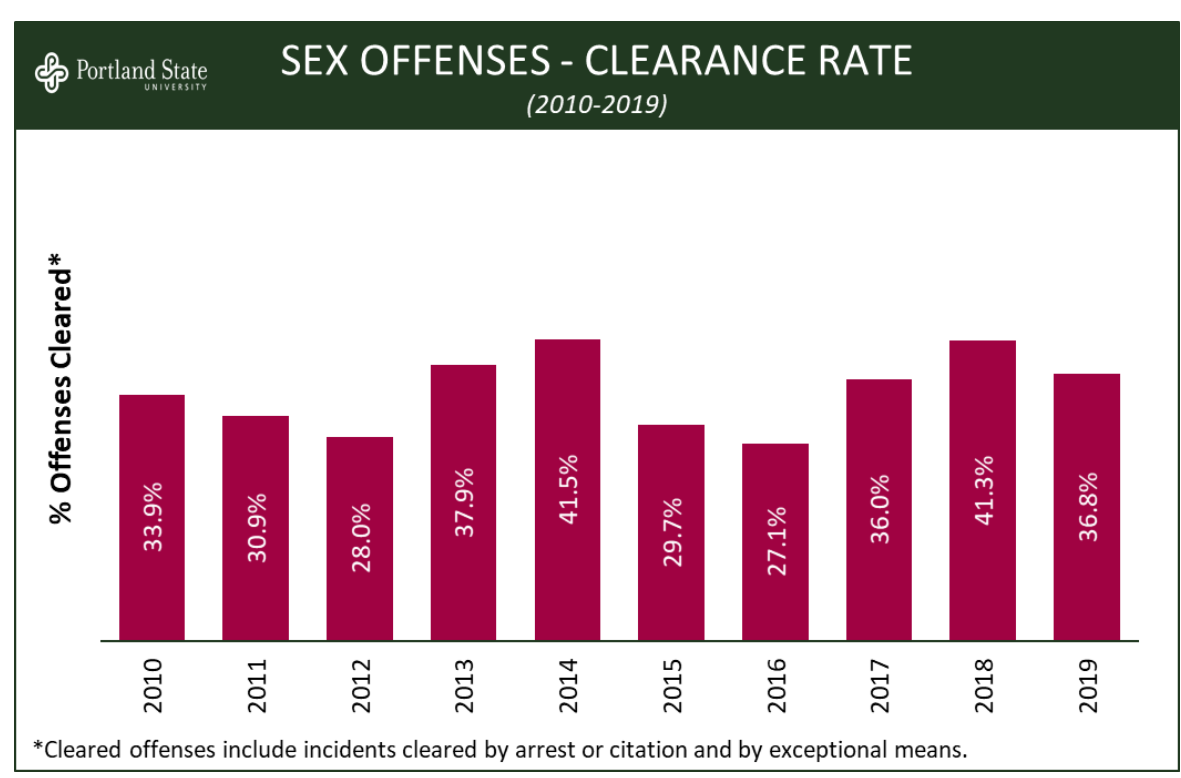




\section{VANDALISM/ARSON}

\section{Introduction \& Offense Subtypes}

In this section we will be examining Vandalism/Arson offenses in Bend, Oregon between 2010 and 2019. This offense subgroup consists of Destruction/Damage/Vandalism of Property and Arson. Oregon has three varying degrees of "criminal mischief," depending on the cost of the damaged property, that are most consistent with the FBI's definition of Destruction/Damage/Vandalism of Property. Additionally, Oregon's Arson in the 1 st and $2^{\text {nd }}$ degree and Reckless burning are the most consistent with the Arson offenses analyzed in this report. Provided below are the FBl's definitions for each offense subtype in this section of the report. We also provide the aggregate counts and rates for each offense in Bend between 2010 and 2019. The remainder of this section will analyze Vandalism/Arson offenses collectively.

It should be noted that because NIBRS reporting allows multiple offenses to be reported for a single incident, there may be some crossover between Vandalism/Arson and other related offenses. For example, if someone breaks a window of a car to steal a laptop from the inside, this can be reported in a few different ways. While one agency may report a Theft from a Motor Vehicle, another agency may report both the Theft from a Motor Vehicle and Vandalism, due to the broken window. Therefore, we are unable to be sure how many Vandalism/Arson offenses are stand alone and how many are the consequence of committing a separate offense.

\section{Destruction/Damage/Vandalism of Property}

The definition of Destruction/Damage/Vandalism of Property provided by the FBI is, "To willfully or maliciously destroy, damage, deface, or otherwise injure real or personal property without the consent of the owner or the person having custody or control of it." This was the most common offense subtype within this category. There were 7,277 instances of vandalism, accounting for $97.2 \%$ of all Vandalism/Arson offenses. The average number of Destruction/Damage/Vandalism of Property offenses per year was 727.7 and the average annual rate was 8.6 per 1,000 residents.

\section{Arson}

The FBI defines Arson as, "To unlawfully and intentionally damage or attempt to damage any real or personal property by fire or incendiary device." Arson was significantly less common than vandalism over the study period, accounting for $2.8 \%$ (211) of all Vandalism/Arson offenses. The average number of Arson offenses per year was 21.1 and the average annual rate was 0.3 per 1,000 residents.

\section{Annual Trend}

There was a total of 7,488

Vandalism/Arson offenses in Bend during the 10-year study period, or an average of 748.8 offenses per year. As shown in Figure 91, the

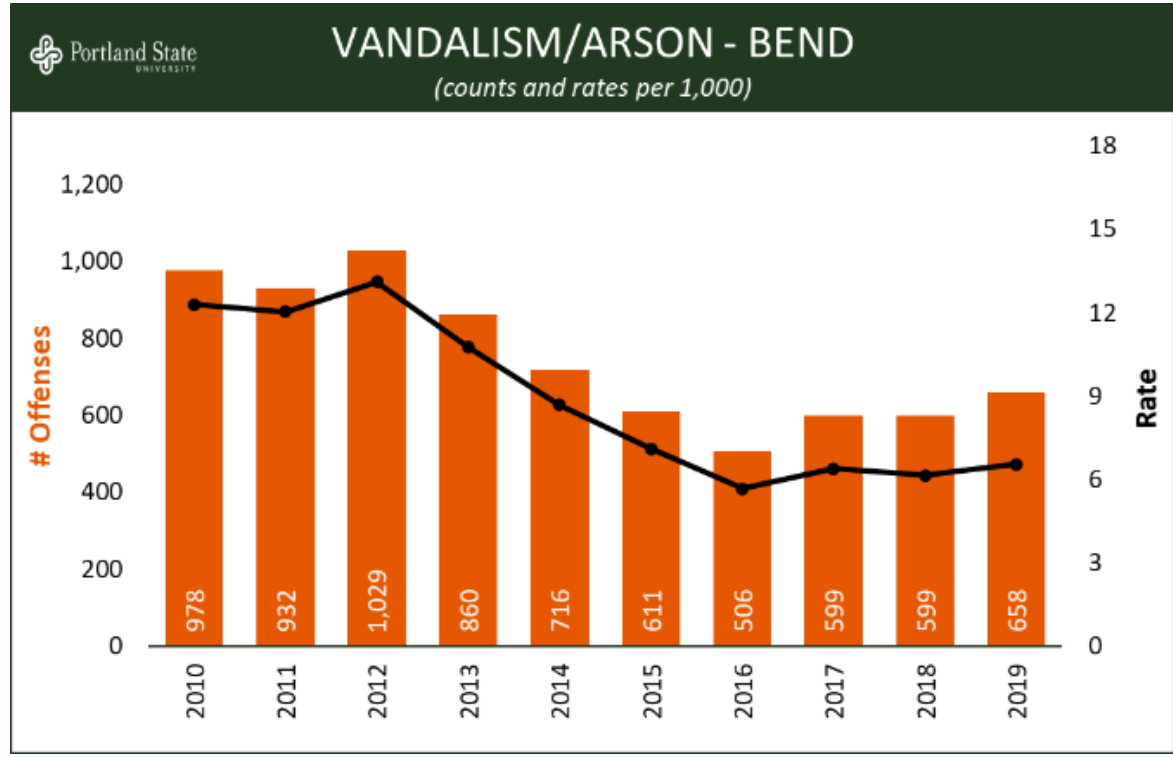

Figure 91 
number of offenses has decreased between 2010 to 2019 , with an overall reduction of $-32.7 \%$. To account for changes in the underlying population, we calculated the annual rate of Vandalism/Arson per 1,000 residents using U.S. Census estimates. After calculating for this, the rate demonstrates a decreased of $-46.8 \%$ from 2010 (12.3 per 1,000) to 2019 (6.5 per 1,000). However, as demonstrated in Figure 91 above, Bend has experienced a slight uptick in Vandalism/Arson offenses in recent years. Since 2016 (5.7 per 1,000), these rate for these offenses have increased by $15.4 \%$ as of 2019 (6.5 per 1,000). See Figure 91 for a more detailed annual breakdown of Vandalism/Arson offenses in Bend.

\section{Temporal Patterns}

We analyzed monthly/seasonal patterns in Vandalism/Arson offenses by calculating the average number of offenses per month across the 10-year study period. ${ }^{25}$ Bend averaged 61.5 Vandalism/Arson offenses per month during this period of time. Higher monthly averages were found during January, March, May, June, July, August, and September. While these were above average, there was no month that met our threshold for well above average (i.e., 2+ StDev). Similarly, none of the months would be considered well below average (i.e., 2+ standard deviations below average).

Regarding the distribution of Vandalism/Arson offenses by day of week, the only days that were above average with Friday and Saturday. However, there were no days that exceeded our definition for well above average (i.e., 2+ StDev) or well below average (i.e., 2+ standard deviations below average).

Figure 94 documents the distribution of Vandalism/Arson offenses in Bend by time of day across the 10year study period. Offenses were

above average between 5:00pm and 1:00am. The highest peak occurred at $5: 00 \mathrm{pm}(8.6 \%)$, which was the only hour of day that was found to be well above average (i.e., 2+ StDev). There were no hours of day that were found to be well below average (i.e., 2+ standard deviations below average). Overall, our analysis demonstrates that Vandalism/Arson offenses tend to occur at nighttime.

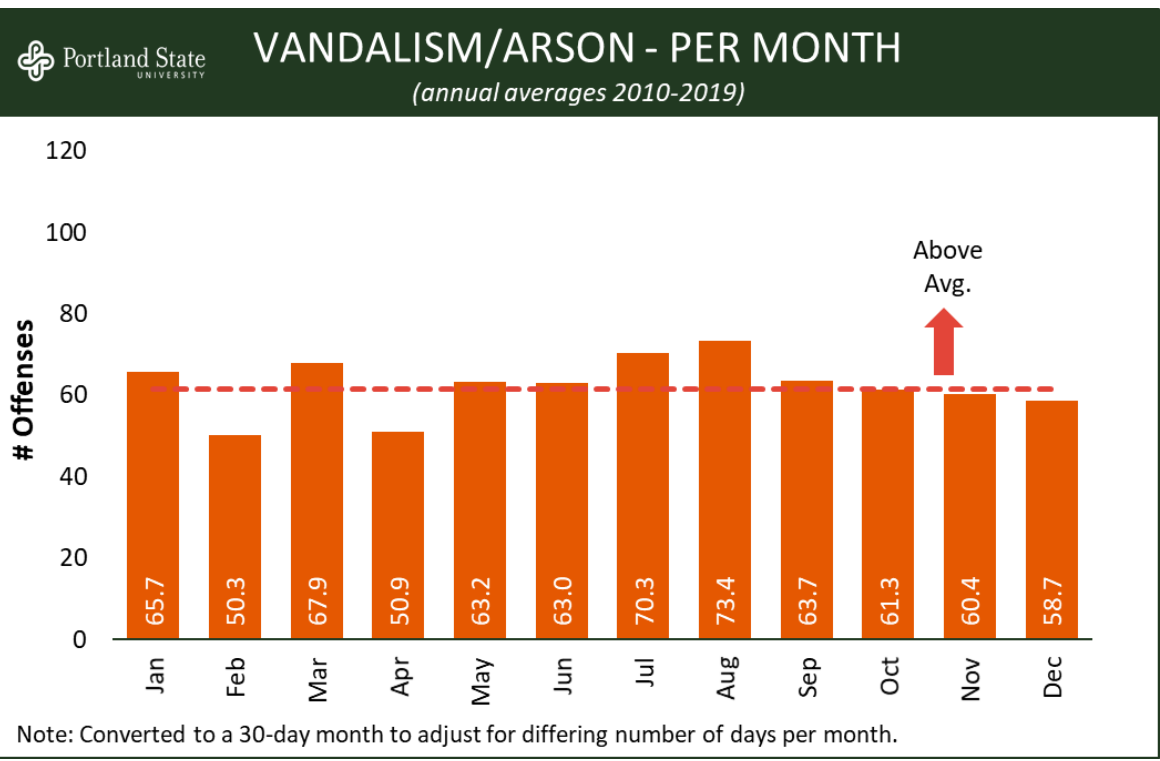

Figure 92

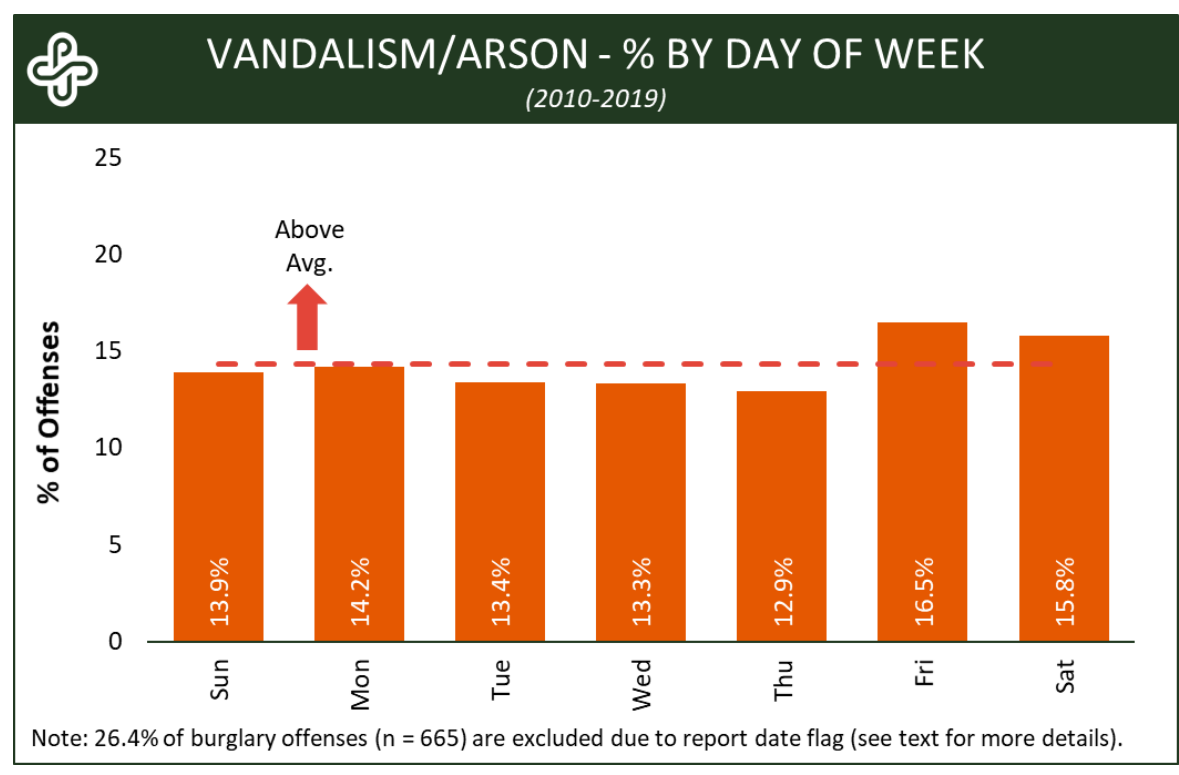

Figure 93

\footnotetext{
${ }^{25}$ Monthly counts were standardized to a 30-day month to control for the fact that some months have more days than others.
} 
When analyzing Vandalism/Arson offenses by the hour per day of week, it becomes apparent that the number of offenses increases on Friday, Saturday, and Sunday nights between 5:00pm and 2:00am. The number of offenses were well above the average (i.e., $2+$ StDev) on Wednesday at $5: 00 \mathrm{pm}(1.4 \%)$, Friday nights at $5: 00 \mathrm{pm}(2.2 \%)$ and $11: 00 \mathrm{pm}$ $(1.4 \%)$, Saturday nights at $12: 00 \mathrm{am}$ $(1.4 \%)$, and Sunday nights at 12:00am (1.5\%). See Figure 95 for a more detailed breakdown of Vandalism/Arson offenses by hour per day of week in Bend over the study period.

\section{Geographic Pattern}

The most common location type for Vandalism/Arson offenses during the study period was a Roadway, with almost a third $(32.5 \%, 2,431)$ of all offenses occurring at a road, sidewalk, or other area within this category. The second most common location type reported was a Residence/Home, which comprised a fifth $(19.7 \%$, $1,474)$ of all offenses. The third most common location type for Vandalism/Arson was a Parking Area $(12.4 \%, 930)$. Together, these three locations account for $64.6 \%(4,835)$ of all Vandalism/Arson offenses in Bend between 2010 and 2019. See Table 32 for the top ten most common location types.

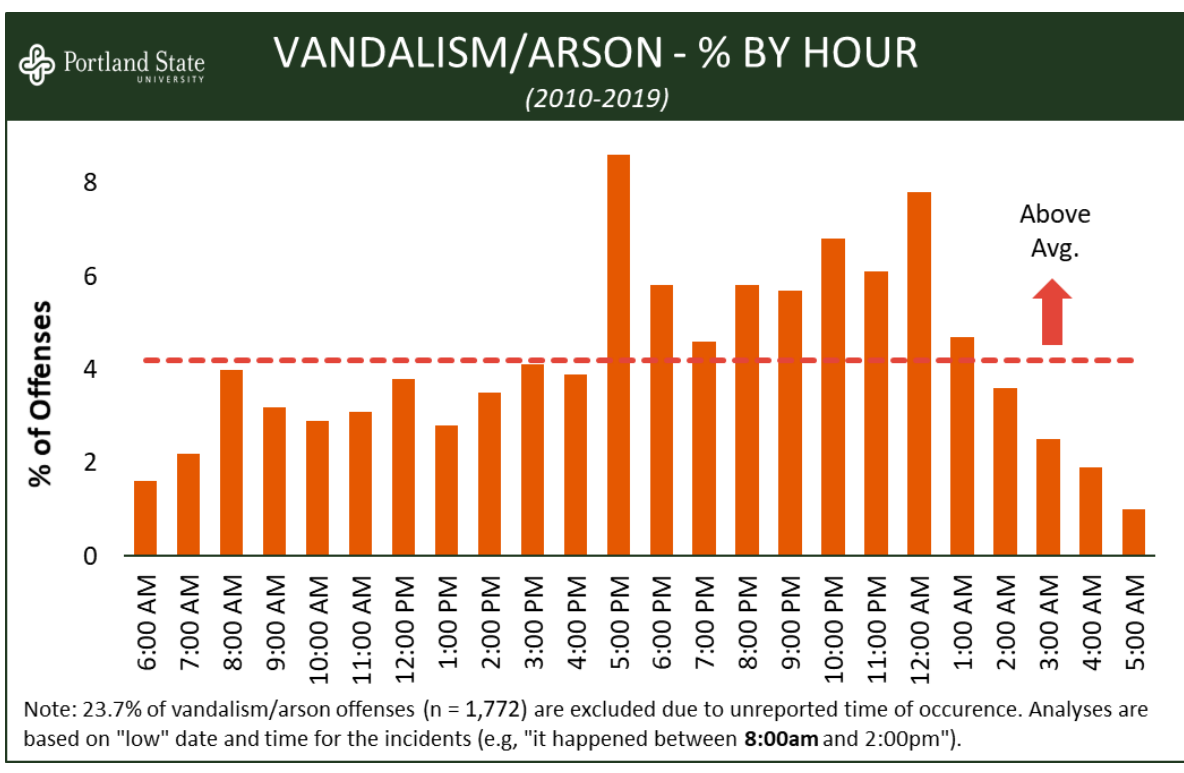

Figure 94
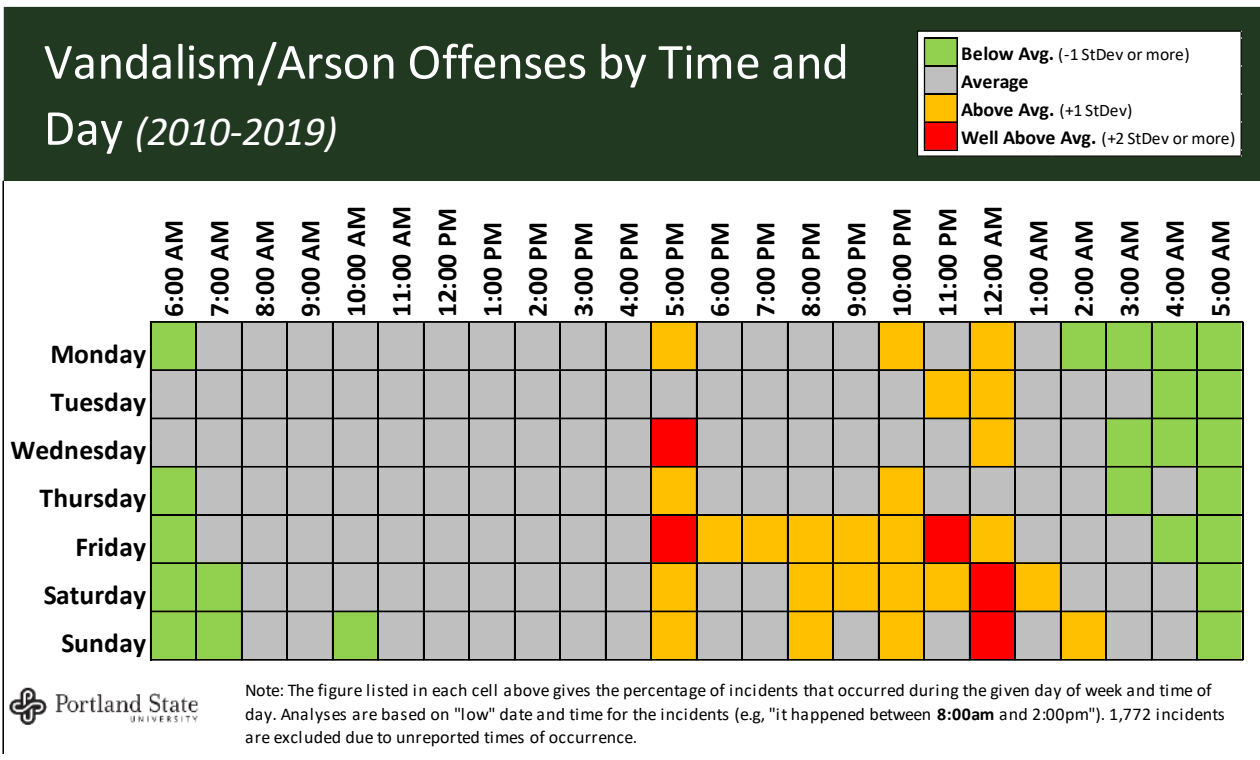

Figure 95

\begin{tabular}{|c|c|c|}
\hline \multicolumn{3}{|c|}{$\begin{array}{c}\text { क्⿱宀 } \text { Portland State VANDALISM/ARSON - LOCATION TYPE } \\
(2010-2019)\end{array}$} \\
\hline Location Type & $f$ & $\%$ \\
\hline Roadway & 2,431 & $32.5 \%$ \\
\hline Residence/Home & 1,474 & $19.7 \%$ \\
\hline Parking Area & 930 & $12.4 \%$ \\
\hline Other/Unknown & 662 & $8.8 \%$ \\
\hline Commercial/Office Building & 515 & $6.9 \%$ \\
\hline Park/Playground & 154 & $2.1 \%$ \\
\hline Restaurant & 121 & $1.6 \%$ \\
\hline School & 119 & $1.6 \%$ \\
\hline Hotel/Motel/Etc. & 107 & $1.4 \%$ \\
\hline Bar/Nightclub & 94 & $1.3 \%$ \\
\hline All Other Locations & 881 & $11.8 \%$ \\
\hline Total & 7,488 & $100.0 \%$ \\
\hline
\end{tabular}

Table 32 


\section{Victim \& Arrestee Information}

\section{Victim Type}

The most common victim type for Vandalism/Arson offenses during the study period was an Individual, with almost two thirds $(62.3 \%)$ of all victims falling into this category. The second most common victim type reported was a Business, which comprised about a third $(30.4 \%)$ of all victims. These two victim types combined account for $92.7 \%$ of the Vandalism/Arson victims in Bend. See Table 33 for a more detailed breakdown of victim types involved in Vandalism/Arson offenses.

\section{Arrestee Demographic Profile}

The average age for arrestees of Vandalism/Arson offenses was 28.6 years old. The most common age group for arrestees was people between the age of 18 and 24 (27.0\%), followed by 25 to 34 (26.4\%) and 13 to $17(16.8 \%)$. These age groups represent $70.2 \%$ $(1,397)$ of all Vandalism/Arson arrestees in Bend during the study period. See Figure 96 for a more detailed age breakdown for arrestees.

\section{Sex}

Most Vandalism/Arson arrestees in Bend during the study period were reported as Male (83.7\%).

\section{Race \& Ethnicity}

Among arrestees where race was documented, the majority (94.1\%) were White, followed by Black or African American (4.7\%). American Indian or Alaska Native (11), Asian (7), and Native Hawaiian or Other Pacific Islander (4) people accounted for $1.2 \%$ of arrestees. With regard to ethnicity,

\begin{tabular}{|lcc|}
\hline \multicolumn{2}{|c|}{ VANDALISM/ARSON - VICTIM TYPE } \\
Victim Type & $f$ & $\%$ \\
\hline Individual & 5,045 & $62.3 \%$ \\
Business & 2,460 & $30.4 \%$ \\
Government & 372 & $4.6 \%$ \\
Society/Public & 140 & $1.7 \%$ \\
Other & 51 & $0.6 \%$ \\
Religious Organization & 22 & $0.3 \%$ \\
Financial Institution & 14 & $0.2 \%$ \\
\hline Total & 8,104 & $100.0 \%$ \\
\hline
\end{tabular}

Table 33

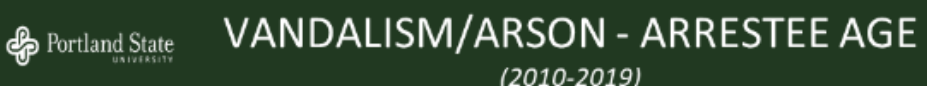

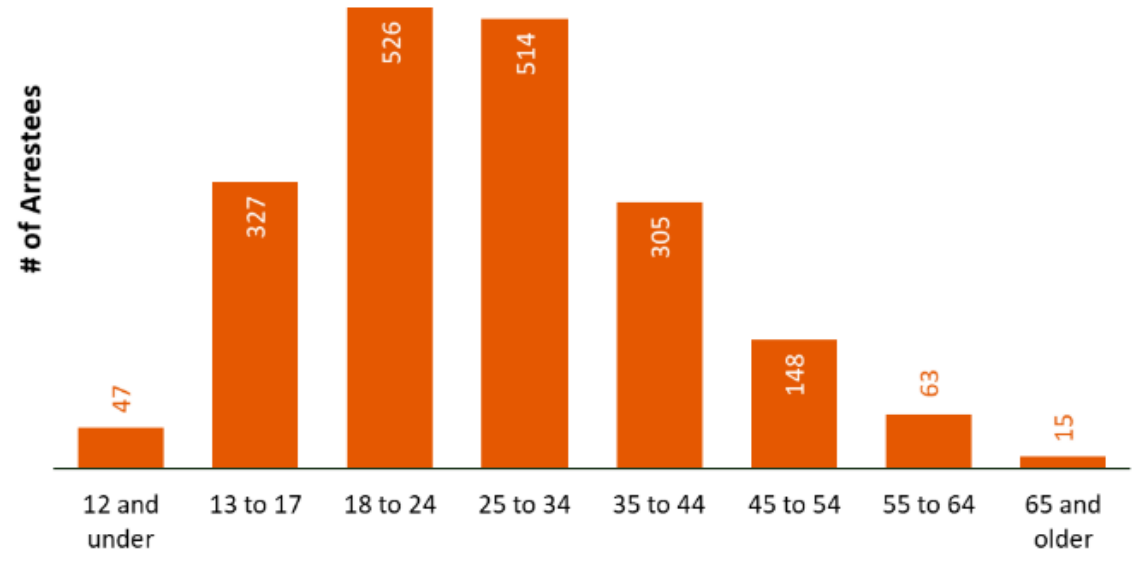

Figure 96

饮 VANDALISM/ARSON - ARRESTEE DEMOGRAPHICS (2010-2019)

\begin{tabular}{|lrc|}
\hline Demographic* & Arrestees \\
\hline Sex & $f$ & $\%$ \\
Male & 1,628 & $83.7 \%$ \\
Female & 317 & $16.3 \%$ \\
Race & & \\
White & 1,789 & $94.1 \%$ \\
Black or African American & 90 & $4.7 \%$ \\
All Others Combined & 22 & $1.2 \%$ \\
Ethnicity & & \\
Not Hispanic or Latino & 806 & $93.6 \%$ \\
Hispanic or Latino & 55 & $6.4 \%$ \\
Residency & & \\
Resident & 1,310 & $89.8 \%$ \\
Nonresident & 149 & $10.2 \%$ \\
*Actual sample sizes vary based on the missing data for each category &
\end{tabular}

Table 34 
6.4\% of Vandalism/Arson arrestees were identified as Hispanic or Latino.

\section{Residency}

Of the Vandalism/Arson arrestees whose Residency status was known, $89.8 \%$ were residents of Bend. See Table 34 below for a more detailed depiction of all arrestee demographics information.

\section{Property Losses}

\section{Property Descriptions}

Overall, the most common property that was damaged in a

Vandalism/Arson offense during the 10 -year study period was an

Automobile (28.1\%). This was followed by Structure/Single dwelling (8.0\%), Structure/Other commercial (7.0\%), and Structure/Other (6.2\%). Together, these property descriptions account for almost half $(49.3 \%, 3,954)$ of all property damaged in a Vandalism/Arson offense over the study period. See Table 35 for the top ten most common descriptions of property damaged.

\begin{tabular}{|lrc|}
\hline Property Description & $f$ & $\%$ \\
\hline Automobile & 2,238 & \\
Structure/ Single dwelling & 642 & $28.1 \%$ \\
Structure/ Other commercial & 558 & $8.0 \%$ \\
Structure/ Other & 516 & $7.0 \%$ \\
Vehicle Parts & 508 & $6.5 \%$ \\
Building Materials & 266 & $6.4 \%$ \\
Household Goods & 258 & $3.3 \%$ \\
Structure/ Public & 239 & $3.2 \%$ \\
Tools & 212 & $3.0 \%$ \\
Trucks & 170 & $2.7 \%$ \\
All Other Locations & 2,370 & $2.1 \%$ \\
\hline Total & 7,977 & $29.7 \%$ \\
\hline
\end{tabular}

Table 35

\section{Costs Associated with Vandalism/Arson}

In this section we estimate the direct costs associated with damaged and/or burned property as a result of Vandalism/Arson offenses in Bend during the 10-year study period. In order to estimate the total financial losses attributable to this offense, we replaced any missing values with the statewide mean value for a given item and year.

Between 2010 and 2019, Bend experienced $\$ 7,865,039$ in damaged property losses resulting from Vandalism/Arson offenses. This means that there was an average loss of $\$ 785,503$ per year as a result of these offenses. The annual costs of damaged has remained relatively stable between 2010 and 2019, with slight increases in years that experienced more burned property loss. This is because the average loss per

Destruction/Damage/Vandalism of Property during this time was $\$ 834$, while the average loss per Arson was $\$ 6,112$. See Figure 97 for a yearly breakdown of Bend's property losses resulting from Vandalism/Arson offenses.

Figure 97

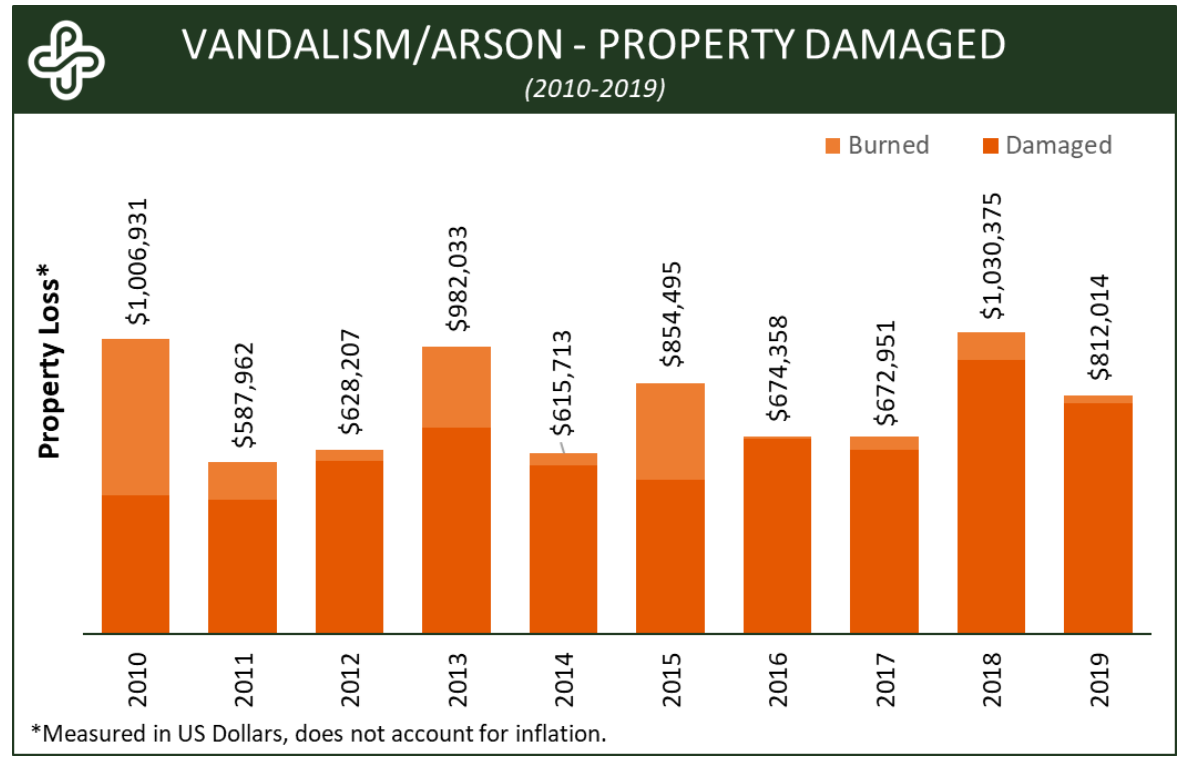




\section{Clearance Rate}

Of the 7,488 Vandalism/Arson offenses between 2010 and 2019, $23.0 \%(1,722)$ were Cleared by Arrest/Citation or by Exceptional Means. The average annual clearance rate during this time was $24.0 \%$, or 172.2 offenses per year. The clearance rate for Vandalism/Arson in Bend has steadily increased over the past decade, and as of 2019, the clearance rate has increased by $66.4 \%$ since 2010 . Considering the low national average for property crime clearance rates, this is a very interesting finding, and more efforts should be made to analyze why the clearance rate for Vandalism/Arson offenses is so high in Bend. See Figure 98 for an annual breakdown of clearance rates over the study period in Bend.

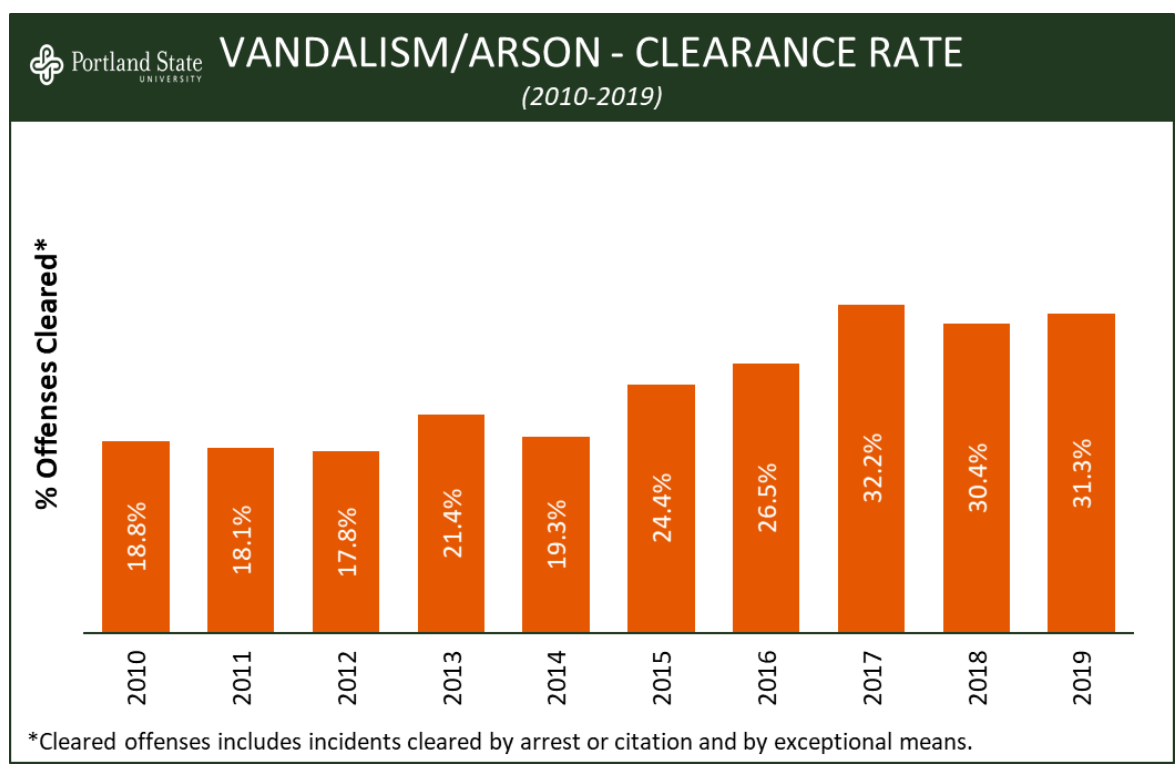

Figure 98 


\section{WHITE-COLLAR CRIME}

\section{Introduction \& Offense Subtypes}

In this section we will be examining White-Collar Crime offenses in Bend, Oregon between 2010 and 2019. It should be noted that this section is comprised of the FBI's "Fraud Offenses" category, as well as other miscellaneous financial and/or con offenses that are not typically coded as a fraud offense. The term "White-Collar Crime" was initially coined by the famous sociologist Edwin Sutherland which he described as, "a crime committed by a person of respectability and high social status in the course of his occupation." 26 This long-persevering definition often evokes an image of wealthy businessmen in "white collars" committing large fraud schemes or embezzlement, however most offenses within this category of crime are lower-grade financial or fraudulent crimes committed by average people.

This offense subgroup consists of Impersonation,

Counterfeiting/Forgery, False

Pretenses/Swindle/Confidence Game, Credit Card/Automated Teller Machine Fraud, Identity Theft, Wire Fraud, Extortion/Blackmail, Embezzlement, and Bribery. Although there are many ORS codes that correspond with these offenses, some Oregon statutes that fall within this category include:

Criminal impersonation (ORS 156.815), Trademark counterfeiting (ORS 647.135), Theft by deception (ORS 164.085), and Identity theft (ORS 165.800). Provided below are the FBI's definitions for each offense

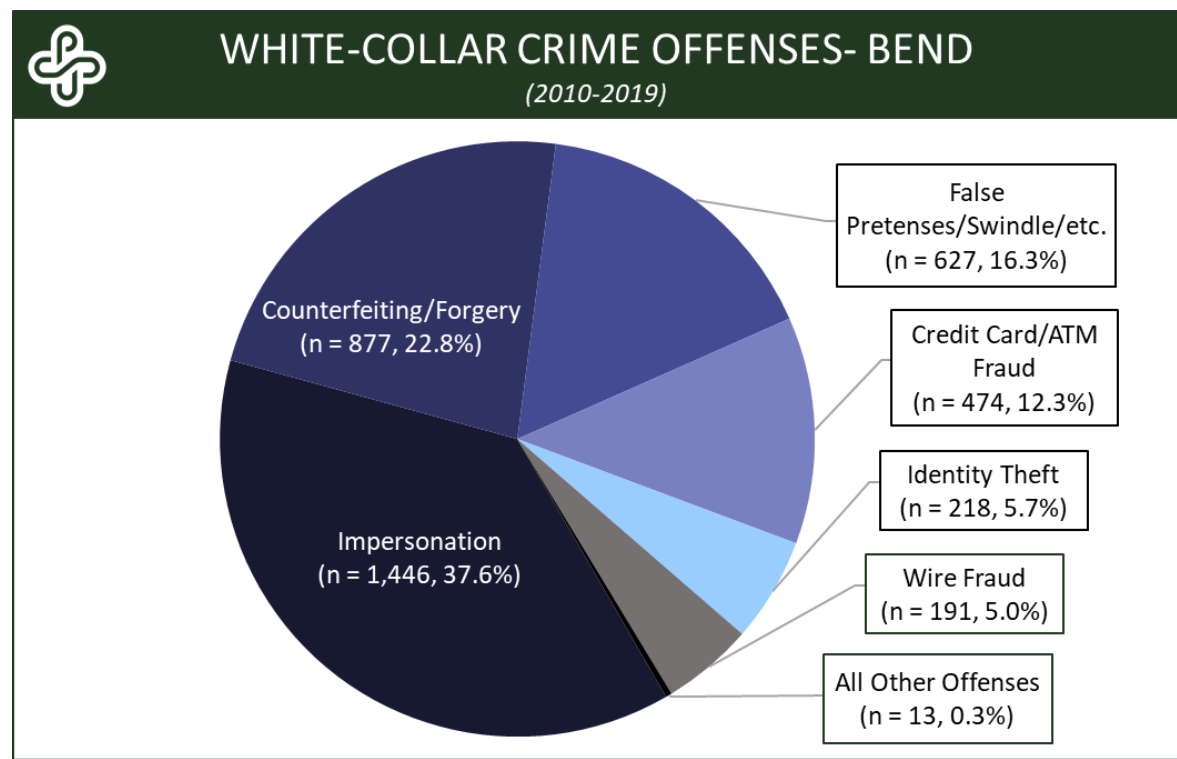

Figure 99

subtype in this section of the report. We also provide the aggregate counts and rates for each offense in Bend between 2010 and 2019. The remainder of this section will analyze White-Collar Crime offenses collectively.

\section{Impersonation}

The FBI defines Impersonation as, "Falsely representing one's identity or position and acting in the character or position thus unlawfully assumed to deceive others and thereby gain a profit or advantage, enjoy some right or privilege, or subject another person or entity to an expense, charge, or liability that would not have otherwise been incurred." This was the most common subtype of WhiteCollar offenses in Bend during the years examined. There were 1,446 instances of Impersonation, accounting for $37.6 \%$ of all White-Collar offenses. The average number of Impersonation offenses per year was 144.6 and the average annual rate was 1.8 per 1,000 residents. However, it should be noted that in July 2011, Bend experienced a dramatic increase in Impersonation offenses. This anomaly accounted for $27.3 \%$ (395) of Impersonation offenses over the study period. Although we will not remove this anomaly from the "Introduction \& Offense Subtypes" section, 2011 will be removed from certain analyses so that we can better depict patterns over time without this dramatic increase interfering with the data. 


\section{Counterfeiting/Forgery}

Counterfeiting/Forgery as defined by the FBI, is "The altering, copying, or imitation of something, without authority or right, with the intent to deceive or defraud by passing the copy or thing altered or imitated as that which is original or genuine; or, the selling, buying, or possession of an altered, copied, or imitated thing with the intent to deceive or defraud." Counterfeiting/Forgery was the second most common subtype of White-Collar offenses in Bend during the study period, accounting for $22.8 \%$ (877) of these crimes. The average number of offenses per year was 87.7 and the average annual rate was 1.0 per 1,000 residents.

\section{False Pretenses/Swindle/Confidence Game}

The FBI classifies False Pretenses/Swindle/Confidence Game as, "The intentional misrepresentation of existing fact or condition or the use of some other deceptive scheme or device to obtain money, goods, or other things of value." This was the third most common subtype of White-Collar offenses in Bend, accounting for $16.3 \%$ (627) of offenses. The average number of False

Pretenses/Swindle/Confidence Game offenses per year in the city was 62.7 and the average annual rate was 0.7 per 1,000 residents.

\section{Credit Card/Automated Teller Machine Fraud}

Credit Card/Automated Teller Machine Fraud is defined by the FBI as, "The unlawful use of a credit (or debit) card or automated teller machine for fraudulent purposes." Credit Card/ATM Fraud was the fourth most common subtype of White-Collar offenses between 2010 and 2019, representing 12.3\% (474) of White-Collar offenses. The average number of offenses per year was 47.4 and the average annual rate was 0.5 per 1,000 residents.

\section{Identity Theft}

The FBI defines Identity Theft as, "Wrongfully obtaining and using another person's personal data (e.g., name, date of birth, Social Security number, driver's license number)." The fifth most common White-Collar offense was Identity Theft, which accounted for 5.7\% (218) of offenses during the tenyear study period. The average number of Identity Thefts per year was 21.8 and the average annual rate was 0.2 per 1,000 residents.

\section{Wire Fraud}

The FBI classifies Wire Fraud as, "The use of an electric or electronic communications facility to intentionally transmit a false and/or deceptive message in furtherance of a fraudulent activity." The was the sixth most common White-Collar offense during the study period, which accounted for $5.0 \%$ (191) of all offenses. The average number of Wire Fraud offenses per year was 19.1 and the average annual rate was 0.2 per 1,000 residents.

\section{Extortion/Blackmail}

Extortion/Blackmail is defined by the FBI as, "The unlawful use of a credit (or debit) card or automated teller machine for fraudulent purposes." Extortion/Blackmail was the third least common subtype of White-Collar offenses between 2010 and 2019, representing 0.2\% (6) of White-Collar offenses.

\section{Embezzlement}

Embezzlement as defined by the FBI, is "The unlawful misappropriation by an offender to his/her own use or purpose of money, property, or some other thing of value entrusted to his/her care, custody, or control." Embezzlement was the second least common subtype of White-Collar offenses in Bend during the study period, accounting for $0.1 \%(4)$ of these crimes. 


\section{Bribery}

The FBI classifies Bribery as, "The offering, giving, receiving, or soliciting of anything of value (e.g., a bribe, gratuity, or kickback) to sway the judgment or action of a person in a position of trust or influence." This was least common subtype of White-Collar offenses in Bend, with only three incidents of Bribery occurring over the ten-year study period.

\section{Annual Trend}

There was a total of 3,846 WhiteCollar offenses in Bend during the 10 -year study period, or an average of 384.6 offenses per year.

Excluding the dramatic spike in 2011, the number of White-Collar offenses has experienced a slight increase of $14.8 \%$ between 2010 and 2019. To account for changes in the underlying population, we calculated the annual rate of WhiteCollar offenses per 1,000 residents using U.S. Census estimates. After calculating for this, the White-Collar rate demonstrates a decrease of $9.2 \%$ from $2010(4.5$ per 1,000$)$ to 2019 (4.1 per 1,000).

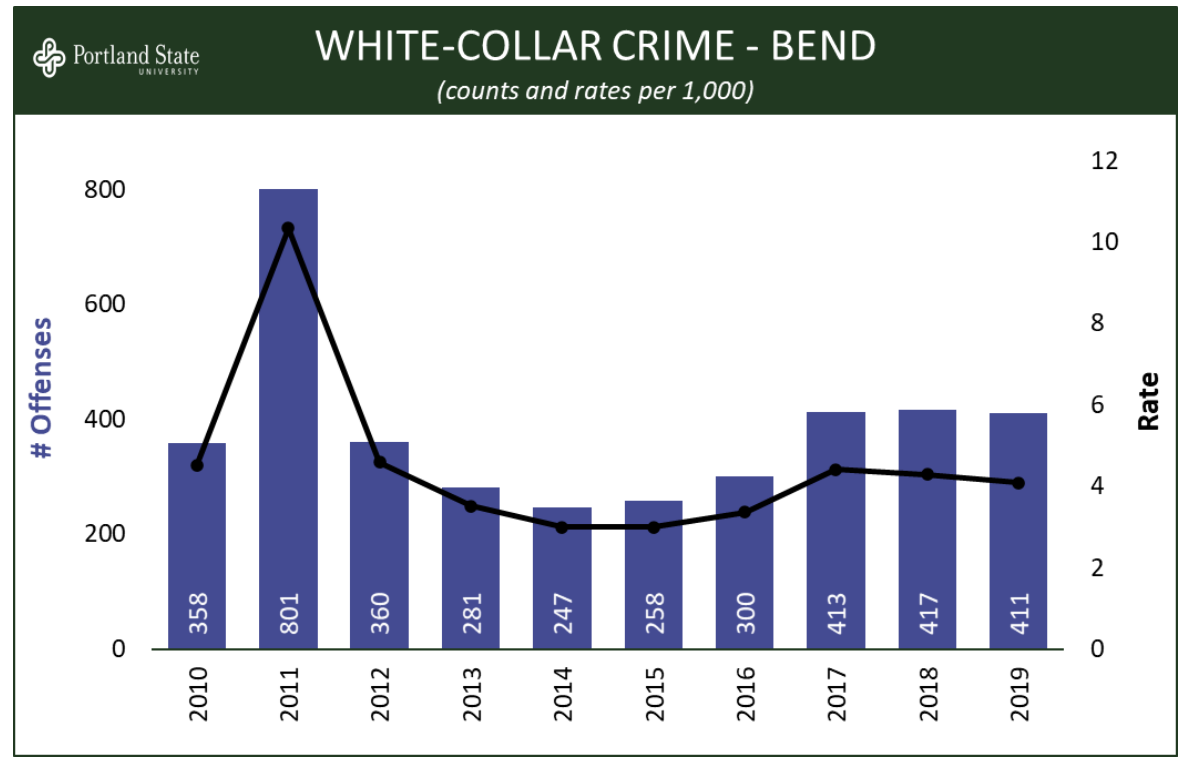

Figure 100

As shown in Figure 100 above, Bend experienced a dramatic spike in 2011 due to the large number of Impersonation offenses that occurred in July 2011. In the following analyses, we will remove the data from 2011 so we can better depict temporal patterns of White-Collar Crime in Bend.

\section{Temporal Patterns}

We analyzed monthly/seasonal patterns in White-Collar offenses by calculating the average number of offenses per month across the 10year study period, excluding $2011 .^{27}$ Bend averaged 27.8 robberies per month during this period of time. Higher monthly averages were found for January, February, May, October, and December. While above average, the only month that met our threshold for well above average (i.e., 2+ StDev) was January (38.8). None of the months were found to be well below average (i.e., 2+ standard deviations below

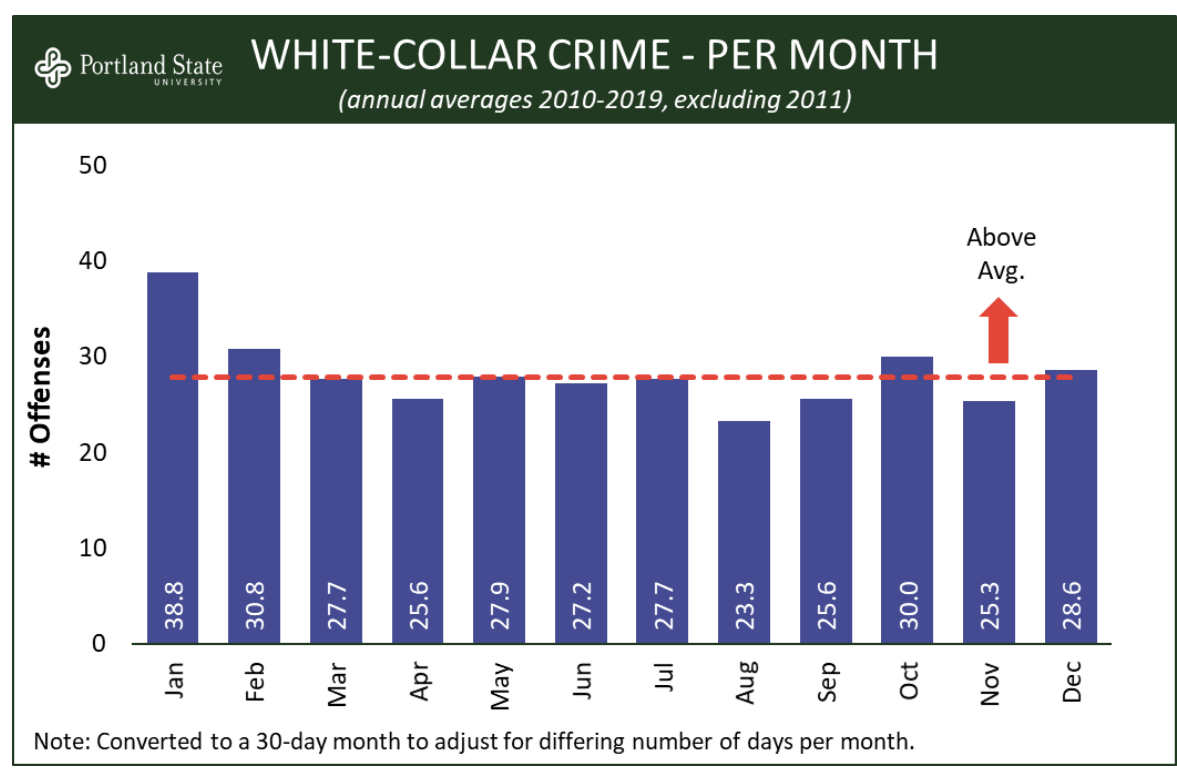

Figure 101

\footnotetext{
27 Monthly counts were standardized to a 30-day month to control for the fact that some months have more days than others.
} 
average).

Regarding the distribution of WhiteCollar offenses by day of week, we found that Monday through Friday was above average. However, there was no day that exceeded our definition for well above average (i.e., 2+ StDev). Similarly, there was no day that was found to be well below average (i.e., 2+ standard deviations below average). In short, temporal fluctuations by day seem to be limited for White-Collar Crime.

Figure 103 documents the distribution of White-Collar offenses in Bend by time of day across the 10-year study period, excluding 2011. It should be noted that averages of the preceding and following hours were substituted for 8:00am, 12:00pm, and 12:00am due to spikes in the data that were likely caused by reporting errors. Offenses were above average between 8:00am and 7:00pm. However, there was no hour of day that was found to be well above average (i.e., 2+ StDev). Likewise, there was no hour of day that was found to be well below average (i.e., 2+ standard deviations below average). Our analysis demonstrates that there is little to no temporal fluctuation in White-Collar crimes based on the hour of day.

For our analysis regarding Larceny/Theft offenses by time of day and day of week, averages of the preceding and following hour were taken for 8:00am, 12:00pm, and 12:00am to control for outliers likely resulting from reporting estimates. When analyzing White-Collar offenses by the hour per day of week, it becomes apparent that the number of offenses increases during the weekdays between 9:00am and 5:00pm. Mondays
WHITE-COLLAR CRIME - \% BY DAY OF WEEK (2010-2019, excluding 2011)

25

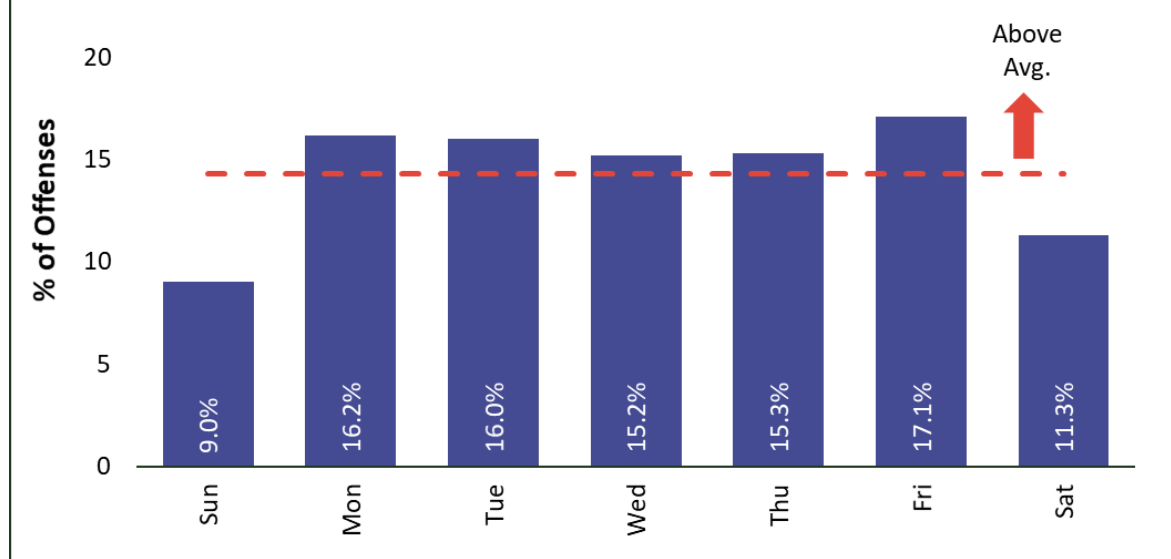

Figure 102

\& Portland State WHITE-COLLAR CRIME - \% BY HOUR (2010-2019, excluding 2011)

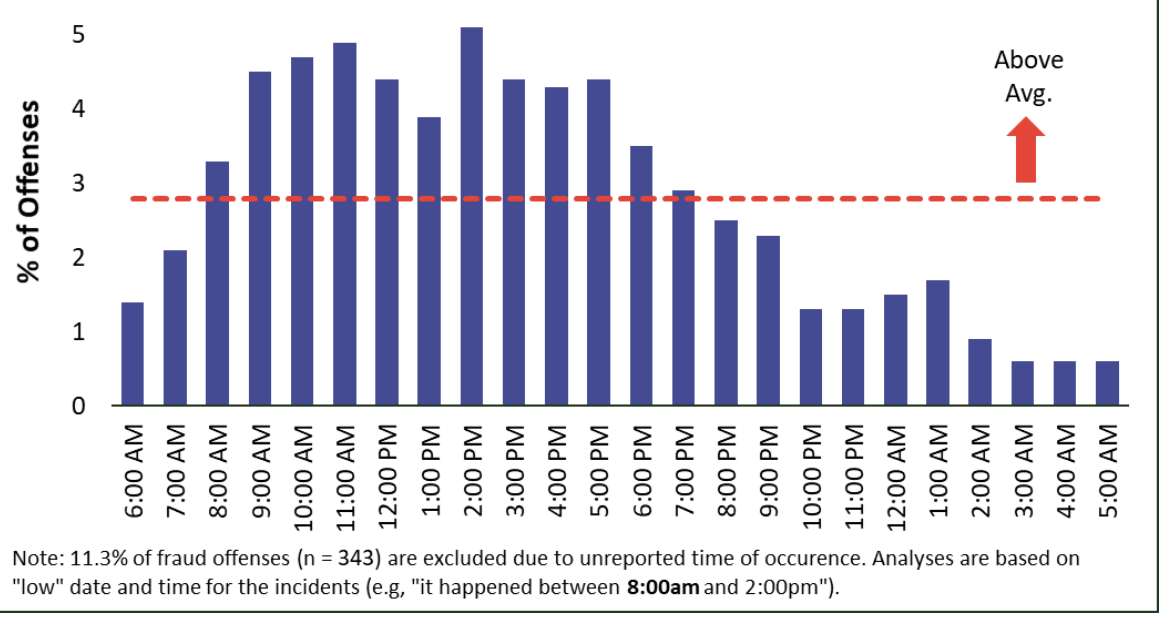

Figure 103

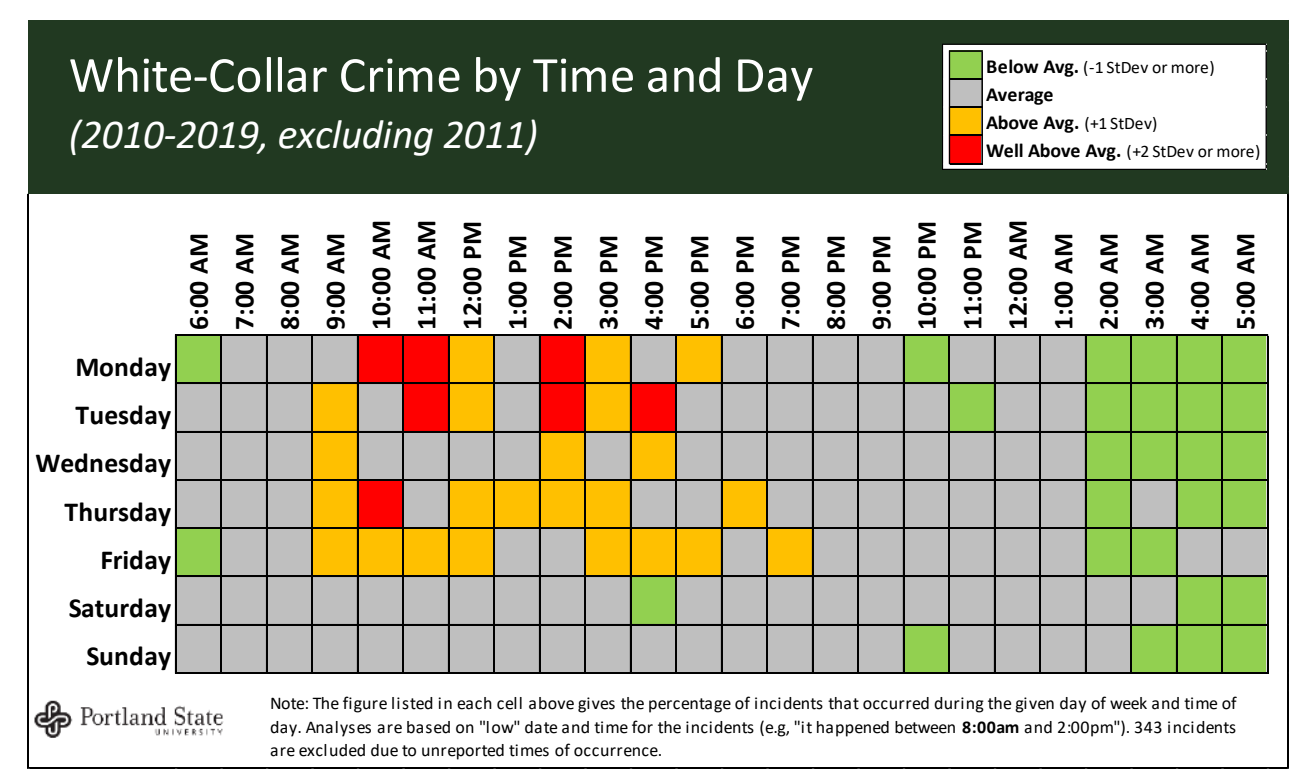

Figure 104 
were well above the average at 10:00am (1.0\%), 11:00am (1.1\%), and 2:00pm (1.0\%). Additionally, the number of offenses were well above the average on Tuesdays at 11:00am (1.0\%), 2:00pm (1.2\%), and $4: 00 \mathrm{pm}(1.2 \%)$ as well as Thursdays $(1.0 \%)$ at 10:00am. See Figure 104 for a more detailed breakdown of White-Collar offenses by hour per day of week.

\section{Geographic Pattern}

The most common location type for White-Collar offenses during the study period was Residence/Home, with about a quarter $(22.5 \%)$ of all offenses occurring at someone's residence. The second most common location type reported was a Bank/Savings and Loan, which comprised $19.7 \%$ of all offenses. These two locations combined accounted for almost half $(42.2 \%, 1,625)$ of all White-Collar offenses. See Table 36 for the top ten most common location types for White-Collar Crime in Bend over the study period.

\begin{tabular}{|lcc|}
\hline $\begin{array}{l}\text { 色 Portland StateWHITE-COLLAR CRIME - LOCATION TYPE } \\
\text { (2010-2019) }\end{array}$ & \\
\hline Location Type & $f$ & $\%$ \\
\hline Residence/Home & 867 & $22.5 \%$ \\
Bank/Savings and Loan & 758 & $19.7 \%$ \\
Other/Unknown & 453 & $11.8 \%$ \\
Roadway & 264 & $6.9 \%$ \\
Department/Discount Store & 247 & $6.4 \%$ \\
Commercial/Office Building & 215 & $5.6 \%$ \\
Convenience Store & 180 & $4.7 \%$ \\
Restaurant & 157 & $4.1 \%$ \\
Grocery/Supermarket & 120 & $3.1 \%$ \\
Medical Building & 96 & $2.5 \%$ \\
All Other Locations & 489 & $12.7 \%$ \\
\hline Total & 3,846 & $100.0 \%$ \\
\hline
\end{tabular}

Table 36

\section{Victim \& Arrestee Demographic Profiles}

\section{Age}

The average age for victims of White-Collar offenses during the 10year study period was 45.2 years old. The most common age group for victims of this type of crime was people between the age of 35 to 44 , which made up about a quarter (515) of all victims. The second most common age group for victims was people between the age of 25 to 34 (444), followed by people between the age of 45 to 54 (441). This indicates that victims of White-Collar Crime tend to be older than victims of other offenses analyzed in this report.

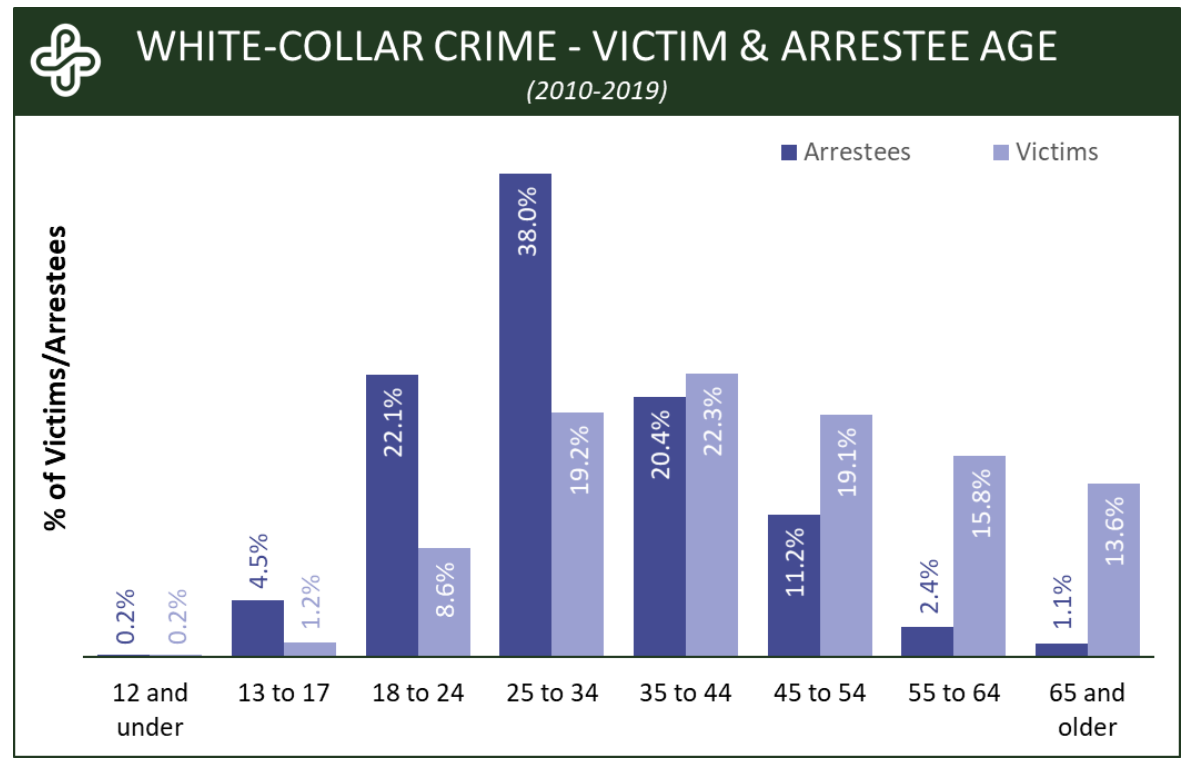

Figure 105

The average age for arrestees of White-Collar offenses was 32.2 years old, with almost a third of arrestees being between the age of 25 and 34 (312). This was followed by 18 to 24 (182) and 35 to 44 (168). See Figure 105 for a more detailed age breakdown for both victims and arrestees.

\section{Sex}

Of the victims of a White-Collar offense whose sex was known, slightly over half were female $(53.6 \%)$. Whereas a little over half of the arrestees for this type of offense were Male (59.5\%). 
Among victims where race was documented, the vast majority $(99.0 \%)$ were White. Black or African American people represented $0.3 \%$ of victims and Asian (8), American Indian or Alaska Native (6), and Native Hawaiian or Other Pacific Islander (1) people accounted for $0.7 \%$ of victims. With regard to ethnicity, $3.0 \%$ of victims were identified as Hispanic or Latino.

Most of the White-Collar arrestees were White $(93.5 \%)$, followed by Black or African American (4.7\%). People who identified as American Indian or Alaska Native (6), Asian (6), and

\begin{tabular}{|c|c|c|c|c|}
\hline \multicolumn{5}{|c|}{$\begin{array}{l}\text { WHITE-COLLAR CRIME - DEMOGRAPHICS } \\
\qquad(2010-2019)\end{array}$} \\
\hline Demographic* & \multicolumn{2}{|c|}{ Victims } & \multicolumn{2}{|c|}{ Arrestees } \\
\hline Sex & $f$ & $\%$ & $f$ & $\%$ \\
\hline Male & 1,067 & $46.4 \%$ & 489 & $59.5 \%$ \\
\hline Female & 1,235 & $53.6 \%$ & 333 & $40.5 \%$ \\
\hline \multicolumn{5}{|l|}{ Race } \\
\hline White & 2,147 & $99.0 \%$ & 751 & $93.5 \%$ \\
\hline Black or African American & 6 & $0.3 \%$ & 38 & $4.7 \%$ \\
\hline All Others Combined & 16 & $0.7 \%$ & 14 & $1.7 \%$ \\
\hline \multicolumn{5}{|l|}{ Ethnicity } \\
\hline Not Hispanic or Latino & 554 & $97.0 \%$ & 365 & $92.4 \%$ \\
\hline Hispanic or Latino & 17 & $3.0 \%$ & 30 & $7.6 \%$ \\
\hline \multicolumn{5}{|l|}{ Residency } \\
\hline Resident & 1,166 & $86.8 \%$ & 545 & $84.9 \%$ \\
\hline Nonresident & 178 & $13.2 \%$ & 97 & $15.1 \%$ \\
\hline
\end{tabular}

\section{Table 37}

Native Hawaiian or Other Pacific Islander (2) comprised $1.7 \%$ of the arrestees. Regarding those with reported ethnicity, $7.6 \%$ of arrestees were Hispanic or Latino.

\section{Residency}

Of the White-Collar Crime victims whose Residency status was known, $86.8 \%$ were residents of Bend.

Likewise, out of the arrestees with known Residency status, $84.9 \%$ of arrestees were residents of Bend. See Table 37 above for more detailed demographic information.

\section{Offense Characteristics}

\section{Victim Type}

The most common victim type for White-Collar Crime offenses during the study period was an Individual, with almost three quarters $(67.9 \%)$ of all victims falling into this category. The second most common victim type reported was a Business, which comprised about a quarter (15.3\%) of all victims. These two victim types combined account for almost all $(93.5 \%, 4,105)$ of the White-Collar Crime victims in Bend.

\section{Number of Victims}

\begin{tabular}{|lrc|}
\hline \multicolumn{3}{c}{ WHITE-COLLAR CRIME - VICTIM TYPE } \\
(2010-2019)
\end{tabular}

Table 38

Most White-Collar offenses during the 10-year study period involved a single victim $(92.7 \%, 2,247)$. During this time, $6.3 \%$ (152) of offenses involved two victims, $0.8 \%(20)$ involved three to five victims, and $0.2 \%(5)$ involved six or more victims. The largest number of victims involved in an offense was 12 , which only occurred once. 


\section{Number of Known Offenders}

Most White-Collar offenses over the 10-year study period had only one known offender $(81.5 \%, 987)$. During this time, $12.8 \%$ (155) of offenses involved two known offenders and $5.7 \%$ (69) involved three to six known offenders.

\section{Property Losses}

\section{Property Descriptions}

Overall, the most common property that was stolen in a White-Collar crime during the 10-year study period was someone's Identity (34.3\%). This was followed by Money (23.5\%), Credit/Debit cards (7.1\%), and Negotiable Instruments (4.1\%). The FBI defines Negotiable Instruments as, "documents, other than currency, that are payable without restriction; an unconditional promise or order of payment to a holder upon issue, possession, on demand, or at a specific time; endorsed checks (including forged checks that have been endorsed), endorsed money orders, endorsed traveler's checks, bearer checks, and bearer bonds." 5 See the table above for the top ten most common descriptions of property stolen as a result of White-Collar Crime in Bend.

The most common property that was counterfeited or forged in a WhiteCollar crime over the study period was Money $(52.2 \%)$. This was followed by Negotiable Instruments (15.8\%) and Non-Negotiable Instruments (11.9\%). The FBI classifies Non-Negotiable Instruments as, "documents requiring further action to become negotiable; unendorsed checks, money orders, traveler's checks, stocks, bonds, blank checks, etc."Error! Bookmark not defined. See the table above for the top ten most common descriptions of property forged as a result of WhiteCollar Crime in Bend.

\begin{tabular}{|lrc|}
\hline Property Description & \multicolumn{1}{c|}{$\begin{array}{c}\text { WHITE-COLLAR CRIME - PROP. STOLEN DESCRIPTIONS } \\
(2010-2019)\end{array}$} & $\%$ \\
\hline Identity- Intangible & 1,401 & $34.3 \%$ \\
Money & 960 & $23.5 \%$ \\
Credit/Debit cards & 288 & $7.1 \%$ \\
Negotiable Instruments & 169 & $4.1 \%$ \\
Purse/Wallet & 146 & $3.6 \%$ \\
Identity Documents & 105 & $2.6 \%$ \\
Consumable Goods & 57 & $1.4 \%$ \\
Clothes/Furs & 44 & $1.1 \%$ \\
Computer Hard/Software & 37 & $0.9 \%$ \\
Radio/TV/VCR & 34 & $0.8 \%$ \\
All Other Items & 840 & $20.6 \%$ \\
\hline Total & 4,081 & $\mathbf{1 0 0 . 0 \%}$ \\
\hline
\end{tabular}

Table 39 
In this section we estimate the direct costs associated with stolen and counterfeited/forged property as a result of White-Collar Crime in Bend during the 10-year study period. In order to estimate the total financial losses attributable to this offense, we replaced any missing values with the statewide mean value for a given item and year. It should also be noted that these property loss statistics likely underrepresent the financial losses associated with White-Collar Crime. For example, when someone's identity is stolen, the property value reported is $\$ 0$ because there is no direct financial loss associated with something

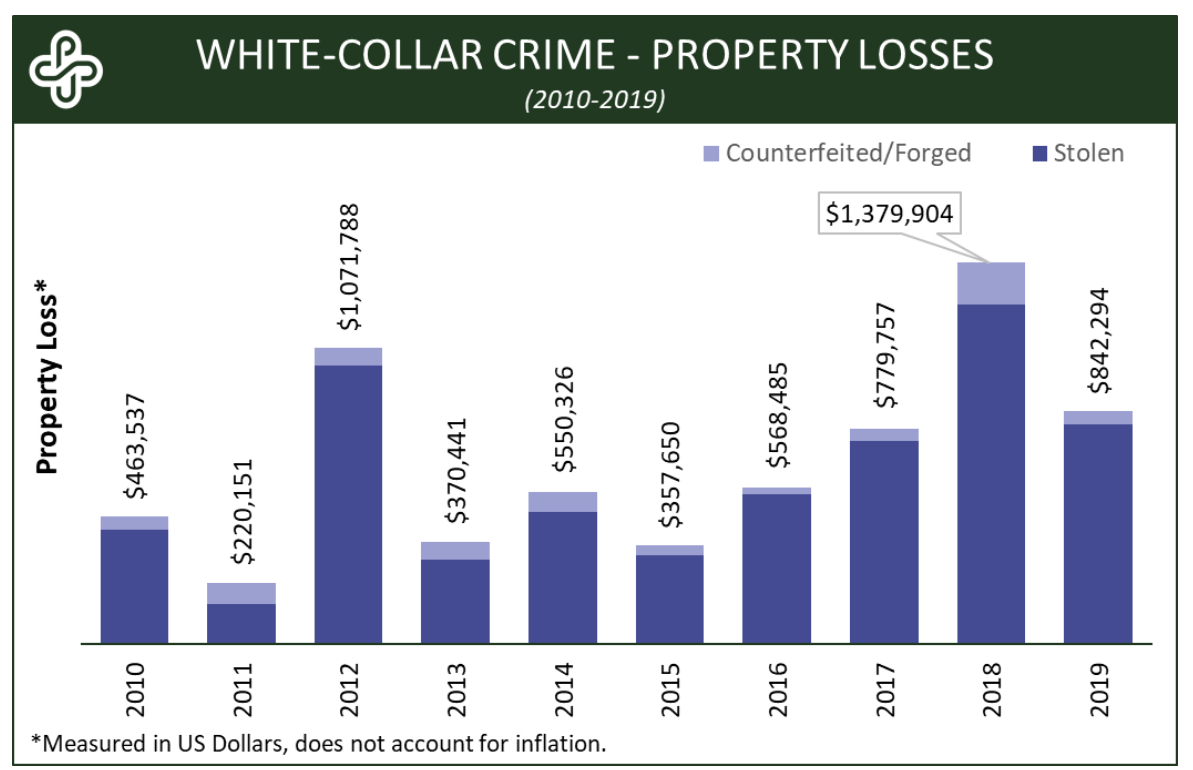

Figure 106 intangible like identity. However, identity theft usually involves financial consequences for the victim that may come after the police report has already been submitted. This is likely true for many WhiteCollar crimes, and therefore these figures likely minimize the financial losses experienced by victims of White-Collar Crime.

Between 2010 and 2019, Bend experienced \$6,604,333 in property losses resulting from White-Collar Crime. This means that there was an average annual loss of $\$ 660,433$, and the average loss per offense during this time was \$1,717. As demonstrated in Figure 106, the annual property losses resulting from White-Collar Crime have steadily increased between 2010 and 2019, an overall $81.7 \%$ increase.

\section{Property Stolen}

There were 4,081 financial losses resulted from property being stolen, and the total cost of stolen property over the ten-year study period was $\$ 5,982,726$. This means that the average annual loss of stolen property resulting from White-Collar Crime was $\$ 598,272$ and the average cost of stolen property per offense was $\$ 1,466$.

\section{Property Counterfeited/Forged}

There were 873 instances of counterfeited/forged property losses in Bend, with the total cost over the study period being $\$ 621,607$. The average annual loss during this time was $\$ 62,160$ and the average cost per counterfeited/forged loss was $\$ 712$. See Figure 106 for a yearly breakdown of Bend's property losses resulting from White-Collar Crime. 


\section{Clearance Rate}

Of the 3,846 White-Collar Crime offenses between 2010 and 2019, $24.8 \%$ (953) were Cleared by Arrest/Citation or by Exceptional Means. The average annual clearance rate during this time was $26.4 \%$, or 95.3 offenses per year. The clearance rate for White-Collar Crime in Bend has steadily increased over the past decade, and as of 2019 , the clearance rate has increased by $50.1 \%$ since 2010 . See Figure 107 for an annual breakdown of White-Collar clearance rates over the study period in Bend.

\section{WHITE-COLLAR CRIME - CLEARANCE RATE}

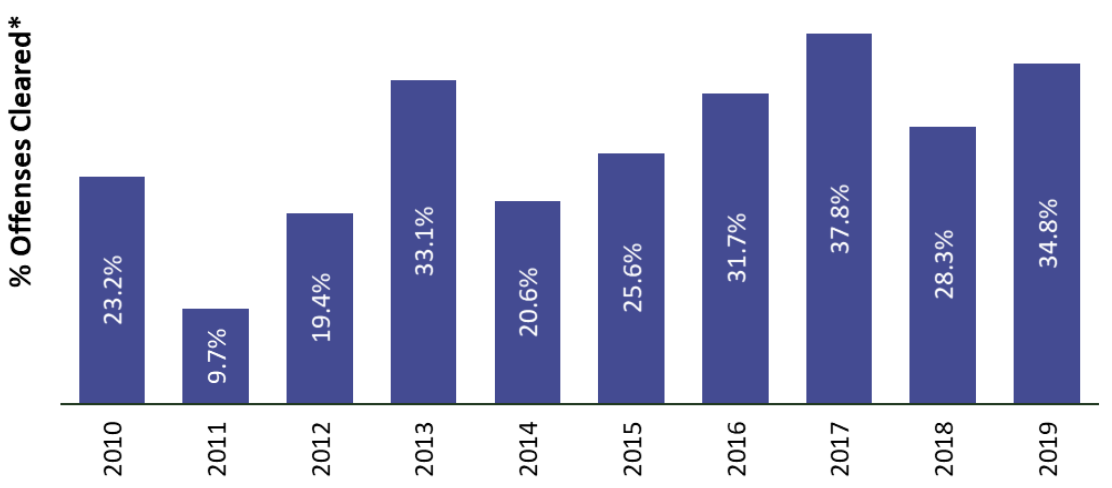

*Cleared offenses include incidents cleared by arrest/citation and incidents cleared by exceptional means.

Figure 107 